$\mathrm{X}$.

\title{
Orthopädische Technik.
}

Von

Dr. med. Otto Thilo, Riga (Russland).

Mit 7 Abbildungen im Text und 137 Abbildungen auf Tafel I-XIX.

Die hier in Bild und Wort beschriebene Technik ist zum grössten Teil eine Drahttechnik.

Sie bietet dem Arzte die Möglichkeit, mit eigener Hand Schienen, Korsette und auch Übungsvorrichtungen ohne Schwierigkeit herzustellen.

Die Notwendigkeit dieser Möglichkeit wird immer mehr anerkannt; denn immer mehr sind die Orthopäden bemüht, eigene Werkstätten einzurichten, damit sie das Anpassen und Eingewöhnen der Apparate besser durchführen können.

Zur Erleichterung dieser Anpassung sind alle hier beschriebenen Apparate stellbar. - Auch die Anfertigung und Aufstellung der Übungsvorrichtungen habe ich möglichst genau in Wort und Bild beschrieben.

Ein besonderer Abschnitt ist der Beschreibung ihrer Verwendung gewidmet. In einem anderen Abschnitt ist an Beispielen erläutert, wie ich meine Übungsvorrichtungen zu Kraftbestimmungen und anderen diagnostischen Zwecken verwende. Bei der Beschreibung der verschiedenen Vorrichtungen sind auch hie und da einige Krankengeschichten hinzugefügt, um an ihnen genauer den Gebrauch der einzelnen Vorrichtungen zu erläutern.

\section{Inhaltsverzeichnis.}

Seite

I. Druckverbände mit Filz. Taf. I . . . . . . . . . . . . . . . . . 10z

II. Verstellbare Krücken mit Riemenschweben. Taf. I . . . . . . . . . . 107 


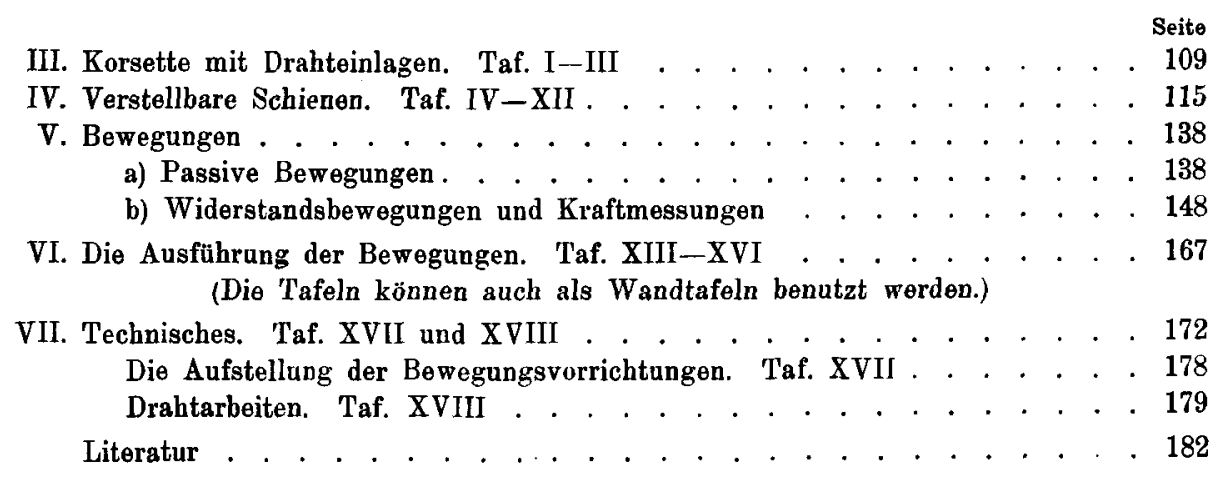

\section{Druckverbände mit Filz ${ }^{1}$ ).}

Bei den frischen Verstauchungen des Fussgelenkes verhindern fest angelegte Druckverbände ziemlich sicher das Eintreten erheblicher Schwellungen, da sie die Blutungen unter der Haut stillen und auch z. T. jene Blutansammlungen im Gelenke verhüten, welche so sehr die Heilung des verletzten Gelenkes verzögern.

Das einfache, feste Einwickeln mit Binden ist für derartige Druckverbände ungeeignet.

Erstens werden sie schlecht vertragen, da sie einen sehr empfindlichen Druck auf den häufig stark verletzten Knöchel ausüben. Zweitens können sie ihren Zweck, die Blutung zu stillen, doch nicht erreichen. Sie überbrücken den Raum zwischen Knöchel und Fusswurzel, lassen daher den hauptsächlichen Sitz der Blutungen und Ansammlungen frei rom Drucke. Diese Übelstände vermeide ich dadurch, dass ich vor dem Anlegen der Binden den verletzten Knöchel mit einem Stücke dicken, weissen Filzes bedecke, in welches ich ein längliches Loch schneide. Dieses Filzstück wird nach Art eines sogenannten "Hühneraugenringes" mit dem Loche auf den verletzten Knöchel gelegt.

Hierdurch gelingt es, den Knöchel fast vollständig vom Drucke der Binden zu befreien und einen Druck hauptsächlich auf seine Umgebung auszuüben.

Statt des Filzes Watte zu verwenden, ist nicht empfehlenswert, weil die Watte ziemlich bald einschrumpft, sich zusammenrollt und die gelockerten Binden dann einen ungleichmässigen Druck ausüben.

Ich gebe den Filzstücken gewöhnlich eine Länge von etwa $14 \mathrm{~cm}$, eine Breite von $6 \mathrm{~cm}$. Die Länge des Loches beträgt etwa $5 \mathrm{~cm}$, die Breite $2 \mathrm{~cm}$. (Fig. 1.)

1) Vergl. Monatsschr. f. Unfallheilkunde. 1896. Nr. 8. 
Bei Verletzung des äusseren Knöchels lege ich stets auch auf den inneren, unverletzten Knöchel ein entsprechendes Filzstück und zwar in der Weise, dass zwischen dem Filzstücke des inneren Knöchels und dem des äusseren ein Zwischenraum von einigen Zentimetern bleibt, damit an dieser Stelle kein Druck von den Binden ausgeübt werde. Hierdurch erhalte ich eine freie Bahn für den Rückstrom des Blutes. Auch die Achillessehne lasse ich vom Filz unbedeckt.

Dieser druckfreie Zwischenraum (Fig. 1 b) ist von der grössten Wichtigkeit, ohne ihn wird mein Filzdruckverband überhaupt gar nicht vertragen. Bei stark vorspringendem Knöchel empfiehlt es sich eine doppelte Lage Filz zu verwenden.

Die Innenseite beider Filzstücke ist mit Leinwand zu füttern, damit der rauhe Filz die Haut nicht zu sehr reibt. Quer über die Fusssohle lässt man ein dünnes Band verlaufen, welches die Filzstücke miteinander verbindet und so verhindert nach oben zu rutschen.

Besonders wichtig ist diese ,Strippe“ beim Anziehen eines Stiefels. Bei Schnürstiefeln ist es unnötig die Filzstücke mit Binden zu bewickeln, man zieht einfach einen Strumpf über die Filzstücke und über den Strumpf den Stiefel. Die Strippe an der Fusssohle verhindert dann das Hinaufrutschen der Filzstücke und das Schnüren des Stiefels macht den Druck durch Binden entbehrlich. So manchem Leser mögen wohl diese Vorschriften als zu peinlich erscheinen, leider aber habe ich nur zu oft bemerkt, dass viele Kollegen meine Vorschriften gar nicht beachteten. Sie legten einfach ein Stück Filz ohne Ausschnitt für den Knöchel auf das Gelenk, umwickelten hierauf Filz und Gelenk recht fest mit Binden und wunderten sich dann darüber, dass der Verband nicht vertragen wurde. Hat man den Verband richtig angelegt, so stillt er bald die Schmerzen, besser als alle Eisblasen und Kompressen; denn die Eisblasen drücken die Fussspitze nach unten and stillen doch nur unvollkommen die innere Blutung, während der Filzdruckverband bald die Blutung stillt und dem Gelenke einen festen Halt gibt. Selbstverständlich reicht dieser Halt nur für leichtere Verstauchungen aus, bei denen es sich mehr um Blutungen ausserhalb des Gelenkes handelt.

Bei ernsteren Verletzungen ist nach dem Anlegen des Filzdruckverbandes, stets der Fuss in einer Blechschiene mit Fussstütze hochzulagern. (Taf. IV, Fig. 25.)

Doch glaube ich am besten durch folgenden Fall meine ganze Art der Behandlung zu erläutern.

Ein Kollege, Dr. T. in Riga, hatte durch einen Fehltritt von einer Schwelle im Dunklen, sich eine Verstauchung des Fusses zugezogen. Obgleich sofort sehr heftige Schmerzen eintraten, war der sehr energische, lebhafte Mann noch einige Stunden herumgehumpelt, bis ihm schliesslich das Auftreten unmöglich wurde. Nachdem er sich zwei Tage hindurch mit Kompressen von Bleiwasser $u$. dergl. behandelt hatte, schickte er zu mir wegen ganz unerträglicher Schmerzen. Ich fand den Fuss sehr geschwollen, den äusseren Knöchel sehr empfindlich, den inneren ganz schmerzlos. 
Ich legte einen Filzdruckverband an, und lagerte den Fuss hoch in einer Blechschiene, die bis zur Kniekehle reichte. Am Fussteil der Schiene befestigte ich eine Blechsohle mit nach oben gebogenen Rändern (etwa 3 Zentimeter hoch nahm ich die Ränder). Den Einschnitt für den Hacken nahm ich recht lang, damit jch durch diesen Einschnitt über dem äusseren Knöchel ein dreieckiges Tuch ziehen konnte. An der inneren Seite der Schiene wurden die Zipfel des dreieckigen Tuches geknotet. Der auf diese Art erzeugte seitliche Zug bewirkte eine Drehung des Fusses um seine Längsachse nach aussen und erhielt ihn in überkorrigierter Stellung (Plattfussstellung).

Die Schmerzen liessen in einigen Stunden nach. Ich wechselte den Verband alle 24 Stunden. In zwei Tagen war die Schwellung so bedeutend geschwunden, dass ich den äusseren Knöchel bequem durchfühlen konnte. Es hatte ein Bruch des äusseren Knöchels etwa zwei Zentimeter oberhalb seines Endes stattgefunden.

Trotzdem war der Kollege nicht im Bette zu erhalten. Über meinen Filzverband zog er einen Schnürstiefel, an dem die Sohle durch eine Blecheinlage an der äusseren Seite verbreitert war $^{1}$ ) und versorgte einen Teil seiner ärztlichen Praxis, allerdings fahrend. Trotz seiner 60 Jahre erlangte er bald die volle Gebrauchsfähigkeit seines Fusses. Allerdings wurde er zugleich einige Wochen mit Massage und Widerstandsbewegungen behandelt. Er hatte also mit seinem Gelenkbruche nur einige Tage zu Bette gelegen, obgleich zwei Tage lang der Bruch sehr vernachlässigt war.

Grossen Nutzen habe ich auch von meinen Filzverbänden bei den Gelenkergüssen der Bluter gesehen. Ich hatte Gelegenheit, drei Bluter jahrelang zu behandeln. Der eine derselben, ein höchst begabter Polytechniker, sagte mir, als er in meine Behandlung kam, das einzige wirksame Mittel gegen seine Gelenkschwellungen seien Einwickelungen mit Watte und Binden. Alles andere habe ihm keinen Nutzen geschaffen. Sehr bald vertauschte er die Watte mit meinem Filzverbande.

Der zweite, viel jüngere Bluter, war anfangs sehr gegen meinen Filzverband, weil er sich an Kompressen mit kaltem Wasser seit Jahren gewöhnt hatte. Jetzt legt er sofort meinen Filzverband an, sobald er Schmerzen in einem Gelenke spürt. Hat der Verband zwei Tage gelegen, so werden Massage und leichte Widerstandsbewegungen angewandt, überhaupt brauchten beide Bluter fortlaufend Massage und Widerstandsbewegungen.

Folgendermassen lege ich einen Filzdruckverband an das

\section{Kniegelenk.}

Das Knie wird mit einem weissen, dicken Stücke Filz bedeckt, in dessen Mitte ein herzförmiges Loch entsprechend der Grösse der Kniescheibe geschnitten ist. Unter die Kniekehle lege ich gleichfalls ein Stück Filz ron etwa 20 Zentimeter Länge, 9 Zentimeter Breite. Zwischen beiden Filzstücken muss ein Zwischenraum von einigen Zentimetern bleiben. (Fig. 2 b druckfreier Zwischenraum).

1) Vergl. Seite 124 und Taf. VIII. 
Mit starken Leinen- oder Gummibinden kann man über der Filzkappe jetzt einen sehr festen Druck ausüben, ohne den Unterschenkel abzuschnüren, da die Venen in der Kniekehle und auch die Vena saphena vom Drucke freibleiben. Durch die Filzkappe ist man imstande, den Druck auf die Umgebung der Kniescheibe sehr gleichmässig und stark auszuüben. Bekanntlich ist ja gerade diese Stelle häufig der Sitz von Erkrankungen und Ansammlungen. Vergl. König, ,Die spezielle Tuberkulose der Knochen und Gelenke." Berlin 1896. Hirschwald. Das Rutschen des Filzes nach unten verhindert man durch ein Band, das man am Filz und am Hosengurt befestigt, oder durch Heftpflaster.

In einem Falle befestigte ich den Filz mit Gummiheftpflaster, welches ich gürtelförmig über den Filz um das Knie schlang. Es handelte sich in diesem Falle um eine vernachlässigte Verenkung der Kniescheibe nach aussen. Die Kranke wurde alle Augenblicke durch Überspringen der Kniescheibe nach aussen im Gehen gehindert.

Ich legte auf die äussere Seite des Knies ein Stück Filz mit einem Ausschnitte für die Kniescheibe, befestigte dieses mit Heftpflaster und Binden. So erreichte ich, dass die Kranke einige Monate hindurch ohne Überspringen der Kniescheibe ging. Auf dem Lande konnte der Verband nicht erneuert werden und es erfolgte wieder die Verrenkung. Jetzt trägt Patientin ein Gummikniestück über meinem Verbande und kann monatelang ohne Verbandwechsel die Kniescheibe in ibrer Stellung erhalten.

In einem anderen Falle war durch eine gewaltsame Bewegung im Kniegelenk ein Stück des Zwischenknorpels abgelöst und nach aussen getreten (Luxatio menisci). Man konnte es durch die Haut deutlich fühlen, in der Nähe des äusseren Randes der Kniescheibe. Da die Verletzung schon vor vier Monaten stattgefunden hatte, verstand es die Kranke, mit den Fingern das Stück an seinen Bestimmungsort zu befördern. Hatte sie das Stück zum Verschwinden gebracht, so konnte sie ungestört weite Gänge machen, bis es plötzlich wieder hervortrat und beim Gehen bedeutende Schmerzen verursachte.

Auch in diesem Falle gelang es mir, durch den oben beschriebenen Filzdruckverband mit Heftpflaster, Binden und Gummikniekappe das Knorpelstück an der richtigen Stelle zu erhalten, so dass es beim Gehen nicht mehr hervortrat.

Ich führe diese Fälle zum Teil auch deshalb hier an, weil sie zeigen, wie genau man mit Filzverbänden den Druck auf ganz bestimmte Punkte ausüben kann.

Bei Knieen, die in Winkelstellung stehen (Ankylosen), passt man die Filzkappe leicht an, wenn man dreieckìge Stücke aus dem Rande derselben schneidet. (Fig. 2a.)

$\mathrm{Zu}$ Filzdruckverbänden eignen sich schon jene gröberen niederen Sorten des Wollfilzes, mit welchem die Pferdegeschirre gepolstert werden. Noch besser ist jener weiche dicke Wollfilz den man unter den Sattel legt. Dieser ist jedoch sehr kostspielig. 
Bei den verschiedenartigsten Formen der Kniegelenkentzündung leisten mir die Filzdruckverbände in Verbindung mit Massage und Widerstandsbewegungen vortreffliche Dienste (Vergl. Monatsschrift f. Unfallk. 1895, Nr. 11).

Sehr häufig lege ich unter den Filz einige Streifen Heftpflaster und erziele so

\section{Feuchtwarme Druckverbände mit Heftpflaster und Filz.}

Einen Streifen Heftpflaster von 4 Zentimeter Breite und 25 Zentimeter Länge klebe ich über die Kniescheibe der Länge nach auf das Bein, zu jeder Seite dieses Streifens einen Streifen von derselben Breite und Länge. Hierauf lege ich die Filzkappe und umwickele dann das Knie mit Binden. Das Ganze wirkt wie eine feuchtwarme Einpackung. Diese Wirkung kann man steigern, wenn man über den Filz noch Watte legt. Beim Massieren wird das Heftpflaster nicht abgenommen. Man braucht nur Reispuder auf das Pflaster zu streuen und kann dann bequem auf dem Pflaster massieren.

Besonders günstig wirkt dieser feuchtwarme Verband auf Narben. Sie werden weicher und können so leichter durch Massieren (dehnende Bewegungen) vom Knochen gelöst werden. Bei den Narben der Hand und Finger leisten diese Verbände mit Heftpflaster mir ganz ausgezeichnete Dienste.

\section{Die Überbeine}

behandelte ich mit Filzdruckverbänden folgendermassen. Ein kreisförmiges, dickes Filzstück von etwa $2 \mathrm{~cm}$ Durchmesser und ein entsprechender Kork von etwa $1 / 2 \mathrm{~cm}$ Dicke werden auf einen Heftpflasterstreifen gelegt und zwar auf die unbestrichene Seite desselben.

Mit einer langen, starken Nadel legt man Nähte durch Kork, Filz und Heftpflaster. Klebt man jetzt den Kork mit dem Heftpflaster auf das Überbein, so wird er stets genau auf dem Überbein vom Heftpflaster erhalten, namentlich wenn der Heftpflasterstreif gürtelförmig die Gliedmasse umschliesst.

Befindet sich das Überbein auf der Streckseite des Armes, so ist auf die Beugeseite gleichfalls ein Filzstück zu legen, damit beim Einwickeln mit Binden eine Abschnürung der Gliedmasse verhindert werde. Am Fussrücken klebe ich bloss mit Heftpflaster einen Kork mit Filz auf das Überbein und bewirke den Druck durch das Schnüren des Stiefels, die Binden fortlassend.

Diesen Verband lasse ich wochenlang ununterbrochen Tag und Nacht liegen.

Überbeine, die schon längere Zeit bestehen, durchstosse ich mit dem Skalpell und massiere ich aus, vor dem Anlegen des Filzdruckverbandes.

Zum Schluss dieses Abschnittes halte ich es nicht für überflüssig darauf hinzudeuten, dass es sich empfiehlt, anstelle der Wattepolsterung so viel als irgend möglich die Filzpolsterung zu verwenden. - 


\section{Verstellbare Krücken mit Riemenschweben ${ }^{1}$ ).}

Gewiss werden wohl viele Kollegen die Beobachtung gemacht haben, dass es oft die grössten Schwierigkeiten bereitet einen Kranken zu veranlassen, sich Krücken anzuschaffen und Gehversuche mit ihnen anzustellen.

Kranke, welche nur einige Wochen oder Tage die Krücken benutzen sollen, z. B. einige Rheumatische oder Nervenleidende führen stets an, es lohne sich nicht, für eine so kurze Zeit, Krücken anzuschaffen, sie würden schon auch ohne dieselben auf die Beine kommen.

Infolgedessen versäumen sie oft den Zeitpunkt, bis $\mathrm{zu}$ welchem es noch möglich gewesen wäre, das Gehen wieder zu erlernen und bleiben so ihr Lebelang bettlägerig.

Wieviele Kinder mit Kinderlähmungen, wieviele Hysterische und vor allem wieviele Rheumatische fallen nur deshalb sich und anderen durch Bettliegen zur Last, weil man sie bei ihren ersten Gehversuchen nicht ausreichend unterstützte und antrieb.

In der Sammlung klin. Vorträge von Volkmann 1897 habe ich es versucht darzulegen, wie solche Gehübungen anzustellen seien. Hier will ich nur eine Art von Krücken beschreiben, welche es mir im hohen Grade erleichterte, bettlägerige Kranke zum Gehen zu veranlassen. Diese Krücken kann man für jede Körperlänge schnell einstellen. Ich halte von ihnen immer einige vorrätig. Wünsche ich nun einen Kranken zum Gehen zu veranlassen, so übergebe ich ihm persönlich die Krücken leihweise und leite persönlich seine ersten Gehversuche. Hat sich der Kranke an das Gehen mit Krücken gewöhnt, so trennt er sich häufig ungern von ihnen, obgleich er oft schon längst ohne dieselben gehen könnte. In solchen Fällen nehme ich ihm unbarmherzig meine geliehenen Krücken ab, da ich sie für andere Kranke brauche und er sich ja selbst welche anschaffen kann.

Die Herstellung meiner Krücken ist eine sehr einfache und billige. Man setzt sie aus zwei flachen Holzstäben (Breite $3,5 \mathrm{~cm}$, Dicke $1 \mathrm{~cm}$ zusammen. (Fig. 3.) Bei $\mathrm{C}$ und $\mathrm{B}$ werden diese beiden flachen Holzstähe durch zwei Rundstäbe $\mathrm{CF}$ und $\mathrm{AB}$ miteinander verbunden. Die Stäbe sind der Länge nach durchbohrt, so dass man einen Eisendraht von etwa $5 \mathrm{~mm}$ Dicke durch dieselben schieben kann. Auf die Enden der Eisenstäbe legt man Kupferscheiken und vernietet dann. Die Kupferscheiben haben vor Eisenscheiben den Vorzug, dass sie die Lösung der Nieten erleichtern. Statt der Drahtstäbe Holzschrauben zu verwenden ist nicht ratsam, da die Holzschrauben im Langholz der Rundstäbe schlecht haften.

Dem Stabe $A B$ gebe ich eine Länge von $11 \mathrm{~cm}$, dem Stabe CF $20 \mathrm{~cm}$.

Der Abstand CD des Rundstabes CF vom oberen Ende der Krücke ist

$15 \mathrm{~cm}$ lang zu nehmen. Der Abstand CB etwa $30 \mathrm{~cm}$. Die Punkte D und $\mathrm{E}$ verbinde ich durch einen Riemen miteinander (am besten amerik. Rohleder oder schwarzes russisches Siromätleder) ${ }^{2}$ ).

1) Vergl. Monatsschr. f. Unfallheilkunde. März 1897.

2) Bei D und $E$ werden Riemen und Holzstab mit Draht umwickelt. Die Enden des Riemen werden mit den tinden des Drahtstabes CF vernietet. 
Der Riemen bildet eine Schwebe, welche sich sehr genau den Formen der Achselhöhle anpasst und so besser als ein Polster den Druck vermindert. Bekanntlich wird ja jetzt als Sitz der Velozipede nicht mehr ein Polster angewandt, sondern ein breiter Riemen, der nach Art einer Hängematte ausgespannt ist. Ausserdem federn auch noch die oberen Enden (CD und EF) und tragen so sehr bedeutend dazu bei, den Druck in der Achselhöhle zu vermindern.

Für Personen, die schon längere Zeit hindurch Krücken benutzt haben, und abgehärtete Achselhöhlen besitzen, sind weiche Auflagen auf den Riemen nicht erforderlich, für empfindliche Anfänger dagegen kann man den Riemen mit einer doppelten Filzlage decken und mit dünnem Leder überziehen.

Das Verstellen der Krücken wird durch die Hülse (H) am unteren Ende der Krücke bewerkstelligt. Diese Hülse $H$ ist $20 \mathrm{~cm}$ lang, aus starkem Weissblech gefertigt und mit drei Streifen Weissblech von $0,5 \mathrm{~cm}$ Breite oben in der Mitte und unten umschlossen. Die Hülse wird auf das untere Ende der Krücke so geschoben, dass sie nur mit ihrer oberen Hälfte die Krücke umschliesst. In ihre untere Hälfte schiebt man den Verlängerungsstab, den man von einem vorrätig gehaltenen langen vierkantigen Holzstabe sägen lässt und mit einem Gummipuffer unten versieht (Fig. 3).

Das Verlängerungsstück befestige man mit einer Holzschraube.

Obgleich man diesem Verlängerungsstück eine beliebige Länge geben kann, so empfiehlt es sich doch in drei Grössen Krücken vorrätig zu halten eine Grösse für Kinder, eine für mittelgrosse Personen, eine für besonders lange und schwere Kranke $(60,80,100 \mathrm{~cm})$.

Mit diesen Grössen wird man wohl meist in Krankenhäusern auskommen. Für diese sind ja stellbare Krücken jedenfalls ein Bedürfnis, da sich in ihnen mit der Zeit eine Menge von Krïcken aufsammeln, welche eigentlich keinem Kranken passen.

Auch für im Wachstum begriffene Kinder sind stellbare Krücken unentbehrlich, falls man ihnen nicht alle halbe Jahre neue Krücken anschafft.

Überhaupt muss ich hier zum Schluss darauf hinweisen, dass viel mehr Kranke Krücken benutzen sollten, als es im allgemeinen geschieht.

Wieviele unglückliche Gestalten sieht man auf den Strassen mit beiden Händen auf einen kurzen Stab gestützt mühsam dahinhumpeln, die auf Krücken viel besser gehen würden! Auch bei vielen Gelenkerkrankungen der unteren Gliedmassen sind die jetzt so sehr gebräuchlichen Stützvorrichtungen gar nicht genügend.

König ${ }^{1}$ ) hat gewiss mit Recht darauf hingewiesen, dass sie oft nur sehr unvollkommen die Gelenke entlasten.

Viel besser und billiger erreicht man das Ausheilen der Gelenke, wenn man sie mit Pappeschiene feststellt, die Kranken erst eine Zeit lang zu Bett liegen lässt, dann unter den gesunden Fuss eine hohe Sohle legt und den Kranken auf Krücken gehen lässt.

1) König, Die spezielle Tuberkulose der Knochen und Gelenke. Berlin 1896. Aug. Hirschwald. 
Ich sah im Elisabeth-Hospital zu Petersburg bei Dr. E. Anders dieses Verfahren im grossartigsten Massstabe mit dem besten Erfolge angewandt.

Selbstverständlich sind die Schienen sobald als irgend möglich zu entfernen, damit aktive und passive Bewegungen vorgenommen werden können.

\section{Korsette mit Drahteinlagen'1).}

\section{Gipskorsette mit Drahteinlagen.}

Über den Trikot wickele ich 3 bis 4 Lagen Gipsbinden, dann umschliesse ich das Korsett mit 6 bis 7 Stücken verzinntem Eisendraht von etwa $1 \mathrm{~mm}$ Dicke (Fig. 5).

Die Drahtenden werden hakenförmig zurückgebogen, so dass sie etwa $3 \mathrm{~cm}$ voneinander abstehen, damit man hier das Korsett zum Abnehmen bequem durchschneiden kann. Um die hakenförmigen Drahtenden wird ein starker Zwirn geschlungen und dann gebunden.

Sehr häufig lege ich hinten zuerst von oben nach unten noch einige Drähte und umschliesse diese Längsdrähte mit den erwähnten Querdrähten. Diese Längsdrähte haben eine Dicke von $2-3 \mathrm{~mm}$ und die Form Fig. 7 III, Taf. II. Ich lege einen derartigen Draht auf den Rücken und gleichfalls einen zu jeder Seite der Schnurnaht. Diese Drähte erhöhen sehr die Festigkeit des Korsettes und verhindern auch beim Anlegen sicher alle Faltenbildungen.

Über die Drähte wickele ich wieder einige Lagen Gipsbinden und lasse dann das Korsett etwa eine Stunde am Körper trocknen. Dann durchschneide ich es auf einem untergelegten Bleistreifen mit dem Messer vorn. Hierauf vernähe ich die Schnittränder. Ich durchnähe auch das Korsett mit langen Stichen hinten und zu beiden Seiten der Schnurnaht. Darnach lasse ich es zunächst 10 Stunden bei Zimmerwärme langsam trocknen und dann erst in meinem Trockenapparate, den ich aus einem Pappzylinder und einer Gasoder Benzinflamme herstelle.

Durch einen Pappdeckel wird die Wärme im Apparate geregelt.

Infolge der Drahteinlagen erhält sich die Form des Korsettes sehr gleichmässig beim Trocknen. An den übergipsten Drahtenden (Fig. 5) kann man die Haken zum Schnüren sehr bequem und fest anbringen. Ich benütze hiezu die käuflichen Haken aus verzinntem Eisendraht. Auf jedes Ende der eingegipsten Drähte lege ich einen Haken und nähe dann mit einem einzigen langen durchgehenden Drahte auf jeder Seite alle Haken.

Als Achselstützen bringe ich jederseits einen Drahtrahmen an (Fig. 4 a) Drahtdicke 3 bis $4 \mathrm{~mm}^{2}$ ). Er wird gleichfalls an die eingegipsten Drähte genäht. Man kann ihn bequem höher und niedriger stellen, wenn man die unteren Nähte durchschneidet. Die Achselstützen werden mit dickem Filz ge-

1) Vergl. Langen becks Archiv. 1895.

2) Die Drahtenden werden mit dünnem Draht umwickelt und verlötet. Siehe im Anhang Drahtarbeiten. 
polstert. Durch den Filz ziehe ich mit einer Packnadel ein Stück Korsettschnur, welche ich durch die Schlinge eines Stückes Lampendocht ziehe und knote. Mit diesem Docht wird die Schulter nach hinten gezogen, Bisweilen empfiehlt es sich an der Achselstütze vorn einen Bügel zur Befestigung des Dochtes anzubringen (Fig. 6). Dieser Bügel drängt auch zugleich die Schulter zurück. Die hinteren Enden der Dochte befestigt man mit Korsettschnur an einen Bügel aus Eisendraht ( 4 bis $5 \mathrm{~mm}$ Dicke), der hinten (Fig. 4 b) an das Korsett genäht wird. Ich halte es für nötig diesen Drahtbügel so lang zu nehmen, dass er die Schulterhöhe erreicht damit die angezogenen Dochte die Schultern nicht nach unten drücken. Das Korsett selbst darf hinten nicht höher sein, als unter den Achseln, da man sonst die Schultern nicht genügend zurückziehen kann. Leider findet man diesen Fehler an vielen Korsetten, sie drücken dann die Schultern nach vorn und vergrössern so den Buckel, anstatt ihn zu verringern. Den Drahtbügel kann man im Schraubstock bequem zurück oder nach vorn biegen, je nach Bedürfnis. Statt der Calot'schen Klappe macbe ich Filzeinlagen am Rücken, die ich von Zeit zu Zeit erhöhe.

\section{Zelluloidkorsette}

fertige ich mit Drahteinlagen genau so an, wie das soeben beschriebene Gipskorsett. Als Modell hierzu benutze ich ein Gipskorsett mit Drahteinlagen, an dem noch keine Armstützen usw. (Fig. 5) angebracht sind. Man braucht gar nicht von diesem Gipskorsett einen Abguss zu nehmen sondern kann es unmittelbar als Modell benutzen. Sollte das auf ihm angefertigte Zelluloidkorsett etwas zu weit sein, so hat man nur vorn von den Schnitträndern ein wenig abzuschneiden. Für die Armenpraxis oder für kleine Kinder, die schnell wachsen und bald neuer Korsette bedürfen, kann man auch Korsette aus Trikot, Leinbinden and Leim mit Drahteinlagen anfertigen und wann sie trocken geworden sind, mit Zelluloidlösung innen und aussen anstreichen.

Diese Korsette sind allerdings etwas schwerer als reine Zelluloidkorsette, dafür aber sehr billig und haltbar.

Das Gewicht der Drahteinlagen, Armstützen usw. ist sehr gering. Die 7 gürtelförmigen Drahteinlagen (Fig. 5) wiegen nur $25 \mathrm{~g}$.

Aus dieser Darlegung wird man wohl ersehen, dass mein System bei der Herstellung von Korsetten dem System Mon i e r entspricht, welches heutzutage auf den verschiedensten Gebieten der Technik allgemein anerkannt ist. Nach diesem System wurden anfangs nur Blumentöpfe aus Zement und Draht angefertigt. Heute ist es für Hochbauten unentbehrlich. (Vergl. Anhang „Drahtarbeiten" S. 179.)

\section{Zeugkorsette mit Rundstäben.}

Schon seit vielen Jahren ${ }^{1}$ ) verwende ich bei Zeugkorsetten anstatt der flachen Stützen, runde. Ich habe einige hundert Zeugkorsette mit Rundstäben

1) Vergl. Langenbecks Archiv 1895. 
angefertigt und kann nur sagen, das "Rundsystem" hat sich mir hier ebenso bewährt, wie auf vielen anderen Gebieten der Technik.

Ich verwende steifen Eisendraht oder auch Stahldraht von 3-4 mm Dicke. Man kann diesen Draht im Schraubstock biegen und so sehr bequem den verschiedenartigsten Körperformen anpassen; jedenfalls bequemer als Flacheisen. Gewiss zieht man bisher die Flacheisen den Rundeisen vor, weil man befürchtet, dass die schmalen Rundstäbe empfindlicher drücken, als die breiten Flacheisen.

Diesen Übelstand vermeidet man leicht, wenn man unter jeden Rundstab, eine dünne Stahlplanchette schiebt, wie sie für die gewöhnlichen Damenkorsette benutzt wird (Fig. 7).

Das untere Ende eines jeden Rundstabes biege ich zu einem Ringe von etwa $6 \mathrm{~mm}$ Durchmesser (Fig. 9). Hierzu benutze ich eine Vorrichtung, die ich mir zu diesem Zwecke ersonnen habe (Fig. 133, Taf, XIX vergl. Anhang Drahtarbeiten S. 179). Guten Eisen- oder Stahldraht kann man ohne vorherige Erwärmung mit meiner Vorrichtung zu einem Ringe biegen und es ist nicht erforderlich, mit einem Hammer hierbei nachzuhelfen. Zur Benutzung wird mein Bieger in einen Schraubstock gespannt. Mit den so vorbereiteten Stäben kann man Korsette herstellen mit einem Bügel über der Hüfte und ohne Bügel.

\section{Korsette ohne Hüftbügel}

stelle ich folgendermassen her: ich lasse ein Stoffkorsett, vorn und hinten zum Schnüren, möglichst genau anpassen und in den Rücken und Bauchteil desselben einige Planchetten schieben, damit es bei der Anprobe ohne Falten sitze. Mit Bleistift ziehe ich auf dem angelegten Korset dort Striche, wo ich die Stützen anzubringen wünsche.

Die Rundstäbe werden nach dem Schema Fig. 10 numeriert. Auf den Ring eines jeden Rundstabes wird seine Nr. mit einer römischen Ziffer gefeilt.

Für I, II, V, VI kommen Stäbe von 2-4 Millimeter Dicke zur Verwendung. Die Dicke schwankt nach der Körpergrösse.

Diese Stäbe biegt und formt man genau nach den Bleistiftstrichen auf dem angelegten Korsett.

Man lasse den Patienten beim Anbiegen der Stäbe zuerst sitzen, damit man die Länge der vorderen Stäbe bestimmen kann.

Die vorderen Stäbe müssen übrigens 2 Zentimeter vor der Hüftbeinspitze angelegt werden, da sie sonst sehr empfindlich drücken können. Hat man im Sitzen die Länge der vorderen Stäbe bestimmt, so lasse man den Kranken stehen, da beim Stehen infolge der veränderten Beckenstellung die Biegungen der Wirbelsäule erheblich anders als beim Sitzen ausfallen. Besonders auffallend ist dieses an den Rückenstäben. Ihnen ist eine Biegung zn geben, die zwischen der Krümmung der Steh- und Sitzbiegung der Wirbelsäule liegt.

Wer erst mit eigner Hand für verschiedene Körperstellung Korsettstützen gebogen hat, der wird einsehen, dass Korsette nie so genau am Körper sitzen können, wie oft angenommen wird. - 
Nachdem man über die Bleistiftstriche Zeugstreifen mit der Näbmaschine hat nähen lassen, schiebt man unter dieselben zuerst die Stahlplanchetten und dann über diese die nach den Körperformen gebogenen Stäbe.

Die ringförmigen unteren Enden der Stäbe werden in taschenartige Lederhülsen geschoben (Fig. 7), die man an das Korsett näht. Der Ring ist gleichfalls anzunähen, damit die Stäbe sich nicht drehen. Auf die oberen Enden der Stäbe setze ich die Armstützen (Fig. 9). Sie bestehen aus einem Stücke Draht (Dicke 5 Millimeter). Die Enden desselben sind im rechten Winkel abgebogen. Auf diese abgebogenen Enden werden Messingröhren von 10-12 Zentimeter Länge geschoben (Fig. 9) und mit Streben befestigt. Die Streben werden mit verzinntem Draht bewickelt und mit einer Lötlampe gelötet. Ich gebe diesem Draht mejst die hier abgebildete gradlinige Form, da derartig gestaltete Armstützen weniger empfindlich auf die Muskeln der Achselhöhle drücken, als die allgemein gebräuchlichen halbmondförmigen. Man kann aber auch den Armstützen die Form Fig. 11 und Fig. 8 geben, indem man eine Bruststütze mit Ring für Befestigung des Dochtes anbringt. Er wird mit dünnem Drahte angebunden und verlötet.

Der Draht der Armstützen wird mit dickem, weissen Filz benäht. Man hüte sich, die Polsterung zu umfangreich zu gestalten, da sonst ein Druck auf die Armnerven ausgeübt wird, die längs der Oberarmknochen verlaufen und so leicht Vertaubungen entstehen.

Die so gepolsterte Armstütze erbält einen Überzug von Korsettstoff, der an das Korsett mit einigen Stichen geheftet wird.

Derartige Armstützen verhüten durch ihre Form und Polsterung mit Sicherheit das Wundwerden der Achselhöhle, welches nur zu häufig durch die aus Flacheisen geschmiedeten und mit Leder iberzogenen halbmondförmigen Armstützen verursacht wird.

Wünscht man die Armstützen höher zu stellen, so ziehe man sie von den Korsettstützen und lege in die Röhren Eisenstäbchen von 1/2-1 Zentimeter Länge (Fig. 9), die man zu diesem Zwecke jedem Patienten einhändigt. Das Niedrigerstellen wird besorgt, indem man Stücke von den Korsettstützen schneidet.

Das richtige Einstellen der Armstützen ist von der grössten Bedeutung für die Behandlung der Verkrümmungen und Entzündungen der Wirbelsäule. Hierin wird oft viel gefehlt bei wachsenden Kindern.

Die Stäbe für den Rücken (siehe Numerierschema III und IV, Fig. 10) werden am oberen Ende einfach umgebogen (Fig. 7). Zu ihnen verwende ich stets einen Draht, der etwas dicker ist, als die Seitenstäbe. Zum Zurückziehen der Schultern wird Lampendocht an den obersten Ösen der hinteren Schnürnaht mit Korsettschnur befestigt, über die Schulter gelegt und durch eine Korsettschnur an der Armstütze befestigt (Fig. 7). Um das Herabziehen der Schultern möglichst zu vermeiden, sind die Rückenstäbe recht lang zu nehmen.

Bisweilen lege ich auf den Rücken ausser den Stäben III und IV noch einen dritten Stab (Fig. 10, VII). Dann ist am oberen Ende dieses Stabes 
VII eine zweite Korsettschnur zu befestigen, welche an den Achseldocht gebunden wird.

Diesen Stab VII verwende ich nur, wenn die Vorwölbung am Rücken bedeutend ist. Ich glaube nicht, dass der Stab VII die Wölbung zurückdrückt, es glauben das aber viele Mütter und Ärate und daher lege ich zu ihrer Beruhigung den Stab an. Natürlich bedürfen die Korsette oft mehrerer Anproben. Sie haben aber hierbei den Vorzug, dass alle Änderungen an ihnen sehr schnell vorgenommen werden können, besonders wenn man es nicht von vornherein vollständig fertig stellt. Ich lasse die Enden der Rundstäbe erst dann mit Leder benähen, wenn das Korsett einige Tage getragen ist und nicht mehr drückt. Man lasse das Korsett sofort ablegen, wenn ein Stab drückt und warte nicht darauf, dass der Patient sich vielleicht "an das Korsett gewöhnt".

Man ziehe hierauf den betreffenden Stab heraus, ändere seine Biegung, wähle für ihn eine günstigere Körperstelle usw. Ist das Korsett richtig angelegt, so sitzt es derartig fest am Körper, dass man bei einigermassen stark entwickelten Hüften, nicht imstande ist, es nach unten zu schieben, wenn man mit den Händen die Armstützen erfasst und einen starken Zug nach unten ausübt.

Bei schwach entwickelten Hüften verhüte ich das Herabrutschen des Korsetts durch einen Gurt aus Lampendocht, der unter dem Korsett über den Hüften getragen wird. Ich lasse ihn vorn mit Korsettschnur binden und ziehe ihn durch 4 Schlaufen aus Docht, die an das Korsett genäht sind. Durchaus zu verwerfen ist es, den Gurt an das Korsett zu nähen. Er schmiegt sich dann nicht mehr genügend dem Körper an. Ist er aber bloss durch 4 Schlaufen am Korsett befestigt, so schliesst der weiche Gurt so genau, dass er wohl kaum über die Hüften rutschen kann, jedenfalls nicht leichter als die starren Hüftbügel (Fig. 12).

Übrigens kann man auch mit Rundstäben sehr bequem herstellen.

Korsette mit Hüftbügeln (Fig. 8 und 11).

Die Stäbe I und II werden von einem Drahte umschlungen, dessen Enden man mit dünnem, verzinnten Drabt bewickelt und verlötet. Der so entstandene Hüftbügel wird mit zwei Drähten an den Ledertäschchen $I$ und II befestigt. Um den Hüftbügel wird eine Ärt Ledertasche gelegt, die verhältnismässig weit ist, um Verschiebungen des Bügels zu gestatten. Diese Tasche ist oberhalb des Bügels an das Korsett zu nähen. Die Tasche wird mit einer Klappe aus Stoff verdeckt.

Eine Bruststütze kann gleichfalls an der Armstütze befestigt werden (Fig. 8 und 11). Der Druck der Stütze wird vermindert durch ein Stück Zinkblech, welches mit Filz gepostert ist. Das Blech wird mit dünnem Drahte an der Bruststütze derartig befestigt, dass es drehbar ist und sich stets flach auflegt.

\section{Gegen Hïhnerbrust}

verwende ich die Vorrichtungen Taf. III, Fig. 13 und 14. 
Ein Drahtgestell (4 Millimeter Dicke) wird mit Zinkblech beschlagen. Die unbezogenen Blechränder werden mit Einschlagösen befestigt. Durch die Einschlagösen wird Filz angenäht. An den Korsettstïtzen (Fig. 7, Taf. II) wird die Vorrichtung mit Korsettschnur befestigt. Ein Gurt aus Docht wird um den Rücken gelegt und gleichfalls an den Korsettstützen vorn befestigt.

Kopfstütze aus Draht (Taf. III, Fig. 15).

An Stelle des Notmastes u. dergl. verwende ich ein Drahtgestell, das nach Art einer Kravatte den Hals umschliesst ${ }^{1}$ ).

Mit diesem Gestell stützt sich der Kopf auf die Schultern, die wiederum auf ein Korsett sich stützen, welches mit Achselstützen versehen ist (Fig. 7, Taf. II) and durch Gurte die Schultern nach hinten zieht. Das Gestell besteht aus einem Rahmen, der aus einem einzigen Stück steifen Draht von 3 Millimeter Dicke gebogen ist (Fig. 16a). Er wird durch zwei kleinere Rahmen verstärkt, die an mehreren Stellen mit verzinntem Draht gebunden und gelötet werden. Dieses Gestell kann man sehr bequem und genau anpassen, indem man es mit den Händen oder im Schraubstock entweder zusammendrückt oder ausreckt.

Der obere und untere Rand wird mit Filz benäht und mit einem glatten Stoffe bezogen. Hinten lasse ich einen Riemen anbringen und eine Schnalle mit Draht annähen (siehe Anhang Drahtarbeiten). Ausserdem ist noch das Gestell hinten mit einer Korsettschnur am Korsett $\mathrm{zu}$ befestigen, damit es sich nicht dreht oder nach vorn rutscht. Auf den Schultern wird das Gestell an den Gurten befestigt, welche die Schultern nach hinten ziehen.

Bei Schiefhals kann man an diesem Gestell bequem aus dickem Draht seitliche Stützen anbringen, welche die Drehung oder seitliche Neigung des Kopfes beseitigen.

Ausser diesen Seitenstützen verwende ich in schwereren Fällen des Schiefhalses noch Zïge aus Heftpflasterstreifen, die ich über die Stirn oder unterhalb des Kinnes lege. Das freie Ende des Heftpflasters wickele ich um ein Stück Sohlenleder, welches ein Loch für die Korsettschnur hat, die entweder am Kopfhalter oder an den Armstïtzen des Korsettes befestigt wird.

Das hintere mit einer Schnalle versehene Ende ist verstellbar (Fig. 16). Daher kann man die Vorrichtung für verschiedene Halsweiten einstellen.

\section{Liegerolle gegen Verkrümmungen der Wirbelsäule.}

Zum Überkorrigieren der seitlicben Verkrümmungen benutze ich eine Rolle, welche an der vorgewölbten Stelle des Rumpfes befestigt wird.

Fig. 17, Taf. III zeigt die Befestigung der Rolle. Ein Gurt aus Docht wird über die linke Schulter gelegt, der andere um den Leib.

Diese Befestigung erhält die Rolle stets genau auf der Stelle, an welcher der Druck ausgeübt werden soll und gestattet trotzdem dem Kranken kleine

1) In schweren Fallen gipse ich Dach $\mathrm{Ca}$ lot. Auch hierbei verwende ich meine Drahteinlagen. Vergl. Calot, Die Behandl. der tuberkul. Wirbelsäulenentz., übersetzt von Ew ald. Stuttgart. Enke. 1907 
Lageveränderungen im Bette. Es empfiehlt sich bei der in Fig. 17 dargestellten Lagerung die linke Schulter gegen die Wand stützen zu lassen, an welcher das Bett steht.

Die Kranken gewöhnen sich bald an diese Lagerung und können dann sogar die ganze Nacht in ihr schlafen.

Bei vorstehender Hüfte lasse ich die Rolle auf diese Hüfte legen und den einen Gurt um den Leib schnallen, den anderen um ein Bein schlingen. In vielen Fällen ist es notwendig, die Rolle abwechselnd auf die Hüfte oder auf den Rücken zu legen.

Bei schweren Verkrümmungen lasse ich diese Lagerung wochenlang Tag und Nacht durchführen. Das Aufstehen gestatte ich nur zu den Übungen, zum Essen usw.

Die Anfertigung der Rolle.

In einen Schlauch aus festem Matratzenstoff von 40 Zentimeter Länge, 20 Zentimeter Breite lässt man recht fest Holzwolle stopfen und dann die Rolle mit einem Möbelstoffe beziehen. Zwei Gurte aus Lampendocht umschliessen die Rolle (Fig. 18) und werden mit einigen Stichen an den Stoff genäht. Durch diese Gurte zieht man die Dochte, welche um den Leib geschnallt werden. Am einen Ende des Dochtes befindet sich ein Stück Riemen, am andern eine Schnalle.

\section{Verstellbare Schienen.}

\section{Beinsehienen aus Blech.}

Die Herstellung von Blechschienen bereitet nur sehr geringe Schwierigkeiten. Mit einer guten Blechschere ja sogar mit einer guten Schneiderschere schneidet man ein dünnes Blech, mindestens ebenso bequem wie Pappe mit einem Messer. Das Umbiegen der Ränder über Holz oder Eisenstäben geht schnell von statten. Hierauf formt man leicht über dem eignen Unterschenkel dachrinnenartige Schienen. Ich habe im russisch-türkischen Kriege 1877 auf den Verbandplätzen oft derartige Schienen hergestellt und sie haben sich stets besser bewährt, als die aus nasser Pappe angefertigten Schienen. Die Blechschienen haben ausserdem in Feldlazaretten den Vorzug, dass man sie leicht sterilisieren, also längere Zeit benutzen kann, während Pappschienen erneuert werden müssen und so dazu nötigen durch grössere Vorräte von Pappe das Gepäck sehr zu erschweren. Dünnes Blech ist kaum schwerer als dicke Pappe. Sehr zu empfehlen ist es einige flache zugeschnittene Blechstücke im Verbandwagen zu führen. In Friedenszeiten fertigt man selbstverständlich nur ausnahmsweise mit eigner Hand Blechschienen an. Ich lasse mir grössere Mengen vom Klempner herstellen und halte stets einen grösseren Vorrat. Als früherer Landarzt führte ich in meinem Wagen fast immer derartige Schienen bei mir. Hatte ich sie zu Hause gelassen, so vermisste ich 
sie oft schmerzlich, denn ich verlor dann oft viel Zeit mit dem Herstellen von Pappschienen, Holzschienen u. dergl.

Die auf Tafel IV abgebildeten Schienen können für sehr verschiedene Beinlängen eingestellt werden. Bei Knochenbrüchen kann man sie zuerst als Liegeschienen und dann als Gehschienen benutzen.

Die Blechteile haben ähnlich den Dachrinnen gewulstete hohle Ränder, welche jederseits ein Rohr bilden. In diese Röhren wird ein langer U-förmig gebogener Draht $(6 \mathrm{~mm})$ geschoben (Fig. $24 \mathrm{U})$. Wünscht man eine Schiene zu verlängern, so zieht man den U-förmig gebogenen Draht aus den Röhren und schiebt in jedes Rohr ein Stück dicken Drahtes (vergl. Fig. 20) Verlängerung.

Die Röhren sind am oberen Ende durch einen Drahtbügel verschlossen, so dass der eingeschobene Draht hier einen Halt findet.

Übrigens kann die Schiene auch verlängert oder verkürzt werden, indem man die Fussstütze verschiebt. Gepolstert wird mit dünnen Kissen aus Holzwolle oder zusammengefalteten Handtüchern, die man auf den Grund der Schiene legt. $\mathrm{Zu}$ beiden Seiten des Beines schiebe ich je nach Bedürfnis kleine, feste, wurstförmige Kissen aus Holzwolle ein, die sich ganz besonders zum Korrigieren von Knochenbrüchen eignen.

Zum Überkorrigieren der Knöchelbrüche benutze ich das in Fig. 25 und 26 abgebildete Drahtgestell mit Schnalle und Riemen, welches die Möglichkeit bietet, einen seitlichen Zug auszuüben. Der Riemen ist mit einer doppelten Filzlage zu polstern.

Ich halte diese Art des Überkorrigierens für viel bequemer als das Korrigieren durch seitliche Gewichtszüge. Bei Oberschenkelbrüchen oder Druckmeisselungen des Femur (bei Genu valgum) ersetze ich die seitlichen Gewichtszüge durch kleine wurstförmige feste Kissen, die ich zwischen Bein und Schienenrand schiebe. Hierauf extendiere ich, indem ich am Bügel U (Fig. 20) den Gewichtszug anbringe. Meistens verwende ich hierbei kein Heftpflaster; denn die Schiene ist am Fusse genügend befestigt durch den Riemen, der über den Fussrücken verläuft (Fig. 20). Ich nehme den Riemen $3 \mathrm{~cm}$ breit und polstere ihn mit einer doppelten Filzlage. Auf diese Art extendiere ich im Augenblick ein krummes Knie mit $15 \mathrm{~kg}$, ohne dass irgendwelche Druckschmerzen am Fussrücken entstehen. Oberhalb der Achillessehne lagere ich den Unterschenkel auf einen breiten Riemen oder breiten Docht, der mit doppelter Filzlage zu polstern ist (Fig. 20). Unter das Fussende der Schiene lege ich eine glatte Holzplatte. Das Fussende des Bettes stelle ich hoch.

Leider wird das Überkorrigieren bei Knöchelbrüchen nur zu oft ungenügend ausgeführt. Überhaupt sieht man nach Knöchelbrüchen nur zu häufig Plattfüsse, Klumpfüsse und Spitzfüsse, weil - wie mir scheint - in der Privatpraxis die Verwendung von Schienen noch zu wenig verbreitet ist und Gipsverbände die Stellung des Fusses häufig sehr verschleiern. Bei Schienen ist das viel weniger der Fall, ausserdem bieten Schienen die Möglichkeit schon frühzeitig Massage und Bewegungen vorzunehmen.

Ich lasse bei Knochenbrüchen während der Bewegungen des Fusses das Bein in den Schienen liegen und entferne bloss die Fussstütze (Fig. 24). 


\section{Technisehes:}

Die Blechteile lasse ich aus verzinntem Eisenblech $(0,5 \mathrm{~mm}$ Dicke) herstellen nach den in Fig. 22 I und II gegebenen Massen. Für Knochenbrüche und für Gehschienen empfiehlt es sich statt der Teile I und II eine einzige Blechrinne von etwa $60 \mathrm{~cm}$ Länge zu verwenden, die etwas konisch sich verjüngt.

Die zu Röhren umgebogenen Stücke lasse ich nicht einfach verlöten, sondern mit Einschlagösen befestigen oder mit Draht vernähen, da sie so bedeutend widerstandsfähiger sind. Die Rohrenden müssen durch Streifen dicken Bleches verstärkt werden (Fig. 20, 24 usw.), die man mit Kupfernieten befestigt.

Die Röhren lässt man über einem Eisenstabe von $1 \mathrm{~cm}$ Dicke anfertigen, damit der U-förmig gekrümmte Eisenstab von $6 \mathrm{~mm}$ bequem in ihnen verschoben werden kann.

Verschlossen werden die Röhren des Blechteiles II oben durch einen Drahtbügel von $6 \mathrm{~mm}$, dessen Enden rechtwinkelig abgebogen sind (Fig. 20). Befestigt am Blechteil wird der Bügel mit Bindedraht, welchen man durch Einschlagösen zieht, die in der Nähe der rechtwinkelig umgebogenen Bügelenden liegen. Diese Befestigung bietet die Möglichkeit, den Drahtbügel bequem zu entfernen, falls die Röhren verstopft sind. Der Bügel u (Fig. 20) wird mit einem starken Bande am Blechteile I befestigt, der Teil I am Teile II.

Die Fussstiitze besteht aus einem Drahtgestell (Fig. 21), an dem eine Blechsohle mit aufwärts gebogenen Rändern befestigt ist (Fig. 19). In der Blechsohle befinden sich Einschlagösen, welche den Querteilen (Fig. 21a und b) des Drahtgestelles entsprechen. Durch diese Ösen ziehe ich eine feste dünne Schnur und befestige so die Blechsoble. Die unteren Enden des Drahtgestelles (Fig. 21 c, c) ruhen auf dem Fussende der Schiene. Durch die Enden c, c wird ein langer Stift geschoben, nachdem man die Enden c, c auf das Fussende gesetzt hat. Das umgebogene Ende des Stiftes wird mit einem Bande an der Schiene befestigt. Jetzt kann die Fussstütze nicht mehr abgehoben werden. Mit einer Schnur S (Fig. 19) befestigt man die Fussstütze an einer Einschlagöse des Blechteiles I (Fig. 20). Diese Schnur ist in Fig. 20 nicht abgebildet, wohl aber in Fig. 19, 21, 23.

Die seitlichen Ränder der Blechsohle (Fig. 19 und 20) sind rechtwinkelig aufwärts gebogen, um seitliche Drehungen des ganzen Beines zu verhüten.

Sie bieten ausserdem die Möglichkeit den Fuss ganz ohne Binden an Blechschuh zu befestigen. Es genügt hierzu vollständig, einen Riemen oder Docht über den Fussrücken zu legen und an beiden Enden zu befestigen. Der Riemen ist mit Filz zu polstern. Auf das Knie lege ich eine Filzkappe mit einem Loche für die Kniescheibe und umwickele es mit Binden.

Bei Verletzungen im Knie oder Oberschenkel genügt olt die in Fig. 21 abgebildete Fussstütze d. i. ein Drahtgestell ohne Blechschuh.

Die Querteile (Fig. 21 a und b) verbinde ich miteinander durch gelochtes Blech oder Drahtgewebe, welches ich mit Filz polstere. Besonders für Schweissfüsse kann ich diese steigbügelartige Vorrichtung sehr empfehlen. 
Der U förmige gebogene Draht (Fig. 20, 24, 25 U) ist aus steifem verzimnten Eisendraht $(6-7$ Millimeter Dicke) anzufertigen. An seinem Sohlenteile ist mit Bindedraht ein zweites Stück zu befestigen (Fig. 20, 24, 25).

Für Gehschienen (Fig. 24) werden die beiden Drähte mit Blech beschlagen. Durch Löcher dieses Bleches wird mit Draht Sohlenleder angenäht.

Die Streckung krummer Kniee mit meinen Schienen ist auf Taf. V dargestellt. Fig. 32 zeigt ein krummes Knie, dessen Kniekehle sich auf eine verstellbare Riemenschwebe stützt. Diese Stützung ist nach meinen Erfahrungen von der grössten Wichtigkeit, denn sie entspannt die Beugemuskeln des Kniegelenkes. Ganz besonders wichtig ist diese Stützung aber nach Sehnendurchschneidungen bei starkgekrümmten Knien. Es ist ja ganz allgemein anerkannt, dass eine plötzliche gewaltsame Streckung in diesen Fällen meist mit grossen Gefahren verbunden ist. Man schient daher unmittelbar nach der Durchschneidung das Knie zunächst in gekrümmter Stellung und streckt erst allmählich. Zu dieser allmählichen Streckung eignet sich meine Schiene mit mittlerer Stützung (Fig. 32) ganz besonders.

Übrigens halte ich es nach meinen Erfahrungen für durchaus notwendig, bei Kniegelenkentzündungen Durchschneidungen der Beugesehnen weit häufiger vorzunebmen, als es im allgemeinen geschieht. Bei gekrümmten, schmerzhaften Knieen wirkt eine Durchschneidung der Beugesehnen ebenso erlösend, wie eine Iridektomie bei Glaukom. Ich sehe daher gar nicht ein, warum man diesen ganz ungefährlichen Eingriff nicht schon frühzeitig vornehmen soll. Hat sich erst eine Bayonettstellung ausgebildet, dann liegen die Verhältnisse schon viel ungünstiger.

Bei Durchschneidungen unter der Haut kann man Verletzungen des Nerv. peroneus sicher vermeiden, wenn man nach der Vorschrift von Gocht, vor der Durchschneidung das Knie stark beugt und die Beugemuskeln pharadiziert.

Zur Entspannung der BeugemuskeIn bei frischen Entzündungen usw. stelle ich die Riemenschwebe immer so, dass sie einige Zentimeter unter der Kniekehle sich befindet. Wenn nun das Knie durch Binden oder Riemen so weit gestreckt wird, dass es die Riemenschwebe erreicht, so lässt der Gegenzug der Beugemuskeln nach und das Knie verharrt schmerzlos in seiner Stellung.

Nach einigen Tagen wird die Riemenschwebe niedriger gestellt usw. Ich habe oft auf diese Art die sehr empfindlichen Kniee der Bluter ohne Schwierigkeiten gestreckt und habe es oft gesehen, dass sofort Schmerzen eintreten, wenn vom Kranken oder seinen Angehörigen die Riemenschwebe entfernt wurde. Oft entstanden hierdurch sehr grosse Rückschritte, so dass ich die Riemenschwebe wieder sehr bedentend höher stellen musste. Leider wurde dieser mittlere Stützpunkt bisher nur wenig berücksichtigt, namentlich bei den Schienenhülsenverbänden und es entsteht dann leicht wie die Bandagisten sagen ein "Spitzknie.“

Fig. 27 und 28 zeigen das Schema der von mir geübten allmählichen Kniestreckung. Ich wandte sie schon im russisch-türkischen Kriege 1877 an und 
es gelang mir bei einem Soldaten ein Knie zu strecken, das nach einem Knieschusse eben erst in Winkelstellung ausgeheilt war ${ }^{1}$ ).

Eine spitzwinkelige Verkrümmung des Kniegelenkes bei der die Ferse am Sitzknorren lag, streckte ich in drei Monaten mit Schiene 35, 36. Es handelte sich hier um eine spastische halbseitige Lähmung, die schon mehrere Jahre bestand.

Ein mit Filz gepolsterter Drahtbügel stützte sich gegen den Sitzknorren, der Unterschenkel ruhte in der Blechschiene mit Fussstütze. Gestreckt wurde mit der Kniekappe (Fig. 37, 39). Anfangs ging das Strecken verhältnismässig leicht von statten, zum Schluss traten allerdings grössere Schwierigkeiten ein, welche nur durch sorgfältige Berücksichtigung des mittleren Stützpunktes (Schema Fig. 28 m. S.) beseitigt wurden. Ich benutzte im Anfang die Schiene Fig. 35, 36, später die Schiene Fig. 32 mit Riemenschwebe, zuletzt die Schiene Fig. 30 mit Gewichtszug bei U. (Siehe Seite 116.)

Bei frischen Verletzungen und Entzündungen des Kniees leichteren Grades genügt oft die Schiene Fig. 31. Die eigentümliche mittlere Biegung der Schiene ist durchaus erforderlich um die Binden zusammenzuhalten, welche um das Knie gewickelt werden.

Diese Binden bilden zugleich einen mittleren Stützpunkt für die Kniekehle. Vor dem Anlegen der Schiene lege ich stets meinen Filzdruckverband an (siehe Seite 103 und Taf. I, Fig. 2). Um zu verhüten, dass die Schiene nach unten rutscht, befestige ich an ihrem oberen Ende ein starkes Band, welches um einen Gurt geschlungen wird, der über dem Hemde um den Leib gelegt ist. Ich lasse diesen Gurt aus Lampendocht anfertigen und vorn mit einem Bande zusammenbinden. Eine Schnalle ist hier zu vermeiden, da sie drückt.

Sowohl über diese Schiene Fig. 31, als über die Gehschiene Fig. 24 kann man Beinkleider ziehen.

Verstellbare Gehschienen sind auf Taf. VI dargestellt. Die Gehschiene aus Blech, die auf Taf. IV in Fig. 24 abgebildet ist, lasse ich nur vorübergehend bei frischen Verletzungen und Entzündungen des Beines tragen.

Fig. 37 zeigt eine Gehschiene aus Flacheisen oder Flachstahl mit gestanzter Hohlkehle. An ihrem unteren Ende ist eine Blechscheide befestigt, in die ein U förmig gebogener Bügel aus Flachstahl geschoben wird (Fig. 37, Fussbügel).

Ich halte derartige Bügel in verschiedenen Grössen vorrätig und kann daher meine Schiene sehr bedeutend verlängern oder verkürzen.

Zur feineren Einstellung dienen Stücke ron Bandeisen, welche jederseits in eine Blechscheide geschoben werden, nachdem man den Fussbügel herausgezogen hat (Fig. 38).

Am oberen Ende der Schiene befindet sich ein Sitzbügel, der mit Filz gepolstert wird. Das Bein liegt auf drei Stützpunkten 1. auf dem Sitzbügel, 2. auf einem Riemen unter der Kniekehle (Fig. 37 m. S. $==$ mittlerer Stütz-

1) Vergl. Monatsschrift f. Unfallheilkunde. 1895. Dezember. 
punkt, 3. auf einem Riemen oberhalb der Achillessehne. Von oben hin wird die Schiene gehalten 1. durch einen. Docht in der Schenkelbeuge (in Fig. 37 nicht dargestellt), 2. durch eine lederne mit Filz gepolsterte Knieknappe, 3. durch einen Riemen, der über den Fussrücken geschnallt wird.

Dieser Riemen verhindert auch die Schiene nach unten zu rutschen und nur selten wird es notwendig, sie an einem Tragbande zu befestigen, welches über eine Schulter gelegt wird.

Die hier beschriebenen Riemen genügen nach meinen Erfahrungen vollständig zur Befestigung der Schienen und machen Schienenhülsen aus Leder unnötig. Meine Art der Befestigung hat den Vorzug, dass sie den Blutkreislauf des Beines gar nicht behindert, denn alle Riemen sind so angeordnet; dass sie nirgends ringförmig das Bein umschliessen. Es bleiben überall Bahnen offen, welche ungehindert den Rückstrom des Blutes gestatten. Bei empfindlichen Knieen lege ich zuerst einen Filzdruckverband an (vergl. Seite 104 und Taf. I, Fig. 2), dann eine kurze Drabtschiene von der Form Fig. 33, die nach der Krümmung des Kniees gebogen wird und hierüber erst die Gehschiene (Fig. 37).

Bei ernsteren frischen Kniegelenkerkrankungen, die grössere Schmerzen verursachen, verwende ich die Blechschienen Fig. 24, 30, 32.

Technisches. Die aus Flacheisen oder Flachstah] gestanzten Schienen lasse ich stets verzinnen, da man dann sehr bequem den Sitzbügel und die Blechscheiden mit Bindedraht befestigen und mit einer Lötlampe verlöten kann.

Der Sitzbügel wird aus steifem verzinnten Eisendraht $(7 \mathrm{~mm})$ hergestellt. Die Enden werden in die Hohlkehle der Schienen gefügt, verstrebt, mit Bindedraht umwickelt (siehe Anhang Seite 179 u. Taf. XIX) und verlötet.

Die Blechscheiden für den Fussbügel werden oben mit einem Stück Bandeisen geschlossen (Fig. 38). Dieses Stück Bandeisen wird mit Bindedraht an der Schiene befestigt. Bandeisenstücke zum Stellen halte ich in Längen von $1-3 \mathrm{~cm}$ vorrätig. Die Blechscheide ist an der Innenseite nicht vollständig geschlossen, damit man bequemer die zum Stellen dienenden Bandeisenstücke herausbefördern kann.

Ich lasse die Blechscheiden stets über einem Stücke Bandeisen zusammenbiegen, das einige Millimeter breiter ist als der Stahl des Fussbügels, damit der Bügel bequem aus- und eingeschoben werden kann.

Die Schnallen für die Kniekappe sind mit Bindedraht an einem langen Drahte befestigt, welcher an der Innenseite der Schiene in der Hohlkehle verläuft. Die genauere Befestigung der Schnalle mit Bindedraht siehe Anhang Drahtarbeiten, Seite 179 u. Taf. XIX (Fig. 135).

Die Befestigung der Schnallen an einem langen durchgehenden Drahte hat nach meinen Erfahrungen viele Vorzüge vor der allgemein gebräuchlichen Befestigung mit Riemen und Nieten. Die Nieten schwächen die Schienen, ähnlich wie Holz durch Astlöcher geschwächt würde. Der durchgehende Drabt aber, der in der Mitte und beiden Enden mit Draht gebunden wird, verstärkt die Schiene. Die mit. Draht gebundenen Schnallen sind sehr halt- 
bar, ausserdem kann man sie nach Belieben verschieben und so für verschiedene Stellungen des Knies einstellen, dann sind sie auch so kurz angebunden, wie man es durch Riemen nicht erreichen kann.

Die Fussbuigel lasse ich stets aus Stahl in einer Messerfabrik herstellen und so lochen, dass die Löcher etwa $2 \mathrm{~cm}$ voneinander abstehen. Die Löcher am Sohlenteil dienen dazu, um Sohlenleder mit Draht anzunähen oder bei Brüchen des Sohlenteiles ein Stück Stahl oder Bandeisen aufzunieten. Die Löcher in den Seitenteilen des Bügels benutze ich, um mit weichem Eisendraht $(1 \mathrm{~mm})$ den Riemen, welcher über dem Fussrücken geschnallt wird, so zu befestigen, dass er nicht nach oben rutscht. Auch die Schnallen der Kniekappe verbinde ich durch einen dünnen Draht mit dem oberen Teile der Schiene, damit die Kniekappe nicht abwärts rutscht.

Bisweilen lasse ich über die Blechscheiden Lederhüllen ziehen, um die Schiene zu verdecken. Sebr zu empfehlen ist es, die Schiene mit Tuchstreifen zu bewickeln, die vernäht werden, zur Schonung der Beinkleider.

Den Fussbügel befestige ich gewöhnlich gar nicht an der Stiefelsohle, da ich bemerkt habe, dass die Kranken am besten gehen, wenn sie den Fuss frei bewegen können und mit dem Sohlenteil des Fussbügels auftreten. Nur auf besonderen Wunsch der Kranken verwende ich die in Fig. 40 abgebildete Befestigung des Fussbügels. Auch einen Steigbügel für die Fusspitze benutze ich nur selten.

Die Kniekappe (Fig. 37, 39) lasse ich aus starkem Leder fertigen. In ihrer Mitte lasse ich ein Loch für die Kniescheibe anbringen, in der Mitte jeder Seite befindet sich ein tiefer Einschnitt, damit sich die Kappe besser dem Knie anschmiegt (Fig. 37). Die Riemen dürfen nicht an die Kniekappe genäht werden, da die Nähte bald ausgerissen wurden. Ich ziehe die Riemen durch 4 kleine Querriemen, welche ich mit Einschlagösen oder Kupfernieten befestige. $Z$ wischen beiden Riemen befindet sich jederseits eine Einschlagöse, durch welche eine Korsettschnur gezogen wird, deren Enden ich mehrmals um die Schiene schlingen und dann binden lasse. An dieser Stelle eine Schnalle anzubringen, ist nicht ratsam, da sie auf den Gelenknerven drückt.

Die Drahtschiene (Fig. 42) verwende ich hauptsächlich nach Kinderlähmungen, da sie sehr leicht ist. An Stelle des Sitzbügels verwende ich einen Sitzriemen. Er wird von den Kranken sehr gelobt, da er beim Liegen und Sitzen viel weniger stört, als der gebräuchliche Sitzbügel. Diesen Bügel habe ich nach oben verlegt, wo er gar nicht stört. Übrigens verwende ich auch an meinen Stelzfüssen aus Draht oder Blech derartige Sitzriemen. Ein Lehrer in Riga, dessen Bein so hoch abgenommen wurde, dass nur $10 \mathrm{~cm}$ vom gauzen Bein übrig blieben, trägt einen ron mir angefertigten Stelzfuss aus Draht mit Sitzriemen seit acht Jahren und ist imstande, ununterbrochen bis sechs Kilometer zu gehen, ohne Druckschmerzen zu empfinden.

Das Überkorrigieren von Spitzfüssen, Klumpfüssen und Plattfüssen ist auf Tafel VII dargestellt.

Die Entstehung von Spitzfïssen nach Lähmungen habe ich schon oft 
dadurch verhindert, dass ich unmittelbar nach der Lähmung meine Schiene ${ }^{1}$ ) (Fig. 43, 44) anlegte.

Die Fussspitze stützt sich gegen den Sohlenteil der Schiene (Fig. 44, Bandeisen), die Wade ruht auf zwei Riemenschweben. Ein Riemen wird über den Fussrücken geschnallt und drückt die Ferse derartig nieder, dass ein spitzer Winkel (Hackenfuss) entsteht. Der Druck eines derartigen Riemens wird sehr gut vertragen. Das weiss ein jeder, der seine Schlittschuhe mit einem ähnlichen Riemen befestigt hat. Trotzdem empfiehlt es sich, den Riemen mit Filz zu polstern oder unter die Zunge des Stiefels Filz zu nähen. Ich lasse die Schienen Tag und Nacht tragen und nur zweimal täglich entfernen zum Bewegen und Massieren (Bewegungen mit meinen Apparaten siehe Seite 167 u. Taf. XIII).

Nachts lasse ich einen Sack aus festem Stoff über die Schienen ziehen um die Bettwäsche zu schonen.

Bei veralteten Spitzfüssen reicht selbstverständlich die Schiene allein nicht aus. Ich mache dann die üblichen Durchschneidungen und gewaltsamen Bewegungen in der Narkose und lege dann sofort meine Schiene an.

Wenn man die Schiene Fig. 44 als "Liegeschiene" benutzt, so empfiehlt es sich bei $\mathrm{S}$ einen zweiten Drahtbügel anzubringen, damit die Ferse nicht auf der Matratze liegt. Für Gehschienen ist dieser Bügel nicht zu empfehlen da er beim Treppensteigen sehr stört.

Spitzfüsse nach Knochenbrüchen bei Unfallkranken, die mir zur Nachbehandlung übersandt wurden, habe ich stets sehr erfolgreich mit der Schiene Fig. 44) und mit meinen Bewegungsvorrichtungen behandelt. Obgleich die Kranken sehr gut mit meiner Schiene gehen können, empfiehlt es sich doch, sie möglichst viel liegen zu lassen. In vielen Fällen sind auch zur Beseitigung von Spitzfüssen lange Schienen für das ganze Bein erforderlich, die sich gegen den Sitzknochen stützen. An diesen Schienen bringe ich Steigbügel an (vergl. Taf. IV, Fussstütze Fig. 21).

An Stelle dieser Fussstïtze (Fig. 21) genügt auch oft eine einfache Vorrichtung, die man an der Stiefelsohle befestigt. Ein starker Draht (1,5 mm), nach Art einer Haarnadel gebogen, wird quer zwischen Sohle und Oberleder durchgeschoben, nachdem man vorher mit einem langen Stichbohrer mit abgebrochener Spitze vorgearbeitet hat. Die durchgeschobenen Enden des Drahtes werden zusammengedreht. Hierauf werden die lang vorstehenden Drahtteile so nach aufwärts gebogen, dass zu jeder Seite der Sohle eine lange Drabtöse entsteht. An diesen Ösen kann man bequem Riemen oder Schnüre anbringen, mit denen man die Fussspitze nach oben zieht, indem man die Riemen an der Schiene befestigt.

\section{Zur Behandlung des Klumpfusses}

verwende ich die auf Taf. VII abgebildeten Vorrichtungen.

Selbst bei verhältnismässig nicht sehr ausgeprägten Klumpfüssen nehme ich doch meistens Sehnendurchschneidungen unter der Haut und gewaltsame

1) Vergl. auch Allgem. mediz. Zentralzeit. 1897. Nr. 37 u. 38. Thilo, Schienen gegen Klumpfuss und Plattfuss. 
Bewegungen in der Narkose vor. Hierauf befestige ich eine Soble aus Zinkblech ${ }^{1}$ ), die mit Filz gepolstert ist (Pig. 51, 52), durch Heftpflasterstreifen am Fusse. Der Streifen a, Fig. 50, wird zuerst quer über die Haut der Fusssohle gelegt, dann erst lege ich die Blechsohle an und wickele nun den Streifen a um Fuss und Blechsohle. Hierauf winde ich spiralig den Streifen um den Unterschenkel und erziele so eine Plattfussstellung des Fusses.

Ein zweiter Heftplasterstreifen b verläuft quer über die Sohle und zu beiden Seiten des Unterschenkels. Jetzt umwickelte ich Blechsohle, Fuss und Heftpflaster mit weichen Marlibinden. Hierüber lege ich $z \mathfrak{u}$ beiden Seiten des Unterschenkels zwei Filzstreifen, welche durch eine Strippe miteinander verbunden werden (Fig. 49). Ein Stück Filz wird auf den Fussrücken gelegt und nun alles wiederum mit weichen Marlibinden umwickelt. Dieser ganze Verband wird von aussen mit einer sirupdicken Zelluloidlösung angestrichen. Man kann übrigens auch den Filz mit Binden umwickeln, die reich mit Zelluloidlösung getränkt wurden, doch ist dieses für die Finger weniger angenehm.

Während des Anstreichens mit Zelluloidlösung lasse ich ein Stück Pappe vor das Gesicht des Kindes halten und das Fenster öffnen.

Nachteilige Wirkungen des verdampfenden Azetones habe ich übrigens nie gesehen. Der so angefertigte Zelluloidverband hält sehr fest, schon wegen der an der Blechsohle befestigten Drähte (Fig. 49, 52). Ich lasse ihn gewöhnlich nur zwei Wochen ununterbrochen am Fusse und wandele ihn dann in einen abnehmbaren Verband um.

Ich durchschneide ihn vorn über einem untergeschobenen Streifen Bleiblech, entferne aus seinem Inneren das Heftplaster und die Binden innerhalb des Filzes. Die Blechsohle und der Filz sind fest mit den Zelluloidbinden verbunden und bleiben im Verbande.

Haken zum Schnüren werden angenäht und der ganze Verband wird von aussen wieder mit Zelluloidlösung angestrichen. Der so bearbeitete Verband kann wochenlang getragen werden, besonders, wenn man ihn von Zeit zu Zeit wieder mit Zelluloidlösung anstreicht.

Ganz selbstverständlich kann man an Stelle der Zelluloidbinden auch Gipsbinden verwenden, indem man über die Blechsohle usw. Gipsbinden wickelt.

Sehr wichtig ist nach meinen Erfahrungen auch die Stütze für die grosse Zehe (Fig. 49, 50). Sie drängt die grosse Zehe so nach innen, dass sie unter die zweite Zehe zu liegen kommt; denn die Sohlenspitze, an der sie befestigt (Fig. 52), ist sehr stark abgeschrägt. Diese bedeutende Überkorrektur darf man sich nur dann erlauben, wenn man an der äusseren Seite der Sohle genügend Raum für die verdrängten Zehen schafft. Dieses erreiche ich durch die ganze Form der Sohle und dadurch, dass ich den äusseren Rand der Sohle an der Spitze ein wenig erhöhe. Man sieht in Fig. 52, dass an der Spitze der Blechsohle ein Stück Blech quer unter die Sohle gelegt und mit Einschlagösen befestigt ist.

1) Ein ähnlicher Verband wurde von mir schon beschrieben in $\mathrm{Hoffas}$ Zeitschrift für orthopäd. Chir. Bd. VI. 
Die Enden dieses Blechstuickes werden rechtwinkelig nach oben gebogen. Das am inneren Rand befindliche Stück (Stütze für die grosse Zehe) ist höher als das am äusseren Rande.

Übrigens vertausche ich den Zelluloidverband bald mit meiner Schiene (Fig. 43, 44), da diese bedeutend energischer überkorrigiert als der Verband.

Zuerst lasse ich einen Stiefel anfertigen, dessen Spitze an der Innenseite stark abgeschrägt ist (Fig. 53, Taf. VIII), um die grosse Zehe genügend zurückzudrängen. Wie sehr dieses möglich ist, erkennt man leicht, wenn man Füsse sich ansieht, die längere Zeit mit unserem modernen schmalspitzen Schuhwerk bekleidet wurden.

Am Mittelstück der Sohlen, welches die Schuhmacher "das Grelenk" nennen, lässt man ein Stück Bandeisen anbringen und über diesen einen starken Drahtbaken befestigen (Fig. 47). Der Draht wird doppelt genommen, ähnlich wie bei einer Haarnadel (siehe auch Fig. 43). Mit dünnem Drahte, den man zwischen Sohle und Oberleder durchzieht, wird der Haken an der Sohle befestigt. Der dünne Draht wird mit dem Haken verlötet (Fig. 47). Der so befestigte Haken wird in die Schiene eingehakt (Fig. 43). Über den Fussrücken wird ein Riemen geschnallt. Fr ist in Fig. 43 nicht abgebildet, wohl aber in Fig. 44.

Mit dieser Schiene können die Kranken sehr gut gehen, obgleich sich der Fuss immer in überkorrigierter Stellung befindet. Ich lasse die Schiene und den Stiefel Tag und Nacht tragen, nur zweimal täglich wird sie entfernt zum Massieren und Bewegen (vergl. Seite 167 und Taf. XIII, Fig. 86, 87.)

Falls man nicht über einen geeigneten Schuhmacher verfügt, so kann man auch selbst ohne Schwierigkeiten eine Art Stiefel herstellen, indem man die Blechsohle (Fig. 51), Zelluloidbinden und Strümpfe benutzt.

Auf den Fussrücken legt man eine schmale Bleiplatte, um beim $\mathrm{Ab}$ nehmen bequem durchschneiden zu können. Hierauf wird ein baumwollener Strumpf auf den Fuss gezogen und die mit Filz gepolsterte Sohle (Fig. 51) angelegt. Fuss und Soble werden mit weichen Marlibinden umwickelt und mit Zellu]oidlösung angestrichen. Hierüber wird ein zweiter Strumpf gezogen und wieder mit Zelluloidlösung angestrichen. Man darf jedoch nur wenig Zelluloidlösung verwenden, da sonst der Verband zu steif wird.

Man lässt den Verband 24 Stunden am Fusse, durchschneidet ihn dann, versieht ihn mit Haken und benutzt ihn hierauf wie den oben beschriebenen Stiefel zum Anhaken an die Schiene ${ }^{1}$ ).

Ist der Klumpfuss genügend korrigiert, so lasse ich am Tage einen Stiefel tragen, dessen Sohle ${ }^{2}$ ) an der äusseren Seite durch Einlegen von Bandeisen verbreitert ist (Fig. 53, Taf. VIII).

Bei ähnlichen Fussleiden der Pferde wird das Hufeisen gleichfalls an einer Seite verbreitert und schützt so vor dem „Umklappen“ des Hufes.

1) Bei Verwendung fertiger, gekaufter Stiefeln wird die Schnurnaht bis zur Spitze verlängert und an der Sohle ein Hacken befestigt.

2) Vergl. Illustrierte Monatsschr. für ärztl. Polytech. April 1893. Thilo, Breite Sohlen gegen das Unklappen des Fusses. 
Der Absatz ist auch etwas nach aussen zu rücken und darf nicht niedrig sein, sondern muss, wie schon Hermann Meyer vorschrieb, „mässig hoch“ sein.

Nachts lasse ich noch monatelang durch meine Schiene den Fuss in überkorrigjerter Stellung erhalten. Überhaupt ist die Nachbehandlung der Klumpfüsse viel länger fortzusetzen als es im allgemeinen geschieht. Nur zu häufig werden Kinder mit Klumpfüssen, nachdem die gröbsten Störungen durch Gipsverbände und Sehnendurchschneidungen beseitigt sind, gänzlich aus der Behandlung entlassen. Sie tragen dann sehr ungeeignetes Schuhwerk und quälen sich dann ihr ganzes Leben hindurch mit den verschiedenartigsten Beschwerden. Gewiss ist es die Pflicht eines jeden Chirurgen und auch Hausarztes, die Eltern darauf aufmerksam zu machen, dass Klumpfüsse ein sehr hartnäckiges Leiden sind, welches eine jahrelange Überwachung durch einen Spezialarat verlangt. Ein Schuhmacher genügt zu dieser Überwachung nicht.

Wie hartnäckig Klumpfüsse sind, das weiss ein jeder erfahrene Orthopäd, der häufig jene Klumpfüsse $z u$ behandeln hat, die einmal als „vollständig geheilt" von sebr verschiedenartigen Ärzten entlassen wurden. Wie lange diese "vollständige Heilung" vorhielt, das erfahren diese Ärzte selbst meist nicht. Die Eltern der Kindern haben eben das Vertrauen zu ihnen verloren und suchen sie nicht mehr auf.

\section{Zur Behandlung des Plattfusses}

verwende ich gleichfalls die auf Tafel VII, Fig. 43, 44 abgebildete Schiene. Am Mittelstück der Stiefelsohle wird am Innenrande ein Haken angebracht (Fig. 47). Mit diesem wird der Fuss in den Schienen eingehakt und in Klumpfussstellung erhalten.

Hierauf lasse ich Stiefel tragen, deren Sohlen am Innenrande verbreitert sind (Taf. VIII, Fig. 53). Dieses Verbreitern führt jeder einigermassen geschickte Schuhmacber so aus, dass man es kaum bemerkt, besonders da heutzutage Sohlen getragen werden, deren Rand weit vorsteht. Auch den Absatz versteht mein Schuhmacher so nach aussen zu rücken, dass man das eingelegte Bandeisen gar nicht bemerkt $\mathbf{1}$ ).

Bei ähnlichen Erkrankungen der Pferde wird das Hufeisen gleichfalls an einer Seite verbreitert und verhindert so sicher das "Umklappen" des Hufes.

Streng zu achten darauf ist, dass der Schuhmacher durchaus den inneren Sohlenrand geradlinig macht und den äusseren leicht abschrägt (Fig. 53). Streng darauf $z u$ sehen ist, dass der Schuhmacher anch wirklich über die Sohle in ihrer ganzen Breite die Bandeisen legt und an der Innenseite sie um $1 \mathrm{~cm}$ vorstehen lässt.

Ich habe es oft erlebt, dass beides die Schnhmacher gern vermeiden. Sie legen ein kleines Stückchen Blech in den inneren Rand eines Stiefels mit schmaler Spitze. Ganz selbstverständlich sieht das entsetzlich aus und selten besitzen Damen den Heroismus, solch einen Stiefel zu tragen.

1) Man kann auch fertige Stiefel mit breiten Spitzen kaufen und von einem „Flickschuster" die Bandeisen usw. anbringen lassen. 
Sehr zu achten ist auch darauf, dass der Stiefel fest am Fusse sitzt. Wenn sich der Fuss im Stiefel dreht, so nützt er wenig. Schon Hermann vo M eyer verlangt, dass bei Plattfuss der Absatz "mässig hoch" sei und er verwirft niedrige Absätze. Ebenso sehr verurteilt Hermann von Me yer ${ }^{1}$ ) die Plattfusseinlagen. Er sagt in seiner ausgezeichneten Arbeit über Klumpfuss und Plattfuss: „Die herkömmliche Auffassung erblickt ihre Hauptaufgabe darin, das innere Fussgewölbe zu beben und den hervortretenden inneren Knöchel zurückzudrücken. Sie arbeitet deswegen auch mit gewölbten Unterlagen unter dem inneren Fusssohlenrande und mit eisernen Schienen an der inneren Seite des Fussgelenkes. Es ist unverkennbar, dass durch beide Mittel das Auswärtsrutschen des Kalkaneus nicht gehemmt werden kann. Im Gegenteil muss die gewölbte Unterlage, welche eine nach aussen abfallende schiefe Ebene darstellt, das Auswärts-Rutschen nur befördern, wenn nicht eine sehr feste und widerstandsfähige Wand an der äusseren Seite des Schuhes angebracht ist. Dass aber eine solche kaum in genügender Stärke hergestellt werden kann, beweist der Umstand, dass bei dem Schieftreten des Schuhes auch die stärkste Kappe dem Andrängen der Ferse nachgibt.

Die vielfach angewendete gewölbte Unterlage unter dem inneren Fussrande mag daher in dem ersten Augenblicke recht wohltätig erscheinen, muss aber das Übel notwendig verschlimmern".

Meine ganze Behandlung des Plattfusses ist begründet auf der von Hermann von Meyer festgestellten Tatsache, dass der Plattfuss durch eine Drehung des Fusses um seine Längsachse entsteht. Diese Tatsache wird wohl ein jeder anerkennen, der die Knochenpräparate $\mathrm{M}$ e yers gesehen hat, welche im Senckenbergmuseum zu Frankfurt a. M. aufbewahrt werden.

Ich lasse die Kranken zunächst gegen zwei Wochen zu Bette liegen und mit meiner Schiene den Fuss Tag und Nacht in Klumpfussstellung erhalten. Zweimal täglich wird massiert und geübt (vergl. Bewegungen Seite 167, Taf. XIII, 86). Hierauf lasse ich die Schiene nur noch nachts anlegen und am Tage Stiefel mit meinen verbreiterten Sohlen tragen. Diese Behandlung hat sich mir seit mebr als zehn Jahren sehr bewährt. Unter meinen Kranken befinden sich viele, die früher erfolglos Plattfusseinlagen getragen haben.

\section{Gegen Hackenfuss}

verwende ich die auf Taf. VIII, Fig. 57-61 abgebildeten Schienen. Hierzu muss der Stiefel etwas länger als gewöhnlich sein, damit man an der Spitze bequem die Schiene befestigen kaun. Ein Stïck dünnes Bandeisen von etwa $2 \mathrm{~cm}$ Breite wird auf die innere Fläche der Sohle ihrer ganzen Länge nach gelegt, damit sich die Sohlenspitze nicht umbiegt (Fig. 59). Auf das Bandeisen wird eine lederne Einschubsohle gelegt. Das Bandeisen wird an der Einschubsohle befestigt ganz vorn in der Mitte, und am Hackenteil.

Auf den Fussriicken ist unter die Zunge Filz zu legen, damit die Zehen nicht gedrückt werden.

1) H. v. Meyer, Ursache und Mechanismus des erworbenen Plattfusses. Jena. Fischer. 1883. Seite 49. 
Zwei Riemen werden am Stiefelabsatz befestigt (Fig. 58). Zwei Schnallen werden mit Draht an der Schiene angebracht (Fig. 60). Mit einem gepolsterten Dochtgurt stützt sich die Schiene gegen den Unterschenkel. Zieht man jetzt die Riemen an, so tritt Sohlenbeugen ein.

Gegen Hammerzehen verwende ich die Einschubsohle ${ }^{1}$ ), Fig. 54, Taf. VIII. Eine starke dünne Schnur wird unter die grosse Zehe gelegt und mit Heftpflaster wird Schnur und Zehe umwickelt. Die Enden der Schnur werden durch zwei Löcher der Einschubsohle gezogen und unter der Sohle geknotet. Über Fuss und Einschubsohle wird der Strumpf gezogen, über den Strumpf der Stiefel.

Die Streckung gekrümmter Zehen mit Hilfe eines Streifens Sohlenleder und Heftpflaster zeigt Fig. 55, 56. Ich wandte diese Behandlung unter anderen bei einer achtzigjährigen Dame an, die nur noch mühsam gehen konnte, weil ihre Zehen sich derartig krümmten, dass ihre Nägel sehr empfindlich von der Sohle gedrückt wurden. Ich legte die Streifen Sohlenleder unmittelbar auf die Haut, ganz ohne Polsterung. Sie wurden vortrefflich vertragen und beseitigten auf Jahre jegliche Beschwerden.

In schwereren Fällen verwende ich Bandeisen, die mit Filz gepolstert und gleichfalls mit Heftpflaster befestigt werden, und durchschneide die Sehnen. Ohne Heftpflaster halten sich die Verbände überhaupt gar nicht.

Ich greife jedoch ungern zu dem starren Bandeisen, da es oft sehr erheblich drückt und auch die Filzpolsterung leicht den Verband zu dick macht.

\section{Verstellbare Armschienen aus Blech.}

Die auf Taf. IX dargestellten Schienen sind ebenso gebaut, wie meine Beinschienen aus Blech (Taf. IV, Beschreibung Seite 117). Nur der Blechteil für die Hand ist anders als die Fussstütze. Es ist nur der eine Rand aufgebogen, um eine Stütze für die Hand zu gewähren, wenn sie in einer Binde getragen wird, die um die Schulter gehängt ist. Der Blechteil für die Handfläche wird am Drahtgestell (Fig. 66) mit dünnem Drahte oder Band befestigt, welche man durch Ösen zieht, die ins Blech geschlagen sind (Fig. 62, 63). Den Blechteil für die Hand kann man bequem vom Gestell ziehen und dann sehr verschiedenartig einstellen (Fig. 65, 67).

Man kann den ganzen Arm in gestreckter Stellung auf die Schiene lagern (Fig. 62), aber auch in gebeugter, indem man das Drahtgestell einfach einbiegt (Fig. 63). Ein Gelenk ist hier an dieser Stelle ganz unnötig, falls man nur steifen 5 bis $6 \mathrm{~mm}$ dicken Draht verwendet.

\section{Die Brüche der Unterarmknochen}

werden noch immer vielfach mit Gipsverbänden behandelt, obgleich doch richtig angelegte Schienen viel bequemer und schneller die Gebrauchsfähigkeit

1) Vergl. Hoff as Zeitschr. f. orthop. Chir. 1895. Bd. IV. Thilo, Einschubsohlen zur Geradriclitung der Zehen. 
der Hand herstellen. Zur Behandlung der Unterarmbrüche halte ich stets einige Schienen vorrätig. In einigen Minuten sind sie angelegt, also viel schneller als Gipsverbände. Der Handrücken ruht auf der Schiene. Oberund Unterarm werden in rechtwinkliger Stellung von den Schienen erhalten (Fig. 63). Ein Heftpflasterstreifen bedeckt den Handrücken und die vordere Hälfte des Unterarmes. Das vordere freie Ende des Heftpflasterstreifens ist um ein Stück schmalen Sohlenleders geschlungen, in dessen Mitte sich ein Loch befindet.

Zieht man durch dieses Loch eine Schnur, so erhält man einen Zügel, mit dem man bequem die vorderen Bruchenden der Unterarmknochen nach vorn ziehen kann, wenn man die Schnur am vorderen Ende der Schiene befestigt. Natürlich muss die Schiene so lang sein, dass ihr vorderes Ende weit uiber die Fingerspitzen hinausragt. Ausserdem muss der Oberarm fest durch Binden gegen seinen Schienenteil gehalten werden.

Auf die Bruchstelle lege ich ein Stück Filz, welches durcb Binden befestigt wird und so eine Kreuzung der Unterarmknochen verhütet. Auch die Hand wird mit Binden umwickelt, jedoch so, dass die Finger frei beweglich bleiben. Mehrmals täglich lasse ich Fingerübungen vornehmen, indem um die Fingerspitzen Korsettschnüre geschlungen werden, die an ihrem unteren Ende kleine Blecheimer mit Gewichten tragen. Die Schnüre werden über den vorderen Schienenrand bei den Übungen gezogen. Auch im Sciultergelenk lasse ich Bewegungen machen. Der Kranke fasst den in der Schiene liegenden Arm mit der gesunden Hand, um ihn beim Heben und Senken zu unterstützen. Auch im Ellbogengelenk sind möglichst frühzeitige Bewegungen zu machen. Gewöhnlich kann man schon einige Tage nach dem Bruch vorübergehend die Schiene entfernen und vorsichtig das Ellbogengelenk bewegen. In den ersten Tagen lasse ich jedoch die Schienen nicht entfernen. Zum Massieren werden nur die Binden vom Unterarm abgewickelt und der Arm bleibt in der Schiene liegen. Nachts wird der Arm mit Hilfe einer Schnur, die am vorderen Ende der Schiene befestigt ist, an einem Nagel aufgehängt, der in die Wand geschlagen wird, an welcher das Bett steht. Unter den Oberarm lege ich alsdann eine Rolle. Ich habe durch diese Behandlung oft in zwei Wochen Unterarmbrüche so weit geheilt, dass die Kranken mit dem gebrochenen Arm eine Hantel von 3 bis 4 Pfund über den Kopf heben konnten und leichte Arbeiten ausführten. Steifheiten der Finger hatte ich nie zu beklagen und auch die Ellbogen und Schultergelenke blieben frei beweglich. Derartige Erfolge kann man gewiss mit Gipsverbänden und überhaupt ohne Übungen und Massage nicht erreichen.

Ich habe oft Gelegenheit, ausgeheilte Unterarmbrüche zu sehen, die ohne Bewegungen und Massage behandelt wurden. Fast immer sind in diesen Fällen geringe Versteifungen im Ellbogen- oder Schultergelenk bemerkbar, ja in einigen Fällen waren sie so bedeutend, dass ich die Gelenke monatelang mehrmals täglich üben und massieren liess, um nur einigermassen sie beweg. lich zu machen. In einem Falle fand ich nach Abnahme des Gipsverbands, der drei Wochen gelegen hat, das Ellbogen- und Handgelenk sehr bedeutend 
versteift; nur die Bruchstelle war vollständig beweglich. In den meisten Fällen war die Steifheit nur dadurch entstanden, dass die Kranken ihre Gelenke $\mathrm{zu}$ wenig bewegt hatten. Im Verbande hatte weder das Ellbogen- noch auch das Schultergelenk gelegen; die Verbände wurden nur bis zum Ellbogen angelegt. Offenbar waren die Schmerzen und Versteifungen der Gelenke durch Entzündungserreger entstanden, die von der Bruchstelle aus durch Blutund Lymphbahnen in die Gelenke verschleppt wurden und dort einen guten, ungestörten Nährboden fanden, weil die Gelenke nicht bewegt wurden.

Ich habe auf diese Ursachen schon im Jahre 1897 hingewiesen und Leichenuntersuchungen zur Begründung meiner Annahme mitgeteilt.

Ganz selbstverständlich benutze ich meine Schienen nicht bloss für Brüche der Unterarmknochen, sondern auch bei vielen anderen Erkrankungen, z. B. bei Gelenkentzïndungen, Verletzungen und Schwellungen der Hand usw. Hand.

Die Schiene (Fig. 63) eignet sich ganz besonders zum Hochlagern der

Die in Fig. 64 angegebenen Masse sind nach dem Arm eines mittelgrossen Menschen bestimmt.

Meine Armschienen für Erwachsene kann man auch als Beinschienen für Kinder benutzen, indem man den Teil für die Hand aufwärts biegt.

\section{Die Versteifungen des Ellbogengelenkes ${ }^{1}$ )}

behandele ich mit den auf Taf. X abgebildeten Vorrichtungen.

Ein Gurt aus Docht von etwa $3 \mathrm{~cm}$ Breite wird um den Brustkorb unterhalb der Achselhöhlen geschnallt. An diesem Gurt lasse ich dann auf dem Rücken, entsprechend der Wirbelsäule zwei Dochte nähen (Fig. 70), von denen der eine über die rechte Schulter, der andere über die linke gelegt wird. Die Enden der beiden Dochte zieht man durch Schnallen, die am Gurt auf der Brust befestigt sind (Fig. 68).

An den Docht, welcher über die Schulter des versteiften Armes verläuft, lasse ich einen dritten Docht nähen hinter der Schulter und mit einem Stücke dicken Filzes unterpolstern. Das freie Ende des Dochtes wird durch eine Schnalle am Handgelenke gezogen. Diese Schnalle ist an einem Dochte befestigt, welcher das Handgelenk umschliesst. Er ist etwa $5 \mathrm{~cm}$ breit und seine Enden sind so aneinander genäht, dass er einen Ring bildet, durch den man bequem die Hand schieben kann (Fig. 69). Da dieser Ring beim Anziehen der Schnalle zum Ellbogen hin gezogen wird, so lasse ich um ihn einen schmalen Docht nähen, welcher den Daumen umschlingt oder zwischen Zeige- und Mittelfinger verläuft. Er verhindert den Ring zum Ellbogen hin zu rutschen.

Der Gurt mit den Achseldochten wird unter dem Rocke getragen und ist daher unsichtbar.

In der ersten Zeit darf der Kranke natürlich die Schnalle am Handgelenke nur ganz leicht anziehen und auch dann nur etwa eine halbe Stunde

1) Vergl. Pet. med. Wochenschr. 1900. Nr. 44. 
angezogen erhalten, damit keine Schmerzen entstehen. Hat er sich aber erst an die Vorrichtung gewöhnt, so weiss er ganz genau, wie stark er anziehen darf, wann er die Schnalle zu lösen hat, um Bewegungen vorzunehmen usw. Viele Kranke haben es erlernt, die ganze Nacht hindurch den Arm angezogen zu erhalten.

Aktive und passive Bewegungen siehe Seite 167 und Tafel XIV, Fig. 102 und 103.

\section{Zum Strecken verkrïmmter Ellbogengelenke}

benutze ich die auf Tafel X dargestellte Schiene aus Draht von $5 \mathrm{~mm}$ Dicke. Die Schiene ist durch einen Gurt befestigt, der um die Schulter geschnallt ist (Fig. 71).

Ein mit Fjlz gepolsterter Bügel stützt sich gegen den Oberarm. Der Unterarm ruht auf einer Schwebe, der Ellbogen auf einer Lederkappe, die mit Filz gepolstert ist. Sie hat ein Loch für den Ellbogen und ist überhaupt ganz so gestaltet wie meine Kniekappe, 'Taf. VI, Fig. 39. Die Schnallen sind mit Draht angebunden (siehe Anhang, Drahtarbeiten, Taf. XIX). Die Schnallen können beliebig verschoben und gestellt werden, indem man sie durch ein starkes Band feststellt, das an den Enden der Schiene befestigt ist. Ich habe mit dieser Schiene viele Unfallkranke erfolgreich behandelt, aber auch hartnäckige Versteifungen nach rheumatischen Erkrankungen. Bei bedeutender Winkelstellung kann man die Schiene krumm biegen. Ganz selbstverständlich wurden nebenbei mit meinen Vorrichtungen sehr ausgiebig Bewegungen gemacht. Die Schiene lasse ich Tag und Nacht tragen, nur zu den Bewegungen wird sie abgenommen.

Die Versteifungen des Schultergelenkes behandele ich gleichfalls mit der soeben beschriebenen Zugvorrichtung, nur wird der Docht, welcher das Gelenk beugt, nicht durch eine Schnalle am Handgelenk, sondern durch eine Schnalle am Ellbogengelenk gezogen (Fig. 74). Die Schnalle ist befestigt an zwei Schlingen aus Docht, deren Enden unter einem rechten Winkel aneinander genäht sind (Fig. 75) und zwar gerade an der Nahtstelle.

Diese Schlingen werden einfach über den Arm wie ein Ärmel gezogen. Bewegungen siehe Taf. XIV.

\section{Bei krummen steifen Fingern}

biege ich ein Stück Bandeisen zunächst genau nach der Krümmung des Fingers. Ich decke ibn mit einem Streifen Filz, den ich durch Löcher des Bandeisens (Taf. XI, Fig. 76) vernähe.

Hierauf lege ich die so entstandene Schiene derartig an den Finger, dass sie von der Fingerspitze bis zur Handwurzel reicht (Fig. 77). Befestigt wird die Schiene mit Heftpflaster, damit die Schiene nicht abrutscht. Über das Heftpflaster ziehe ich eine Hülle von Trikot. Derartige Hüllen lasse ich aus langen Trikotstreifen in verschiedener Breite mit der Nähmaschine anfertigen. 
Stets halte ich einige Meter von ihnen vorrätig und schneide von diesen ein Stück, wenn ich Fingerverbände anlege. Auch bei frischen Fingerverletzungen ziehe ich diese Trikothüllen über die Jodoformgaze und dergl. Das hintere Ende der Hüllen vernähe ich an Heftpflasterstreifen, die entweder um den Finger oder um die ganze Hand geschlungen sind. Hierdurch verhüte ich mit grosser Sicherheit das Abrutschen des Verbandes. Ganz allgemein wird ja dieses Abrutschen dadurch verhütet, dass man entweder die ganze Hand und das Handgelenk mit Binden umwickelt oder den Fingerverband durch ein Band mit einer Binde befestigt, welche das Handgelenk umschliesst.

Ich halte diese allgemein gebräuchlichen Arten der Befestigung für unzweckmässig; denn sie stören den Blutkreislauf der Hand und behindern in hohem Grade den Gebrauch der ganzen Hand. Alle diese Übelstände werden durch einen Heftpflasterstreifen beseitigt.

Schon oben habe ich darauf hingewiesen, dass ich die Fingerschiene genau nach der Krümmung des Fingers biege, wenn ich sie zum ersten Male anlege. Diese Vorschrift ist streng einzuhalten. Wollte man gleich von vornherein eine ganz gerade Schiene an einen stark gekrümmten Finger legen, so würden sich so bedeutende Schmerzen einstellen, dass der Kranke sich kaur dazu noch entschliessen würde, die Schiene fernerhin zu verwenden. Hat man jedoch die Schiene zunächst genau nach der Krümmung des Fingers gebogen, so gewöhnt sich leicht der Kranke an dieselbe und nun kann man alle zwei bis drei Tage die Schiene ein wenig strecken und dann anlegen. So gelingt es dann oft ganz allmählich und schmerzlos stark gekrümmte Finger zu strecken und beweglich zu machen.

Wichtig ist es das Bandeisen stets breiter als den Finger zu nehmen (77). Man vermeidet dann sicher Abschnürungen und Schwellungen. Leider wird diese Regel überhaupt bei allen Schienen oft zu wenig berücksichtigt.

Auf die Narben an der Hand lasse Heftpflaster kleben und Tag und Nacht wollene Handschuhe tragen. Das Heftpflaster wirkt dann wie ein feuchtwarmer Umschlag.

\section{Zur Behandlung steifer Daumen}

verwende ich die auf Taf. XI abgebildeten Vorrichtungen (Fig. 78-80).

Ein Stück Bleirohr von 1,5 bis $2 \mathrm{~cm}$ Durchmesser wird gekrümmt und an der Biegungsstelle geschlitzt, damit man es bequem an dieser Stelle verengern oder erweitern kann (Fig. $78 \mathrm{~A}$ und B).

Die Biegungsstelle wird mit Filz gepolstert ebenso ein Docht mit Schnalle, der um das Handgelenk geschnallt wird. Besonders nach Phlegmonen der Hand und rheumatischen Erkrankungen habe ich häufig sehr erfolgreich diese Vorrichtung benutzt. Übungen des Daumens siehe Taf. XVI und Beschreibung Seite 178.

Zur Hebung des eingeschlagenen Daumens dient das gekrümmte Bandeisen (Fig. $79 \mathrm{~A}$ und B). Es ist sorgfältig mit Filz zu polstern und der Teil, auf dem der Daumen ruht, muss ganz allmählich gestreckt werden. 
Vorrichtung gegen Schreibstörungen. Fig. $80 \mathrm{~A}$ und B.

Schon oben wies ich darauf hin, dass wir keine einzige Handfertigkeit uns ohne Übungen aneignen können. Verlieren wir die einmal gewonnene Handfertigkeit, so gelingt es uns nicht, ohne Übungen sie wieder zu erlangen. Aussichtslos ist daher der Versuch durch Ruhe, Bäder, Arzneien oder Massage ohne Übungen, jene Gebrauchsstörungen der Hand zu beseitigen, die unter dem Namen Schreibkrampf, Klavierkrampf usw. bekannt sind.

Gewiss werden Bäder, Arzneien und Massage oft unentbehrlich sein, um die Erkrankungen fortzuschaffen, welche den Ausgangspunkt der Gebrauchsstörungen bildeten, schwerlich aber wird ein Klavierspieler die verlorene Geläufigkeit der Finger durch Handbäder oder Elektrizität wieder erlangen.

Nur ganz allmählich gesteigerte Übungen können ihm dauernd die Reizund Schwächezustände seiner Hand beseitigen und bleibend die verlorene Leistungstähigkeit herstellen.

Ebenso wird ein Schreiber seine verlorene Fertigkeit nur dadurch wiedererlangen können, dass er seine Hand allmählich wieder an die sehr zusammengesetzten Haltungen und Bewegungen gewöhnt, die zum Schreiben erforderlich sind. Er wird unter Vermeidung gewisser Schwierigkeiten, sich in seine frühere Tätigkeit gleichsam wieder hineinzuschleichen haben.

Hierzu ist zunächst eine Schreibweise zu erwählen, welche die Haltungen und Bewegungen der Hand möglichst erleichtert und vereinfacht.

Um dieses zu erreichen, verwende ich den auf Taf. XI dargestellten Federhalter.

Die in Fig. 80 abgebildete Vorrichtung dient dazu, einen Federhalter derartig an Zeige- und Mittelfinger zu befestigen, dass man schreiben kann, ohne den Daumen zum Halten des Federstieles zu benutzen.

Es können mithin Personen, die entweder den Daumen gänzlich verloren haben oder wegen Steifheit oder Schwäche desselben nicht imstande sind, einen Federstiel zu halten, schreiben, wenn sie den Federstiel vermittelst der hier in Fig. 80 abgebildeten Vorrichtung am Zeige- und Mittelfinger befestigen.

Da eine derartige Befestigung die Fingermuskeln vom Halten des Feder. stieles befreit, so dass sie beim Schreiben nur noch die zur Führung der Feder erforderlichen Bewegungen auszuführen haben, so erscheint sie als ganz besonders geeignet für die Behandlung jener Reiz- und Schwächezustände der Hand, die unter dem Namen "Schreibekrampf" zusammengefasst werden.

Sie beseitigen eben jene ununterbrochenen Muskelzusammenziebungen, welche jedes dauernde Festhalten eines Gegenstandes so sehr ermüdend machen.

Schon das Nussbaum'sche Braçelet, welches den Fingerbeugern das Halten der Feder abnimmt und den Streckern aufbürdet, schaffit oft grosse Erleichterung. Die hier beschriebene Vorrichtung entlastet die Beuger, ohne die Strecker zu belasten und befreit somit die Hand vollständig von einer nicht unbedeutenden Arbeitslast. Natürlich kann diese plötzliche Befreiung ebensowenig sofort alle Schreibstörungen beseitigen, wie die Entlastung der 
Akkommodation durch Konvexgläser einem Weitsichtigen sofort alle asthenopischen Beschwerden fortschafft.

Nur bei allmählicher Gewöhnung kann die durch meinen Federbalter vollständig veränderte Schreibweise zur Heilung eines Schreibekrampfes beitragen, wenn derselbe vorher durch Ruhe, Massage, Elektrizität, Fingergymnastik usw. gründlich von einem Arzte behandelt worden ist.

Auch die Schreibübungen mit meinem Federhalter werden nur diejenigen Kollegen erfolgreich leiten können, die Übung in der Behandlung von Schreibekrämpfen besitzen.

Die in Fig. 80 abgebildete Schnürvorrichtung lässt man aus Korsettstoff (Drell) anfertigen, nach beistehendem Schnitt A. Zu jeder Seite der Schnürnaht werden drei Drahthaken angenäht. Zum Schnüren befestige man eine dünne, recht fest gedrehte Hanfschnur mit einem Knoten an dem Haken 1, führe sie über den Federstiel von einem Haken zum anderen und befestige sie hierauf mit einer Schleife am Haken 3. Durch leichte Beugebewegungen überzeuge man sich jetzt davon, ob das Korsett nicht zu fest oder zu lose sitzt.

Wünscht man das Korsett abzulegen, so ziehe man den nach oben konisch verjüngten Federhalter heraus und streife es wie einen Handschuhfinger $a b$.

Man kann übrigens das Korsett, ist es erst einmal richtig eingestellt, beim An- und Ablegen bequem mit dem Federstiel zusammen auf- und abziehen, ohne Lösung der Schnur. Man darf mit dem Korsett nur die zwei ersten Glieder der Finger umschliessen (nicht drei Glieder) damit eine leichte Beugestellung derselben möglich ist (Fig. 80).

Der Mittelfinger ist stärker zu beugen als der Zeigefinger. Als beste Haltung für die Hand erwies sich mir die von Gowers anempfohlene ${ }^{1}$ ).

Ich lasse bei den ersten Schreibuibungen den Daumen nicht an den Federstiel legen, sondern auf das Papier (Fig. 80), um den Fingern das krampfhafte Festhalten der Feder abzugewöhnen. Ist dieses gelungen, etwa nach 5 bis 6 Tagen, so gestatte man wieder den Daumen durch leichtes Anlegen zur Führung der Feder zu verwenden.

Zunächst lasse ich nur die von Gowers empfohlenen horizontalen und wellenförmigen Striche ohne abzusetzen ziehen, bis sich die Hand vollständig an die neue Federhaltung gewöhnt hat. Dieses gelingt am besten wenn man das Papier auf eine glattpolierte Tischplatte legt. Das Schreiben von Buchstaben verbiete ich und gestatte bei den ersten Versuchen nur fünf Minuten morgens und fünf Minuten nachmittags zu üben.

Nach den Übungen wird massiert und es werden leichte aktive Bewegungen des ganzen Armes und der Finger gemacht. Massage und Bewegungen vor den Schreibübungen sind durchaus zu verwerfen.

Allmählich gehe man zu diagonalen Strichen und lateinischen Buchstaben über und verlängere die Übungsdauer.

1) W. R. Gowers Handbuch der N.-Krankh., übersetzt von Dr. K. Grube. Bunn 1892. Cohen. 
Schon vor Beginn der Übungen mit der rechten Hand lasse ich die linke Hand gleichfalls mit dem Korsett im Schreiben üben, damit Patient nach erfolgter Heilung, abwechselnd rechts und links schreiben kann.

Die Gefahr, dass an der linken Hand sich gleichfalls ein Schreibkrampf ausbilde, ist nach Gowers Angabe nicht so gross, als man allgemein annimmt.

Er meint, es geschehe etwa in der Hälfte der Fälle und berichtet von einem Beamten, der bei rechtsseitigem Schreibkrampfe zwölf Jahre lang mit der linken Hand ganz unbehelligt schrieb, so lange bis sich die rechte Hand wieder erholte und ungehindertes Schreiben gestattete.

Mir ist folgender Fall bekannt. Ein Konditor in Riga litt am Schreibkrampfe der rechten Hand und schrieb sich mit der Linken ein. Nachher war er genötigt die Konditorei aufzugeben und wurde Bankbeamter. Als solcher schrieb er zwanzig Jahre lang schön und schnell mit der linken Hand Das Schreiben mit der rechten blieb jedoch nach wie vor unmöglich. Er. brachte stets nur einige krampfhafte Striche zustande, die nach unten gerichtet waren, wenn er es versuchte, mit der rechten Hand zu schreiben. Ich glaube, dass die Einübung der linken Hand sich noch günstiger gestalten würde, wenn man möglichst vorsichtig und langsam damit vorgehen wollte und z. B. ein Jahr für das Erlernen festsetzen wollte.

Man erwäge doch nur, dass Kinder und auch Erwachsene zum vollständigen Erlernen des Schreibens mit der rechten Hand Jahre brauchen. Gewiss würde ein grosser Teil von ibnen durch Schreibkrämpfe am Erlernen des Schreibens verhindert werden, wenn sie es versuchen wollten in einigen Monaten Fertigkeiten zu erlangen, die erst in Jahren erreichbar sind.

Sehr häufig liest man die Ansicht, dass die Schreibstörungen der Neurastheniker und Hysterischen einer örtlichen Behandlung unzugänglich seien und ausschliesslich durch eine Besserung des Allgemeinbefindens beseitigt werden könnten. Selbstverständlich wäre es ja sehr unrichtig in derartigen Fällen das Allgemeinbefinden unberücksichtigt zu lassen. Ebenso unrichtig erscheint es mir jedoch, alles von der Besserung des Allgemeinbefindens zu erwarten und darüber die örtliche Behandlung zu vernachlässigen. Folgende Gründe scheinen mir hierfür zu sprechen.

1. Es ist durchaus nicht gesagt, dass jede Schreibstörung, an der ein Neurastheniker leidet, unbedingt von seiner Neurasthenie herrührt. Sie kann z. B. durch leichte Fingerverletzungen, rheumatische Erkrankungen, durch Überanstrengungen infolge eines Sportes, durch unrichtige Federhaltung, schlechten Sitz, ungeeignete Schreibtische, kurz durch hundert andere Ursachen bedingt sein.

Einen grossen Teil dieser Ursachen kann man mit Leichtigkeit durch Änderung der Verhältnisse, Massage und Übungen beseitigen, während sie wohl kaum durch jene Heilmittel zu beeinflussen sind, welche gegen die Neurasthenie angewandt werden.

2. Selbst in den Fällen, wo die Neurasthenie oder Hysterie die Ursache von Schreibstörungen sind, ist keineswegs nur dann ein Schwinden dieser 
Störungen zu erwarten, wenn die Neurasthenie, Hysterie gebessert werden. Unsere Erfahrungen zeigen es ja nur zu deutlich, dass die verschiedenartigsten Krankheitserscheinungen der verschiedensten Körperteile bei Neurasthenie und Hysterie kommen und vergehen, ohne dass der Allgemeinzustand sich bessert. Man denke nur an die Lähmungen der Hysterischen, an das lange Register von Krankheitserscheinungen, welches Beard u. a. für die Neurasthenie anfgestellt haben.

Diesen Erfahrungen entsprechend habe ich öfters Neurastheniker und Hysterische von ihren Schreibstörungen befreit, obgleich es mir nicht gelang durch meine Allgemeinbehandlung wesentlich ihr Befinden zu verbessern.

Hierher zählt unter anderen der in meiner Abhandlung "Fingerübungen " ) mitgeteilte Fall von Schreibstörung. Der vielbeschäftigte Sekretär schreibt häufig ungestraft bis 8 Stunden täglich. Trotzdem oder vielleicht gerade deshalb ist sein nervöser Zustand kaum gebessert. Unregelmässiges Leben im Winter, forcierte Gebirgstouren und Erholungsreisen im Sommer erhalten seine Neurasthenie recht gleichmässig.

Ebenso gelang es mir eine hysterische Kassiererin so vollständig von ihren Schreibstörungen zu befreien, dass sie mir sehr lange, höchst überschwängliche Dankesbriefe schreibt, die nebenbei sehr sorgfältige Schilderungen never Leiden enthalten und so den Beweis liefern, dass meine Allgemeinbehandlung mit Bädern, Arzneien usw. nicht sehr erfolgreich war, während ihre Schreibstörungen durch Massage, Übungen usw. schwanden.

Da ich im Obigen so sehr die örtliche Behandlung der Schreibstörungen betont habe, so glaube ich hier nochmals wiederholen zu müssen, dass ich ni $\mathrm{e}$ eine Schreibstörung ohne Berücksichtigung des Allgemeinbefindens behandele.

Wo es nur irgendwie durchführbar ist, verlange ich stets von meinen Kranken, dass sie eine Zeitlang vollständig ihrem Berufe entsagen, womöglich ihren Beruf wechseln. Durch Bäder, Diätkuren, Landaufenthalt, Arzneien suche ich ihr Allgemeinbefinden zu verbessern. Von der grössten Bedeutung ist es, den gesunkenen Mut der meist sehr verzweifelten Kranken zu heben. Dieses geschieht am besten durch ruhiges Zureden und Bekanntmachen mit Geheilten.

\section{Zur Beugung steifer Finger ${ }^{2}$ )}

verwende ich weiche Handschuhe aus Baumwolle (Fig. 81), an deren Fingerspitzen ich Lampendochte vor etwa $1 \mathrm{~cm}$ Breite nähen lasse. Die freien Enden dieser Dochte zieht der Kranke durch Schnallen, die an einem breiteren Dochte befestigt sind, der um das Handgelenk befestigt wird und am Handschuh angenäht ist. Diesen Docht nimmt man etwa $2 \mathrm{~cm}$ breit. Seine Schnalle wird auf der Rückseite des Handgelenkes an den Handschuh genäht und mit einem Stück Filz gepolstert von etwa $4 \mathrm{~cm}$ Länge, $3 \mathrm{~cm}$ Breite. Ein zweites Stück Filz von derselben Grösse lege ich unter die Schnallen für die Dochte der Finger. Wichtig ist es, die Filzstücke nur so lang zu nehmen,

1) Petersb. med. Wochenschr. 33. 1895.

2) Monatssebrift f. orthop. Chirurgie u. physikalische Heilmethode 1901, Nr. 3 u. 4. 
dass ihre Enden einander nicht berühren. Es muss vielmehr an der Innenseite und Aussenseite des Handgelenkes eine Lücke zwischen den Filzstücken bleiben. Diese Lücken überbrückt der Docht, welcher um das Handgelenk geschnallt wird, ohne hier einen Druck auszuïben. Er lässt so Bahnen frei, durch welche das Blut aus der Hand strömen kann. Hierdurch vermeidet man sicher Blutstockungen und Vertaubungen der Hand. Bisweilen empfiehlt es sich, die Filzstiicke doppelt zu nehmen. Eingehender habe ich diese mechanischen Verhältnisse in meinem Abschnitte "Druckverbände mit Filz“ besprochen (Seite 101).

Zu Schnallen eignen sich am meisten die Riemenschnallen ohne Rollen. Ihr stumpfer Dorn ist leicht zu lösen und durchdringt auch leicht den weichen Stoff des Dochtes. Ausserdem nutzt er den Docht nicht so schnell ab, wie die spitzen Dornen der Hosenschnallen. Von Wichtigkeit ist auch der in Fig. 81 abgebildete Rundstab. Er gestattet die Finger nur bis zu einem ganz bestimmten Punkte zu beugen. Ist dieser Stützpunkt erreicht, so finden die Finger eine Ruhelage, in der sie stundenlang schmerzlos liegen können, so dass meine Kranken oft die ganze Nacht hindurch ununterbrochen ihre steifen Finger bei angezogenen Schnallen halten. Natürlich kommt hierbei alles darauf an, dass die Dicke des Rundstabes richtig gewählt ist. Hat man den Stab zu dünn genommen, so entstehen in den Streckmuskeln der Finger schmerzhafte Spannungen, welche den Kranken bald nötigen, die Schnallen zu lösen.

Schon nach einigen Tagen kann man meistens an Stelle des dicken Stabes einen dünneren legen und so fort, bis man schliesslich den Rundstab ganz fortlässt und die Fingerspitzen bis an die Handfläche schnallt.

Hat man den Rundstab vom Handschnh entfernt, so empfiehlt es sich, die Dochte von den Spitzen des Handschuhfingers zu trennen und an die Rückseite des Handschuhfingers zu nähen, etwa 1,5 cm entfernt von der Spitze. Es gelingt dann bequem durch Anziehen der Schnalle, die Fingerspitzen gegen die Handfläche zu ziehen.

Durchaus notwendig ist es, beim ersten Anlegen des Handschuhes den Rundstab möglichst dick zu nehmen, damit der Kranke keine Beschwerden vom Gebrauche des Handschuhes verspürt. Sehr häufig ziehen die Kranken gleich von vornherein $z u$ straff die Schnallen an, leiden dann an heftigen Schmerzen in den Fingern und sagen dann, "ich vertrage den Handschuh nicht, für andere Hände mag er sehr gut sein, meiner Individualität ist er nicht richtig angepasst". Gegen solche unglückliche Ideen kämpfen Götter selbst vergebens; daher ist es am besten, sie prophylaktisch zu behandeln.

Den Rundstab befestige ich folgendermassen am Handschuh: Mit einer Packnadel ziehe ich zwei Stücke Korsettschnur durch die Handfläche des Handschuhes und durch zwei Löcher im Rundstabe. Die Korsettschnüre werden über dem Rundstab geknotet. Wo sehr dicke Rundstäbe erforderlich sind, empfiehlt es sich, sie aus dicken Korkplatten zusammenzunähen oder Blechrollen zu verwenden, weil dicke Holzstäbe zu schwer sind. 
Sehr häufig lasse ich einige Tage meinen Handschuh tragen und einige Tage die Bandeisen anlegen (Seite 129). Bisweilen lasse ich den Handschuh nur zur Nacht anlegen und am Tage die Hand zu kleinen Arbeiten benutzen.

Ausdrücklich führe ich hier an, dass ich mich nie mit der Verwendung meiner Handschuhe begnüge, sondern stets zweimal täglich massieren und mit meinen Apparaten üben lasse. Einige Kranken üben stundenlang in meiner Anstalt mit meinen Apparaten und erreichen nur hierdurch oft noch in recht verzweifelten Fällen durch eigene Kraft und Ausdauer eine gebrauchsfähige Hand. Gerade meine Erfolge an steifen oder gelähmten Arbeiterfingern lenkten die Aufmerksamkeit der Unfallversicherungs-Gesellschaften auf meine Anstalt und veranlassen sie fortdauernd, mir ihre Verletzten zu übersenden. Sie haben eben die Erfahrung gemacht, dass häufiger durch meine Behandlung hohe Entschädigungssummen bedeutend herabgesetzt wurden.

\section{Schienen zur Verhütung der Greifhand.}

Nach Taf. XII, Fig. 82-84 kann diese Schienen jeder Klempner oder Schlosser anfertigen.

Ich lasse aus Draht von etwa $4 \mathrm{~mm}$ Dicke einen Rahmen genau nach Fig. 84 anfertigen $(20 \mathrm{~cm}$ lang, $10 \mathrm{~cm}$ breit, am hinteren Ende ein Bügel von etwa $20 \mathrm{~cm}$ Länge). Die Drahtenden werden mit dünnem verzinntem Drahte gebunden und verlötet. Gleich hinter dieser Lötstelle wird eine Brücke aus verzinntem Blech angebracht (2,5 cm breit). Auf diese Brücke werden 4 Stücke Bandeisen genietet (jedes Stück $10 \mathrm{~cm}$ lang). Die Brücke lasse ich mit dickem Filz decken.

Am hinteren Ende der Schiene wird ein Stïck Lampendocht angebracht.

Legt man die Handfäche auf die Blechbrücke, so kann man bequem jeden einzelnen Finger auf einem der vier Stücke Bandeisen befestigen, da die Bandeisen ein wenig gedreht werden können.

Ist einer der erkrankten Finger stärker als die anderen gekrümmt, so biegt man das Stück Bandeisen, auf dem er ruhen soll, nach seiner Krümmung. Befestigt wird jeder Finger auf seinem Bandeisen durch einen Streifen Heftpflaster.

Gleich hinter der Brücke ist eine Schnalle mit Draht an die Schiene gebunden.

Durch diese Schnalle wird mit Hilfe eines Riemens das Handgelenk gestreckt (Fig. 82). Am hinteren Ende der Schiene ist gleichfalls eine Schnalle und ein Riemen angebracht. (In Fig. 82 und 83 nicht abgebildet.)

Nach meinen Erfahrungen sind folgende Kleinigkeiten für die Verwendung der Schiene von der grössten Bedeutung.

1. Die Bandeisenstücke müssen durchaus um einen halben Zentimeter breiter sein, als die Finger, damit die Finger nicht abgeschnürt werden, wenn man sie mit Heftpflaster umwickelt. Auch müssen sie an den Nietstellen etwas verschmälert sein, damit man sie um die Nieten ein wenig drehen kann. Beim Umwickeln der Heftpflasterstreifen ist es wichtig, dass man die Bandeisenstücke ausbreiten kann. 
2. An Stelle des Heftpflasters darf man nie schmale Zeugbinden verwenden, da sich sonst die ganze Hand aus der Schiene zieht.

3. In der Nähe des Handgelenkes ist eine zweite Schwebe (Fig. 83) anzulegen, damit hier die Hand einen Stützpunkt findet. Man schlingt einfach an dieser Stelle einen Lampendocht um die Schiene und zieht eine Korsettschnur durch die Enden des Dochtes, welche die Möglichkeit bietet, die Schwebe bald höher, bald tiefer zu stellen.

4. In den ersten Tagen nach dem Anlegen der Schiene darf man die Schnalle über dem Handgelenk nur ganz leicht anziehen, damit sich der Kranke ganz allmählich an die Schiene gewöhne.

\section{Bewegungen ${ }^{1}$.}

\section{A. Passive Bewegungen.}

Wir sind daran gewöhnt, bei allen ernsteren Erkrankungen die Ruhe für ein unentbehrliches Heilmittel zu halten. Das gilt bei allgemeinen Erkrankungen des ganzen Körpers, es gilt aber auch bei den Frkrankungen einzelner Teile, so lautet z. B. eine uralte Regel für die Behandlung entzündeter Gelenke: „Schmerzhafte und geschwollene Gelenke sind durch starreVerbände in der Ruhe zu erhalten. Erst, nachdem die Schmerzen und Schwellungen geschwanden sind, darf man die Gelenke wieder allmählich an Bewegungen gewöhnen.

Die Ruhe also galt als das Heilmittel und die Bewegungen wurden geradezu wie eine Art Gift betrachtet.

Diese Lehre von der Ruhe galt viele Jahre hindurch unbestritten. Erst im Laufe der letzten Jahrzehnte wurde sie so wesentlich eingeschränkt, dass bei vielen innern Leiden jetzt die Ruhe als ein Gift betrachtet wird und die Bewegung als ein Heilmittel gilt. Ich erinnere hier nur an die jetzige Behandlung der Rückenmarksdarre, vieler Herzleiden usw.

Hingegen werden entzündete Gelenke wohl immer noch hauptsächlich mit starren Verbänden behandelt.

Bewegungen nimmt man an ihnen wohl nur vor, um fehlerhafte Stellungen zu beseitigen, und betrachtet dann diese Bewegungen als ein notwendiges Übel, nicht aber als ein Heilmittel. Ja sogar rheumatische Gelenke werden nicht selten durch starre Verbände solange in der Ruhe erhalten, bis sie zur ewigen Ruhe eingehen, d. h. so vollständig versteifen, dass kein Mittel ihre Beweglichkeit wieder herstellen kann.

Dieses erscheint um so auffallender, als doch schon vor vielen Jabren zuverlässige Ärzte darauf hingewiesen haben, dass bei vielen rheumatischen Gelenkerkrankungen die Bewegungen ein ganz ausgezeichnetes Heilmittel seien.

1) Siehe Monatsschrift für Unfallheilkunde 1902, Nr. 3. 
So hörte ich unter anderem vor vielen Jahren folgenden Ausspruch meines Lehrers Prof. Ernst v. Bergmann in Berlin: "Wenn wir einen Kranken chloroformieren, dessen Kniegelenk infolge einer frischen rheumatischen Gelenkentzündung in Beugestellung sich befindet, so fällt es nicht schwer, das Gelenk zu strecken und hin- und herzubewegen. Erwacht der Kranke, so ist er oft für längere Zeit vollständig frei von Schmerzen, obwohl er vor den Bewegungen bei der leisesten Berührung seines Knies geradezu aufschrie. Es werden offenbar die entzündlichen Neubildungen auf den Grelenkflächen durch die Bewegungen zerrieben und so zerstört".

Diese Annahme Bergmann's ist jedenfalls für Blutergelenke und Tuberkelgelenke durch die neveren Untersuchungen König's ${ }^{1}$ ) bestätigt worden.

Ich selbst ${ }^{2}$ ) habe Beobachtungen an Lebenden und Leichen über den Einfluss von Bewegungen auf entzündete Gelenke angestellt und meine physiologischen Untersuchungen und Erwägungen an einem anderen Orte veröffentlicht. Hier gehe ich nicht weiter auf dieselben ein. Ich will hier nur ganz kurz andenten, wodurch die grossen Vorurteile entstanden sind, welche so allgemein gegen Bewegungen bei Gelenkentzündungen bestehen.

Nach meinen sehr zahlreichen Beobachtungen werden die passiven Bewegungen meistens viel zu gewaltsam vorgenommen. Dieses gilt besonders von den Masseuren in Deutschland. Ich habe selbst im Anfange meiner ärztlichen Tätigkeit diesen Fehler begangen. Es war dieses während des russisch-türkischen Krieges im Kaukasus. Wenn ich in meinen Krankensaal trat, so zitterten geradezu die Kranken vor mir. Sehr bald jedoch bemerkte ich, dass man mit der rohen Gewalt mehr schadet als nützt. Die Kranken "spannen" und dann ist es oft unmöglich, selbst bei einem grossen Kraftaufwande passive Bewegungen vorzunebmen.

Beginnt man hingegen in der ersten Sitzung mit Bewegungen von $10-15^{0}$, so gewinnt man das Vertrauen des Kranken, er entspannt willig seine Muskeln und es gelingt oft schon in den nächsten Sitzungen Bewegungen von $30-40^{\circ}$ vorzunehmen. Bei besonders empfindlichen Gelenken ist es am besten, das erste Mal vor den Bewegungen zu chloroformieren und die nächsten Male Morphium unter die Haut zu spritzen. - Hiernach gelingt es fast immer meinen Kranken, an meinen Apparaten mit eigener Hand passiv ihre kranken Gelenke zu bewegen und mancher von ihnen, der sehr ungern passive Bewegungen von fremder Hand duldet, bewegt mit eigener Hand oft stundenlang recht empfindliche Gelenke an meinen Apparaten. Es liegen hier eben die Verhältnisse so wie beim Katheterisieren. So mancher Kranke lässt sich höchst ungern von einem anderen katheterisieren, führt jedoch selbst sich schnell und sicher einen Katheter ein.

Jedoch ich hoffe, dieses alles am besten durch Beispiele zu erläutern.

1) König, Die spezielle Tuberkulose der Knochen und Gelenke. Berlin 1896. Aug. Hirschwald.

2) Thilo, Beweg. als Heilmittel entzündlicher Gelenke. Allgemeine medizinische Zentralzeit. 1897. Nr. 68 u. 69. 


\section{Das Kniebeugen}

war bei einem sehr nervösen jungen Manne infolge eines Falles auf das linke Knie und infolge einer eiternden Wunde in der Nähe der Kniekehle weder aktiv noch passiv möglich. Der Kranke ging Wochen lang mit steifem Knie and klagte über heftige Schmerzen. Als ich ihn chloroformierte, gelang es mit Leichtigkeit, das Knie zu beugen. In der Narkose bewegte ich abwechselnd mit einem Kollegen das Knie 15 Minuten lang ununterbrochen hin und her. Hierauf legte ich das Bein bei gekrümmtem Knie in eine Schiene. Als ich am nächsten Tage das Bein aus der Schiene nahm und es passiv bewegen wollte, gelang es nicht sonderlich, wohl aber bewegte der Kranke am Apparate (Taf. XIII, Fig. 88) ganz willig mit eigener Hand sein Knie passiv. In einigen Tagen machte er so grosse Fortschritte, dass er oft mehrmals täglich über eine Stunde das Knie mit eigener Hand bewegte. In einigen Wochen war sein Knie vollständig hergestellt.

Ich glaube, dass ich ohne meinen Apparat wohl schwerlich in so kurzer Zeit sein Bein hergestellt hätte. Passive Bewegungen durch die Hand eines Gymnasten wären sehr zeitraubend gewesen (der Kranke hat oft 2-3 Stunden täglich am Apparat gearbeitet), und ausserdem sträubte sich der Kranke gegen alle passiven Bewegungen von fremder Hand. Eine böswillige Absicht lag hierbei gewiss nicht vor, da er doch stundenlang mit eigener Hand an sich die Bewegungen ausführte. Auch an einem Pendelapparat oder Zanderapparat hätte er schwerlich stundenlang geübt; denn bekanntlich sind passive Bewegungen mit diesen Apparaten bei schmerzhaften Gelenken höchst empfindlich, und der hochgradig nervöse junge Mann hätte wohl schwerlich es ausgehalten, stundenlang mit eigener Hand sich Schmerzen zu bereiten.

Ich werde häufig von Kollegen gefragt, welches etwa die längste Dauer der Bewegungen sei. Hierauf muss ich nach meinen langjährigen Erfahrungen stets antworten.

Ich habe es oft gesehen, wie Rheumatiker, Bluter, Tuberkulöse und andere Kranke ihre recht empfindlichen Gelenke mit meinen Apparaten über eine Stunde mehrmals täglich passiv bewegten. Sie gaben stets an, dass die Bewegungen ihre Schmerzen der Gelenke milderten. Ich konnte also bisher eine Grenze für die Dauer schonend ausgeführter passiver Bewegungen nicht feststellen. Diese Erfahrungen werden verständlich, wenn man überlegt, dass man doch seine gesunden Gelenke viele Stunden am Tage bewegen muss, um sie vollkommen "gelenkig“ zu erhalten.

Versteifte Gelenke bedürfen daher noch mehr der Bewegung, um ihre verlorene Beweglichkeit wiederzuerlangen. Selbstrerständlich müssen diese Bewegungen möglichst schonend sein, d. h. man muss sich bemühen, die Reibung der Gelenkflächen herabzusetzen. Daher wird es auch einem Kranken, der eine Verstauchung des Fussgelenkes erlitten hat, sehr wohltuend sein, wenn nach Stillung der inneren Blutung das Gelenk schonend bewegt wird, bei hochgelagertem Beine. Sehr nachteilig hingegen wird ihm das Gehen sein. Leider ist diese einfache Wahrheit nicht so allgemein anerkannt, als 
man glauben sollte; denn leider wird nicht selten von Naturärzten das Gehen bei frischen Verstauchungen als Naturheilmittel warm empfohlen. Solche unklare naturphilosophischen Idjeen richten vielen Schaden an. Nach meinen Erfahrungen ist es am besten, wenn Kranke mit verstauchten Fussgelenken (sehr häufig Knöchelbrüche) wenigstens 4-5 Tage liegen und im Liegen Gehbewegungen machen.

Ganz selbstverständlich ist es durchaus erforderlich, dass diejenigen Kollegen, welche meine Vorrichtungen für ihre Kranken verwenden wollen, vorher am eigenen Körper alle Bewegungen erproben und einüben. Ich selbst habe alle hier beschriebenen Vorrichtungen zuerst am eigenen Körper erprobt. Nur so gelang es mir, Bewegungen zu ersinnen, die möglichst wenig Beschwerden verursachen und doch zugleich möglichst wirksam sind, nur so gelang es mir auch, meine Apparate allmählich derartig zu vereinfachen, dass man sie jetzt in jeder Bauernstube herstellen und verwenden kann. Die meisten meiner Apparate waren anfangs ziemlich zusammengesetzt und nur dadurch, dass ich jahrelang unermüdlich und unbarmherzig an ihnen verbesserte und vereinfachte, gelang es mir, ihnen ihre jetzige einfache Form zu geben.

Ich führe dieses hier ausdrücklich an, weil viele Ärzte es immer noch nicht genügend anerkannt haben, dass Bewegungsvorrichtungen möglichst einfach sein müssen. Ich glaube, dass die Bewegungskuren erst dann eine allgemeinere Verbreitung finden können, wenn sie mit so einfachen und billigen Apparaten ausgeführt werden, dass sie auch den weniger bemittelten Kranken zugänglich sind. Nur dann wird es möglich sein, in einer Anstalt mehrere Kranke gleichzeitig dieselben Bewegungen ausführen zu lassen. In meiner Anstalt können z. B. gleichzeitig zehn Personen das Kniebeugen an meinen Apparaten vornehmen, ebenso viele Kranke Armbewegungen usw. Nur so bin ich imstande, jedem Kranken die ausreichende Zeit für seine Bewegungen zu gewähren und ihn ausreichend persönlich zu beaufsichtigen. Erst durch solche Massenübungen wird es gelingen, so viele und grosse Erfolge zu erringen, dass alle bisherigen Vorurteile gegen die Bewegungskuren schwinden.

\section{Fälle von Kniegelenkleiden.}

\section{Bluterkniee.}

1. Baron Arthur v. B., 17 Jahre alt, entstammt einer Bluterfamilie. Ein Bruder und ein Onkel mütterlicherseits starben an Blutungen. Infolge häufiger Gelenkschwellungen konnte der Kranke beide Kniegelenke nur bis etwa $160^{\circ}$ strecken. Anfangs wurden passive Bewegungen mit dem Apparate vorgenommen (Taf. XIII, Fig. 88) und hierauf Widerstandsbewegungen (Fig. 89), ausserdem wurde massiert. Nach drei Monaten war die Bewegung des Knies vollständig frei, obgleich schon mebrere Jahre hindurch die Steifheit und Winkelstellung der Kniee bestanden hatte.

2. Polytechniker L., stud. chem. (19 Jahre alt), konnte sein rechtes Knie nur wenig hin- und herbewegen, meist stand es in nahezu rechtwinke- 
liger Stellung, so dass er 11 Jahre lang mit einer Krücke gehen musste. Durch Massage, passive Bewegungen und eine Schiene gelang es mir, das Knie in vier Monaten zu strecken, so dass er ohne Krücke im chem. Laboratorium gehen und arbeiten konnte. Leider war die Beweglichkeit im Kniegelenk mangelhaft, da ich damals, ror 14 Jahren, meine Apparate noch nicht so ausgiebig benutzte und beherrschte wie jetzt. Es war eben das Knie während der ganzen Behandlung zu wenig bewegt worden. Infolgedessen war der Erfolg überhaupt nicht bleibend. Ich sah den Kranken L. vor einem Jahre wieder mit einer Krücke gehen.

3. Gymnasiast M. (Bluter), 11 Jahre alt, kam zu mir, als sein Knie etwa drei Monate lang geschwollen war und nur bis zu einem Winkel von $150^{\circ}$ gestreckt werden konnte. Es sah bläulich aus und man konnte deutlich in ihm Ansammlungen von Flüssigkeiten fühlen.

Ich legte meinen Filzdruckverband an, jedoch nahm ihn der sehr eigensinnige Knabe immer wieder ab, so dass ich ihn schliesslich ohne Verband liess und mich darauf beschränkte, ihn mit Massage und Bewegungen zu behandeln.

Ich liess ihn mit meinem Apparat (Fig. 89) das Kniestrecken in der Weise ausführen, dass er den Unterschenkel des gesunden Beines hinter den des kranken Beines legte und nun gleichsam mit dem gesunden Bein das kranke Knie passiv bewegte.

Es gelang so während der Sommerferien, also etwa in zwei Monaten, die Schwellung und Winkelstellung des Knies vollständig zu beseitigen.

Aus diesen drei Fällen ersieht man wohl, dass selbst bei geschwollenen und versteiften Blutergelenken passive Bewegungen von grossem Nutzen sind. Natürlich ist hierbei die grösste Vorsicht erforderlich; denn alle gewaltsamen Eingriffe führen ja bei Blutern leicht zu Blutungen, die sehr schwer zu stillen sind. Infolgedessen sind steife Blutergelenke ganz besonders empfindlich gegen Bewegungen.

Aus diesem Grunde habe ich auch die Reihe meiner Beispiele mit den Blutergelenken eröffnet, hoffend, der Leser werde sich sagen, wenn selbst für die Gelenkergüsse der Bluter passive Bewegungen ein Heilmittel sind, so ist gewiss das Vorurteil gegen Bewegungen bei anderen Gelenkerkrankungen übertrieben. Zur Bekämpfung dieses Vorurteiles mögen auch noch die folgenden Beispiele dienen.

\section{Scharlachkniee.}

Fall 1. Der Scharlach war ganz besonders bösartig und hatte zu Übertragungen des Giftes auf die verschiedenartigsten Organe gleich im Beginn der Krankheit geführt, bevor die Kranke in meine Behandlung gelangte. Trotzdem gelang es, das noch ein wenig eiternde Knie durch Bewegungen vollständig beweglich und gebrauchsfähig zu machen.

Fall 2 war noch ziemlich frisch. M. B., Mädchen von 9 Jahren, Tochter eines Tischlers, batte vor 14 Tagen einen Scharlach durchgemacht. Es bestand eine eiterige Geschwulst hinter einem $\mathrm{Ohr}$, die ich eröffnete, und 
eine eiterige Fistel am rechten Knie, welches wenig beweglich war und meist in einer Beugestellung von etwa $130^{\circ}$ stand.

Da die Kranke ziemlich weit entfernt von mir wohnte und daher nicht täglich in meine Anstalt gebracht werden konnte, stellte ich in ihrer Wohnung eine Vorrichtung her, mit der sie zunächst passiv, nachher mit Widerstand ihr Knie unter der Aufsicht der Mutter bewegte.

Ausserdem legte ich meinen Filzverband und meine Schiene an. Die Fistel verheilte schnell and in drei Monaten war das Knie gut beweglich und gebrauchsfähig.

Fall 3. Carl B., 14 Jahre alt. Infolge von Scharlach war sein rechtes Knie wenig beweglich, meist stand es unter einem spitzen Winkel gekrümmt, so dass B. fünf Jahre lang auf einem Beine mit einer Krïcke ging. Das kranke Knie war mit 16 Narben von grösseren Schnitten und Fisteln bedeckt, von denen eine noch eiterte.

Passive Bewegungen, Filzdruckverband, Schienen stellten ihn im Laufe von drei Jahren so vollständig her, dass er Schlittschuh laufen und mit mir grössere Fusstouren unternehmen konnte. Ein Jahr arbeitete er als Schlosser in einer Maschinenfabrik von $6 \mathrm{Uhr}$ morgens bis $6 \mathrm{Uhr}$ abends, jetzt ist er in meiner Anstalt als Mechaniker beschäftigt. Der Kranke wurde am 31. Jan. 1894 in der Gesellschaft dentscher Ärzte zu Riga von mir vorgestellt.

\section{Kniegelenkleiden nach örtlichen Infektionen.}

Fall 1. Der fünfjährige Knabe M. hatte im Juni 1898 sich durch schlechtes Schubwerk die linke Ferse durchgerieben. Durch Unsauberkeit entwickelte sich hier eine stark entzündete Wunde. Etwa eine Woche nach Heilung der Wunde schwoll das linke Knie plötzlich stark an, so dass man eine bedeutende Menge von Flüssigkeit durchfühlen konnte. Ich war genötigt, den Knaben in eine Kinderklinik zu senden, da ich ihn bei mir nicht aufnehmen konnte. Dort wurde das Kniegelenk durch einen Schnitt an dei inneren Seite der Kniescheibe eröffnet und eine eiterig-seröse Flüssigkeit wurde entleert. Zwei Monate nach der Operation war die Schnittwunde kaum verheilt, als ich schon Bewegungen, Massage und meinen Filzdruckverband anwandte. Auch in diesem Falle massierte ich anfangs nur den Oberschenkel, oberhalb des Knies.

Es gelang mir, in sechs Wochen das Knie rollständig gelenkig und gebrauchsfähig zu machen. Auch jetzt, nach drei Jahren, ist das Knie vollständig gesund.

Fall 2. Gutsbesitzer Z., 40 Jahre alt, hatte, wie er angab, unzählige Male am Tripper gelitten. Plötzlich schwoll sein Knie (ohne äussere Veranlassung) so stark an, dass er zu Bett liegen musste. Durch passive Bewegungen, Filzdruckverband und kurze Pappschiene wurde er in 14 Tagen soweit hergestellt, dass er eine Reise von Riga nach Paris ohne besondere Unterstützung machen konnte. 


\section{Tuberkulöse Kniee.}

Fall 1. Gymnasiast Bernhard G., 18 Jahre alt, kam im September 1895 in meine Behandlung.

Seit dem Juni 1894 begann ohne eine besondere Veranlassung sein linkes Knie allmählich anzuschwellen und schmerzhaft zu werden. Er war in Berlin und in Riga mit Einspritzungen von Jodglyzerin behandelt worden, ohne Erfolg.

Als er in meine Behandlung kam, war das Knie bedeutend angeschwollen. Durch einen Schienenhülsenapparat wurde es in gestreckter Stellung gehalten. Es zeigte sich in diesem Falle besonders deutlich, wie die Schienenhülsenapparate die Schwellung des Knies begünstigen. Der Unterschenkel und der Oberschenkel werden eingeschnürt und das Knie quillt hervor, wie ein abgebundener Finger. Durch meinen Filzdruckverband geschieht das Gegenteil. Das Knie wird eingewickelt und die Blut- und Lymphbahnen oberhalb des Knies bleiben frei von jeglichem Drucke, ja sogar am Knie lasse ich eine Bahn für die Vena saphena frei. Nach Entfernung der Lederhülsen von seinem Apparat gab ich der Schiene die in meiner Anstalt gebräuchliche Form ${ }^{1}$ ). Im Laufe von zwei Jahren gelang es, die Geschwulst durch Bewegungen und Massage vollständig $\mathrm{zu}$ beseitigen.

Die Beweglichkeit des Knies war gering, trotzdem ging G. sehr gut und fühlte sich ganz gesund. Er ist jetzt praktischer Arzt in St. Petersburg.

Theodor B., 5 Jahre alt, rechtes Knie bedeutend angeschwollen seit einem Jahre, ohne bestimmte Veranlassung, bedeutende Mengen von Flüssigkeit fühlbar etwa bis zur Mitte des Oberschenkels an der vorderen Seite. Knie kann nur bis $160^{\circ}$ gestreckt werden.

Ich dachte an eine Eröffnung des Gelenkes und befragte hierüber einen Spezialkollegen um Rat. Doch wir versprachen uns beide nicht viel Erfolg von dieser Operation, und so legte ich denn einen Filzdruckverband bis zur Hälfte des Oberschenkels an, streckte durch meine Schiene allmählich den Oberschenkel. Die Schiene stützte ich gegen den Sitzknorren und bot so die Möglichkeit zu gehen, ohne dass der Knabe auf den Fuss des kranken Beines trat. Ausserdem wurden passive Bewegungen und Massage angewandt. Im Laufe eines halben Jahres bildete sich die Flüssigkeitsansammlung im Gelenk zurück.

Jetzt, nach dreijähriger Behandlung, ist die Schwellung vollständig geschwunden und man fühlt deutliche Unebenheiten an den Gelenkknorren. Es hatten also bedeutende krankhafte Veränderungen am Knochen stattgefunden, die durch den Druckverband und die Bewegungen zurückgebildet wurden.

Die Kniescheibe ist beweglich und es werden aktive Beugungen und Streckungen im Gelenk ausgeführt. Auf der Strasse geht der Kranke grosse Strecken.

1) Vergl. Monatsschr. f. Unfallheilk. 1895. Nr. 11. 
Nach den bisherigen Erfolgen habe ich Aussicht, sein Knie ebensoweit herzustellen, wie das Scharlachknie des Karl B. (vergl. Seite 143), der Schlittschuh läuft und grössere Fusstouren macht.

Jedenfalls ist der Fall Theodor B. ganz besonders ungünstig und zeigt daher besonders deutlich, dass Bewegungen und Massage, mit Vorsicht angewandt, selbst in solchen Fällen ganz gefahrlos für die allgemeine Gesundheit sind und auf das Gelenk sehr günstig einwirken.

Ganz selbstverständlich darf man derartige Gelenke nicht mit Klopfungen behandeln. Hingegen sind kräftige Streichungen der Muskeln oberhalb des Knies von grossem Nutzen. Das Knie selbst massiere ich in solchen Fällen entweder gar nicht oder nur mit ganz leichten Streichungen. Klopfungen wende ich überhaupt bei entzündeten und verletzten Gelenken nie an.

Leider aber bilden die Klopfungen noch immer bei vielen Masseuren den Hauptteil der Massage, und unwillkürlich wenden sie dieselben auch bei entzündeten Gelenken an.

Auch die passiven Bewegungen werden von ihnen nicht selten ungefähr so ausgeführt, wie ein Brisement forcé. Die Kranken ächzen und stöhnen dabei. Natürlich sind die Folgen sehr schlimm, und Ärzte, welche nicht mit eigner Hand massiert haben, sondern die Massage nur vom Hörensagen kennen, müssen selbstverständlich zu der Ansicht gelangen, bei entzündeten Gelenken ist die Massage zu vermeiden.

Nach meinen Erfahrungen sind passive Bewegungen so lange gefahrlos, als sie schmerzlos ausgeführt werden. Man vermeicet dann sicher Gefässverletzungen und hat daher auch nicht Verschleppungen von Krankheitserregern nach entfernteren Körperteilen zu befürchten. Eine Beschleunigung des Blutkreislaufes tritt ja allerdings ein, aber diese allein bedingt doch keine Gefahr. Im Gegenteil, sie ist eines der besten Heilmittel, welches wir besitzten. Wir wenden sie z. B. an, wenn wir bei Venenentzündungen der Wöchnerinnen die Beine hochlagern, und gewiss sitzen doch hier häufiger infizierte Gerinnsel an einigen Venenverzweigungen. Ich sah in der Klinik von Ernst von Bergmann Hände hochlagern, die mit Milzbrand vergiftet, hochgradig geschwollen waren.

Der Erfolg war ausgezeichnet. Die Kranken wurden gerettet.

Ich behandle Venenentzündungen mit Hochlagern und passiven Bewegungen. Die entzündeten und schmerzhaften Stellen lasse ich natürlich unmassiert. Meine Art der Behandlung möge folgender Fall erläutern.

Frau W., 40 Jahre alt, litt im Jahre 1899 an einer Lungenentzündung, die ziemlich regelmässig verlief. Plötzlich bemerkte sie eine schmerzhafte Geschwulst in der linken Leistengegend. Allmählich schwoll das ganze linke Bein an. In diesem Zustande hatte sie vier Monate gelegen, als mich ihr Hausarzt aufforderte, die Behandlung fortzusetzen. Ich war von dieser Aufforderung nicht sehr erbaut. Die ganze Umgebung der linken Leistengegend war sehr empfindlich, das ganze linke Bein war stark geschwollen, der linke Fuss stand in Spitzfusstellung und konnte nur unvollkommen ron ilhr zurückgebogen 
werden (Dorsalflexion eingeschränkt), das linke Knie war schmerzhaft und wenig beweglich. -

Ich massierte mit eigner Hand zwei Wochen lang täglich das ganze Bein bis zur Leistengegend und auch die Gesässmuskeln (Mm. glutaei) der linken Seite. Den Unterleib und die Leistengegend liess ich unmassiert. Passive Bewegungen des Beines wurden folgendermassen vorgenommen. Taf. XIV. Fig. 94. Ein dreieckiges Tuch wurde um das linke Kniegelenk geschlungen und in der Kniekehle mit Filz gepolstert. Am dreieckigen Tuche wurde eine Schnur befestigt, die über eine Rolle verlief, welche in die Zimmerdecke über dem Bette geschraubt war. Die Kranke konnte das freie Ende der Schnur erfassen, anziehen und so passiv das Bein erheben. Hierbei bog sich das Knie nach Möglichkeit und der Fuss glitt auf dem Bette hin und her. Das Gleiten wurde dadurch ermöglicht, dass an der Matratze Wachstuch befestigt war, auf welchem der mit einem Strumpfe bekleidete Fuss hin- und herrutschte. War die Kranke rom Ziehen ermüdet, so liess sie von einem Dienstmädchen die Rollenschnur ziehen und so ihr Bein bewegen. Meistens war das Bein hochgelagert und zweimal täglich wurde Fussrückenbeugen (Dorsalflexion) derartig ausgeführt, dass die Kranke $250 \mathrm{~g}$ an einer Schnur, die um die Fusspitze geschlungen war, zog (Fig. 86).

Die Leistengegend beklebte ich mit Heftpflasterstreifen, auf welche ich grössere Mengen Watte legte. Diesen Verband rerwende ich gewöhnlich an Stelle der feuchtwarmen Umschläge. Nach einigen Wochen legte ich heisse Hafersäckchen auf die Leistengegend.

Schon nach zwei Wochen nahm die Geschwulst des Beines bedeutend ab. Ich überliess einer Schülerin ron mir die Massage und besuchte die Kranke zweimal wöchentlich. Nach zwei Monaten konnte die Kranke in ihrem Zimmer auf und ab gehen. Nach fünf Monaten zog sie an den Meeresstrand und ging dort im Walde spazieren. Die Massage und die Bewegungen wurden stets fortgesetzt.

Allmählich wurde die Kranke ganz gesund und blieb es bis zum heutigen Tag.

Die Steifheit des Fuss- und Kniegelenkes sind vollständig geschwunden. -

Auch beim Greisenbrand (Arteriosclorosis, Zoege Manteufel) verwende ich mit grossem Erfolge passive Bewegungen.

Ich habe eine grosse Anzahl der rerschiedenartigsten Kniegelenkleiden behandelt und auch viele Kniegelenke gesehen, die von anderen Ärzten behandelt waren; stets habe ich bemerkt, dass dort, wo ich gleich im Beginn der Erkrankung passive Bewegungen und Massage anwenden konnte, das Knie beweglich blieb und dauernde Heilung eintrat. Wo ich hingegen die passiven Bewegungen nicht durchführen konnte und mich auf starre Verbände beschränken musste misslang es nur zu oft, ein brauchbares Gelenk herzustellen. Leider war dieses häufig der Fall wenn ich Kinder unter 5 Jahren zu behandeln hatte. Sie fürchteten sich vor den Bewegungen und "spannten". Infolge dessen konnte ich die Bewegungen nicht schmerzlos ausführen und unterliess sie daher ganz, indem ich mich auf Druckverbände und Feststellung 
des Gelenks beschränkte. Die Folgen hierron waren dann gewöhnlich - ein steifes Gelenk und unvollständige Heilung, d. h. es traten oft nach Jahren wieder Rückfälle auf.

Diese Erfahrungen sind wohl vollkommen verständlich wenn man jene Abbildungen ansieht, die $\mathrm{König}{ }^{1}$ ) ron Tuberkelknieen und Bluterknieen reröffentlicht hat.

Nach seinen Angaben sieht man im Beginn der Frkrankung "Auflagerungen wie geronnenes Hühnereiweis" zu beiden Seiten der Kniescheibe. Diese Gelenkteile werden nur dann von den entsprechenden Gelenkflächen des Schienbeins berührt, wenn das Knie vollständig gestreckt ist. Schon bei einer Beugestellung von $160^{\circ}$ findet hier keine Berührung mehr statt. Hiervon konnte ich mich sehr genau überzeugen, als ich die vortrefflichen Glyzerinpräparate untersuchte, die ich der grossen Güte des Herrn Professor Ludw. Stie da in Königsberg verdanke. Eine Beugestellung von 150 bis $160^{\circ}$ findet man aber gewöhnlich bei entzündeten Kniegelenken. An ihnen werden daher die Gelenkteile nicht mehr aneinander glatt geschliffen und die Auflagerungen werden nicht mehr zerrieben. Sie haften, der Knorpel verliert seine Glätte und wird allmählich zerstört.

Nimmt man hingegen von vornherein Bewegungen vor, so wird der Knorpel geglättet und die Auflagerungen werden zerstört.

Die Bewegungen beim Gehen zerstören gewiss in unzähligen Fällen derartige Auflagerungen und ersticken so die Krankheit im Keime, ganz ebenso wie in den Lungen, ja auch die Tuberkulose oft in ihren ersten Anfängen erlischt. Nur wo von vornherein heftige Schmerzen jede Bewegung unmöglich machen und wo von vornherein die Zerstörungen sehr tief greifen, dort bleibt eine solche Naturheilung aus. Das Knie wird dann immer krummer, die Auflagerungen breiten sich immer mehr aus und bedecken schliesslich alle Gelenkflächen. Fine Zeitlang bleiben noch jene Teile des Gelenkes verschont, an welchen die Kniescheibe einen Druck ausübt, und auch dort, wo bei gebeugtem Knie die Gelenkteile des Oberschenkels auf dem Schienbeine ruhen, erbalten sich noch gute Flächen. Allmählich jedoch werden auch diese Stellen unterminiert und zerstört. Trotzdem findet man aber selbst bei hochgradig zerstörten Gelenken oft hier noch Spuren von glatten Flächen.. Ein deutlicher Beweis, wie sehr Druck und Bewegungen selbst unter sehr ungünstigen Bedingungen Gelenkflächen erhalten oder neu bilden. Alles dieses sieht man ganz vortrefflich auf den Abbildungen König's, und ich hoffe, der Leser wird meinen Deutungen dieser Abbildung beistimmen, wenn er Bänderpräparate von gesunden Gelenken mit kranken Gelenken vergleicht. - - -

Herr Professor König hatte die grosse Güte, mir die Besichtigung seiner Präparate zu gestatten. Ich kann nur bestätigen, dass seine Abbildungen sehr genau die Eigentümlichkeiten der Präparate wiedergaben.

Ich habe bisher hauptsächlich frische Gelenkentzündungen angeführt, die von mir erfolgreich mit passiven Bewegungen behandelt wurden. Ich

1) König, Die spezielle Tuberkulose der Knochen und Gelenke. 
könnte aus den Akten der Rigaer Unfallversicherungsgesellschaften eine grosse Anzahl schwerer Verletzungen anfübren, die durch meine Bewegungen wieder arbeitsfähig wurden. Ich gehe jedoch der Kürze halber überhaupt hier nicht genauer auf Krankengeschichten ein. Ich wollte in dem vorstehenden Abschnitte hauptsächlich durch einige Fälle nachweisen, dass gerade bei frischen Gelenkentzündungen meine Bewegungen besonders exfolgreich sind. Ich wollte nur nachweisen, dass die Vorurteile gegen Bewegungen bei Gelenkerkrankungen hauptsächlich durch eine zu gewaltsame Ausführung der Bewegungen entstanden sind.

Ganz ausdrücklich hebe ich es hier hervor, dass ich bei hochgradig zerstörten Gelenken mit Eiteransammlungen auf Bewegungen verzichte, operativ den Eiter und die abgestorbenen Knochenteile entferne und hierauf mich bemühe, durche starre Verbände das Gelenk unbeweglich zu machen.

\section{B. Widerstandsbewegungen.}

Es ist mir oft aufgefallen, dass viele Menschen und auch manche Ärzte für passive Bewegungen bei steifen Gelenken ein volles Verständnis besitzen, hingegen wenig Sinn für Widerstandsbewegungen und Übungen. So versuchte ich es vor einigen Jahren in Deutschland zwei sehr geschickten Operateuren auseinanderzusetzen, warum wir Orthopäden gegen gewisse fehlerhafte Haltungen und gegen gewisse geringe Verkrümmungen der Wirbelsäule verschiedene Gegenstände auf dem Kopfe balancieren lassen. Es gelang mir nicht, sie davon zu überzeugen, dass derartige Übungen nutzbringend seien. Sie meinten vielmebr, das könne nur die Verkrümmung steigern, in solchen Fällen sollten wir uns auf den Gebrauch unserer Vorrichtungen zum Lagern und Aufhängen, unsere Korsette usw. beschränken. Diesen Anschauungen entsprechend zeigten die Kollegen auch volles Verständnis für meine Schienen und Vorrichtungen zu passiven Bewegungen, als ich aber anfing, meine Widerstandsbewegungen und Übungen zu erläutern, meinten sie, die Sache sei zu spezialistisch und gingen fort. Ich würde hier dieses Erlebnis nicht anführen, wenn nicht andere Orthopäden ähnliche Erfahrungen gemacht hätten. Dieses mangelhafte Verständnis für Übungen scheint mir fast darauf hinzudeuten, dass bei manchen Ärzten der Sinn dafür sehr gut entwickelt ist, Schädlichkeiten aus dem menschlichen Körper zu entfernen, hingegen mangelhaft der Sinn, vorhandene gute Keime und Fähigkeiten im Menschen zu entwickeln. Hierin beschämt sie mancher einfache Bauer, Gärtner, oder Handwerker, der Lehrlinge eingeübt hat.

Es erschien mir notwendig an dieser Stelle auf diese Tatsache aufmerksam zu machen, da ich es für einen Grundfehler halte, wenn jemand ein mangelhaftes Verständnis für Übungen besitzt. Dieser Fehler sollte von Jugend auf in unseren Schulen bekämpft werden.

Ohne Übungen können wir keine Fertigkeiten erlangen. Selbst einen grossen Teil unserer alltäglichen Bewegungen (z. B. den aufrechten Gang, die verschiedenen Arten des Laufes, Sprunges, das Schwimmen) müssen wir 
mühsam durch Übung uns aneignen. Die Vollkommenheit, welche wir in ihnen erreichen, ist unmittelbar von unserer Schulung und Übung abhängig. Auf das deutlichste tritt dieses hervor, wenn wir das stramme Marschieren eines wohlgeschulten Soldaten mit dem plumpen Gange eines Bauern oder hockerigen Stubengelehrten vergleichen. Wohl ohne Übertreibung kann man daher behaupten, dass wir diese ererbten Fähigkeiten erst erwerben müssen, um sie zu besitzen.

Ja sogar ihren Besitz können wir uns nur durch fortdauernde Übung erhalten. Geht uns eine der erworbenen Fähigkeiten verloren, so gelingt es uns nicht, ohne Übungen sie wieder zu erlangen. In höherem Grade ist das der Fall, wenn dieser Verlust nicht allein durch mangelnde Übung, sondern zugleich durch schwächende Erkrankungen verursacht wurde. Daher kann es wohl als auffallend erscheinen, dass die Heilkunst sich meist nur auf die Beseitigung der Erkrankungen beschränkt und darauf verzichtet, durch planmässige Übungen die Wiederherstellung der früheren Leistungsfähigkeit zu erreichen. Sie überlässt fast immer die Übungen dem Willen und der Einsicht des Kranken. So versucht es z. B. wohl nur eine geringe Anzahl von Ärzten, durch planmässige Übungen einen Kranken auf die Beine zu bringen, der infolge nervöser, rheumatischer und ähnlicher Erkrankungen die Fähigkeit zu gehen verloren hat. Besonders in der neueren Zeit haben sich einige Nervenärzte das grosse Verdienst erworben, durch fortdauerndes Zureden und andere seelische Beeinflussungen das Verlangen des Kranken, zu gehen wieder anzuregen. Eine planmässige Übung jedoch derjenigen Muskelgruppen, welche durch ihre Schwäche das Gehen unmöglich machen, findet wohl nur selten statt. Diese mühsame Arbeit wird meist den Masseuren und Masseusen überlassen, und doch beweisen es die Veröffentlichungen zuverlässiger Kollegen, wie häufig es gelingt, Personen, die jahrelang an das Bett gefesselt waren teils aus Schwäche, teils aus mangelnder Willenskraft —, durch hartnäckiges Zureden, durch sorgfältig und ausdauernd geleitete Übungen wieder zum Gehen zu veranlassen.

Wie viele Hysterische, wie viele Kranke mit abgelaufenen Gelenkentzündungen fallen nur deshalb sich und anderen durch Bettliegen zur Last, weil sie es einfach nicht verstehen, das Gehen wieder zu erlernen, weil der letzte Rest ihrer Willenskraft bei den ersten verzweifelten Gehversuchen verloren ging. Wie viele Kinder mit Kinderlähmungen sind nur deshalb so schwer beweglich, weil man sie bei ihren Gehversuchen nicht genügend unterstützte; denn gerade bei Kindern kann ja durch Schulung und Übung unendlich viel erreicht werden. Das beweisen schon die Hände der blinden Kinder.

Diese verkümmerten Hände schildert Johann Wilh. Klein, der Vater des heutigen Blindenunterrichtes, im Anfange vorigen Jahrhunderts folgendermassen ${ }^{1}$ ):

1) Emmerich Gigerl, Die Hand, ihre Kräftigung und Schulung durch Fingerund Handgymnastik. Jahresber. des k. k. Blindenerziehungsinstitutes in Wien. 1893/94. Verlag des Blindeninstitutes.

Arch. f. Orthop., Mechanoth. n. Unf.-Ghir. VI. 2/3. 
„Weniger allgemein (als das über den ganzen Körper ausgebreitete Gefühl) ist die Ausbildung und die Stärke des eigentlichen Tastsinnes bey den Blinden und es kommt dabey viel darauf an, wie die nächsten Umgebungen eines blinden Kindes beschaffen waren und ob man ihm früher Veranlassung gegeben hat, diesen für einen Blinden nicht nur zur mechanischen, sondern selbst zur wissenschaftlichen Bildung so wichtigen Sinn zu üben und zu vervollkommnen. Die blinden Kinder sind hierin höchst ungleich. . . .

„Bey einem in gänzlicher Unthätigkeit bis in sein zehntes Jahr erhaltenen blinden Kinde nehmen besonders die Hände eine ganz eigene Form an. Die Finger bleiben sehr kurz, die Knochen dünn, die ganze Hand ungewöhnlich und schlaff. Weil beym Unterlassen alles Greifens die zum Einwärtsbiegen der Fingergelenke bestimmten Muskeln nicht geübt und gestärkt werden, so lassen sich die Finger. sebr weit auswärts gegen den Rücken der Hand biegen, und eine solche vernachlässigte Hand gleicht mehr einem ledernen $\mathrm{Handschuh}$ als dem bewunderungswürdigen Werkzeuge der Natur, durch welches die grössten und feinsten Kunstwerke hervorgebracht werden.

„Der Erzieher eines solchen Blinden ist doppelt schlimm daran, weil hier in den meisten Fällen die Hände die Stelle der Augen vertreten müssen und selbst das Lesen, sowie die meisten wissenschaftlichen Kenntnisse auf diesem Wege erlangt werden sollen".

Trotz dieser scheinbar uniberwindlichen Schwierigkeiten gelang es Klein durch seine Übungen, die verkümmerten Hände so weit zu entwickeln, dass sie sich zu Arbeiten eigneten, die eben so viel Kraft als feines Tastgefühl erfordern. Ich erinnere hier nur an die schweren Arbeiten der Korbmacherei, an das Klavierstimmen, Klavierspiel und ror allem an das Lesen der Blindenschrift.

Gewiss hatte Klein ein Recht dazu, solch eine Hand „das Auge des Blinden" zu nennen.

In der Wiener Blindenschule wurden diese Übungen neuerdings sehr ausgebildet und hier in Verbindung mit dem "Handfertigkeitsunterrichte" als Vorschule zur Arbeit und Musik bald nnentbehrlich. bekannt.

Ihre glänzenden Erfolge sind durch die öffentlichen Prüfungen allgemein

Wir sehen also, dass schon seit dem Anfange des vorigen Jahrhunderts lähmungsartige Schwächezustände der Hand höchsten Grades durch Übungen von Laien vollständig beseitigt werden.

Trotzdem finden wir in ärztlichen Kreisen für ähnliche Erkrankungen derartige Übungen als Heilmittel nur wenig im Gebrauch. Im Gegenteil, wir lesen es in den verschiedensten medizinischen Handbüchern, dass bei der Behandlung geschwächter Nerven und Muskeln die Anwendung der Elektrizität den Übungen vorzuziehen sei, und doch müssen wir es zugeben, dass wohl kaum ein Arzt imstande ist, durch die Elektrizität Hände, welche in allen ihren Teilen (K nochen, Muskeln, Nerren, Haut) so verkümmert sind, 
wie die der blinden Kinder, zn jenen Leistungen zu befähigen, die Kle in durch seine Übungen erreichte.

Hiermit geben wir zu, dass die medizinische Wissenschaft bei der Behandlung der erwähnten Leiden durch die Elektrizität im Laufe eines Jahrhunderts nicht so weit gelangt ist, wie $\mathrm{K}$ lein mit seinen Übungen.

Dieser Misserfolg rührt wohl hauptsächlich daher, dass man zu einseitig vorging. Man sah im Anfange des vorigen Jahrhunderts in der Elektrizität gleichsam eine neue übertragbare Lebenskraft.

„Docteur, voilà l'image de la vie!" rief Napoleon I. Corvisart zu, als ihm die Zerlegung der Atzalkalien durch den elektrischen Strom gezeigt wurde ${ }^{1}$ ).

Die unmittelbaren Wirkungen dieser neuen Zauberkraft auf Muskeln, welche dem Willen vollständig den Gehorsam versagten, liessen die lästigen Übangen als unnütz erscheinen und man unterliess es, die Anwendung der Elektrizität mit den Übungen zu vereinigen.

Heutzutage ist dieser hundertjährige Zauber gebrochen. Wir haben es eingesehen, dass eine Vereinigung ${ }^{2}$ ) beider Heilverfahren zu erstreben sei, und nur noch grosse praktische Schwierigkeiten verhinderten bisher diese Vereinigung.

Diese Schwierigkeiten zu verringern war seit Jahren mein Bemühen. Daher will ich es versuchen, im nachfolgenden anzudeuten, durch welche Mittel mir eine derartige Vereinigung möglich erscheint. - Die Hauptschwierigkeiten, welche sich einer Verallgemeinerung der Bewegungskuren entgegenstellen, sind wohl folgende:

1. die lange Dauer der einzelnen Sitzung;

2. die lange Dauer der ganzen Kur;

3. die Kostspieligkeit der Kur, welche durch die Kostspieligkeit der Apparate oder der Heilgehilfen bedingt wird.

Diese Schwierigkeiten veranlassten mich, einfache, leicht herstellbare Vorrichtungen zu verwenden, die durch genaue Kraft- und Zeitbestimmungen ein sicheres Urteil über den Erfolg der Behandlung gewähren und zugleich es gestatten, eine grössere Anzahl von Kranken gleichzeitig zu behandeln.

Hierdurch erst war ich imstande, die Kranken in der ausgiebigsten Weise ihre langdauernden Übungen machen $z u$ lassen und sie ohne allzu grossen Zeitaufwand persönlich zu überwachen.

Hierdurch erst erlangte ich die Möglichkeit, durch zahlreiche vergleichende Beobachtungen und Erfahrungen feste Gesichtspunkte über die Wirkung und den Gebrauch der Widerstandsbewegungen zu gewinnen.

Wie ich mir von diesen Gesichtspunkten aus feste Regeln bildete, will ich versuchen, hier kurz mitzuteilen.

Jeder Arzt, der mit eigener Hand Widerstandsbewegungen geleitet hat, wird wohl die Erfahrung gemacht haben, dass er bei Wadenkrämpfen die

1) Histoire de l'électricité et du magnétisme par Becquerel. Paris 1858, p. 33.

2) Ernst Etzold, Klinische Untersuchungen über die Nervennaht. Inauguraldissertation. Dorpat, Mattiessen, 1889. 
krampfhafte Spitzfussstellung nicht selten beseitigen kann, wenn er mit seiner Hand einen leichten Druck auf die Rückseite der Fussspitze ausübt und jetzt den Kranken auffordert, eine Rückenbeugung des Fusses vorzunehmen.

Bei diesen Bewegungen muss kommandiert werden: eins, zwei! und bei einseitigen Krämpfen sind die Widerstandsbewegungen zuerst an dem Fusse vorzunehmen, der vom Krampfe verschont geblieben ist.

Freilich gelingt es nicht immer, in dieser Weise den Krampf zu lösen, und nur eine sehr geübte Hand vermag derartige Widerstände auszuüben.

Diese krampflösende Wirkung der Widerstände beruht wohl zum Teil darauf, dass bei Belastung der Rückenbeuger des Fusses die Tätigkeit der Sohlenbeuger gewohnheitsmässig ausgeschaltet wird.

$\mathrm{Zu}$ allen freien Bewegungen ${ }^{1}$ ) unserer Gliedmassen sind ja zwei einander entgegengesetzte Muskelgruppen erforderlich. Beugungen der Finger können z. B. ohne Mitwirkung der Strecker ebenso wenig ausgeführt werden, als bei krampfhaften Zuständen derselben, d. h. bei ungenauer Anpassung der überreizten Strecker an die Beuger.

Es kann aber trotz der überreizten Strecker die Beugung doch möglich werden, wenn eine geübte Hand die Tätigkeit der Strecker nachahmt. Zum Teil wird wohl aber die krampflösende Wirkung der Widerstände noch durch andere Ursachen bedingt.

Sehr massgebend für die Wirkung der Widerstandsbewegungen ist gewiss wohl auch ihre Beeinflussung jener Organe, welche die zu den Bewegungen erforderliche Muskelkraft liefern. Ich meine Gehirn und Muskeln, die ich kurz mit dem Ausdruck $K=$ Kraft bezeichnen will.

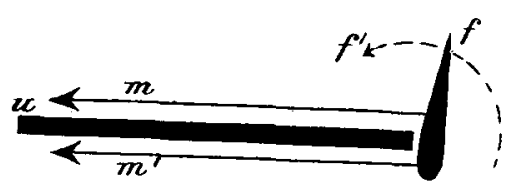

Schema I, Fig. 1.

Bei einer Rückenbeugung des Fusses z. B. hat diese Kraftquelle einen Muskel $m$ (Schema I) und einen Muskel $m^{\prime}$ zu versorgen, da ja zu jeder Bewegung unserer Gliedmassen ohne äusseren Widerstand zwei einander entgegengesetzt wirkende

Muskelgruppen erforderlich sind.

Die Zugkraft dieser beiden Muskeln kann man bei dieser Bewegung einander gleichsetzen $\left(m=m^{\prime}\right.$ Schema I), da bei gleicharmigen Hebeln, an denen zwei Kräfte einander das Gleichgewicht halten, Bewegung eintritt, sobald eine der beiden Kräfte ein wenig gesteigert wird. Diese Steigerung ist so gering, dass man sie bei mechanischen Betrachtungen in der Regel vernachlässigt. Tut man dies nicht, so erhält man Werte, die von 0 nur sehr wenig verschieden sind. Ich setze also im Nachfolgenden $m=m^{\prime}$. Die Kraftquelle $K$ habe bei einer Bewegung von $f$ nach $f^{\prime}$ (Schema I) zwei Muskelzüge $m$ und $m^{\prime}$ zu versorgen, die einander gleich an Stärke sind,

$$
K=m+m^{\prime} \text {. }
$$

1) Mit dem Ausdrucke „freie Bewegungen“ bezeichne ich solche Bewegungen, die ohne äussere Widerstände ausgeführt werden, ähnlich den sogenannten „Freiübungen der Turner. 
Wird nun $m^{\prime}$ durch den äusseren Zug $m^{\prime \prime}$ ersetzt, so braucht die Kraftquelle $K$ nicht mehr $m^{\prime}$ zu liefern, sondern bloss $m$, d. h. bloss halb so viel Kraft, $K=m$.

Wir finden also, dass bei einer Rückenbeugung des Fusses mit Widerstand der menschliche Körper nur halb so viel Kraft zu liefern braucht, als bei einer Rückenbeugung des Fusses ohne Widerstand. Selbstverständlich darf der Widerstand nicht stärker als $m^{{ }^{\circ}}$ sein.

Es wird also bei Ausschaltung von Muskelzügen durch äussere Krräfte der Kraftverbrauch herabgesetzt um so viel, als der ausgeschaltete Muskelzug beansprucht, und wir erkennen somit das interessante Gesetz, dass sorgfältig angepasste Widerstandsbewegungen weniger ermüdend wirken müssen, als Bewegungen, die ohne äussere Widerstände ausgeführt werden.

Bei empfindlichen entzündeten Gelenken spielen gewiss die Druckverhältnisse im Gelenke eine grosse Rolle. Bei allen freien Bewegungen ziehen Beuger und Strecker, also zwei Maskelgruppen die Gelenkenden der bewegten Knochen gegeneinander und erzeugen so einen Druck,

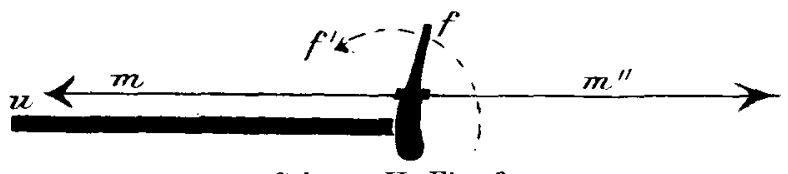

Schema II, Fig. 2.

welcher gleich ist der Zugkraft der Beuger + der Zugkraft der Strecker. Wird nun durch Anwendung eines äusseren Widerstandes eine der Muskelgruppen ausgeschaltet, so wird hiermit auch der Teil des Druckes ausgeschaltet, den der Zug dieser einen Muskelgruppe bewirkte.

Schema I und II (Fig. 1 und 2) möge noch deutlicher diese Verhältnisse veranschaulichen.

$$
\begin{aligned}
u= & \text { Unterschenkel } \\
f= & \text { Fuss } \\
m= & \text { Rückenbeuger des Fusses } \\
m^{\prime}= & \text { Sohlenbeuger } \\
\mathrm{m}^{\prime \prime}= & \text { äussere Kraft } \\
D= & \text { Druck, den die Gelenkkörper bei Bewegungen } \\
& \text { durch die Züge der Muskeln } m \text { und } m^{\prime} \text { erleiden. } \\
& \text { (Bewegungen ohne Widerstand.) } \\
& D=m+m^{\prime} \text { bei freien Bewegungen. }
\end{aligned}
$$

Wird $m^{\prime}$ durch die äussere Kraft $m^{\prime \prime}$ ausgeschaltet, so haben wir, da $m^{\prime \prime}$ in entgegengesetzter Richtung von $m$ wirkt:

$$
D=m-m^{\prime \prime}=0 \text { bei Anwendung der Kraft } m^{\prime \prime} \text {. }
$$

Ist z. B. $m=3 \mathrm{~g} ; m^{\prime}=3 \mathrm{~g} ; m^{\prime \prime}=3 \mathrm{~g}$ so wird:

bei freien Bewegungen (Schema I)

$$
D=m+m^{\prime}=3+3=6 \mathrm{~g}
$$

bei Bewegungen mit einem äusseren Widerstand von $3 \mathrm{~g}$ (Schema II)

$$
D=m-m^{\prime \prime}=0 \text {. }
$$

Also ist bei der in Schema II dargestellten Widerstandsbewegung der Druck der Gelenkflächen gegen einander $=0$. Das ist gewiss nicht bei allen 
Widerstandsbewegungen der Gliedmassen des Menschen der Fall. Jedenfalls aber wird beim Fussgelenk und auch einigen anderen Gelenken der Druck sehr bedeutend herabgesetzt und das ist bei Gelenkentzündungen von der grössten Bedeutung. Man erwäge doch nur, dass nach den neueren Untersuchungen und Berechnungen von $\mathrm{Cartex}{ }^{1}$ ), Ewald, Otto Fischer u. a. der abgelöste Wadenmuskel eines Menschen bis $900 \mathrm{~kg}$ heben kann. Diese gewaltige Kraftentfaltung wird wohl bei Wadenkrämpfen nur annähernd erreicht. Immerhin ist der Druck der Fussknochen gegen das Schienbein sehr bedeutend und eine Herabsetzung des Druckes bis in die Nähe von 0 muss von grosser Heilwirkung sein.

In der Tat geben denn auch einsichtige Kranke an, dass bei derartigen Krämpfen Widerstandsbewegungen, so lange sie nicht zu stark und zu lange ausgeführt werden, sehr wohltuend auf sie einwirken und durchaus einem Drange nach Bewegung entsprechen, dem Folge zu leisten ihnen ohne Widerstände bei Krampfzuständen unmöglich ist.

Gewiss wird diese wohltuende Empfindung auch schon erklärlich, wenn man erwägt, wie wohltuend es auf den Gemützustand des Kranken einwirkt, dass plötzlich durch die Handauflegung des Arztes Bewegungsstörungen schwinden, die bisher unüberwindlich waren. Auch die bedeutenden Hindernisse im Blutkreislaufe werden durch die Bewegungen beseitigt. Wie häufig sieht man dies, wenn bei Wadenkrämpfen durch aktive und passive Bewegungen die Füllung der Venen nachlässt und die Spannungen und Schmerzen im Unterschenkel schwinden.

Freilich wird dies wohl auch durch die Dehnungen der erkrankten Muskeln und Nerven bedingt, welche die Krämpfe verursachen.

Es kommen also wohl kurz folgende Momente bei der Behandlung mit Widerstandsbewegungen in Betracht:

1. Begünstigung des Blutumlaufes;

2. passive Bewegung und Dehnung der erkrankten Nerven und Muskeln;

3. Übung der geschwächten Muskeln und Nerven;

4. Herabsetzung des Verbrauches von Muskelkraft.

$\mathrm{Zu}$ den Widerstandsbewegungen verwende ich hauptsächlich Rollenzüge mit Gewichten. Befestigt man diese Züge an den freien Enden der Gliedmassen, so bilden sie Widerstände für die verschiedenartigsten Bewegungen.

Ein Blick auf die bejgefügten Zeichnungen wird wohl genügen, um zu erkennen, dass man mit ihnen Beugungen, Streckungen, Rollungen etc. mit Widerstand ausführen kann.

Die grosse Vielseitigkeit der Richtungen dieser Widerstände ist ja vielleicht auch durch die Hand eines Gymnasiasten oder durch Gummizüge erreichbar. Schwerlich aber ist die Hand des Gymnasiasten imstande, so

1) Cartex, M. E., Mecanisme du soulevement du Corps sur la pointe des pieds. Journ. d. Phys. et de Pat. gener. Nr. 3. Mai 1901. Paris, Masson. $~ O$ t to Fischer, Die Hebelwirkung des Fusses, wenn man sich auf den Zehen erhebt. Arch. f. Anat. u. Phys. Anat. Abt. 1895. Diese Literatur verdanke ich dem Kollegen Réné du Bois Reymond. 
genau bestimmbare Stärkegrade der Widerstände zu bewirken, wie es mit Leichtigkeit durch Vermehrung oder Verminderung von Gewichten geschehen kann.

Zudem verhindert die grosse Kostspieligkeit und Umständlichkeit der manuellen Widerstände selbst wohlhabende Patienten am ausreichenden Gebrauch derselben.

Gummizüge baben wiederum den Nachteil, dass ihre Dehnbarkeit bei gesteigerter Dehnung schnell abnimmt und sie daher den Muskeln stets einen wachsenden Widerstand entgegensetzen. Da aber die Kraft des Muskels abnimmt, je mehr der Muskel sich zusammenzieht und schliesslich $=0$ wird (siehe Handbuch der Physiol. von Hermann), so übersteigt ein zunehmender Widerstand die Leistungsfähigkeit eines Muskels. Obgleich nun allerdings die meisten Muskeln an Hebeln arbeiten, die bei fortschreitender Bewegung einen geringeren Kraftaufwand erfordern, so reicht dies doch nicht aus, um in jenen Momenten einen wachsenden Widerstand $\mathrm{zu}$ überwinden, wo die Kraft des Muskels sich immer mehr 0 nähert. Dies zeigt sich schon darin, dass bei stark geschwächten Muskeln ununterbrochen wachsende Widerstände die Bewegungen sehr einschränken, während Widerstände, die anfangs allmählich zunehmen und zum Schluss wieder allmählich abnehmen, die Ausgiebigkeit der Bewegungen bedeutend steigern.

Derartige Widerstände kann man mit Rollenzügen herstellen. Dies lehrt ein Blick auf Schema III (Fig. 3).

$U$ stelle einen Unterschenkel dar, $O$ einen Oberschenkel. Die Strichelung unterhalb $O$ bedeutet, dass $O$ als festgestellt anzusehen ist.

An dem freien Ende von $U$ ist die Schnur eines Rollenzuges befestigt. Berühren die Schnur $S$ und der Unterschenkel $U$ einander in einer geraden Linie (bei $\alpha^{\prime}$ ist dies nur annähernd der Fall), so kann das Gewicht $G$ nicht drehend auf den Unterschenkel wirken, da die Spitze des Hebels $U$ auf einem toten Punkte steht. Die gesamte Zugkraft der Schnur wird durch den Hebel auf dessen Stützpunkt übertragen. Beträgt z. B. das Gewicht $G=100 \mathrm{~g}$, so ist, wenn Hebel und Schnur einander in einer geraden Linie berühren, die drehende Wirkung dieser $100 \mathrm{~g}$ gleich 0 .

Bringt man den Hebel in eine derartige Stellung, dass Schnur und Hebel einen Winkel von $90^{\circ}$ bilden (Schema IV [Fig. 4], die punktierten Linien), so ist die drehende Wirkung der $100 \mathrm{~g}$ gleich $100 \mathrm{~g}$, da ja bekanntlich diese rechtwinklige Stellung die günstigste Kraftrichtung gewährt. Es hat also die drehende Wirkung des Gewichtszuges $G$ eine Steigerung von 0 g a uf $100 \mathrm{~g}$ erfahren. Selbstverständlich ist hierbei das Gewicht am Ende der Schnur immer dasselbe geblieben, gleich $100 \mathrm{~g}$.

Die Werte zwischen 0 und $100 \mathrm{~g}$ findet man sehr bequem, wenn man $G=100 \mathrm{~g}$ mit dem $\sin \alpha$ multipliziert, nach der Formel G. $\sin \alpha=\mathrm{P}$.

Die Herleitung der Formel $P=G \sin \alpha$ findet sich allerdings in den Lehrbüchern der Mechanik. Da sie aber vielleicht in der dort gegebenen Form nicht allen Lesern ganz verständlich ist, so gebe ich hier eine von mir ersonnene leichter fassliche Herleitung. Diese geht von dem bekannten Satze 
aus: An einem Hebel halten Kräfte einander das Gleichgewicht, wenn sie in umgekehrtem Verhältnisse der Hebelarme zueinander stehen.

Die Kraft $P$ (Schema IV [Fig. 4l) ist $\mathrm{zu}$ berechnen, also unbekannt, Sie greift rechtwinklig am Hebel $U$ an. Die Kraft $S=G$ denke man sich in der Richtung der Rollenschnur ron $U$ ab aufgetragen. Sie ist nicht senkrecht zu $U$ gerichtet, sondern bildet mit $U$ den $\Varangle \alpha$ : Daher gelangt auch nur ein Teil dieser Kraft $S$ zur Geltung. Ihre drehende Wirkung am Hebel $U$ ist eben so gross, wie ibre drehende Wirkung am kurzen Hebel $a$, den sie unter einem rechten $\Varangle$ angreift.

Da nun an Hebeln Kräfte und Arme in umgekehrtem Verhältnisse zneinander stehen, so haben wir

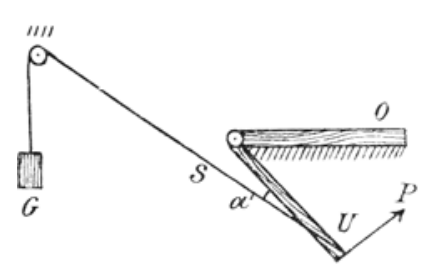

Schema III, Fig. 3.

$$
\begin{aligned}
& a: U=P: S \\
& a=\sin \alpha^{\prime} \\
& U= \\
& P=\sin \alpha^{\prime} \\
& U=S \cdot \sin \alpha^{\prime} \\
& P=G \\
& S=G \cdot \sin \alpha^{\prime} . \\
& P=G
\end{aligned}
$$

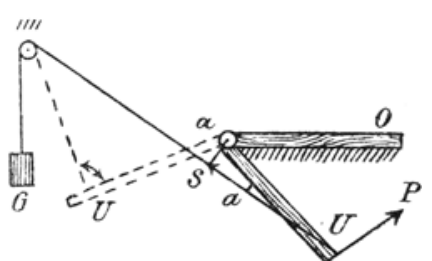

Schema IV, Fig. 4.

für den Winkel $\alpha=30^{\circ}$ ist $100 \sin 30^{\circ}=100.0, \tilde{5}=50 \mathrm{~g}$,

" $, \quad, \quad \alpha=40^{\circ}$ ist $100 \sin 40^{\circ}=100.0,64279=64.279 \mathrm{~g}$,

$" \quad, \quad, \quad \alpha=50^{\circ}$ ist $100 \sin 50^{\circ}=100,0,76604=76,604 \mathrm{~g}$ etc.

Die $100 \mathrm{~g}$ also, welche am freien Ende der Schnur des Rollenzuges sich befinden, wirken folgendermassen drebend:

Bilden Unterschenkel und Schnur des Gewichtszuges einen Winkel

von $0^{0}$, so ist die drehende Wirkung der $100 \mathrm{~g}=0$,

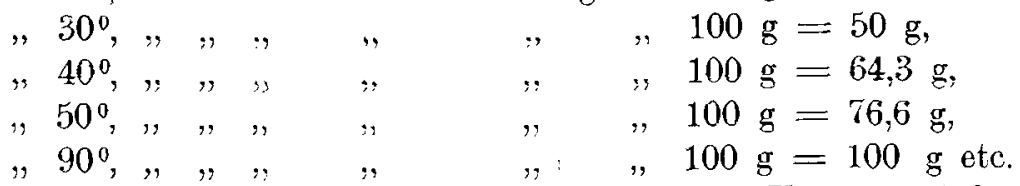

Es hat also der Unterschenkel, wenn Schnur und Unterschenkel einen Winkel ron $0^{\circ}$ bilden, einen Widerstand ron $0 \mathrm{~g} \mathrm{zu}$ überwinden; von $50 \mathrm{~g}$, wenn Schnur und Unterschenkel einen Winkel von $30^{\circ}$ bilden; ron $100 \mathrm{~g}$, wenn Schnur und Unterschenkel einen Winkel ron $90^{\circ}$ bilden.

Man kann zur Herstellung von Widerständen, die allmählich zu- und wieder abnehmen, auch Hebelvorrichtungen benutzen, jedoch ist die Herstellung und der Gebrauch solcher Vorrichtungen umständlicher und man kann mit ihnen nicht so stark geschwächte Muskeln üben wie mit meinen Rollenzügen. Siehe Kraftmessungen S. 159.

An einem Hebel, dessen freies Ende mit einem Gewichte beschwert ist, liegt die Zu- und Abnahme der Widerstände genau ebenso, wie bei den Rollenzügen. In Schema $V$ (Fig. 5) ist die drehende Wirkung des Gewichtes bei $0^{0}=100 \mathrm{~g}$, bei $90^{\circ}=0 \mathrm{~g}$. Auch hier kann man die Zwischenwerte entweder durch die obige Formel oder durch das Parallelogramm der Kräfte finden. In Schema V ist dargestellt, wie man an Hebeln mit Gewichtszügen durch das Kräfteparallelo- 
gramm den Teil der Kraft findet, der drehend auf den Hebel wirkt. $P$ ist senkrecht zum Hebel gerichtet und wirkt daher drehend, $Q$ fällt in die Richtung des Hebels und kann mithin nicht drehend auf den Hebel einwirken. Schema VI (Fig. 6) stellt dar, wie an Hebeln, deren freies Ende mit einem Gewichte beschwert ist, die drehende Wirkung des Gewichtes mit Hilfe des Parallelogramms der Kräfte nachgewiesen werden kann. $P$ wirkt drebend, $Q$ fällt in die Richtung des Hebels und ist unwirksam für die Drehung.

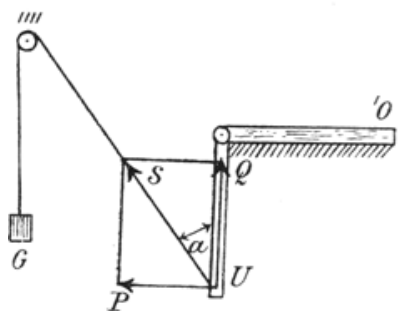

Schema V, Fig. 5 .

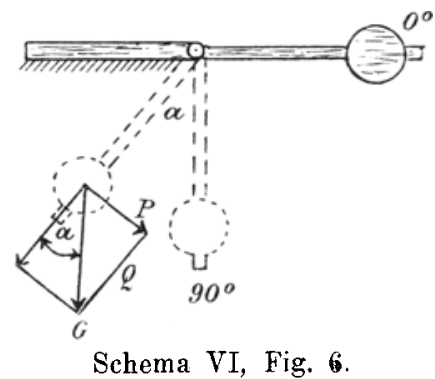

Schema VI, Fig. 6.

Ich hoffe, dass meine obigen Darlegungen den Kollegen verständlich gewesen sind; sollte dies nicht der Fall sein, so bitte ich die Kollegen, welche sich für Widerstandsvorrichtungen interessieren, einen Physiker rom Fach zu fragen, ob meine Darstellungen den Gesetzen der Mechanik entsprechen.

Die Einwirkung von Gewichten und Gewichtszïgen auf die Bewegung ron Hebeln kann also durch Rechnung oder Konstruktion sehr genau festgestellt werden. Schwieriger ist es, die Kraftabnahme des Muskels festzustellen, welche statt hat, wenn der Muskel sich immer mehr und mehr zusammenzieht (Schwann'sches Gesetz). Die Kraftbestimmungen, die von A. Fick ${ }^{1}$ ) hierïber angestellt wurden, beweisen, dass Versuche an Muskeln, die man vom Knochen abgetrennt hat, für die Beurteilung dieser Verhältnisse nicht ausreichen. Fick äussert S. 584:

„Wenn durch die Zusammenziehung des Fingermuskels (Abductor indicis) der Finger über die mittlere Lage ziemlich weit hinausgeführt ist, spannt sich das innere Seitenband des Gelenkes allmählich an und es arbeitet dann der Muskel gegen zwei Kräfte, gegen die Spannung des Verbindungsdrahtes mit dem Myographenhebel und gegen die Spannung des Gelenkbandes. Im Punkte $H$ der Kurve ist also auch keineswegs die Spannung dss Muskels verschwindend klein (20 g wie die Spannung des Drahtes), vielmehr hat sie einen erheblichen Wert, der in Gleichgewicht gehalten wird durch die Gelenkbandspannung. Dass dies in der Tat der Fall ist, kann man an der Härte des Muskels in diesem Stadium deutlich fühlen."

Dieser "erhebliche Wert" ist gewiss oft bei erkrankten Gelenken durch Verdickung der Bänder noch erheblicher, als an dem gesunden Gelenke, mit welchem A. Fick seine Versuche anstellte.

1) A. Fick, Myographische Versuche am lebenden Menschen. Arch. f. gee. Physiol. Bd. 60. Bonn 1895. 
Dieser erhebliche Wert muss also addiert werden zu der Abnahme der Muskelkraft, welche stattfindet, wenn der Muskel sich immer mehr und mehr zusammenzieht, nur so kann man feststellen, um wie viel zum Schluss der Widerstandsbewegung der Widerstand abzunehmen hat.

Da bisher diese Werte nicht berechnet werden konnten, so gibt auch Zander an, dass eine Berücksichtigung dieser Werte „durch praktische Vers u che geschehen muss" bei der Herstellung von Widerstandsvorrichtungen.

Er äussert sich folgendermassen ${ }^{1}$ ): „Die Schwierigkeit ist, den Hebelgesetzen sowohl, als dem Schwann'schen Gesetze bei der Konstruktion der Apparate den berechtigten Einfluss einzuräumen, was nicht durch Berechnung allein, sondern auch durch praktische Versuche geschehen muss. So habe ich beim Apparate B9, Kniebeugen, den grössten Widerstand nicht da gesetzt, wo Ober- und Unterschenkel einen rechten Winkel miteinander bilden, wie es das Hebelgesetz fordert, sondern zirka $30^{\circ}$ v or dieser Stellung, weil man während der Bewegung deutlich fühlt, dass das Maximum von Widerstand an dieser Stelle am leichtesten beseitigt wird."

Also das Schwann'sche Gesetz wurde von Zander durch das Gefühl an seinen Apparaten berücksichtigt, nicht durch Rechnung.

Auch an meinen Vorrichtungen genügt es für praktische Zwecke das Schwann'sche Gesetz durch das Gefühl zu berücksichtigen.

Ob man die Stellung richtig gewählt hat oder nicht, erkennt man am besten, wenn man die Versuche an Muskeln anstellt, die sehr bedeutend geschwächt sind.

Die Bewegung solcher schwacher Muskeln wird ausgiebiger und leichter durch richtig angepasste Widerstände, als ohne Widerstände. Ich habe dies oft Kollegen an meinen Apparaten gezeigt.

Diese ausgiebigen Bewegungen erreicht man jedoch nur, wenn man dem Gewichte die richtige Schwere, der Rolle die in Schema I abgebildete Stellung gibt.

Ich kann den Kollegen, die meine Rollenzüge benutzen wollen, nur raten, durchaus alle Bewegungen am eigenen Leibe zu erproben. Sie werden dann bemerken, dass es am besten ist, wenn man bei Widerstandsbewegungen folgende Stellung der Rolle gibt:

Die Rolle ist so zu stellen, dass Rollenschnur und Längsachse des bewegten Körperteiles annähernd einen rechten Winkel bilden, wenn der bowegte Körperteil die Mitte zwischen äusserster Beugung und Streckung erreicht hat.

Diese Regel reichte sogar für Muskeln aus, die nur $10 \mathrm{~g}$ ziehen konnten An folgendem Beispiele glaube ich am besten die Regel zu erläutern.

Das Strecken des Unterschenkels war am linken Beine der 12jährigen Jenny Liebermann infolge von Kinderlähmung seit der frühesten Jugend im höchsten Grade erschwert. Das Mädchen konnte daher auch ohne Stützvorrichtung am Beine kaum einige Schritte gehen.

1) Dr. A. Levertin, Dr. G. Zander's medico-mechan. Gymnast. Stockholm. Königliche Buchdruckerei 1892. S. 23. 
Setzte man sie auf einen hohen Sessel (Fig. 89 Taf. XIII), so konnte sie den Unterschenkel nicht strecken. Befestigte man das Ende eines Rollenzuges am Fusse (Fig. 89) und belastete das freie Ende desselben mit $50 \mathrm{~g}$, so konnte sie den Unterschenkel hin und her schaukeln und fast bis zu einem Winkel von $180^{\circ}$ strecken.

Diese Bewegung war jedoch nur möglich bei einer Belastung von $50 \mathrm{~g}$ und wenn die Rolle genau in der Höhe des Sitzbrettes angebracht wurde. Wurde die Rolle etwa $10-20 \mathrm{~cm}$ höher als das Sitzbrett angebracht, so waren Bewegungen unmöglich. Auch ist eine sehr leicht sich drehende wohlgeölte Rolle und eine sehr weiche Wollenschnur zu derartigen Bewegungen erforderlich. Reibungswiderstände in der Rollenachse oder Steifheiten der Schnur erzeugen Ungleichheiten des Zuges, die in hohem Grade die Bewegungen erschweren, ja sogar unmöglich machen.

Man ersieht aus allem diesem, wie sehr man imstande ist, durch Rollenzüge sehr gleichmässig zu- und abnehmende Widerstände zu schaffen und wie vollständig man auch die Steigerung der Widerstände durch Gewichtsänderungen beherrscht. Auch auf den Kranken wirkt es sehr günstig ein, wenn er nach Gewichten beurteilen kann, wie seine Kraft wächst.

Ich liess das Mädchen mit dieser Belastung von $50 \mathrm{~g}$ zweimal täglich üben, 5 Minuten lang. Hierauf wurde 15 Minuten lang massiert und dann wieder 5 Minuten geübt.

Bedeutend besser gingen die Bewegungen von statten, wenn ich yor der Kranken in der Höhe des Sessels eine Platte aufstellte und die Kranke dazu antrieb, beim Strecken des Unterschenkels die Platte mit der Spitze des Fusses zu berühren. Es zeigt sich eben hierbei, wie sehr Leistungen gesteigert werden, wenn der Übende ein ganz bestimmtes Ziel vor Augen hat.

Nach 8 Tagen konnte ich die Übung mit $50 \mathrm{~g}$ auf 10 Minuten verlängern, nach einigen Wochen wurde 1 Stunde morgens, 1 Stunde nachmittags mit $50 \mathrm{~g}$ geübt. Nach achtmonatelanger Behandlung konnte die Kranke 2000 g 20 mal nacheinander überwinden und auf der Strasse gegen einen Kilometer ohne ihre Schiene gehen.

Folgende Zahlenzusammenstellung möge diese Kraftzunahme verdeutlichen. Jenny Liebermann, 12 Jahre alt. Kinderlähmung des linken Beines und Fusses seit der frühesten Jugend.

\begin{tabular}{|c|c|c|c|c|}
\hline \multicolumn{4}{|c|}{ Unterschenkelstrecken. } & \multirow{2}{*}{$\begin{array}{c}\text { Fig. } 89 . \\
1896\end{array}$} \\
\hline & 1895 & & 18 & \\
\hline Oktober & November & Dezember & Februar & Mai \\
\hline $50 \mathrm{~g}$ & $200 \mathrm{~g}$ & $300 \mathrm{~g}$ & $600 \mathrm{~g}$ & $2000 \mathrm{~g}$ \\
\hline
\end{tabular}

Der soeben beschriebene Fall scheint mir besonders deutlich zu beweisen, wie wichtig Kraftbestimmungen an Kranken oft sind. Ich gebe daher im folgenden Abschnitt eine kurze Anweisung darüber, wie meine Rollenzüge zu Kraftmessungen verwendbar sind. 


\section{Kraftbestimmungen zu ärztlichen Zwecken.}

Immer mehr macht sich auf allen Gebieten der Naturforschung das Bestreben bemerkbar, nach Mass und Gewicht die untersuchten Verhältnisse zu beurteilen und gewiss ist dieses Bestreben berechtigt; denn gerade jene Zweige der Naturwissenschaft sind am schnellsten und schönsten gewachsen, auf denen es möglich war, mit Zahlen zu rechnen.

Wohl kann es daher auffallen, dass in unserer ärztlichen Kunst die Kraftbestimmungen mit Gewichten und Zahlen noch immer wenig Verwendung finden und dass überhaupt die Angaben über die Leistungsfähigkeit und über den Kräftezustand unserer Kranken in den Berichten der Kollegen oft recht allgemein gehalten sind.

Nur zu häufig findet man Ausdrücke wie "Finger schlaft und kraftlos", "Händedruck schwach" usw. Diese Tatsache scheint mir darauf hinzudeuten, dass wir Heilkünstler, wie überhaupt alle Künstler eine gewisse Abneigung gegen Zahlen besitzen und zwar, wie mir scheint, nicht ganz mit Unrecht. Gerade in der neuesten Zeit haben wir es nur zu oft erfahren, wie sehr Zahlen uns und andere belïgen können.

Selbstverständlich ist daher bei der Yerwendung von Zahlen die allergrösste Gewissenhaftigkeit erforderlich.

Jedenfalls war es mir in einer grossen Anzahl von Fällen nur mit Hilfe von Gewichtsbestimmungen möglich, die Grundursache eines Leidens zu erforschen und die Heilbarkeit desselben zu erkennen.

Doch ich glaube, der Leser wird diese am besten aus den nachfolgenden Mitteilungen ersehen.

Der Korrespondent S. eines grösseren kaufmännischen Geschäftes in Riga, 34 Jahre alt, wandte sich an mich, weil seit etwa einem Jahre das Schreiben ihm erschwert war. Er gab an: Während er früher schnell und schön schrieb, hielt er Zeige- und Mittelfinger in nahezu gestreckter Stellung. Jetzt konnte er nur noch schreiben, wenn er Zeige- und Mittelfinger und Daumen vollständig gebeugt in einer krallenartigen Stellung hielt. Ausserdem gab er an, ihm seien beim Spielen der Klarinette die Handgriffe in der letzten Zeit erschwert. Er spielte nämlich als Dilettant in einem Musikvereine die Klarinette.

Nach meinen bisherigen Erfahrungen über Schreibstörungen hielt ich es für wahrscheinlich, dass eine Schwächung der Fingerbeugemuskeln vorlag.

Als ich jedoch mit meinem Kraftmesser alle Vuskelgruppen nacheinander untersuchte, zeigte sich, dass die Streckmuskelı des rechten Zeigefingers bedeutend schwächer, als die des linken waren.

Ich liess den Kranken seinen Arm so auf den Kraftmesser legen, wie es Fig. 114, Taf. XVI zeigt. In dieser Stellung zog der rechte Zeigefinger $150 \mathrm{~g}$ weniger, als der linke. Es waren also die Streckmuskeln des rechten Zeigefingers geschwächt und daher konnte der Kranke nicht mehr beim Schreiben den Zeigefinger gestreckt halten. Diese Schwächung eines Fingers störte seine ganze Schreibweise. Dieselbe Schwächung erklärt auch den Umstand, dass die Handgriffe beim Spielen der Klarinette erschwert waren. Ich 
habe es oft bemerkt, dass gerade die Streckmuskeln beim Klavier- und Violinspiel von der grössten Bedeutung sind. Da ich in einer Musikschule die Übungen mit meinen Apparaten für Fingergymnastik leite, konnte ich oft an meinem grossen Materiale feststellen, dass bei schlecht entwickelten Fingerstreckmuskeln ganz bestimmte Bewegungen besonders grosse Schwierigkeiten bereiten (Tremolospielen, Spannungen) ${ }^{1}$ ).

Ich hoffe, der Leser wird es zugeben, dass ich ohne meine Kraftmessungen die Ursache der Schreibstörung im soeben erwähnten Falle nicht hätte ergründen können.

In einem anderen Falle stellte ich fest, dass die Schwächung des Daumens eine Schreibstörung bedingte. Die Abzieher des rechten Daumens waren bedeutend schwächer als links (etwa $300 \mathrm{~g}$ ). Durch Übungen an meinen Apparaten und Massage gelang es in 2 Monaten, die Leistungsfähigkeit dieser Muskeln so weit zu erhöhen, dass Patient unbehindert schreiben kann, obgleich seine Schreibstörung sehr viele Jahre bestanden hatte und er bisher vergeblich "Massage gebraucht" hatte.

Gewiss wird wohl der Leser zugeben, dass ohne meine Kraftbestimmung ich schwerlich die Ursache der Schreibstörung erkannt hätte und auch daher nicht imstande gewesen wäre, sie richtig zu behandeln.

Auch den nachfolgenden Fall hätte ich wohl ohne meine Kraftmessungen schwerlich beurteilen und heilen können.

Bei einem Kutscher war infolge eines Pferdebisses in den Oberarm eine Lähmung der Streckmuskeln der Hand und Finger eingetreten. Die faradische Reaktion des N. radial. war ganz geschwunden, die galvanische in geringem Grade vorhanden. Da die Lähmung seit 7 Monaten bestand, erschien eine Heilung ausgeschlossen. Durch meinen Kraftmesser gelang es mir, festzustellen, dass trotz der hochgradigen Entartungsreaktion die. Streckmuskeln der Hand 8 g zogen (vergl. Fig. 108, Taf. XV,). Diese Beobachtung veranlasste mich die Behandlung des sehr störrischen, bösartigen Kranken zu übernehmen.

Es gelang durch Übungen, Mȧssage, Galvanisieren, Hȧndduschen folgende Kraftsteigerung:

$\begin{array}{cccccc}\text { Okt. } 1894 & \text { Jan. } 1895 & \text { März } 1895 & \text { April 1895 } & \text { Mai 1895 } & \text { Mai } 1896 \\ 8 \mathrm{~g} & 300 \mathrm{~g} & 400 \mathrm{~g} & 600 \mathrm{~g} & 700 \mathrm{~g} & 900 \mathrm{~g}\end{array}$

Dieser Kraftsteigerung entsprach auch die Leistungsfähigkeit der Hand. Der geheilte Kranke arbeitet jetzt als Tischler in einer Waggonfabrik für hohen Tagelohn. Die Entartungsreaktion erhielt sich über 2 Jahre. Wäre es mir bei der ersten Untersuchung des Kranken nicht gelungen, festzustellen, dass seine Streckmuskeln $8 \mathrm{~g}$ ziehen konnten, so hätte ich seine Behandlung für aussichtslos gehalten und nicht übernommen.

Dieser von mir schon 1895 veröffentlichte Fall ist gewiss schon dadurch bemerkenswert, dass trotz bestehender Entartungsreaktion, die Hand vollständig leistungsfähig war. Neuerdings habe ich noch zwei derartige Fälle beobachtet.

1) Näheres hierüber siehe Thilo, Fingergymnastik im ,Klavierlehrer“, musikpädagog. Zeitschrift. Berlin 1897. Nr. 20 und 22. 
Vor einiger Zeit gelang es mir mit Hilfe meines Kraftmessers, einen Simulanten zu entlarven.

Der Arbeiter K. der Waggonfabrik "Phönix" in Riga hatte am 7. Februar 1897 den linken Oberschenkel in der Mitte gebrochen.

Er wurde im Rigaer Stadtkrankenhause mit Pappe- und Gipsverbänden 6 Wochen lang behandelt. Der Bruch heilte mit geringer Verkürzung $(1,5 \mathrm{~cm})$ aus. Vom April 1897 bis März 1898 lebte er arbeitslos zu Hause und erhielt von der Waggonfabrik Unterstützungen. Er klagte stets dem Fabrikarzt über Schmerzen im Beine und behauptete, fast gar nicht gehen zu können. Bei der Aufnahme in meine Anstalt (12. März 1898) ging er müh sam auf einen Stab sich stützend durch das Zimmer und hielt das Knie meist in einer leicht übergestreckten Stellung. Bei der Kraftbestimmung der Streckmuskeln des Unterschenkels ergab sich zwischen rechts und links ein bedeutender Unterschied. Rechts zog er $15 \mathrm{~kg}$ (Fig. 89, Taf. XIII), links nur $4 \mathrm{~kg}$. Immerhin wusste ich aus langjähriger Erfahrung, dass Menschen, deren Unterschenkelstrecker $4 \mathrm{~kg}$ ziehen, ganz vortrefflich gehen können. Mittelstarke gesunde Frauen mit einem Körpergewicht von $45 \mathrm{~kg}$ haben häufig nur 4 bis $6 \mathrm{~kg}$ Zugkraft und gehen hiermit sehr gut.

Daher musste ich annehmen, dass der schlechte Gang des Kranken mindestens eine grosse Übertreibung sei.

Nach einigen Tagen bestimmte ich wieder die Zugkraft der Streckmuskeln des linken Unterschenkels. Der Kranke behauptete bei dieser Untersuchung, kaum $1 \mathrm{~kg}$ ziehen zu können. Jetzt war für mich eine böswillige Absicht erwiesen. Als ein warnendes Beispiel für die anderen Arbeiter verwies ich inn in der allerschroffsten Form aus der Anstalt. Da er aber kam und um Verzeihung bat, so nahm ich ihn auf Verwendung des Fabrikarztes wieder an. In solchen Fällen versuche ich es nie, hierauf dem Kranken zu beweisen, dass er gelogen hat. Im Gegenteil, ich lasse seine Vergangenheit unberücksichtigt. Ich beginne bei ihm Übungen mit ganz geringen Gewichten und steigere erst allmählich die Gewichte. Sehr häufig ist es mir gelungen, selbst sehr störrische Menschen in einigen Wochen dahin zu bringen, dass sie Bewegungen mit schweren Gewichten ausführen, die sie vorher für unmöglich erklärten.

Auch dann mache ich solche störrische Kranke meist nicht auf ihre Fortschritte aufmerksam, sondern ich treibe sie langsam vorwärts. Leider erlangt man ja selten bei diesen unglücklichen Charakteren eine Anerkennung. Diese faulen, störrischen Menschen sind unverbesserlich. Hat man die gröbsten Störungen bei ihnen beseitigt, so muss man sie so schnell als möglich aus den Anstalten entfernen. Den Arbeitgebern aber solcher Leute ist es zu raten, sie so schnell als möglich zu entlassen; denn sie wirken im höchsten Grade infizierend auf die anderen Arbeiter.

Diejenigen Kranken, welche behaupten, überhaupt gar keine Bewegungen aktiv ausführen zu können, lasse ich mit meinen Apparaten zunächst passive Bewegungen machen. Oft gelingt mir dann mit Hilfe meiner Apparate das Einschleichen von den passiven Bewegungen in aktive. Dieses Verfahren ver- 
wende ich auch bei der Behandlung von Gelenkneuralgien und hysterischen Bewegungsstörungen ${ }^{1}$ ).

Die weiteren Erfahrungen mit dem soeben besprochenen Kranken K. bestätigten vollständig meine Annahme, dass er ein Simulant sei. Ich beobachtete ihn eines Tages unbemerkt auf der Strasse, wie er schnell und leicht ohne zu hinken, dahin ging. Ich teilte ihm natürlich meine Beobachtung nicht mit, sondern trieb ihn allmählich mit Übungen vorwärts. Ich vermehrte das Gewicht am Anker (Fig. 89) täglich um $1 \mathrm{~kg}$, liess ihn ausserdem üben: Hockstand, Marschieren auf Kommando, Balancieren auf dem geschwächten Beine usw. Ich weiss, dass auf diese Art Simulanten oder wie man sie heutzutage oft nennt, "grobe Übertreiber" "oft ziemlich schnell mürbe werden. Sie gehen dann in einigen Wochen bei Zeugengegenwart gewöhnlich ebenso gut, wie andere Sterbliche und werden dann selbst von jenen Richtern als erwerbsfähig erklärt, die gern zugunsten des Arbeiters entscheiden. Im vorliegenden Falle bot die Direktion der Waggonfabrik, gestützt auf meine Untersuchungen und Angaben, die Summe von 400 Mark als einmalige Entschädigung, wenn der Arbeiter sich verpflichtete, von einer gerichtlichen Klage Abstand zu nehmen. Der Arbeiter ging darauf ein. Er nahm das Geld, "ging dahin und hinkt nicht mehr." Er dient jetzt bei einem anderen Arbeitgeber und ist vollständig erwerbsfähig. Gewiss ist es nicht leicht, einen solchen Kranken zu behandeln. Nir gelingt es nur auch infolge des glücklichen Umstandes, dass ich von Heilgehilfen unterstützt werde, die früher Wärter in einer Irrenheilanstalt waren. Ich kann es den Kollegen nicht genug empfehlen, überhaupt derartig vorgebildete Gehilfen zu Übungskuren zu verwenden. Ein grosser Teil all' jener schönen, schlanken Grenadiere, die man heutzutage als "schneidige Masseure" tätig findet, ist für die Behandlung von Neurasthenischen, Hypochondern, Hysterischen, Tabikern durchaus unbrauchbar.

Auf die Kraftmessungen anderer Muskelgruppen kann ich an dieser Stelle nicht eingehen, ich hoffe jedoch, dass der Leser ohne grosse Schwierigkeiten aus den beigefügten Tafeln XIII-XVI ersehen wird, wie solche Messungen ausführbar sind. Hier beschränke ich mich nur noch darauf, einige allgemeine Gesichtspunkte über Kraftmessungen festzustellen.

Diese lassen sich wohl am besten zusammenfassen in folgende

\section{Allgemeine Regeln.}

1. Alle Kraftmessungen sind so vorzunehmen, dass für den Untersuchten die Gewichte unsichtbar bleiben.

2. Bei mehrfachen Untersuchungen eines und desselben Kranken ist stets dieselbe Höhe der Rolle vom Fussboden und dieselbe Länge der Rollenschnur zu wählen, damit die Winkel, welche die Gliedmassen mit der Rollenschnur bilden, stets bei allen Untersuchungen dieselben seien.

3. Wenn von paarigen Gliedmassen nur die eine erkrankt ist, so nimmt

1) Vergl. Thilo, Zur Behandlung der Gelenkneuralgien. Monatsschrift f. Unfall heilkunde. 1897. Dezember. 
man die Kraftmessungen zuerst an der gesunden vor und zwar lässt man mit der gesunden Gliedmasse zunächst ein ganz geringes Gewicht einige Male ziehen, um den Kranken an die erforderljche Bewegung zu gewöhnen. Dieses ist deshalb notwendig, weil viele, sonst ganz fähige Menschen, oft in Bewegungen an Apparaten ganz auffallend ungeschickt sind. Ich habe schon Kollegen behandelt, welche in den ersten Tagen der Behandlung jedesmal unrichtig die Apparate handhabten, so dass ich ihnen jedesmal von neuem die Übungen vormachen musste. Hat man sich überzeugt, dass die Bewegungen von der gesunden Gliedmasse mit der geringen Belastung richtig ausgeführt werden, so wähle man eine Belastung, die mutmasslich dem Körperbau und Alter des Kranken entspricht. Hierin erlangt man bald ein sehr sicheres Urteil. Zur genaueren Gewichtsbestimmung wählt man am besten das Verfahren, welches die Chemiker beim Wägen verwenden. Findet man z. B. $20 \mathrm{~kg} \mathrm{zu}$ schwer, so hänge man $10 \mathrm{~kg}$ an, sind diese $\mathrm{zu}$ leicht, wird $15 \mathrm{~kg}$ gewählt, waren $10 \mathrm{~kg}$ zu schwer, so sind $5 \mathrm{~kg}$ anzuhängen, hierauf 7,5 oder $2,5 \mathrm{~kg}$. So findet man durch fortgesetztes Halbieren sehr schnell das richtige Gewicht. Bei der Untersuchung von Simulanten oder ,groben Übertreibern“" empfiehlt es sich, mehrmals die Gewichte zu wechseln und beim Untersuchten den Glauben zu erwecken, dass er leichte Gewichte zieht, wenn schwere angehängt sind.

Am nächsten Tage oder auch schon nach einigen Stunden nehme ich häufig eine zweite Kraftmessung vor und beginne hierbei gleich mit dem schwersten Gewichte, welches bei der letzten Messung gezogen wurde.

Ich habe durch Messungen an meinen eigenen Gliedmassen, die ich von anderen sacbkundigen Personen vornehmen liess, festgestellt, dass meine Maximalleistungen fast immer dieselben blieben und nur bisweilen ganz geringe Schwankungen zeigten, welche für praktische Zwecke gar nicht mehr in Betracht kommen. Diese Messungen liess ich so vornehmen, dass ich das Gewicht nicht sehen konnte.

4. Zweierlei Arten von Leistungen sind bei Kraftmessungen zu berücksichtigen :

a) Die einmalige Maximalleistung.

b) Dauerleistungen.

a) Bei den einmaligen Maximalleistungen stellt man fest das grösste Gewicht, welches der Kranke einmal ziehen kann. Zur Feststellung dieser einmaligen Leistung genügt in einigen Fällen eine Federwage, wie sie in jeder Eisenwarenhandlung zu einem geringen Preise käuflich ist. Dr. Johannes $\mathrm{Hahn}$ in Mainz empfiehlt zu Kraftmessungen nicht seine ihm zur Verfügung stehenden Zanderapparate, sondern Rollenzïge, die er an einer Federwage befestigt. Er geht dann „von einer für den Einzelfall bestimmten Winkelstellung aus, z. B. einer Beugestellung von einem rechten Winkel und stellt fest, welche Zug- oder Druckkraft in dieser Stellung geleistet werden kann ${ }^{1}$ ).

1) Genaueres hierüber siehe Monatsschrift für Unfallheilkunde. 1898. Nr. 1. Seite 8. Ans dem medico-mechanischen Zanderinstitut Mainz. Zur Untersuchung von Unfallverletzten, ron Dr. Johannes Hahn. 
Man verwendet die Federwage wohl am einfachsten, indem man sie an Haken hängt, die in verschiedenen Höhen in die Wand geschraubt und am Fussboden befestigt sind. Die zu untersuchende Gliedmasse wird dann durch eine Schnur mit der Federwage verbunden. Ein Rollenzug, wie ihn Hahn verwendet, erscheint mir hierbei entbehrlich.

Natürlich kann man so feine Messungen von $8 \mathrm{~g}$, wie sie beim eben erwähnten Kutscher L. vorgenommen wurden, nicht mit einer Federwage ausführen. Auch die Beobachtungen von Bewegungen gestatten sie nicht, ebenso wenig die Bestimmung von Dauerleistungen.

b) Dauerleistungen festzustellen neben den einmaligen Maximalleistungen, ist durchaus notwendig. Man untersucht hiebei, wieviel Mal ein Kranker in einem bestimmten Zeitraum ein mittelschweres Gewicht ziehen kann.

Ich halte die Feststellung einer Dauerleistung überhaupt zur Beurteilung eines Menschen für unentbehrlich. Ich beurteile wohl nie einen Menschen nach einer Einzelleistung, nie werde ich einen Fechter nach e in em Hiebe beurteilen, nie einen Dichter nach einem Verse. Vielleicht wird mancher vielbeschäftigte Kliniker hiegegen einwenden, er sei zu beschäftigt, um so zeitraubende Untersuchungen auszuführen. Das kann ja wohl der Fall sein, dann aber hat auch dieser Kollege kein Recht, auf sein grosses Material zu pochen; denn ein grosses unzuverlässiges Material redet eine grosse Unwahrheit und kommt überhaupt gar nicht mehr in Betracht. Gewiss sehr mit

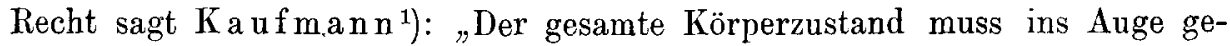
fasst werden. Schwieriger zu beurteilende Folgezustände (von Verletzungen) verlangen speziellere Untersuchungen, die zuweilen wiederholt werden." Ich glaube, die Feststellung von Dauerleistungen ist zur Beurteilung der seelischen und körperlichen Beschaffenheit eines Kranken von grösster Wichtigkeit. Wenn z. B. ein Untersuchter, der auf Simulation verdächtig ist, angegeben hat, er könne kaum $4 \mathrm{~kg}$ einmal mit seinen Unterschenkelstreckern ziehen, so empfiehlt es sich, ihm zu sagen: So jetzt habe ich mehr als die Hälfte von den Gewichten fortgenommen, nun ziehen Sie mal los!

Führt jetat der Kranke eine kleine Dauerleistung mit den $4 \mathrm{~kg}$, d. i. mit dem Gewichte seiner angeblichen einmaligen Maximalleistung aus, so ist das sehr bezeichnend für seine Charaktereigenschaften.

5. Bisweilen findet man die Streckmuskeln des Handgelenkes so sehr geschwächt, dass sie nicht imstande sind, die Hand zu erheben, wenn der Kranke seinen Unterarm auf einen Tisch legt und die Hand über die Tischkante herabhängen lässt. Trotz dieser hochgradigen Schwächung können die Handgelenksstrecker doch noch ein Gewicht von $10-20 \mathrm{~g}$ zieben in der Stellung von Fig. 108, Taf. XV; da dieses Gewicht ja bedeutend geringer ist als das Gewicht der Hand. Am einfachsten führt man diese Untersuchung aus, indem man durch die Lehnen zweier Wienerstühle zwei Stäbe so schiebt, dass sie parallel zueinander liegen. An dem einen Stab lässt man den Unterarm lehnen, so dass die Hand senkrecht herabhängt, über den anderen Stab

1) Ka ufmann, Handbuch der Unfallerkrankungen. Stuttgart. Enke 1897. 
zieht man eine Schnur, welche mit einer Schlinge an zwei Fingern befestigt ist und am freien Ende ein Gewicht $(10-20 \mathrm{~g})$ trägt. Ich verabsäume es nie, bei hochgradig geschwächten Muskeln diese Untersuchung vorzunehmen, da sie allein oft dafür massgebend sein kann, ob eine Lähmung noch heilbar ist oder nicht.

Ähnlich wie beim Handgelenk liegen natürlich auch die Verhältnisse beim Unterarm und Lnterschenkel. Die Stellung Fig. 89, Taf. XIII eignet sich für die Bestimmung sehr geringer Kraftleistungen der Unterschenkelstrecker, man muss nur den Fuss weit unter das Sitzbrett nach hinten schieben und dann den Anker belasten. Für den Unterarm ist die Stellung Fig. 102 erforderlich. Der Ellbogen wird hiebei an die Stuhllehne mit einem Riemen oder Tuch befestigt, die Rolle etwa $2 \mathrm{~m}$ boch über den Fussboden gestellt.

Folgenden interessanten Fall stellte ich im August 1897 in der Versammlung livländischer ${ }^{1}$ ) Ärzte vor: Der 14jährige Knabe K. hatte vor einigen Monaten einen Bruch des inneren Gelenkknorrens am rechten Ellbogengelenk erlitten. Als er sich mir vorstellte, fand ich den Bruch ganz ausgezeichnet verheilt und das Ellbogengelenk vollständig beweglich. Leider aber erschienen alle Oberarm- und Unterarmmuskeln fast vollständig gelähmt. Die Finger konnte er kaum merklich rühren und auch den ganzen Arm konnte er nur ein wenig hin- und herpendeln. Trotzdem war er imstande, mit dem rechten (gelähmten) Arm allein die Übung 95, Taf. XIV, auszuführen und zwar konnte er genau $750 \mathrm{~g}$ so ziehen, dass der Anker mit dem Gewichte sich gleichmässig hob und senkte. Mehr als $750 \mathrm{~g}$ konnte er nicht ziehen, aber auch nicht weniger. Diese Beobachtung verwirte mich zuerst ein wenig, erklärte sich jedoch folgendermassen: Wenn er weniger als $750 \mathrm{~g}$ an den Anker hängte, so wurde der Arm nicht mehr gehoben und blieb unten, nahm er mehr als $750 \mathrm{~g}$, so konnten die Muskeln (latissim. dorsi u. triceps) das Gewicht nicht mehr herunterziehen. Ich konnte auch durch Kraftmessungen am Triceps feststellen, dass er noch gegen $100 \mathrm{~g}$ ziehen konnte. Hiebei liess ich den Oberarm auf die Stuhllehne stützen und hängte die Hand so an der Decke auf, dass der ganze Arm horizontal lag; einen Rollenzug befestigte ich am Handgelenk und der Unterarm zog dann gegen $100 \mathrm{~g}$.

In diesem Abschnitt halte ich es nicht für überfiussig, darauf hinzuweisen, dass man bei allen Beschreibungen der Leistungsfähigkeit eines Kranken nach Möglichkeit Mass und Gewichtsbestimmungen in Zahlen verwenden sollte. Im allgemeinen ist dieses nicht sehr gebräuchlich, man liest z. B. sehr oft von Amputierten, die Stïtzvorrichtungen tragen „Gang tadellos, ausdauernd"6 usw. Mit derartigen Angaben ist nichts anzufangen. Wäre es nicht viel zweckmässiger, nach bestimmten Strecken, die der Amputierte täglich geht, anzugeben, wieviel Kilometer, in welcher Zeit er zurücklegt. Ähnliche Angaben könnte man gewiss auch bei anderen Kranken, Tabikern, Herzkranken usw. geben. In den Krankengeschichten liest man nur zu häufig „Kranker, früher ein guter Fussgänger, ermüdet jetzt leicht"s.

1) Vergl. Verhandlungen der Versammlung livländischer Ärzte zu Wolmar 1898. 
Genauer kann ich an diesem Orte leider nicht auf meine Kraftbestimmungen eingehen. Ich musste mich hier schon darauf beschränken, einige Beispiele anzuführen und einige allgemeine Gesichtspunkte zu besprechen.

Die Untersuchungen mit meinen Apperaten erscheinen vielleicht einigen Kollegen als sehr umständlich und zeitraubend. Jedoch kann ich die Versicherung geben, dass es mir oft gelang, in einigen Minuten genaue Kraftbestimmungen auszuführen und zwar nicht selten an Kranken mit hochgradig geschwächten Muskeln. Die Streckmuskeln der Hand des Kutschers zogen nur 8 g, der Streckmuskel des Unterschenkels beim Mädchen nur $50 \mathrm{~g}$. Ich weiss nicht, ob mit anderen Apparaten genauere Messungen möglich sind. Jedenfalls war in diesen und anderen Fällen die Genauigkeit ausreichend, um festzustellen, dass selbst diese ungünstigen Fälle heilbar seien und der Erfolg meiner Behandlung bewies die Richtigkeit meiner Prognose. So kann ich denn wohl hoffen, dass der geringe Zuwachs an Arbeit, welcher durch die Verwendung meiner Apparate entsteht, die Kollegen nicht abschrecken wird, mit ihnen Versuche anzustellen.

\section{Die Ausführung meiner passiven Bewegungen und Widerstandsbewegungen}

ist auf Taf. XIII, XIV, XV, XVI dargestellt. Diese 4 Tafeln benutze ich in meiner Anstalt als Wandtafeln. Die Nummer der Figuren schreibe ich auf die Rezepte nebst Angaben der Belastung und Zahl der Bewegungen, Zeitdauer usw.

Der Anfänger wird gut tun bei den passiven Bewegungen sich zunächst streng an die auf den Abbildungen angegebenen Rollenabstände und Belastungen zu halten. Ist er schon mit dem Gebrauche der Torrichtungen vertrauter geworden, so kann er ja nach dem Einzelfalle Anordnungen vornehmen. Sehr zu achten ist darauf, dass die Kranken nicht zu viel Gewichte an den Anker hängen. Besonders Unfallkranke tun das sehr gern.

Für die Belastung bei Widerstandsbewegungen ist es sehr schwer allgemeine Regeln aufzustellen da einige Muskeln anfangs nur $10 \mathrm{~g}$ ziehen, allmählich aber bis auf $1000 \mathrm{~g}$ und mehr gelangen können (vergl. Kraftbestimmungen S. 159). Wichtig ist es die Muskeln nie zu übermüden und doch sie längere Zeit hindurch zu üben. Nach meinen Erfahrungen erreicht man meistens das am besten, wenn man mittelschwere Gewichte an den Anker hängt und Dauerbewegungen von 15-20 Minuten ausführen lässt. Durchaus zu verwerfen ist es, bei einer rein örtlichen Erkrankung, z. B. Plattfuss, Klumpffuss $u$. dergl. sehr viele verschiedenartige ,allgemein stärkende* Übungen machen zu lassen. Leider geht in manchen Anstalten hierbei viel Zeit verloren. Ich beschränke mich in solchen Fällen, falls nicht ganz besondere Gründe vorliegen, nur darauf das erkrankte Bein zu massieren und zu üben 
und zwar: Ich lasse das ganze Bein, namentlich aber die am meisten gegeschwächten Muskeln desselben zuerst üben, dann massieren, dann wieder üben.

Mit meinen Apparaten kann man viel mehr Bewegungen vornehmen, als auf den Tafeln abgebildet sind. Ich hielt es jedoch für wichtiger hier nach physiologischen und anatomischen Grundsätzen die Bewegungen anzuordnen, da ja bei Bewegungsstörungen zuerst die Art der Störungen nach anatomischen und physiologischen Regeln festgestellt werden muss und hiernach die Anordnung der Bewegungen sich zu richten, hat.

So ist es z. B. bei Rückenmarkskranken, welche die Beine kreuzweis setzen am besten zunächst hauptsächlich das Abziehen der Beine zu üben (Taf. XIII, Fig. 93). Hat man hierin eine Besserung erlangt, so geht man erst dann zu anderen Bewegungen über, die mehr zusammengesetzt sind. Genauere Angaben über die Arfertigung und Aufstellung meiner Vorrichtungen siehe S. 178 und Taf. XVII, XVIII.

Fig. 85. Sohlenbeugen des Fusses, passiv. Der Unterschenkel ruht auf einer verstellbaren Vorrichtung (Taf. XVII, Fig. 117) derartig, dass zur Entspannung der Wadenmuskeln das Knie gekrümmt ist. Im Hause des Kranken lagert man den Unterschenkel einfach auf einen Holzkasten. Um die Fussspitze ist ein Lampendocht geschlungen, an dem die Rollenschnur befestigt ist. Ein zweiter Lampendocht wird gleichfalls um die Fussspitze geschlungen und dient als Zügel für die Hand.

Es empfiehlt sich die Rolle etwas tiefer zu stellen als es Figur 85 zeigt, etwa so, wie in Figur 86. Dann verläuft die Schnur schräg nach unten. Hierdurch wird ein Abgleiten der Schnur vom Fusse verhütet. Gewöhnlich genügt das Tieferstellen der Rolle. In besonderen Fällen kann man an der Spitze des Stiefels Drahtösen anbringen. Man schiebt ein Stück Draht, welches so gebogen ist wie eine Haarnadel, quer zwischen Sohle und Oberleder durch und dreht beide Drahtenden zusammen.

Nach Verstauchungen des Fussgelenkes lasse ich oft schon zwei Tage nach der Verletzung von Kranken passive Bewegungen von $20-30^{\circ}$ ausfuihren mit einer Belastung von etwa $1 \mathrm{~kg}$. Die Grösse der Belastung ist bei passiven Bewegungen nicht so wichtig, wie bei Widerstandsbewegungen, da der Kranke mit seiner Hand die Bewegungen regelt. Nach einigen Tagen schon gehe ich von passiven Bewegungen zu Widerstandsbewegungen über. Hierbei wird der Zügel für die Hand fortgelassen. Ich beginne diese Bewegungen gewöhnlich mit $0,5 \mathrm{~kg}$ und steigere sehr allmählich. Bei Hackenfuss nach ausgeheilten Entzündungen nimmt man bis 5 kg Belastung. Die passive Bewegung wird so ausgeführt, dass man den Fuss jedesmal einige Sekunden in der äussersten Sohlenbeugestellung verharren lässt, die erreichbar ist. Hierauf erst zieht man den Zügel wieder an.

Das Gewicht also korrigiert die fehlerhafte Stellung, die Hand des Kranken zieht wieder in die fehlerhafte Stellung zurück, um so den Hinund Hergang der Bewegung zu bewirken. -

Dieses ist die Grundregel aller passiven Bewegungen mit meinen Vorrichtungen. 
Fig. 86. Fussriickenbeugen liegend ausgeführt, besonders geeignet im Hause des Kranken nach Verstauchungen, rheumatischen Entzündungen usw. Der Unterschenkel ruht auf einem Holzkasten. Die um den Fuss geschlungene Schnur wird durch einen Roulleauxring aus Porzellan gezogen (Taf. XVIII, Fig. 131), der Ring ist an der Lehne eines Stuhles befestigt. Belastet wird die Schnur mit einem Sack, der Steine enthält. Diese Bewegung ist mir unentbehrlich bei Plattfuss und Klumpfuss.

Bei Plattfuss wird die Schnur am inneren Fussrande befestigt, bei Klumpfuss am äusseren. Man kann die Schnur auch um den Fuss schlingen, der mit einem Stiefel bekleidet ist, jedoch muss sie dann so schräg verlaufen wie in Fig. 86, damit sie nicht rom Fusse abrutscht.

Fig. 87. Passives Fussrïckenbeugen gegen Spitzfuss. Ein Rollenzug mit Gewicht zieht die Fussspitze nach hinten und korrigiert den Spitzfuss (dieser hintere Zug ist in Fig. 87 weggelassen). Die Hand zieht die Fussspitze in die fehlerhafte Stellung zurück, um den Hin- und Hergang zu erzeugen. Befestigung siehe bei Fusssohlenbeugen. Belastung $2-5 \mathrm{~kg}$. Hierauf lasse ich Fussrückenbeugen mit Widerstand ausführen (Fig. 86). Schiene gegen Spitzfuss siehe Tafel VII, Figur 44. Beschreibung der Schiene S. 122

Drehungen des Fusses um seine Längsachse kann man sehr bequem mit einem Schlittschuh ausführen lassen. Man lässt den Fuss mit dem Schlittschuh auf den Fussboden setzen und dann umklappen. Am meisten eignen sich hierzu die sehr billigen "Schraubenschlittschuhe“, die man sehr bequem für verschiedene Grössen einstellen kann. Ich stelle den Kranken so, dass er sich auf zwei Stuhllehnen stïtzt und zähle bis fünf, so lange der Kranke auf dem umgeklappten Fusse steht. Bei stärker ausgebildetem Klumpfuss und Plattfuss korrigiere ich mit meiner Schiene (Taf. VII, Fig. 43). Sohlen (siehe Taf. VIII, deren Beschreibung S. 125).

Fusskreisen halte ich bei Klumpfuss und Plattfuss für durchaus nicht am Platze. Diejenigen Ärzte, welche nicht mit eigener Hand massiert haben und daher von der Ausübung der Massage nichts verstehen, möchte ich auf auf einen Grundfehler aufmerksam machen, der vielen, ,Diplomierten Masseuren“ anhaftet. Diese Herren sind durch ihre Schulung daran gewöhnt, die passiven Bewegungen des Fusses in der Weise auszuführen, dass sie die Fussspitze mit einer Hand anfassen und in eine kreisförmige Bewegung versetzen, kurz, sie bemühen sich, das Fussgelenk zu einem Kugelgelenke umzuarbeiten.

Mir erscheinen diese Bemühungen nicht sehr zweckmässig. Ich weiss es aus Erfahrung, dass es bei korrigierten Klumpfüssen am besten ist, nur Sohlenbeugen und Rückenbeugen vorzunehmen, damit sich einachsige Gelenke ausbilden. Ein wackeliges Fussgelenk ist nach einer Klumpfussbehandlung durchaus nicht erwïnscht, da es ja leider zu oft misslingt, den Muskeln, welche das Auswärtsrollen des Fusses bewirken sollen, eine ausreichende Leistungsfähigkeit zu verleihen, und bei schwachen Muskeln des Fussgelenkes kann ein Umklappen des Fusses nur dann vermieden werden, wenn statt der Muskeln Bänder und Knochenteile die Führung des Fusses in einer Ebene 
bei seinen Bewegungen bewirken, d. h. also, wenn das Gelenk möglichst zwangläufig ist (vergl. Reule a $u x$, Kinematik ${ }^{1}$ ).

Fig. 88. Passives Kniegelenkstrecken. Die Herstellung und Aufstellung der Vorrichtung (siehe Taf. XVIII, Fig. 128) zur Befestigung des Rollenzuges am Fusse dient der Halfter (Taf. XVII, Fig. 126) und die Schnurkutte (Fig. 122).

Der Oberschenkel wird an das Sitzbrett geschnallt wie in Fig. 89. Hierzu wird ein Riemen durcb zwei Schlitze des Sitzbrettes gezogen (Taf. XVIII, Fig. 129).

Der Sessel muss der Stange so nahe wie in Figur 88 nur dann stehen, wenn es sich darum handelt, Streckbewegungen an einem Kniegelenk vorzunehmen, das sonst gut beweglich ist, aber nicht vollständig gestreckt werden kann. Man sieht, dass in dieser Stellung die streckende Rollenschnur annähernd rechtwinkelig zum Unterschenkel gerichtet ist. In derartigen Fällen lasse ich den Unterschenkel nicht so ausgiebig hin- und herpendeln als es möglich ist, sondern ich lasse nur den Teil des Gelenkes einschleifen, der infolge der ungenügenden Streckung verödet ist. Ich lasse das Knie durch den hinteren Rollenzug nur um etwa $30^{\circ}$ beugen und hierauf gleich wieder durch den oberen Rollenzug strecken. Ist die äusserste Streckung erreicht, so lasse ich den Unterschenkel einige Sekunden in dieser Stellung verharren, dann erst Jasse ich mit der Hand den Zügel anziehen und das Knie beugen und so fort. Handelt es sich um ein sehr stark gekrümmtes Knie, so muss der Sessel viel weiter abstehen als in Fig. 88.

Die passiven Bewegungen des Kniegelenkes haben mir auch gute Dienste bei lähmungsartigen Zuständen der Knjegelenkmuskeln geleistet. Näheres über die Behandlung von Kniegelenkentzündungen mit passiven Bewegungen siehe S. 141. Meine Streckschienen für das Knie siehe Taf. V, deren Beschreibung S. 117.

Fig. 89. Kniegelenkstrecken mit Widerstand. Eine an der Rollenschnur befindliche Lampendochtschlinge wird mit einer achtförmigen Windung derartig um den Fuss geschlungen, dass die Dochte sich auf dem Fussrücken kreuzen. Der Oberschenkel wird an das Sitzbrett geschnallt (Fig. 89) durch einen Riemen, den man durch Schlitze im Sitzbrett zieht. Taf. XVIII, Fig. 129. Bei empfindlichem Kniegelenke lasse ich die Übung so ausführen, dass der gesunde Fuss hinter den kranken gelegt wird und so die Bewegungen erleichtert.

Man kann auch, wenn beide Beine geübt werden sollen, an jedem Fusse einen Rollenzug befestigen. Ich lasse dann zuerst mit dem einen Fusse 5 mal ziehen und hierauf mit dem anderen 5 mal usf.

\section{Kniegelenkbeugen mit Widerstand}

führt man gleichfalls mit der Vorrichtung Fig. 89 aus, nur muss der Kranke sich so setzen, dass sein Gesicht der Rolle zugekehrt ist. Hierbei werden auch Fussgelenkmuskeln innerviert, die der N. tibialis versorgt.

1) Die Grundlagen der Reuleaux'schen Kinematik habe ich gemeinverständlich behandelt in einer Besprechung der Reuleaux'schen Arbeit „Kinematik im Tierreiche.“ Biolog. Zentralblatt 1899. 
Fig. 90. Passives Hüftgelenkstrecken. Die Befestigung der Rollenzüge siehe Taf. XVII, Fig. 125. Statt Drahtschlinge lies dort Dochtschlinge. Das Becken ist dadurch festgestellt, dass der Kranke auf dem hohen Sessel sitzt.

Die eine Hand hält die Rollenschnur und leitet die Bewegungen. Den Zeigefinger dieser Hand schiebt man hierbei durch den achtförmigen Haken, an welchem die Schnurkette aufgehängt ist. Taf. XVII, Fig. 122. Mit der anderen Hand hält sich der Kranke am Sitzbrett (vergl. Fig. 91). Es ist gut den hohen Sessel etwas weiter von den Stangen aufzustellen, dann wird beim Bewegen der Oberschenkel vom Sitzbrett abgezogen. Hierdurch ist es möglich, die Bewegung in abduzierter Stellung auszuführen.

Ich habe diese Bewegung sehr erfolgreich angewandt bei Ischias und bei beginnendem Malum coxae senile.

Fig. 91. Velozipedtreten. Nan setzt den Fuss in das Ende der Schnurkette, wie in einen Steigbügel, den Zeigefinger schiebt man durch den achtförmigen Haken (Taf. XVII, Fig. 122). Wenn man den Anker mit $10 \mathrm{~kg}$ belastet, so kann man leicht das Knie so hoch heben, wie es überhaupt möglich ist. Das Strecken des Beines wird durch sein Gewicht sehr erleichtert.

Man kann auch beide Beine mit Rollenzügen belasten und dann abwechselnd im Reitsitz bewegen. Ich ziehe es jedoch vor nicht den Reitsitz zu benutzen, sondern so zu sitzen wie auf einem gewöhnlichen Stuhl, nur mit dem Unterschiede, dass die Sitzknorren weit bis an den Stuhlrand vorgeschoben werden. Ein Bein stiitze ich dann auf einen Holzsessel, das andere bewege ich 5 mal, hierauf stütze ich das bewegte Bein auf den Holzsessel und bewege das vorher gestützte Bein usf.

Fig. 92. Passives Einwärtsrollen des Beines. Die Schnur befestige ich an einem Drahtring, der durch die Sohlenspitze befestigt ist. Man bohrt ein Loch durch Oberleder und Sohle, zieht ein Stück Draht durch, dessen Enden zusammengedreht und dann ringförmig gebogen werden. Man kann übrigens auch die Schnüre an der Spitze eines Schraubenschlittschuhes befestigen. Der Unterschenkel ruht am besten auf einem weichen Kissen, damit er nicht hin- und hergeschoben wird.

In einigen Fällen empfiehlt es sich, bei schlotterigen Kniegelenken, das ganze Bein in eine Blechschiene zu lagern. Oft genügt es auch das Bein mit gebeugtem Knie zu lagern wie in Fig. 85.

Beim Auswärtsrollen legt man den Anker mit den Gewichten auf die andere Seite.

Ich wende diese Bewegungen nach ausgeheilten Schenkelhalsbrüchen und bei Klumpfuss viel an. Wie sehr das Hüftgelenk bei Klumpfuss oft verödet ist, hat schon Hermann Meyer nachgewiesen (vergl. seine Abbildung in ,der Klumpfuss und seine Folgen für das übrige Knochengerüst" S. 64). An Meyer's Präparaten, die im Senckenbergmuseum zu Frankfurt a. M. aufbewahrt werden, sieht man das besonders deutlich.

Das Auswärtsrollen und Finwärtsrollen des Beines mit Widerstand führt man in derselben Stellung aus wie sie Fig. 92 zeigt. Nur den Zug mit der Hand lässt man fort. Bei schlotterigem Knie lagere man das Bein wie 
in Fig. 85 mit gekrümmtem Knie. Bei festem Kniegelenk und bei geringer Belastung des Ankers sind die Drehberegungen im Kniegelenk bedeutungslos.

Fig. 93. Abziehen des aufgehängten Beines mit Widerstand. Der Oberschenkel des linken Beines ist mit einem Riemen an das Sitzbrett zu schnallen (Taf. XVIII, Fig. 129). Die zu dieser Ubung erforderliche leicht herstellbare Vorrichtung gestattet sehr feine Kraftmessungen und Übungen. Ich habe schon Abziehmuskeln geübt, die nicht mehr als $50 \mathrm{~g}$ ziehen konnten und nicht selten wurde ihre Leistungsfähigkeit auf $1000 \mathrm{~g}$ erhöht. Gerade bei diesen Bewegungen tritt es oft besonders deutlich hervor, dass Bewegungen mit richtig angepassten geringen Widerständen leichter auszuführen sind und weniger ermüden, als Bewegungen ganz obne Widerstände. Näheres über dieses von mir schon 1895 aufgestellte Gesetz siehe oben.

Ich habe dieses Gesetz oft Kollegen an Kranken erläutert, die infolge inervöser Erkrankungen ihre Kniee krankhaft aneinandergepresst hielten. Es st eine bekannte Tatsache, dass es oft bei Anwendung erheblicher Kräfte nicht gelingt derartige Kniee auseinander zu bringen. Mir gelang es häufig durch Widerstände für die Abziehmuskeln die Anziehmuskeln zu entspannen und die Kniee so auseinander zu bringen. Ich drückte die Kniee le i ch t gegeneinander und forderte die Kranken auf, die Kniee voneinander zu entfernen.

Derartige manuelle Widerstände erfordern grosse Übung. Viel leichter gelingt der Versuch, wenn der Patient auf dem Rücken liegt, ein Bein aufgehängt ist und mit einem Rollenzuge verbunden wird, der mit etwa $0, \overline{5} \mathrm{~kg}$ belastet ist. In solchen Fällen lasse ich ausser diesen Übungen die Kranken nachts oder einige Stunden am Tage auf dem Rücken liegen und ihre Kniee durch gepolsterte Riemen auseinanderhalten, die um Stangen geschlungen werden, welche zu beiden Seiten des Bettes befestigt sind.

\section{Das Anziehen eines Beines mit Widerstand}

wird in derselben Stellung ausgeführt wie Fig. 93 zeigt. Nur der Anker mit dem Gewicht wird auf die andere Seite gelegt.

Fig. 94. Taf. XIY. Passive Beinbewegungen liegend. Um das Knie wird ein Handtuch oder weicher Gurt geschlungen, an dem eine Rollenschnur befestigt ist. Die Rolle wird über dem Kopfe an der Wand angebracht, der mit einem Strumpfe bekleidete Fuss gleitet bei den Bewegungen auf einem untergelegten Stück Wachstuch hin und her. Bisweilen empfiehlt es sich auch einen zweiten Rollenzug am Fusse zu befestigen, Fig. 94, damit dieser den zurückgezogenen Fuss wieder vorzieht und so das Knie streckt. Diese Bewegung ist ganz besonders schonend. Ich verwende sie viel nach ausgegeheilten Hüftgelenkbrüchen, rheumatischen Erkrankungen des Knies, aber auch bei krampfartigen Zuständen des Beines. (Vergl. auch S. 144, Frau W.)

Fig. 95. Passives Armheben. Die Bewegung wird bei empfindlichem Schultergelenk mit $z$ wei ungleich gestellten Schnurketten ausgeführt (Schnurkette siehe Taf. XVII, Fig. 122). Die Hand des kranken Armes erfasst den Handgriff der länger gestellten Schnurkette. Die Hand des gesunden Armes den Handgriff der kürzer gestellten Schnurkette. Belastet man mit etwa 5 kg 
so hebt das Gewicht des Rollenzuges den gesunden Arm höher als den kranken. Zieht nun die gesunde Hand den Griff nach unten, so sinkt der kranke Arm durch sein Eigengewicht herab. Den Kranken fordere ich stets vorher auf nur mit der gesunden Hand zu ziehen und den kranken Arm vom Rollenzug heben zu lassen.

Bei besonders stark empfindlichen Schultergelenken lege ich den ganzen Arm in eine Pappschiene und stelle stets das Ellbogengelenk fest. Die Bewegungen werden dann besser vertragen. Das trat besonders deutlich in folgendem Falle hervor: Baron 0 . hatte einmal gegen die rechte Schulter einen Stoss von der Deichsel eines Wagens erhalten, dessen Pferde durchgingen. Jahrelang schmerzte ihn das Schultergelenk unbedeutend, störte ihn sonst aber wenig. Plötzlich aber traten so heftige Schmerzen ein, dass der Kranke sogar den Ärmel seines Rockes nicht mehr anziehen konnte und in meine Anstalt mit einem ärmellosen Mantel kam, um sich aufnehmen zu lassen. Ich machte eine Morphiumeinspritzung, massierte sehr zart das auf Druck höchst empfindliche Gelenk und liess die Bewegung Fig. 95 derartig ausführen, dass durch eine Pappschiene das Ellbogengelenk des kranken Armes festgestellt war. In einigen Tagen schwanden vollständig alle Schmerzen, und es wurde ansgeführt die Bewegung Fig. 96 zur Beseitigung der Steifheit des Schultergelenkes. Beide Arme wurden mit gleichen Schnurketten in der Pfeilrichtung a bis zu den Knieen geführt und hierauf in der Pfeilrichtung b zurück in die Stellung, welche Fig. 99 darstellt. Seit jener Zeit sind 3 Jahre vergangen und das rechte Schultergelenk ist vollständig schmerzlos und gebrauchsfähig.

Fig. 96 und 97. Armkreisen. Aus der Stellung Fig. 96 lasse ich beide Arme in der Pfeilrichtung a so führen, dass sie die Stellung Fig. 97 ,erreichen. Hierauf zieht das Gewicht in der Pfeilrichtung $\mathrm{c}$ beide Arme nach oben in die Stellung Fig. 96 usf. Der Stuhl muss etwas weiter von der Stange ubstehen, als es in der Fig. 96 u. 97, um Raum zu sparen, dargestellt ist.

Fig. 98. Passives Zurückziehen des Armes. Sehr häufig klagen die Kranken mit ausgeheilten Schultergelenkentzündungen darïber, dass sie die Hand nicht auf den Rücken legen können, um dort eine Schnalle oder dergl. zu erreichen. Ich lasse in diesen Fällen die Bewegung Fig. 98 ausführen. Der erhobene Arm zieht die Rollenschnur hin und her. Der gesenkte Arm wird vom Rollenzug nach hinten und oben gezogen wenn der erhobene Arm in der Pfeilrichtung $b$ geführt wird. Zieht der erhobene Arm in der Richtung a, so fällt der zurückgezogene Arm durch sein Eigengewicht nach unten und vorn.

Alle diese Bewegungen lasse ich meistens ausführen, ohne die Schulter festzustellen, da ich .auch so, selbst bei hochgradig versteiften Schultern noch volle Beweglichkeit erreicht habe. Allerdings wurden die Bewegungen unterstützt durch die Zugvorrichtung Taf. X, Fig. 74, deren Beschreibung S. 129.

Nur bisweilen lasse ich die Schulter durch einen Riemen festlegen, der um einen Stuhlfuss geschlungen wird und über Brust, Schulter und Rücken des Kranken verläuft. 
Die Bewegung Fig. 95̃ eignet sich ganz besonders für Hysterische, die behaupten sie könnten den einen Arm nicht bewegen.

Ich lasse zunächst den erkrankten Arm den Handgriff der längergestellten Schnurkette fassen und bitte möglichst vorsichtig zu ziehen. Nach einigen Tagen lege ich an den kranken Arm die kurze Schnurkette und an den gesunden die lange. Da die rechte Hand nicht weiss, was die linke tut, so ziehen die Hysterischen dann meistens ganz ruhig drauf los, ja behaupten manchmal sogar: „so geht es leichter".

Fig. 99. Armausbreiten mit Widerstand. Zu achten ist darauf, dass die Übenden stets die Hände in Schulterhöhe halten. Um sie hieran zu gewöhnen ist es zu empfehlen, einen hohen Sessel oder dergleichen so neben sie zu stellen, dass sie die Arme nicht senken können. Ist ein Arm so sehr geschwächt, dass es dem Kranken unmöglich ist, ihn hoch zu halten, so hänge ich ihn auf.

Fig. 100. Abziehen des aufgehängten Armes mit Widerstand. Wenn der Arm sehr geschwächt jst, lege ich ihn in eine Pappschiene und hänge ihn in der Schiene auf.

Fig. 101. Passives Auswärtsrollen des linken Armes. Der Kranke muss mindestens $1,50 \mathrm{~m}$ von der Stange entfernt stehen, damit die Richtung der Rollenschnur beim Ziehen möglichst wenig geändert wird.

Fig. 102. Passives Cnterarmbeugen. Der Oberarm ist an eine Stuhllehne geschnallt (Taf. XVII, Fig. 109). Die Hand des kranken Armes erfasst einen Handgriff des Rollenzuges. Die gesunde Hand erfasst die Schnur über dem Griffe und leitet die Bewegungen.

Die Rollenschnur muss so verlaufen, wie in Fig. 102, wenn der Kranke den Arm nur bis zum rechten Winkel beugen kann. Ist er imstande ihn über $90^{\circ} \mathrm{zu}$ beugen, so muss die Rolle noch niedriger gestellt werden.

Fig. 103. Passives Unterarmstrecken. Der Oberarm ist an das Gitter eines Stuhles mit zwei Riemen geschnallt (die Befestigung des Gitters siehe Taf. XVII, Fig. 119). Zwei Rollenschnüre werden mit Hilfe eines gepolsterten Riemens am Handgelenke befestigt (Fig. 118).

Der Stuhl muss möglichst nahe der Rolle stehen, welche an den Fussboden geschraubt ist. Die Schnur dieser Rolle zieht die Hand nach unten und streckt. Die andere Schnur hebt den Arm und wird von der gesunden Hand geleitet. Man lasse den Arm nur so hoch heben, wie in Fig. 103 und dann wieder sinken.

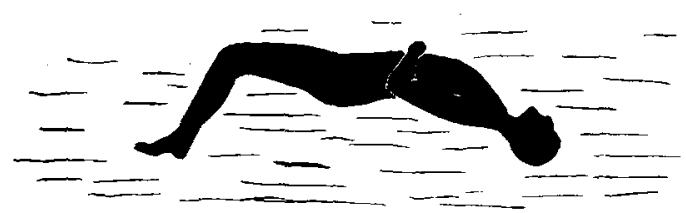

Fig. 7 .

Fig. 104. Nackenstrecken mit Widerstand. Hierzu wird die Kopfkappe (Taf. XVII Fig. 123) benutzt. Die Haken der Kappe werden an Handgriff einer Schnur gehakt, welche über zwei Rollen läuft. Die eine Rolle hängt an einer Stange, die andere ist an den Fussboden geschraubt. Als Steigerung dieser Übung lasse ich die „Brücke“ der Ringkämpfer ausführen (Fig. 7). 
Fig. 105. Kopfdrehung mit Widerstand. Eine weiche dicke Rollenschnur wird mit einer Schlinge so um den Kopf gelegt, dass sie von der Stirn aus zur Rolle hin verläuft. Diese Übung brauche ich viel gegen Schiefhals. (Vergl. auch meinen Geradehalter gegen Schiefhals Taf. III, Fig. 15.

Fig. 106. Taf. XY. Ruderübung. Hierzu sind zwei hängende Rollen (Taf. XVIII, Fig. 130) und zwei an den Fussboden geschraubte Rollen (Fig. 132 A) erforderlich. Jede Hand erfasst einen Handgriff. Die Arme müssen bei dieser Übung stets gestreckt gehalten werden. Die Füsse stützen sich gegen eine Leiste, die mindestens einen halben Meter von den unteren Rollen entfernt ist.

Fig. 107. Auswärtsrollen der Hand mit Widerstand. Durch Kürzerfassen des Stabes kann man den Widerstand verringern. Ich verwende diese Übung viel nach Brüchen der Speiche. Ausserdem beim Klavierkrampf, Schreibkrampf neben anderen Übungen.

Fig. 108. Iandgelenkstrecken nach Radialislähmung. Wenn der Unterarm auf dem Tische liegt, können die Streckmuskeln oft die herabhängende Hand nicht heben. In der Stellung Fig. 108 können sie aber dann häufig noch 10 bis $50 \mathrm{~g}$ ziehen.

Es gelang mir durch diese Übung einige ganz besonders hartnäckige Radialislähmungen zu beseitigen, die nach Verletzungen entstanden waren.

Folgender Fall möge dartun, wie in meiner Anstalt geschwächte Muskeln behandelt werden.

Der Kutscher L. wurde im März 1894 von einem Pferde derart in den rechten Oberarm gebissen, dass sich an der Ansatzstelle des Deltamuskels eine bedeutende Schwellung entwickelte und eine vollständige Lähmung der Strecker des Oberarmes, der Hand und der Finger entstand (Radialislähmung). Bis zum September 1894 wurde L. von einem Kollegen dreimal wöchentlich galvanisiert und Ende September meiner Behandlung übergeben.

Mein Befund bei der Aufnahme war folgender: Am Ansatze des Musculus deltoideus fühlte man kleine drüsenartige Ansammlungen unter der Haut. Strecken des Unterarmes bei geringem manuellen Widerstand war möglich. Legte Patient den Arm auf einen Tisch und liess die Hand herabhängen, so gab er an, sie nicht erheben zu können. Faradische Ströme zeigten gar keine Einwirkung auf die Strecker der Hand und Finger, galvanische Ströme eine ganz geringe Entartungsreaktion. -- Trotzdem hatte ich Grund anzunehmen, dass eine leichte Übertreibung der Gebrauchsunfähigkeit seiner Hand von seiten des Patienten vorliege.

Ich liess ihn seinen Arm so auf das Drahtgestell legen und so die Schnur um Zeige- und Mittelfinger schlingen, wie es etwa Fig. 22 entspricht (Lagerung für Fingerstrecken). Den Eimer belastete ich mit 8 g. Mit meiner Hand erhob ich die seinige beim Kommando "eins! " und liess sie beim Kommando „zwei!“ wieder herabsinken. Allmählich hörte ich auf, die Hand des Kranken zu heben und hielt meine Finger nur ununterbrochen an seine Handfläche leicht angelegt. Ich bemerkte so, dass Patient, seine Finger leicht hebend und senkend, einen Widerstand von $8 \mathrm{~g}$ überwand. 
Natürlich teilte ich dem Patienten nicht meine Bemerkung mit, sondern setzte zweimal täglich die erwähnte Übung mit ihm fort, die dahin führte, dass er in einigen Tagen ohne meine Handauflegung die $8 \mathrm{~g}$ hob. Die allmähliche Kräftigung der Finger möge folgende Übersicht von Kraftmessungen geben:

\begin{tabular}{|c|c|c|c|c|c|c|}
\hline & \multicolumn{5}{|c|}{ Rechte (kranke) Hand } & \multirow{2}{*}{ Linke Hand } \\
\hline & Oktober & Januar & März & April & Mai & \\
\hline & $\mathrm{g}$ & g & g & $g$ & $g$ & g \\
\hline & \multicolumn{6}{|c|}{ Fingerstrecken (Fig. 114). } \\
\hline 2. Finger & 8 & 300 & 300 & 400 & 700 & 900 \\
\hline 3. Finger & 8 & 300 & 300 & 400 & 700 & - \\
\hline 4. Finger & \multicolumn{4}{|c|}{ Nicht gemessen } & 500 & - \\
\hline 5. Finger & \multicolumn{4}{|c|}{ Nicht gemessen } & 400 & - \\
\hline & \multicolumn{6}{|c|}{ Fingerspreizen (Fig. 115) } \\
\hline 1. Finger & 8 & - & - & -- & 570 & 840 \\
\hline 2. Finger & 8 & - & - & - & 570 & 840 \\
\hline
\end{tabular}

Es betrug also die Kraftzunahme beim Fingerstrecken rom 10. September bis 10. Januar gegen $700 \mathrm{~g}$, trotzdem schon 7 Monate seit der Verletzung des Nerven verflossen waren, als Patient im Beginn meiner Behandlung kaum $8 \mathrm{~g}$ mit den Fingerstreckern heben konnte.

Ausserdem war der Kranke im Januar 1895 imstande, eine Weckuhr mit einem Schlüssel aufzuziehen, leichte Tischlerarbeiten auszuführen und aus Eisenblech Löffel u. dergl. zu hämmern. Im Juni 1895 war er wieder in der Fabrik als Arbeiter tätig und zeigt nur noch eine nicht bedeutende Schwäche der ganzen Hand.

Hinzufügen will ich noch, dass Patient täglich massiert und galvanisiert wurde und dass ich einen Teil seiner Besserung diesem Heilverfahren zuschreibe.

Ich glaube aber, dass bei seinem trägen, störrischen Charakter dieses Heilverfahren allein ohne Übungen und ohne mein hartnäckiges Zureden und Aufmuntern zu Bewegungen schwerlich wesentlich die Gebrauchsfähigkeit der Hand gesteigert hätte, besonders da die elektrische Erregbarkeit der Muskeln sich kaum verbessert hat. Dieser Fall wurde von mir hauptsächlich deshalb angeführt, weil mir aus ihm ersichtlich erscheint, dass meine Gewichtszüge auch zu diagnostischen Zwecken und zu einer psychischen Beeinflussung des Patienten benutzt werden können und somit sich auch zu Kraftmessern im Sprechzimmer eines Nervenarztes eignen.

Da die Streckmuskeln der linken, gesunden Hand $900 \mathrm{~g}$ überwanden, also $200 \mathrm{~g}$ mehr als die der kranken Hand, so wurde L. vom Februar bis Mai 1896 abermals von mir behandelt. Dreimal wöchentlich wurde er massiert und übte er an meinem Apparat. Im Mai 1896 überwanden auch die Fingerstreckmuskeln der rechten, kranken Hand $900 \mathrm{~g}$. Es wurde also durch das Üben an meinem Apparat die Kraft der Fingerstreckmuskeln vou 8 auf $900 \mathrm{~g}$ 
gesteigert, d. mehr als verbundertfacht, obgleich in dem vorliegenden Falle die Verhältnisse gewiss ganz besonders ungünstig lagen.

Ich habe noch zwei ähnliche veraltete Lähmungen nach Brüchen des Oberarmknochens in ähnlicher Weise geheilt. In allen diesen drei Fällen erhielt sich die Entartungsreaktion, obgleich die Gebrauchsfähigkeit der Hand und Finger fast normal war.

In einem vierten frischen Falle hatte ich einen schnelleren Erfolg. Baron B. C. wurde im Oktober 1905 während der Revolution in Livland angeschossen. Eine Browningkugel drang in das Ellbogengelenk und blieb dort stecken. In jede Schulter erhielt er einen Schrotschuss. Nach einer Röntgenaufnahme verletzte ein Schrotkorn den linken Nerv. radialis am Ansatze des Deltamuskels. Die Hand war so vollständig gelähmt, dass der Verwundete kaum einen Finger strecken konnte. Die Browningkugel wurde 2 Wochen nach der Verletzung aus dem Ellbogengelenk von Dr. Lieven entfernt. Schon eine Woche nach der Operation überwies mir Dr. Li e ven den Kranken zur Behandlung mit Bewegungen und Massage, obgleich die Schnittwunden noch nicht verheilt waren. Es gelang mir den Arm soweit herzustellen, dass Baron C. schon im März wieder Violine spielen konnte. Die Entartungsreaktion erhielt sich auch hier noch lange, als schon die Hand gebrauchsfähig war.

Ich führe diesen Fall hier deshalb an, um zu zeigen, wie wichtig eine frühzeitige Behandlung mit Bewegungen und Massage ist.

Fig. 109. Passives Fingerbengen. Die Befestigung der Züge am Finger mit Hilfe eines Stofffingers ersieht man aus Fig. 112, Handschuh zum Finger beugen siehe Taf. XII.

Fig. 111. Passives Strecken bei Greifhand. Schiene gegen Greifhand siehe S. 136 und Taf. XII.

Fig. 112. Die Befestigung der Züge in Fig. 109. Auf den zu bewegenden Finger wird eine Hülle aus Korsettstoff (Drell) gezogen. An diese Hülle wird ein dünner Lederstreifen aus Rohhaut genäht. Durchaus ist Rohhaut $z u$ verwenden, da in diesem Falle bald alle Schnüre reissen.

Taf. XVI. Neben den auf Taf. XVI abgebildeten Fingerübungen lasse ich stets bei Bewegungsstörungen und besonders bei Schwächezuständen der Hand und Finger, Übungen des ganzen Armes mit meinen Rollenzügen ausfübren (Taf. XIV, Fig. 95 usw.), da ja dieselben Nerven, welche den grössten Teil der Armmuskeln versorgen, sich auch in die Fingermuskeln hinein verzweigen. Sie innervieren jedenfalls diese Fingermuskeln bei Bewegungen der Armmuskeln. Das erkennt man oft besonders deutlich aus den Mitbewegungen der andern Hand, wenn ein stark geschwächter Arm geübt wird.

Fig. 113. Fingerbengen mit Widerstand. Dieser Apparat wird auch von Klavier- und Violinspielern benutzt zur Entwickelung der Hände ${ }^{1}$ ).

Fig. 114. Fingerstrecken mit Widerstand. Handgelenkstrecken mit Widerstand führt man aus, indem man die Schlinge um das erste Glied

1) Vergl. „Der Klavierlebrer", Organ der Deutschen Musiklehrervereine zu Berlin, Köln, Dresden, Hamburg, Stuttgart. 1897. Nr. 20 u. 21. Berlin, Dr. Thilo, Fingergymnastik. 
zweier Finger legt und die Hand etwas weiter vorschiebt als in Fig. 114. (Vergl. auch Kraftmessungen S. 159 und Streckschienen Taf. XI u. XII.

Fig. 115. Fingerspreizen benutze ich viel beim Schreibkrampfe, aber auch nach Phlegmonen der Hand usw.

Fig. 116. Abziehen des Daumens. Die übrigen Finger liegen im Fingerhalter, der auf das Drahtgestell (Fig. 115) geschoben ist.

Gegen steifen Daumen verwende ich die Vorrichtungen Taf. XI, deren Beschreibung S. 129 und S. 136.

\section{Technisches.}

\section{Die Aufstellung meiner Bewegungsvorrichtungen.}

\section{Rollen}

sind zu den meisten Bewegungen erforderlich.

Nur bei geringer Belastung, z. B. Fussrückenbeugen (Fig. 86, Taf. XIII) kann ich die sehr billigen Rouleauxringe aus Porzellan sehr empfehlen. Auch bei meinen Fingerapparaten ist es besser keine Rollen zu verwenden. Ich fübre das hier ausdrücklich an, da einige Kollegen meine Fingerapparate durch Rollen verschlechtert haben. Eine gute Korsettschnur hält bei den Fingerübungen viele Wochen vor und ist leicht zu erneuern. - Leider sind gute, geräuschlos gehende Rollen im Handel schwer zu haben und daher werden die Anstalten wohl meist genötigt sein, sich Rollen für ihre Zwecke anfertigen zu lassen. Die Fussbodenrollen sind nicht im Handel vorrätig.

Das Stellen der Rollen ist am bequemsten, wenn man sie an einen Drahtring (Fig. 130, Taf. XVIII) hängt, der auf eine Stange gezogen wird. Durch einen Stift, der in Löcher der Stange geschoben wird, stellt man die Rolle schnell höher oder niedriger. Hochhängende Rollen, z. B. Fig. 95 usw. zu verstellen ist sehr unbequem, besonders da es sich empfiehlt diese Rollen $4 \mathrm{~m}$ hoch zu hängen. Man lässt sie am besten auf ihrem Platze und hält die niedrighängenden Rollen an anderen Stangen. Die Stangen dienen nicht nur zum Stellen der Rollen, sondern auch um das Schwanken der Gewichte zu verhüten. Eine Führung der Gewichte durch Ringe auf Drähten ist sehr unpraktisch, da die Reibung am Draht ein Üben mit geringer Belastung unmöglich macht.

\section{Stangen}

zum Aufhängen der Rollen müssen in einer Anstalt möglichst viel vorhanden sein, damit jeder Kranke ungestört seine Übungen ausführen kann. 1. Man kann die Stangen an Reckgestellen befestigen und dann mitten im Saale aufstellen. 2. Man kann sie an einer langen Leiste befestigen lassen, die quer oder der Länge nach durch den Saal verläuft. 3. Man kann sie an der Wand anbringen. 
In jedem Falle kann ich die Befestigung der Stange mit Draht $3 \mathrm{~mm}$ Dicke an der oberen Leiste sehr empfehlen.

Am Fussboden befestige ich die Stangen mit Stiften, die Stangen drehen sich dann, was bei einigen Übungen sehr erwünscht ist, auch kann man im Augenblick die Stangen entfernen, wenn man sie aufhebt und aus dem Drahtbügel zieht.

Der hohe Sessel (Taf. XVIII, Fig. 127)

muss sehr fest gebaut sein. Für die Beine sind durchaus vier starke Klötze erforderlich, die mit Leim und Schrauben befestigt werden. Im Sitzbrette sind Schlitze anzubringen, durch die man Riemen zum Festschnallen des Oberschenkels zieht (Fig. 89). Zwei Eisenklammern befestigt man an der unteren Seite des Sitzbrettes mit Mutterschrauben. Durch diese wird der Rollenbalter für passives Kniestrecken (Fig. 129) gezogen.

Die Schuurkette (Taf. XVII, Fig. 122)

wird für Bewegungen mit 2 Zügeln benutzt. Jeder Zügel ist 1,25 m lang und besteht aus einer doppelten Schnur, die an 5 Stellen mit dünnem Draht gebunden ist. Die Befestigung der Drahtenden siehe Taf. XIX, 134. So entstehen Abteilungen, in welche man Handgriffe oder Dochtschlingen bald höher bald niedriger einhaken kann. Die Schnurkette wird mit einem achtförmigen Haken in die Schleife gehakt, welche sich am Ende einer jeden Rollenschnur befindet (vergl. Fig. 128).

\section{Drahtarbeiten.}

Der Draht wird immer noch verhältnismässig wenig bei der Anfertigung von Verbänden und Schienen benutzt. Vor vielen Jahren hat allerdings schon Pirog off in seine Gipsverbände Drahteinlagen gemacht, doch fand er nicht viele Nachahmer. Auch all' die verschiedenen käuflichen Drahtschienen sind nicht sehr verbreitet.

Diese Tatsache ist um so auffallender, als doch sonst der Draht auf allen Gebieten der Technik die ausgiebigste Verwendung findet. Sogar in der Baukunst ist der Draht unentbehrlich; denn gewisse Hochbauten aus Zement sind ohne Draht unausführbar. Ausserdem hat Prof. Bauschinger wissenschaftlich nachgewiesen, dass die Biegungsfestigkeit von Betonplatten bei $1 \%$ Eiseneinlage fast um das 4 fache steigt. Die Biegungsfestigkeit einer reinen Betonplatte betrage $47 \mathrm{~kg} / \mathrm{cm}^{2}$, sie steigt dann bei $1 \%$ Eiseneinlage auf $178 \mathrm{~kg} / \mathrm{cm}^{2}$ und bei $1,45 \%$ Eiseneinlage auf $247 \mathrm{~kg} / \mathrm{cm}^{2}$.

Alle diese Frfahrungen veranlassten mich schon vor vielen Jahren durch Draht die Festigkeit meiner Schienen und Korsette zu vergrössern. Einige meiner Drabtarbeiten habe ich auch 1895 in Langenbeck's Archiv veröffentlicht.

Im wesentlichen verwende ich den Draht in zweifacher Weise.

1. Ich benutze ihn zu Einlagen für Gips, Zelluloid u. a. Verbände. 
2. Ich fertige aus Draht allein oder aus Draht und Flacheisen Schienen und andere Stützrorrichtungen an.

\section{Allgemeine Regeln für Drahtarbeiten.}

Jeder Fachgenosse, der die oben beschriebenen Drahtarbeiten zu verwenden gedenkt, muss sich einige Kenntnisse über ihre Ausführung aneignen. Derartige Kenntnisse erwirbt man leicht, wenn man einige Korsette mit Drahteinlagen, Schienen usw. mit eigener Hand anfertigt.

Wenn man nur einigermassen die Drahttechnik beherrscht, so gelingt es ohne Schwierigkeiten alle grösseren Arbeiten von einem Drahtarbeiter, Schlosser oder Klempner herstellen zu lassen. Die kleineren Arbeiten, welche bei Anproben, Änderungen oder Reparaturen erforderlich sind, lässt man am bequemsten in der Anstalt von einem geschickten Heilgehilfen ausführen.

Nach meinen langjährigen Erfahrungen ist es sehr zu empfehlen; stets streng an folgenden Regeln festzuhalten:

1. Am besten verwendet man steifen, verzinnten Eisendraht. Der verkupferte Federdraht ist weniger empfehlenswert, da er sehr oft brïchig ist.

Unverzinnten Draht benutze man nur im Notfall, da er gegen den Rost nur sehr unvollkommen durch Anstriche geschützt werden kann.

Der dünne Draht, mit dem gebunden wird, muss stets verzinnt sein, denn er ist sonst schwer zu verlöten.

2. Zum Durchschneiden des Drahtes hat man ganz ausgezeichnete Drahtscheren, mit Kraftiibertragungen. Schon fiir 3-4 Mark erhält man eine Schere, die mit Leichtigkeit Draht von 5 mm Dicke durchschneidet. (Fig. 137, Taf. XIX stellt eine ganz vorzügliche Drahtschere dar, die ich vor einiger Zeit in einem Laden entdeckte.)

3. Das Aneinanderfügen der einzelnen Teile eines Drahtgestelles lasse ich stets mit Hilfe eines dünnen Drahtes (Bindedraht) ausführen. Die Drähte lasse ich an den Stellen, welche aneinandergefügt werden, ein wenig flach feilen und hierauf mit verzinntem "Bindedraht" bewickeln. Die Enden des Bindedrahtes werden nach beistehendem Schema befestigt (Fig. 134). Das Ende A des Bindedrahtes wird auf die aneinandergefügten Drähte gelegt und hierauf mit ihnen zusammen bewickelt. Alsdann wird das Ende $B$ unter dem übergewickelten Bindedraht hindurchgezogen und zwar zieht man das Ende B nicht neben dem Ende A hindurch, wie in Fig. 134, sondern auf der unteren Seite der aneinandergefügten Drähte, die auf der Zeichnung nicht sichtbar sind.

Ich habe es oft bemerkt, dass diese Befestigung der Drahtenden nicht allgemein gebräuchlich bei Drahtarbeitern ist. Sehr häufig werden die Drahtenden von ihnen gar nicht befestigt. Sie bleiben los und werden verlötet. Sie lösen sich dann bald $a b$ und daher behaupten viele Schlosser, das Binden mit Draht tange nichts, man müsse die Drahtteile aneinanderschweissen. Nach Befestigung der Drahtenden (Fig. 134) lasse ich mit einer stumpfen 
Kneifzange den Zwischenraum CD, Fig. III eindrücken. Hierauf wird die ganze Bewickelung mit einer Lötlampe verzinnt. Das überschüssige Zinn wird von der Lötstelle, solange sie noch heiss ist, mit einer Zahnbürste abgestrichen.

Weniger zu empfehlen ist das Löten mit einem Lötkolben. Lötwasser kann man von jedem Klempner erhalten. Alle grösseren Städte bieten die Möglichkeit in Drahtfabriken verzinnen zu lassen. Diese verfügen über grosse Kessel mit geschmolzenem Zinn, in welchem sogar recht umfangreiche Gegenstände verzinnt werden können. Aber auch selbst unter solchen Verhältnissen wird man doch stets in der Anstalt eine Lötlampe bereit halten müssen für kleinere Arbeiten, für Ändererungen, für Reparaturen usw.

4. Das Aneinanderfügen von Drahtteilen wird von den Drahtarbeitern sehr häufig noch anders ausgeführt als ich es hier beschrieben habe. Es werden z. B. zwei Drähte von je $5 \mathrm{~mm}$ Dicke dadurch aneinander befestigt, dass der eine Draht um den andern gewickelt wird. Dieses Verfahren ist für viele Drahtarbeiten durchaus am Platze, für meine Apparate ist es unbrauchbar.

Ebensowenig ist es zu empfehlen, mit sebr langen Drahtstücken zu arbeiten, z. B. aus einem einzigen Stücke eine lange Beinschiene anzufertigen usw. Im allgemeinen muss man danach streben, höchstens Stücke von $1 \mathrm{~m}$ Länge zu verwenden, d.h. also die Gestelle aus kürzeren Drähten zusammenzusetzen.

5. Der Bindedraht von $1 \mathrm{~mm}$ Dicke wird auch von mir zum Befestigen der Schnallen benutzt. Es wird die Schnalle an einem Drahte befestigt durch Achtertouren und hierauf werden die Drahtenden so aneinandergelegt und zusammengedreht (Fig. 8). Die zusammengedrehten Drahtenden werden zum Dorn der Schnalle hin zurückgebogen, damit ihre Spitzen nicht vorstehen.

6. Die Biegungen der Drähte dürfen nicht so ausgeführt werden, dass ein Winkel mit einer deutlichen Spitze entsteht. Die Biegungen müssen stets abgerundet sein, da sonst der Draht an dieser Stelle beim Gebrauche bald bricht. Aus diesem Grunds biege man auch vorsichtig im Schraubstock oder mit einem Drahtbieger, ohne hierbei einen Hammer auf den gebogenen Draht zu schlagen.

7. Der von mir ersonnene Drahtbieger ist zum Gebrauche in den Schraubstock zu spannen (Fig. 133). Hat man ein Drahtende zu einem Ringe zusammengebogen, so ist der in den Löchern der Eisenplatte befindliche Bügel mit einem Hammer von unten herauszuschlagen, da sonst das ringförmige Drahtende nicht vom Bügel befreit werden kann. Um dieses Herausschlagen zu ermöglichen, muss das eine Ende des Bügels etwas länger als das andere sein.

8. In vielen Fällen müssen die Biegungsstellen eines Drahtes durch eine "Strebe" verstärkt werden, $d . h$. der von der Biegung gebildete Winkel muss durch Anfügung eines zweiten Drahtes zu einem Dreiecke abgeschlossen werden (vergl. Fig. 33 usw.). 


\section{Literatur.}

1. König, Franz, Die spezielle Tuberkulose der Gelenke. Berlin. Aug. Hirschwald. 1896.

2. Meyer, Hermann von, Ursache und Mechanismus der Entstehung des erworbenen Plattfusses nebst Hinweis auf die Indikationen zur Behandlung desselben. Jena. Gust. Fischer. 1883.

3. Derselbe, Der Klumpfuss und seine Folgen für das übrige Knochengerüst. Jena. Gust. Fischer. 1888

4. A. Fick, Myograph. Versuche am lebenden Menschen. Bonn 1895. Archiv für die ges. Physiologie. Bd. 60. Emil Strauss.

5. Du Bo is - Re y mond, René, Spezielle Muskelpbysiologie oder Bewegungslehre. Berlin. Aug. Hirschwald. 1903. Allen, die sich mit Orthopädie beschäftigen sehr zu empfehlen.

6. Reuleaux, F., Kinematik im Tierreiche. Braunschweig. Vieweg und Sohn. 1900. Eine allgemeinverständliche Besprechung von Otto Thilo im Biolog. Zentralbl. 1901.

7 Levertin, Dr. A., Dr. G. Z anders medico-mechanische Gymnast. Stockholm. Königliche Buchdruckerei. 1892. P. A. Norstedt u. Söhne.

8. Gigerl, Emmerich, Die Hand, ibre Kraftigung und Schulung durch Finger- und Handgymnastik. Jahresber. d. k. k. Blindeninstitutes in Wien. 1893/94. Verlag des Blindeninstitutes.

9. Bum, Anton, Handbuch der Heilgymnastik, Massage und Orthopädie. Wien 1896. Urban und Schwarzenberg.

10. Herz, Max, Lehrbuch der Heilgymnastik. Wien 1903. Urban und Schwarzenberg.

11. Thilo, Otto, Breite Sohlen gegen das Umklappen des Fusses. Illustr. Monatsschr. d. ärtl. Polytech. April 1893.

12. Derselbe, ebenda, Riemenschwebe an Stelle der Polster. 1895. Nr. 2.

13. Derselbe, Sohlenerböhungen. Rundstäbe als Korsettstätzen. Arch. f. klin. Chir. von Langenbeck. Bd. XLIX. Heft 4.

14. Derselbe, Einschubsohlen zur Geraderichtung der Zehen. Zeitschr. f. arthop. Cbir. von $\mathrm{H}$ off a. 1895. Bd. IV.

Ebenda, Zur Behandlung des Klumpfusses. Gipsverband mit Eisensoble und Filzpolster. Übung. VI. Bd.

15. Derselbe, Schienen gegen Klumpfuss und Plattfuss. Allgem. med. Zentr.-Zeit. 1897. Nr. 37 und 38.

Ebenda, 1897, Nr. 68 und 69, Bewegung als Heilmittel für entzündete Gelenke.

Ebenda, Die Behandlung der Kniescheibenbrüche.

16. Derselbe, Zur Behandlung der Schreibstörungen. Pet. med. Wochenschr. 1896. Nr. 20.

Ebenda, Zur Behandlung der Gelenkneuralg. 1898. Nr. 6.

Ebenda, Verbände gegen Gelenkversteifungen. 1900. Nr. 44.

Ebenda, Kraftmessungen. Verhandl. d. Versamml. livl. Ärzte zu Wolmar. 1898.

17. Derselbe, Apparate f. Fingergym. Deutsch. med. Wochenschr. 1895. Nr. 16.

18. Derselbe, Fingergymnastik. Der Klavierlehrer. Musikpädagog. Zeitschr. Organ d. Deutsch. Musiklehrervereins zu Berlin, Köln, Dresden, Hamburg, Stuttgart. Berlin. Okt. 1897.

19. Derselbe, Kraftbestimmungen zu ärztlichen Zwecken. Münch. med. Wochenschr. 1898. Nr. 30.

20. Derselbe, Fingerübungen. Monatsschr. f. Unfallheilkunde. 1895. Nr. 8.

Ebenda, 1896, Nr. 1, Angriff des Herrn Dr. Thomas gegen die Abhandlung Fingerübungen.

Ebenda, 1896, Nr. 5, Erwiderung von Thilo.

Ebenda, derselbe, Die Behandlung der Gelenkversteifungen. Vortrag, gehalten auf der Versamml. Deutsch. Naturforscher und Arzte 1895 in Lübeck. 
T'hilo, Otto, ebenda, Druckverbände mit Filz. 1896. Nr. 8.

Ebenda, derselbe, Verstellbare Krücken mit Riemenschweben. März 1897.

Ebenda, derselbe, Passive Bewegungen. 1902.

21. Derselbe, Übungen. Samml. klin. Vortr. begründ. v. Rich. Volkmann. 1897. März. Dasselbe, Russisch im Organ des russisch. Kriegsministeriams. 1898. Nr. 5.

22. Derselbe, Methode d'exercises et des mouvement etc. Progrès medical. Archive de Neurologie. 1900 . Nr. 56.

23. Derselbe, Die Behandlung der steifen Finger. Monatsschr. f. orthopäd. Chir. und physik. Heilmethoden. 1901. Nr. 3 u. 4.

\section{Errata.}

Seite 156 , Zeile 14 ron oben lies $\frac{P}{S}=\sin a^{\prime}$ statt $\frac{P}{U}=\sin a^{\prime}$.

Seite 158 , Zeile 28 von oben lies Schema III statt Schema I.

Seite 165 , Zeile 2 von oben lies oder statt und.

Seite 174 , Zeile 22 von oben lies 119 statt 109 .

Seite 180 , Zeile 34 von oben lies anderen statt unteren. 
$1 \underline{a}$

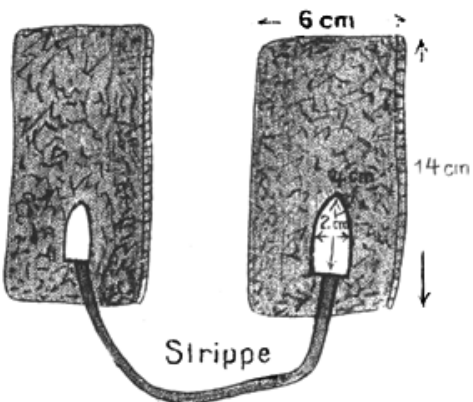

Fig. $1^{a}$ u 1 to Filzdruckverband Fd Fussgelenk Innenseite des Filzes mit Leinewand beziehen Der Filz ist a in Fuss mit Leinbınden zu um wickeln oder im Schnürstiefel zu tragen.

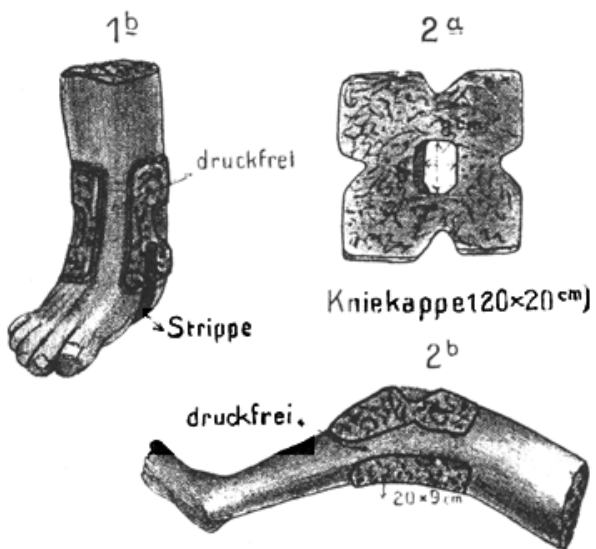

Fig $2^{a}$ u $2^{\text {t }}$ Filzdrudkverband für das Knie.

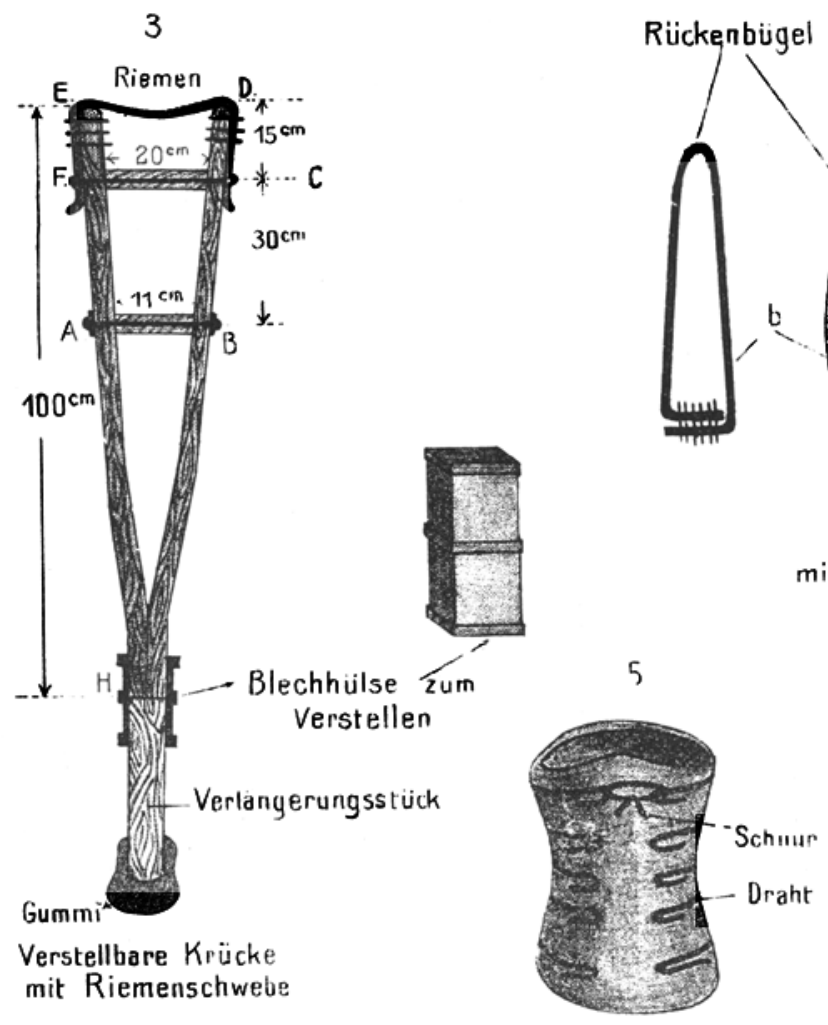

Gipscorset mit ringförınigen Drahteinlonen,über dem Draht 3 Lagen Gipsbinde.
Axelstütze

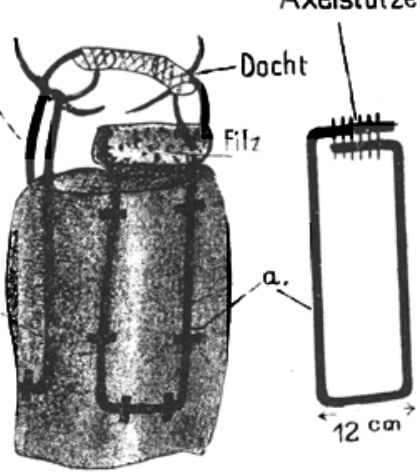

Gipscorset mit Drahteinlagen

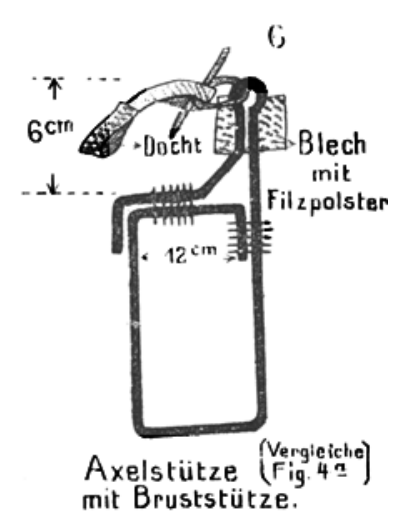



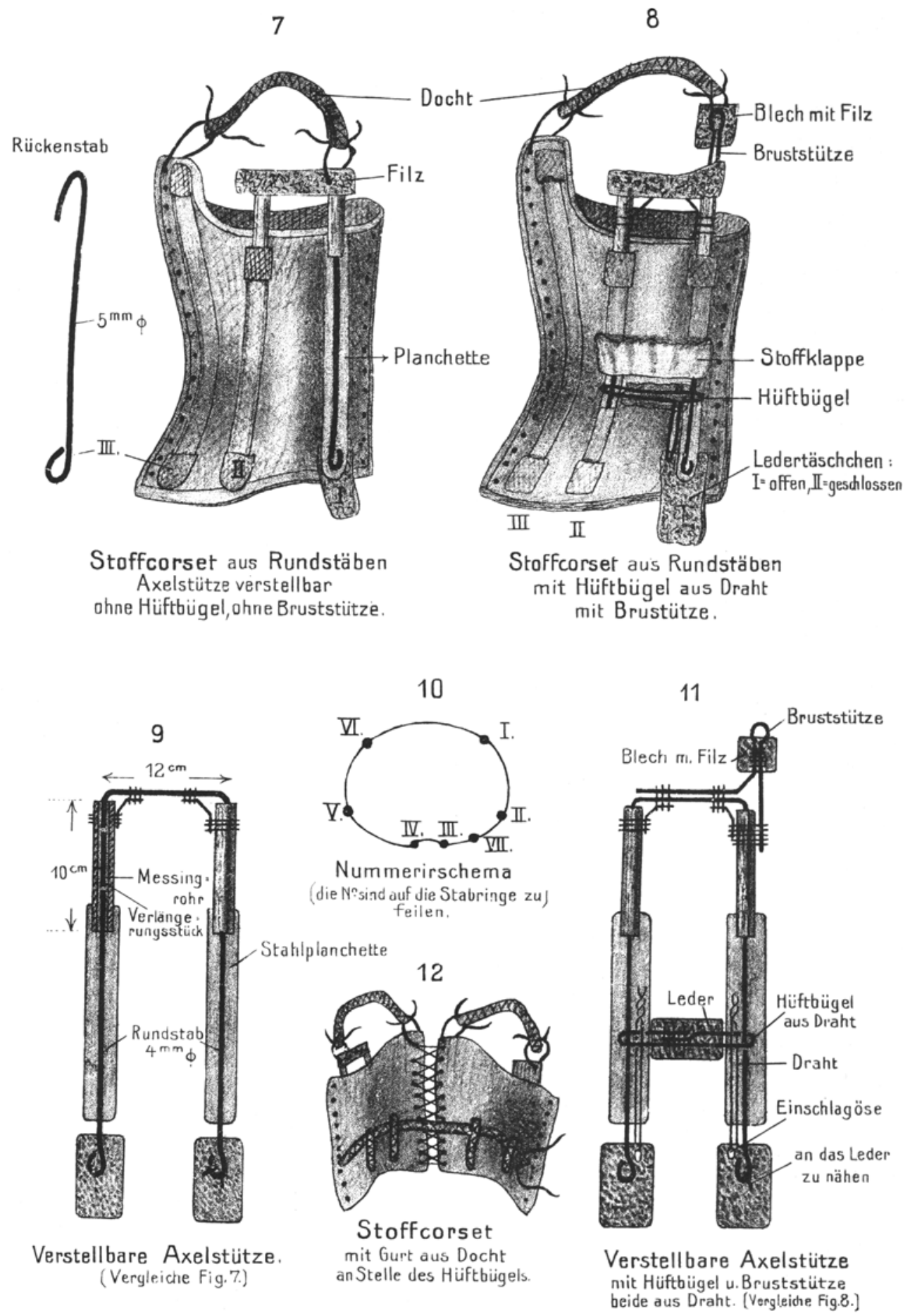


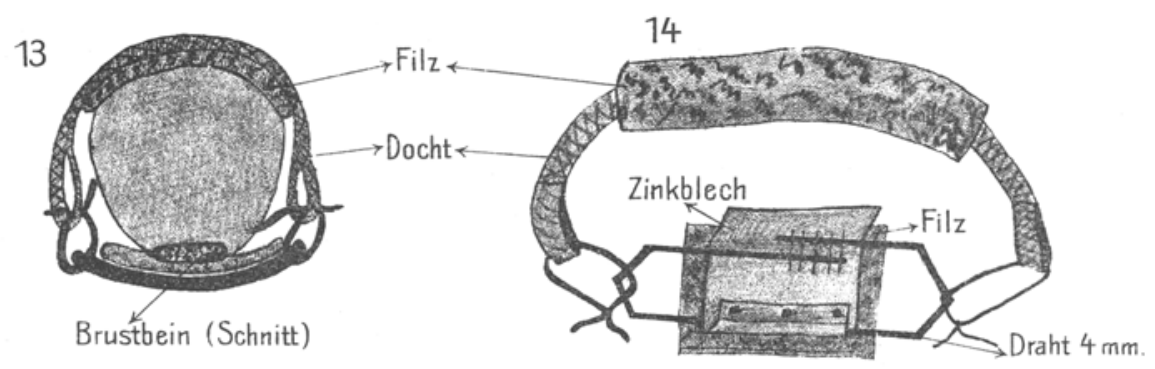

Gegen Hühnerbrust

15

a.d. Achselstützen d. Korset zu befestigen.

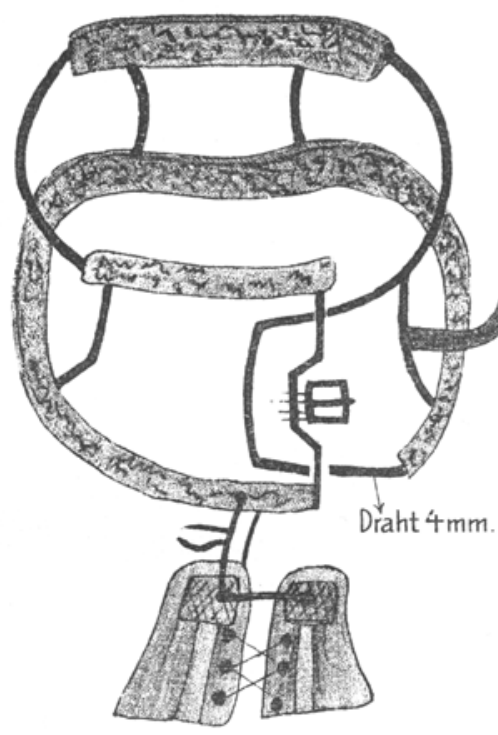

Kopfhalter am Korsei zu befestigen.
16

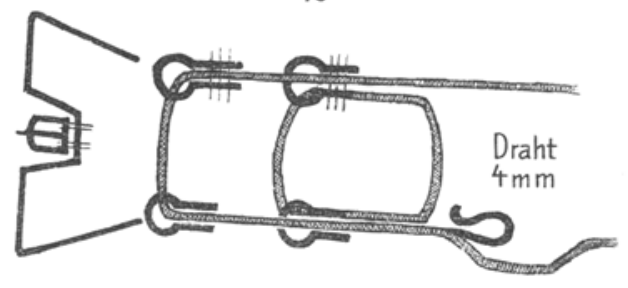

Stellvorrichtung von Fig. 15 u. 16

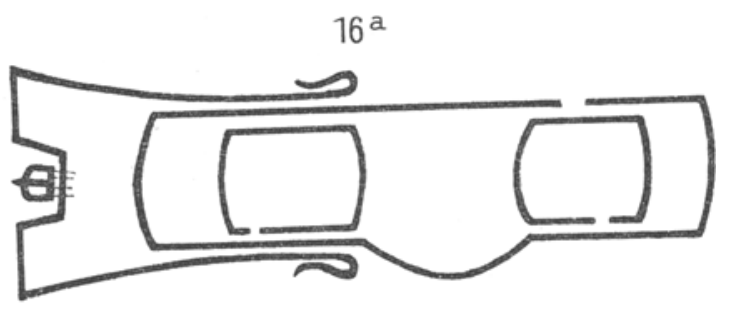

Kopfhalter Fig. 15 ausgebreitet.

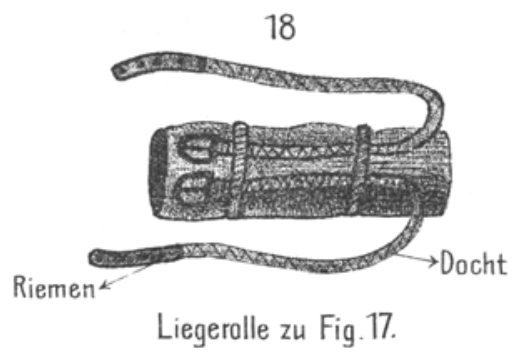

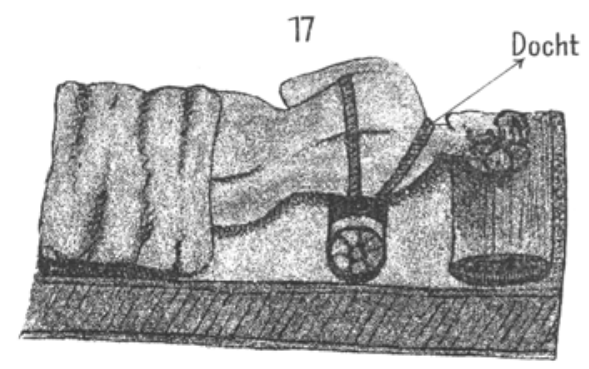

Liegerollen zum Uebercorrigiren d. Wirbelsäule Dr Thllo. 


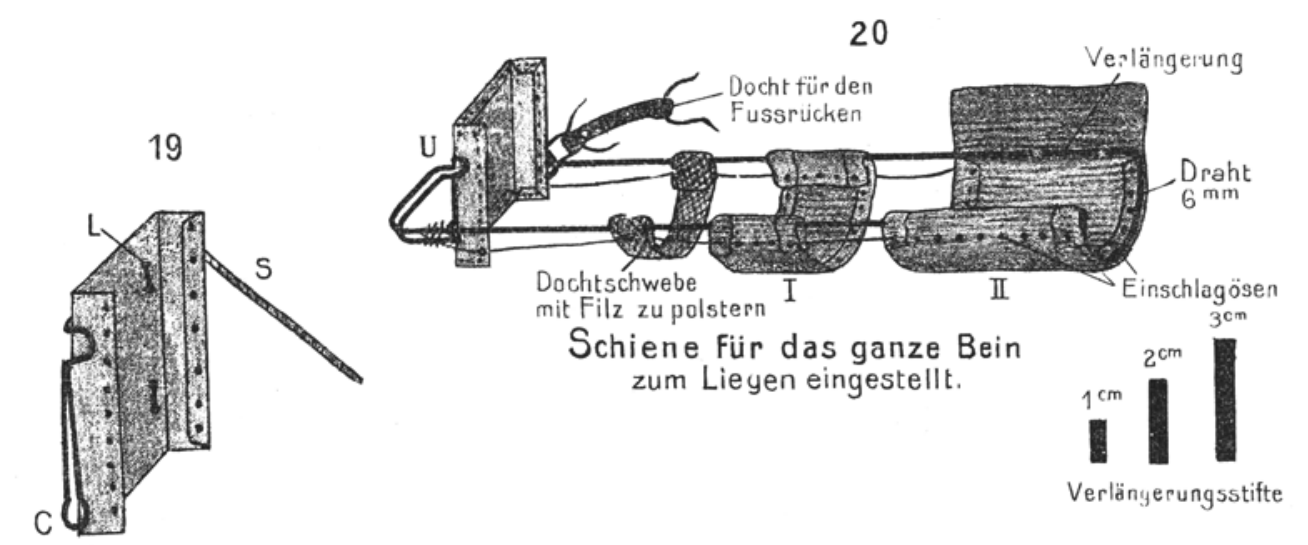

Abnehinbare Fulsstuitze von Fig. 20
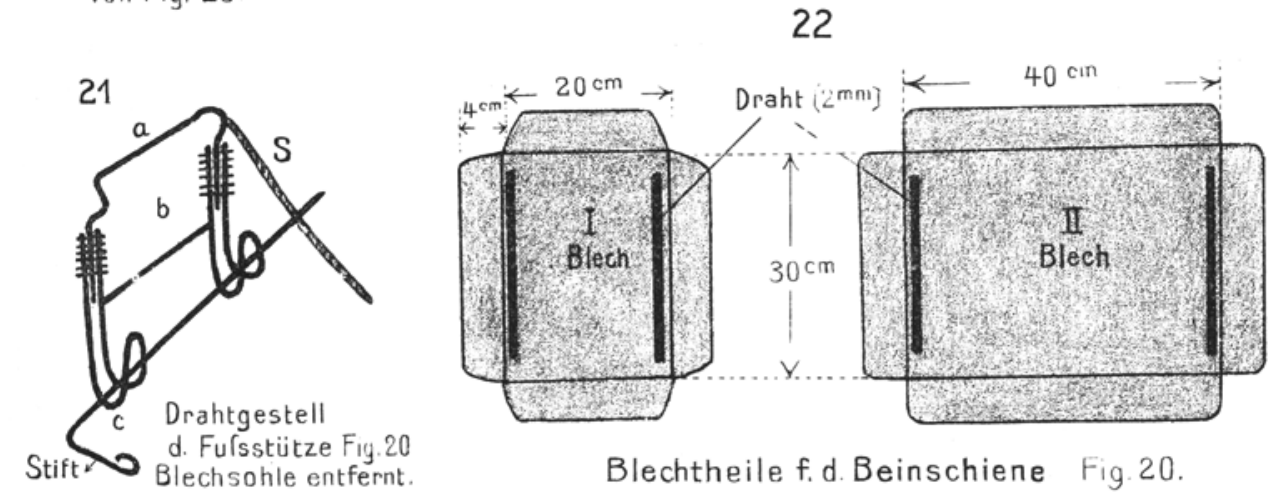

Blechtheile f.d. Beinschiene Fig. 20.
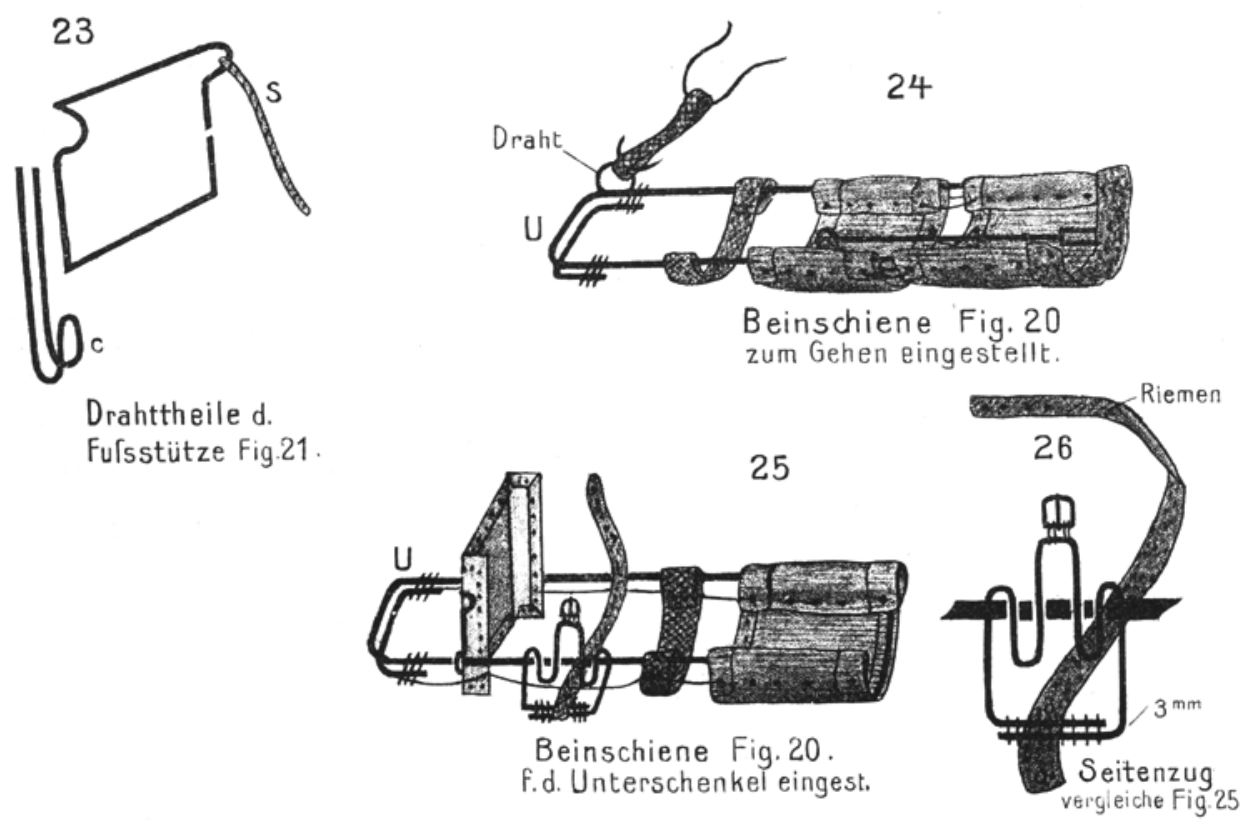


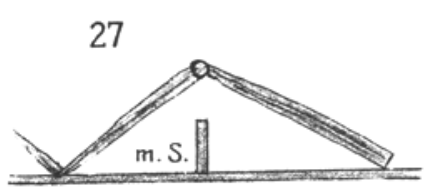

ungestreckt

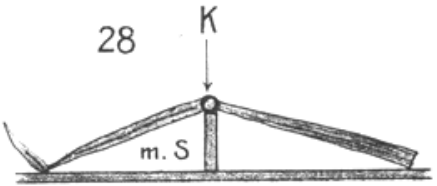

gestreckt

Schema d. Kniestreckung n. Thilo

m. $S .=$ mittlerer Stützpunkt zum Entspannen d. Beugemusc. $K=$ Streckkraft d. Kniekappe.

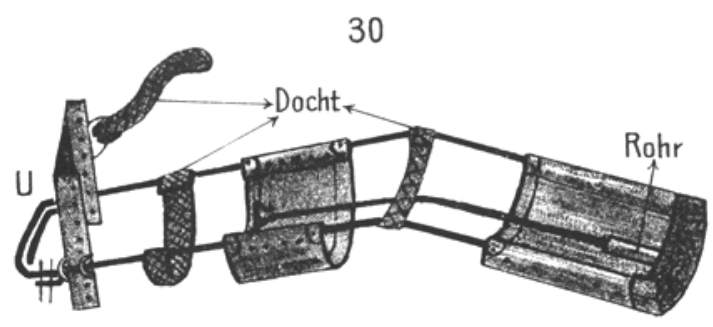

Liegeschiene Fig. 20 z. Kniestrecken eingestellt.

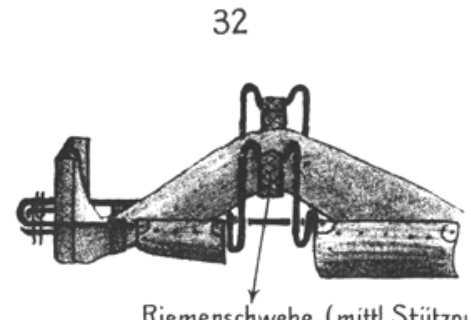

Riemenschwebe (mittl.Stützpunkt)

z. Entspannen d. Beugemusc.

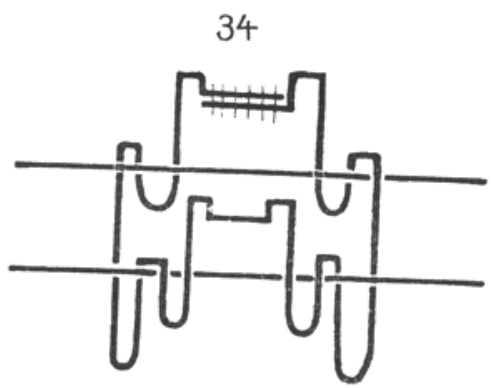

Riemenhalter v. Schiene Fig. 32

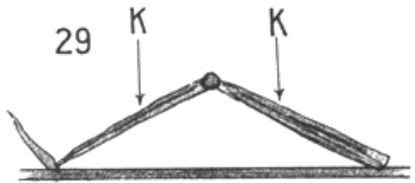

Kniestreckung m. Hülsenschiene ohne mittl. Stützpunkt ohne Kniekappe.

\section{1}

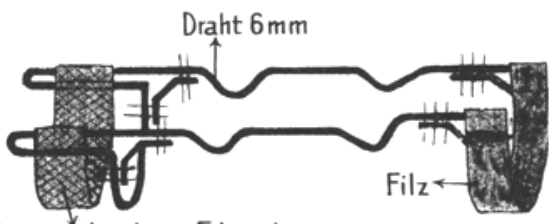

Riemenśchwebe m. Filz polstern

Kniestrecker

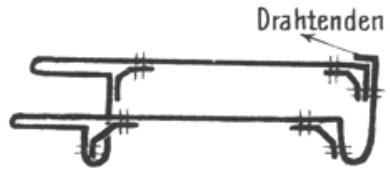

Drahtgestell z. Kniestrecker

Fig. 31.

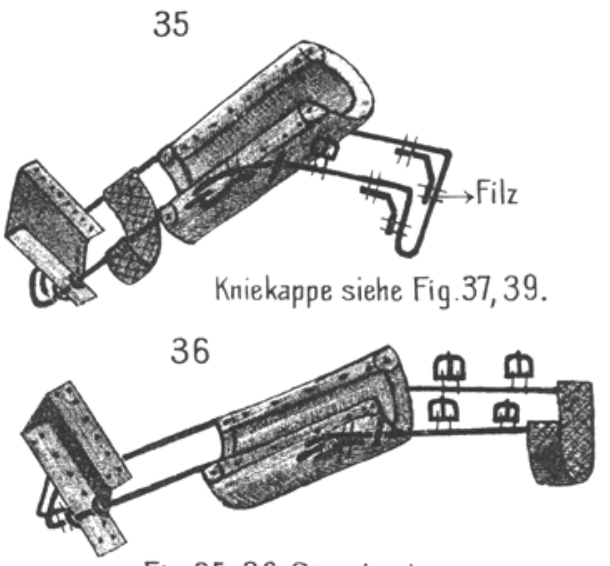

Fig. 35, 36 Streckschiene bei hochgradig spitzwinkelig. Knie. 


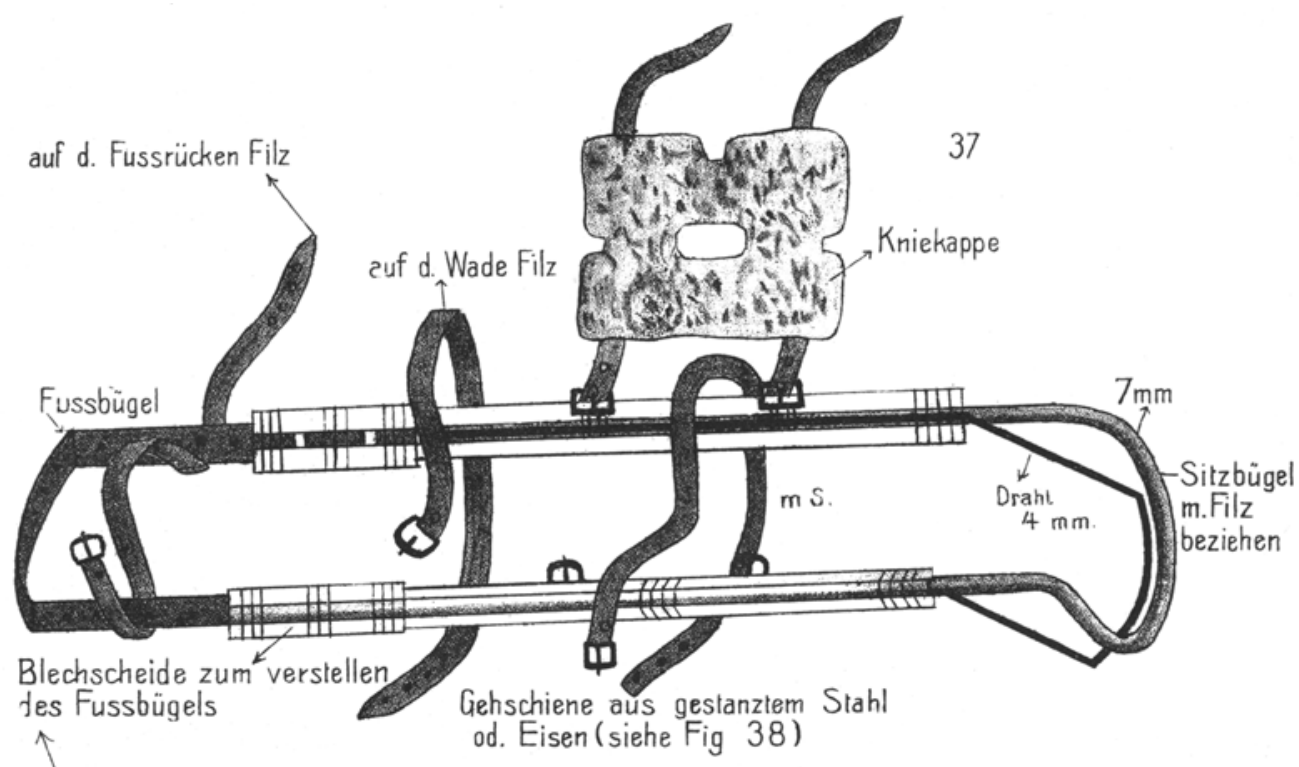

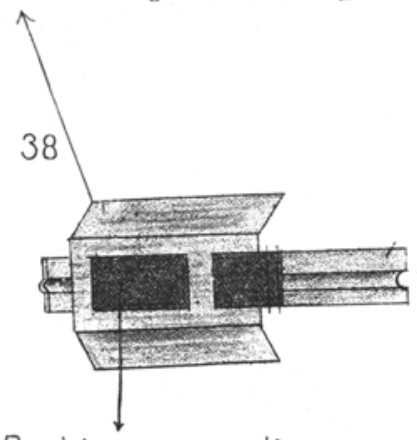

Bandeisen zum verlãngern

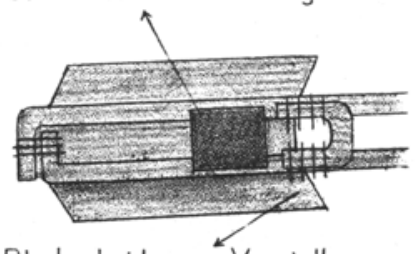

Blechscheide zum Versiellen d. Fussbügel

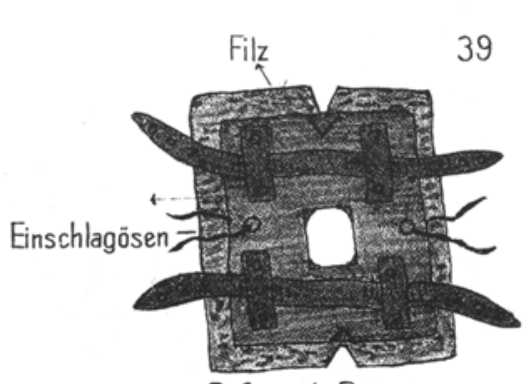

Befest. d. Riemen a. d. Kniekappe

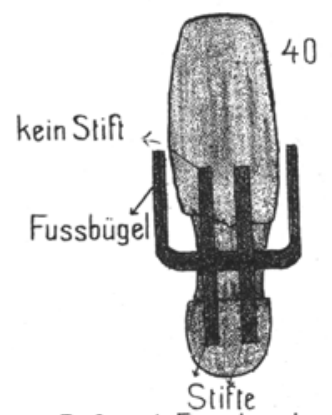

Befest. d. Fussbügel am

Stiefel, über d. Eisen

Halbsohlen u. Absatz

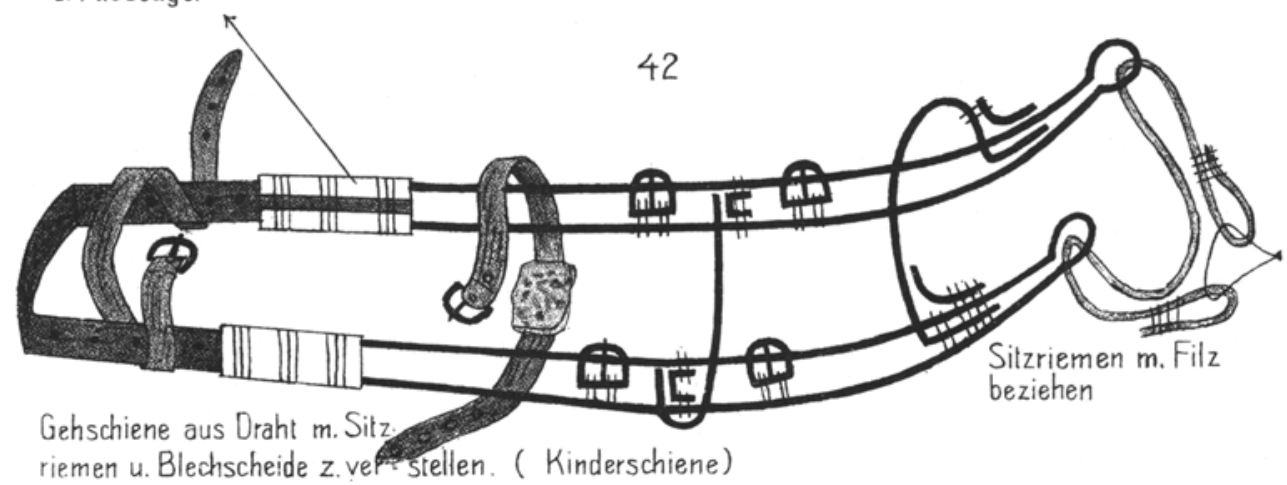
De Thilo. 


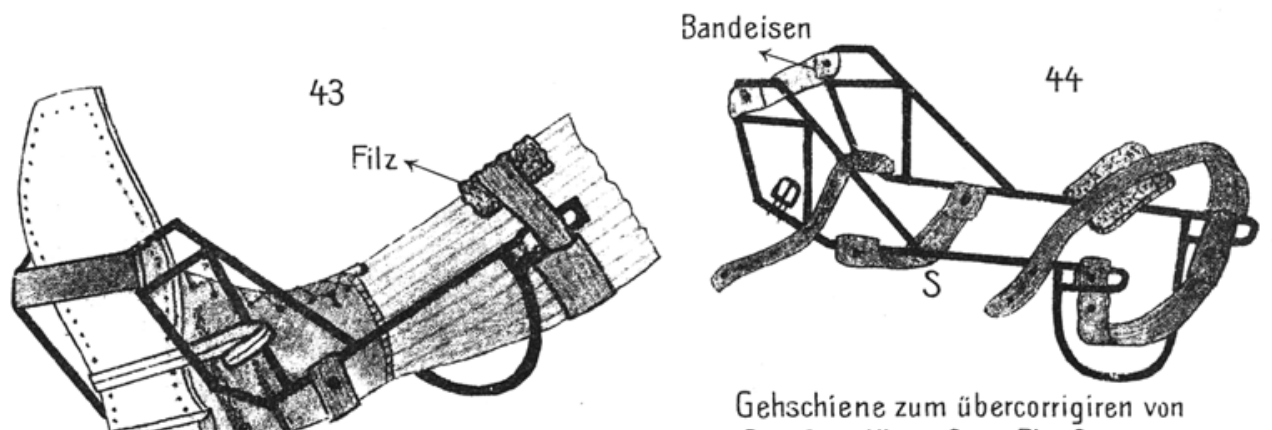

Spitzfuss, Klumpfuss, Plattfuss.
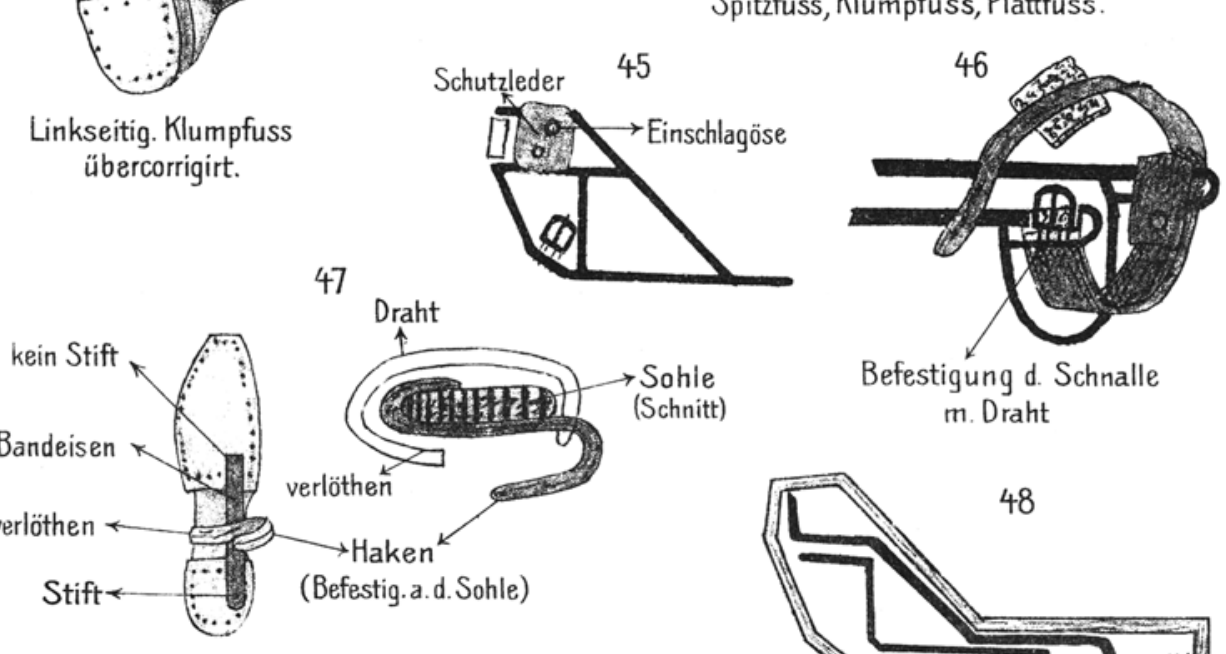

Befestigung d. Schnalle m. Draht

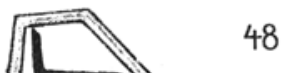

50

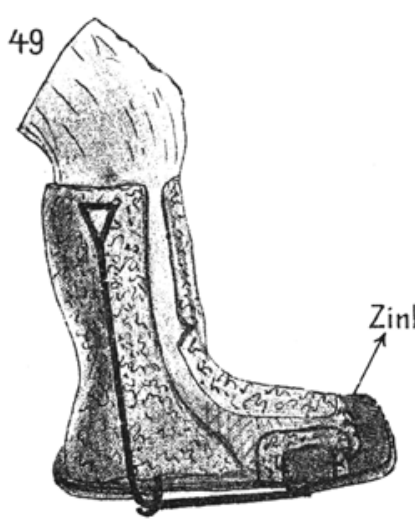

Mit Celluloïdbinden bewickeln
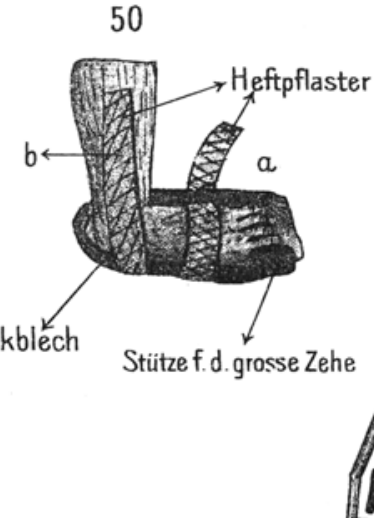

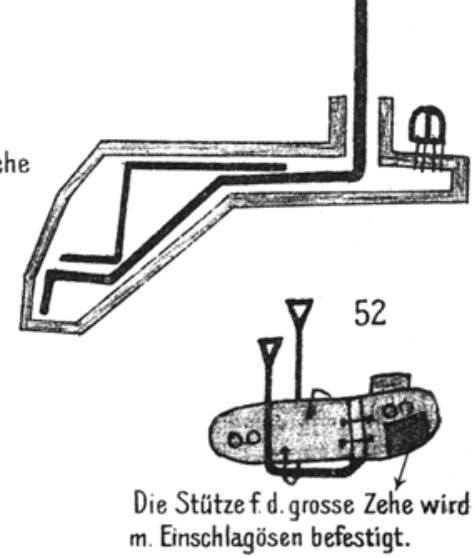

Die Stütze f. d. grosse Zehe wird $m$. Einschlagösen befestigt.

Fig. 44 ausgebreitet 

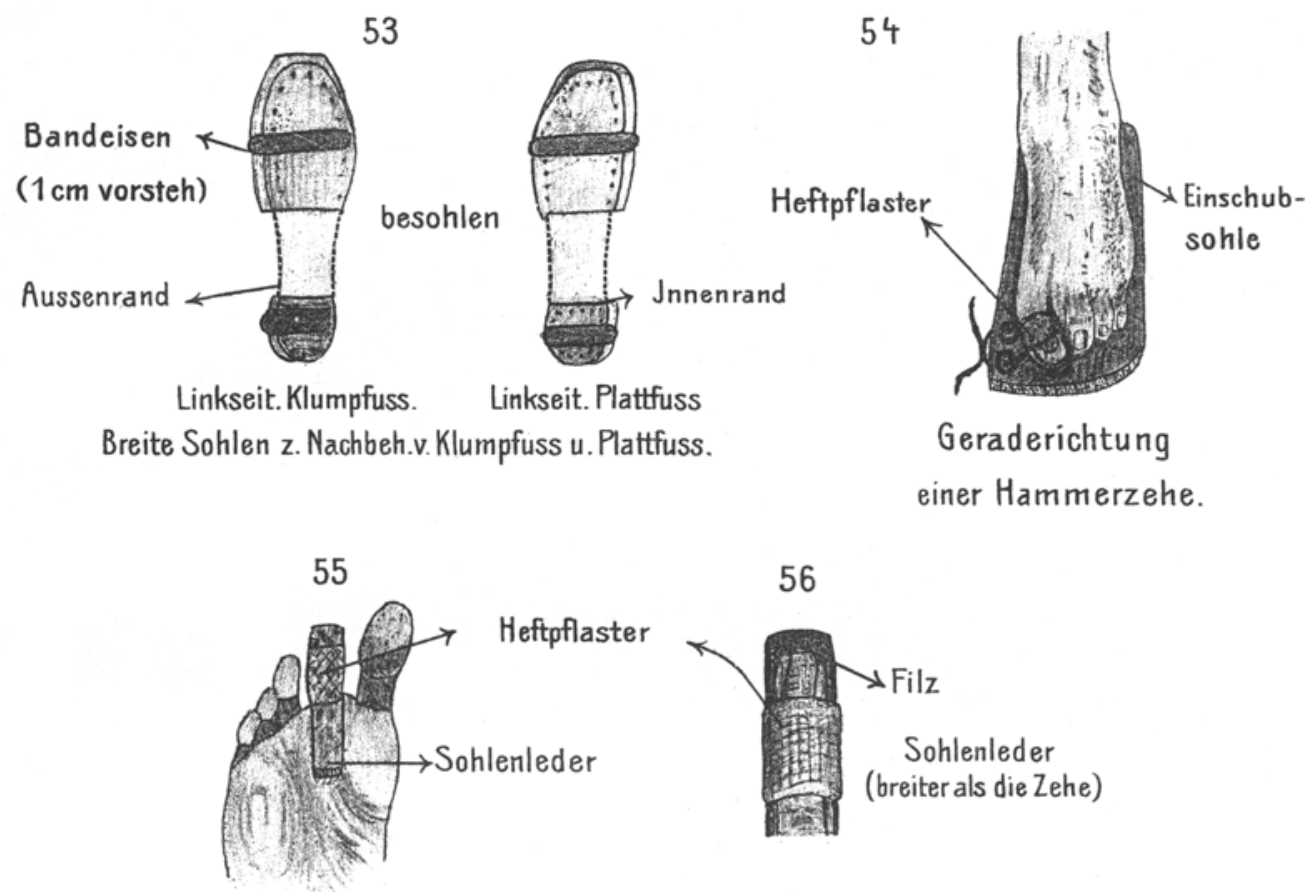

55 u. 56 Streckung gekrümmter Zehen.

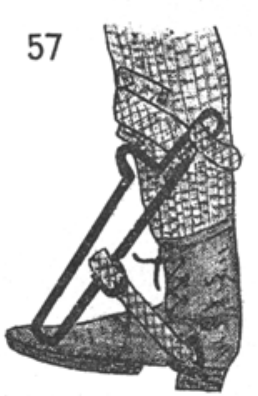

Schiene gegen Hackenfuss.

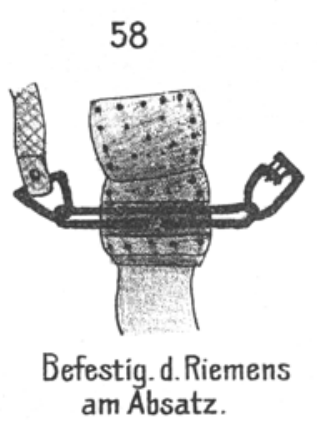

am Absatz.

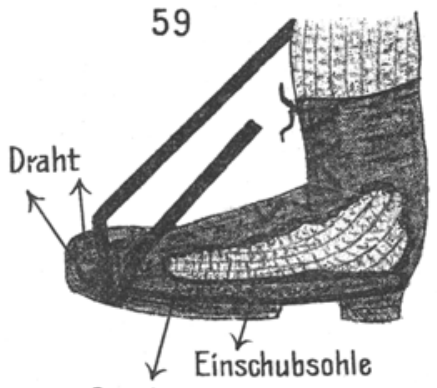

Bandeisen

Filz auf den Fussrücken.

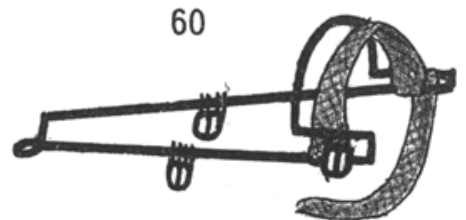

Schiene gegen Hackenfuss s. Fig. 57.

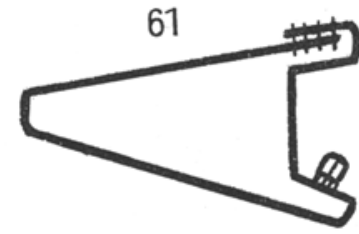

Fig. 60 ausgebreitet. Dr Thflo. 


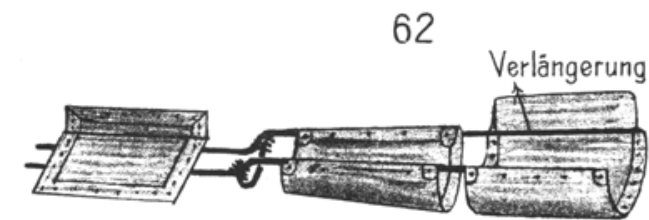

verstellbare Armschiene für den ganzen Arm

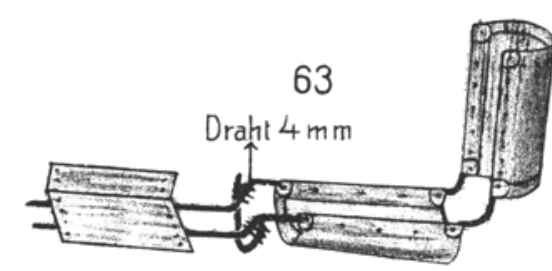

Schiene Fig. 62 in Winkelstellung

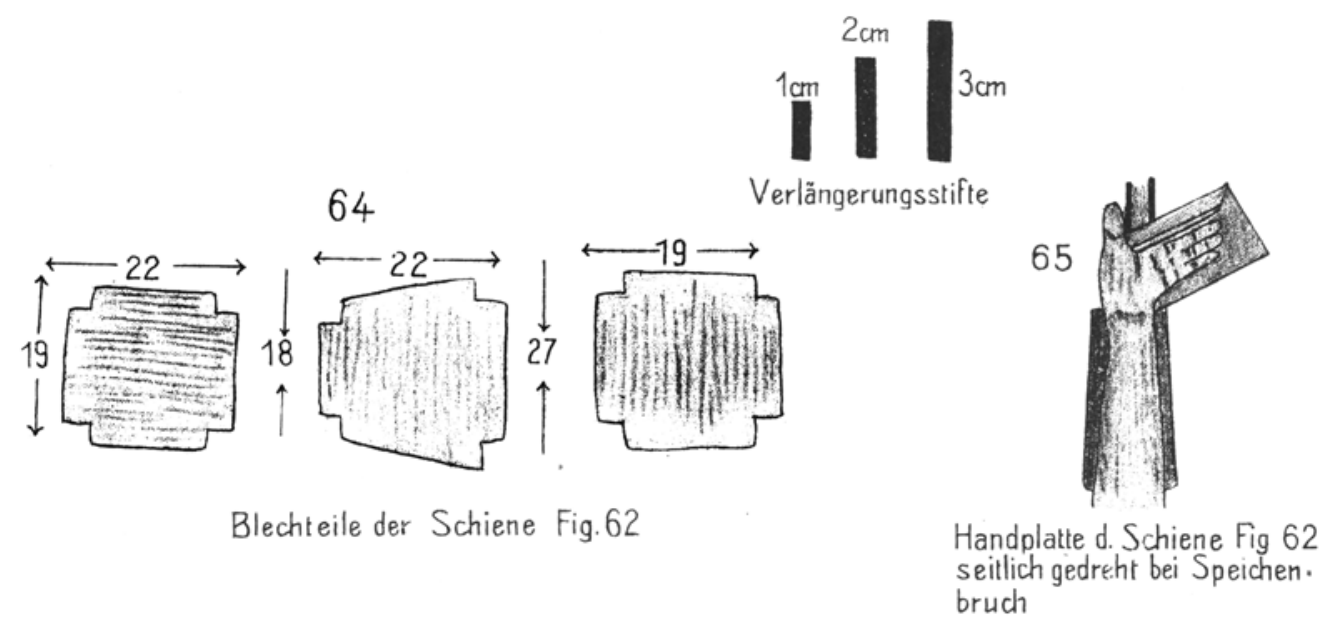

66

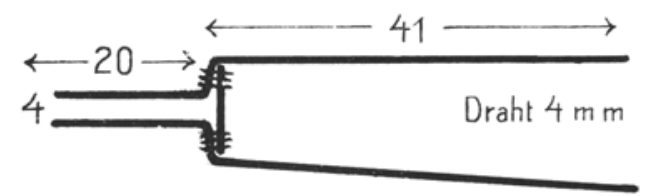

Gestell d. Schiene Fig.62 Für Unterarmschienen wird ein kürzeres Gestell benuizt.

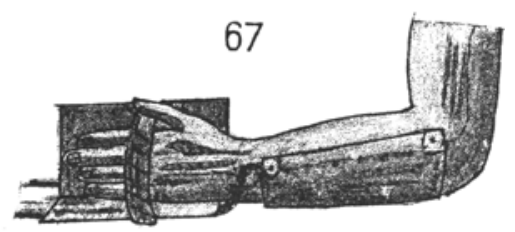

Handplatte der Schiene Fig. 62 senkrecht gestellt ( Unterarmschiene) 


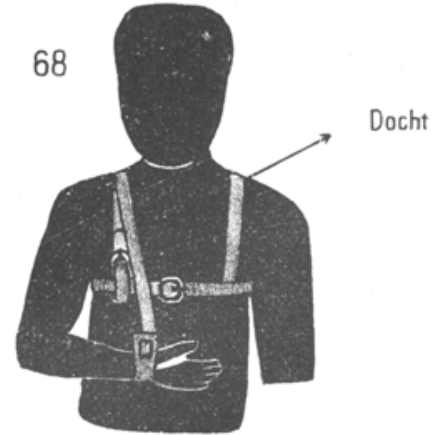

Beugung d. Ellbogengelenk

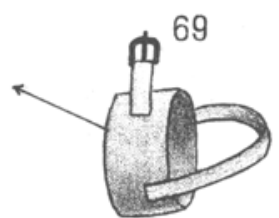

für d. Hand

Vrgl. Fig 68

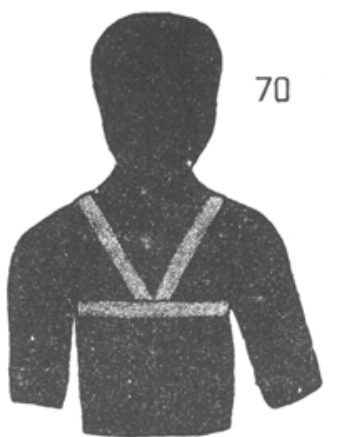

Fig.68v. hinten gesehen.

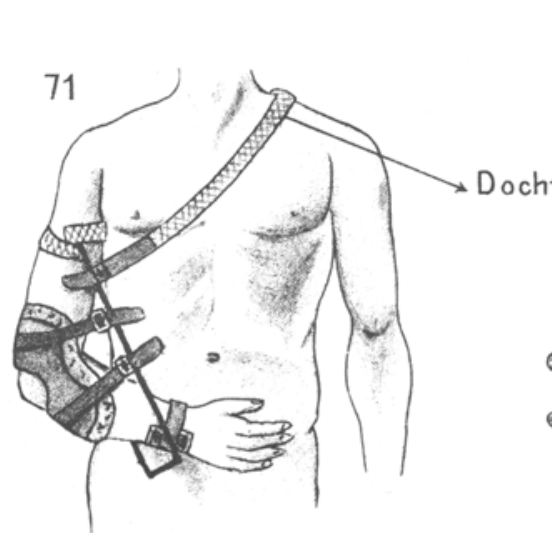

Streckung d. Ellbogengelenk

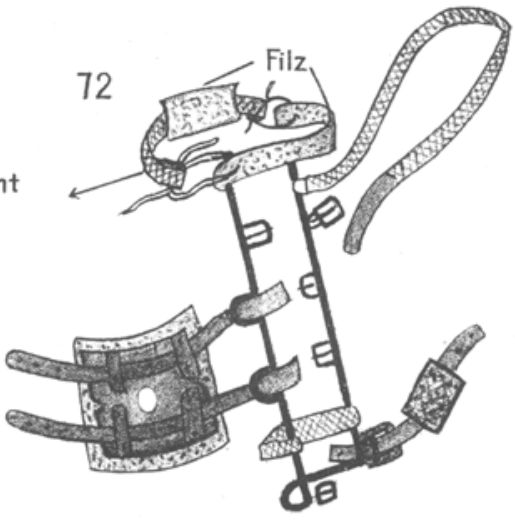

Streckschiene (Fig.71)

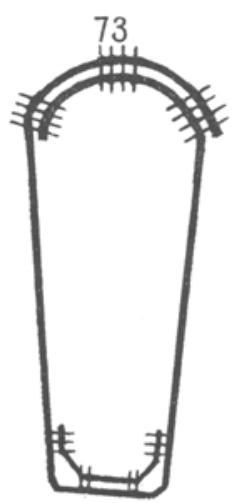

Schiene Fig. 72 (ausgebreitet)

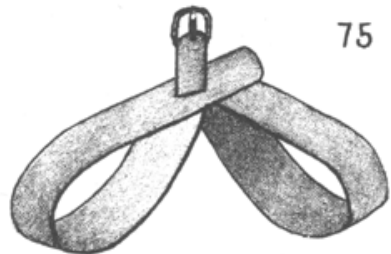

für den Ellenbogen vrgl. Fig 74

Gegen Versteifung d. Schultergelenk . DF Thilo. 

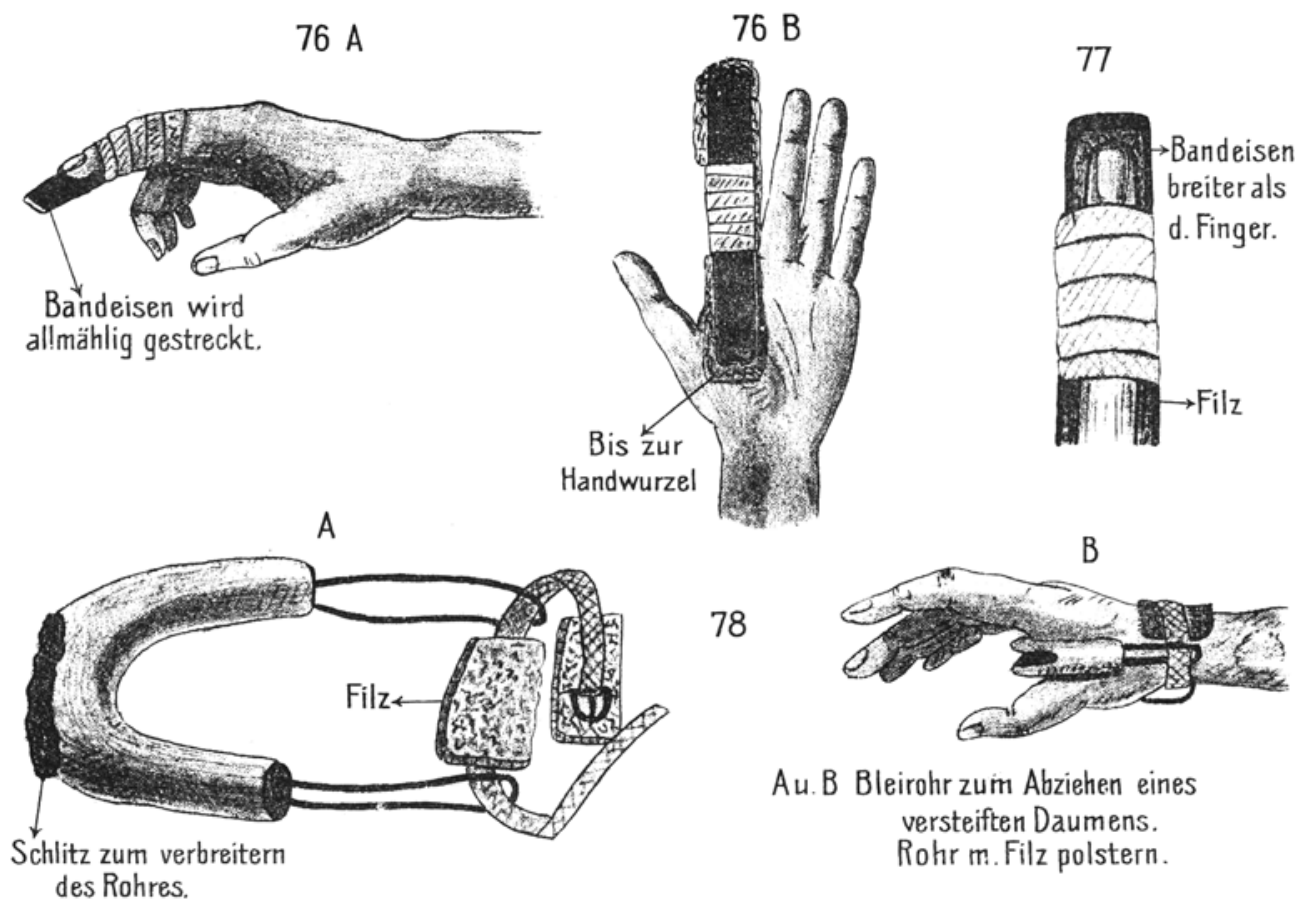

78

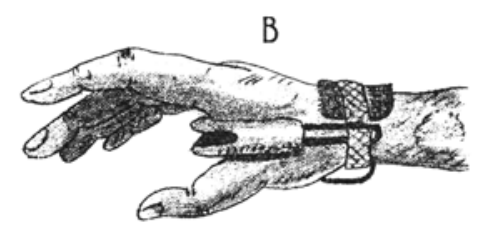

Au. B Bleirohr zum Abziehen eines versteiften Daumens. Rohr m. Filz polstern.

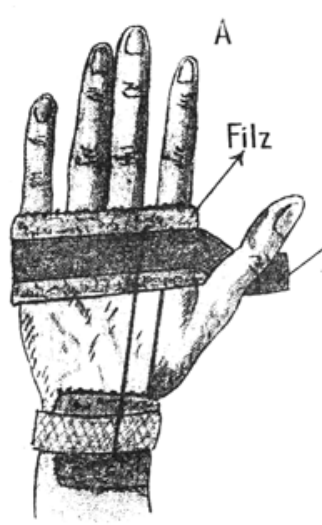

A

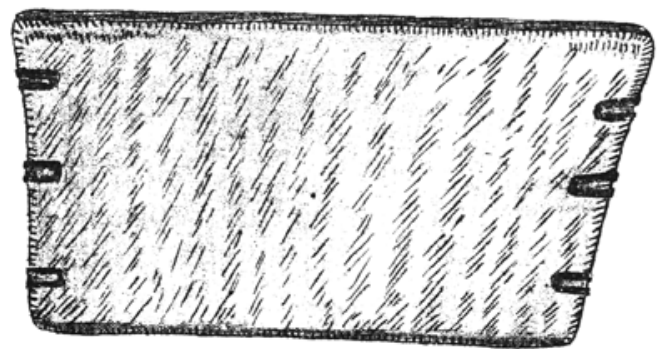

Korsettartiger Federhalter Dr Thilo. (abgewickelt.)

B 79 Bandeisen zurHebung des versteiften Daumen
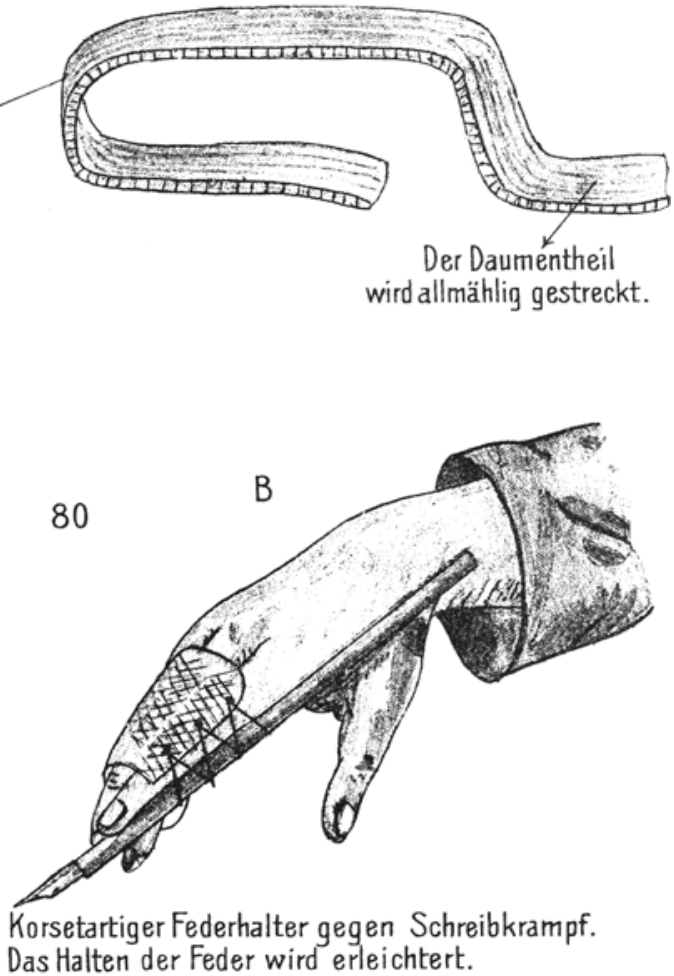


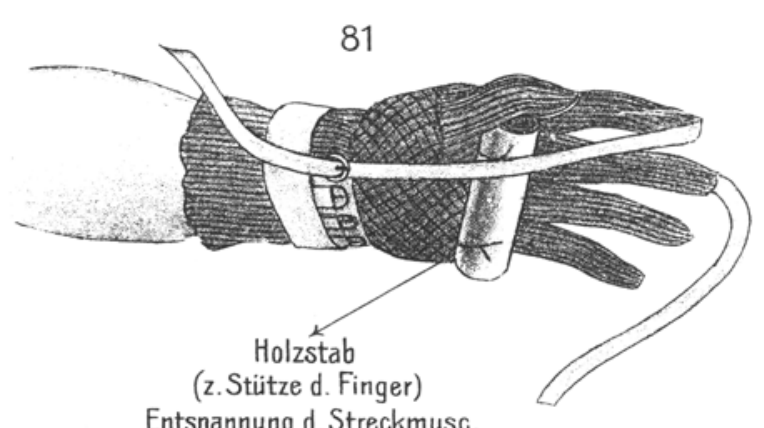

Entspannung d. Streckmusc.

Baumwollener Handschuh m. Dochtzügen z. Beugen steifer Finger.

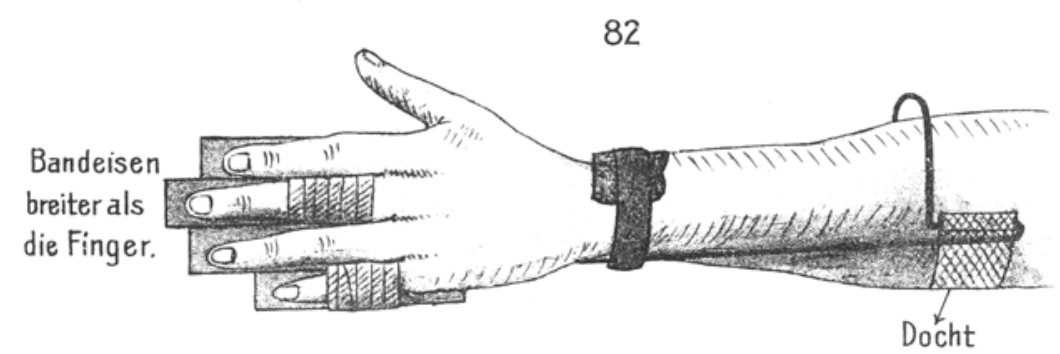

Schiene gegen Greifhand.

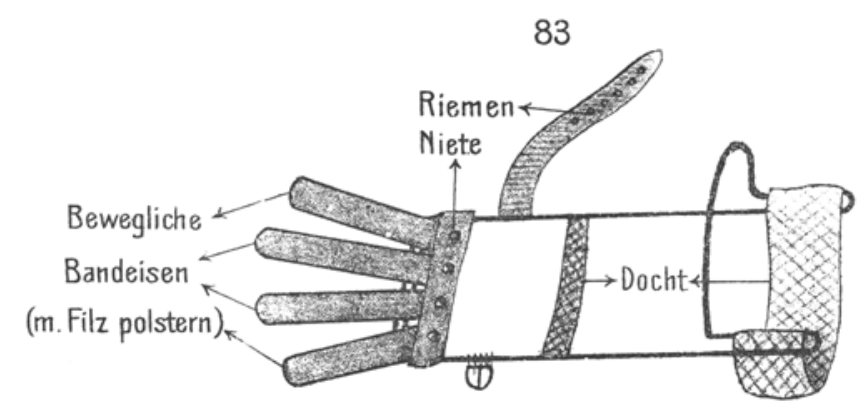

Vrgl. Schiene Fig.

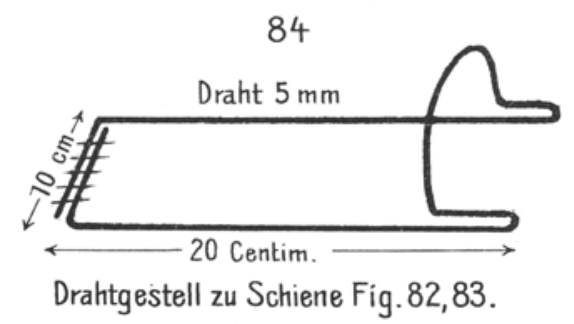

Dr Thflo. 


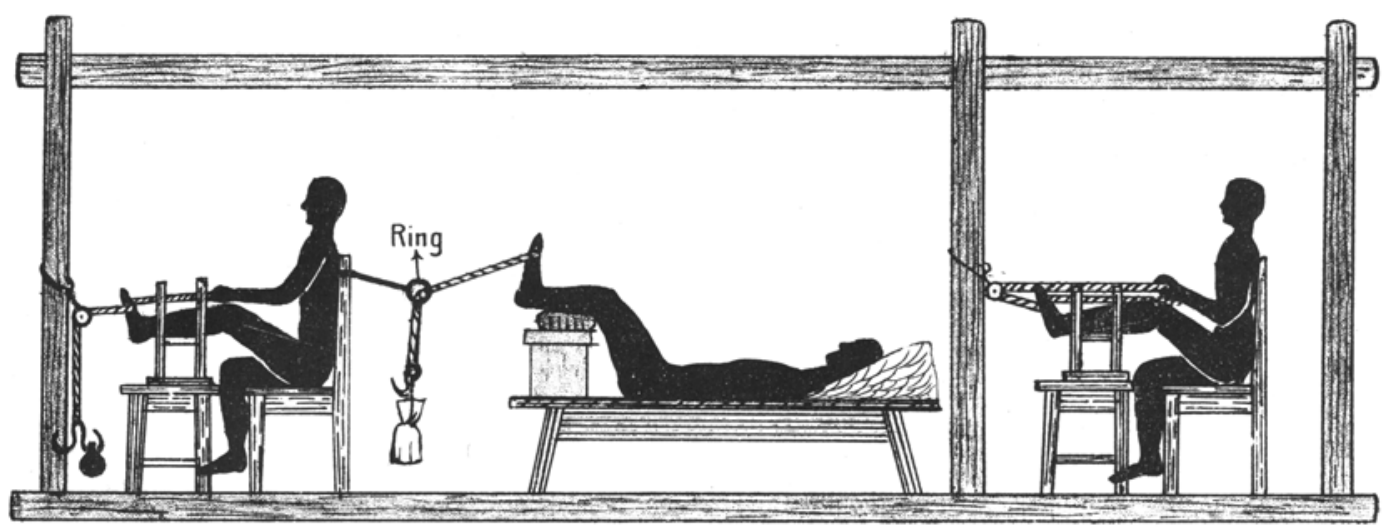

85 Sohlenbeugen

(passiv)
86 Rückenbeugen

(m. Wiederstand)
87 Rückenbeugen (passiv)

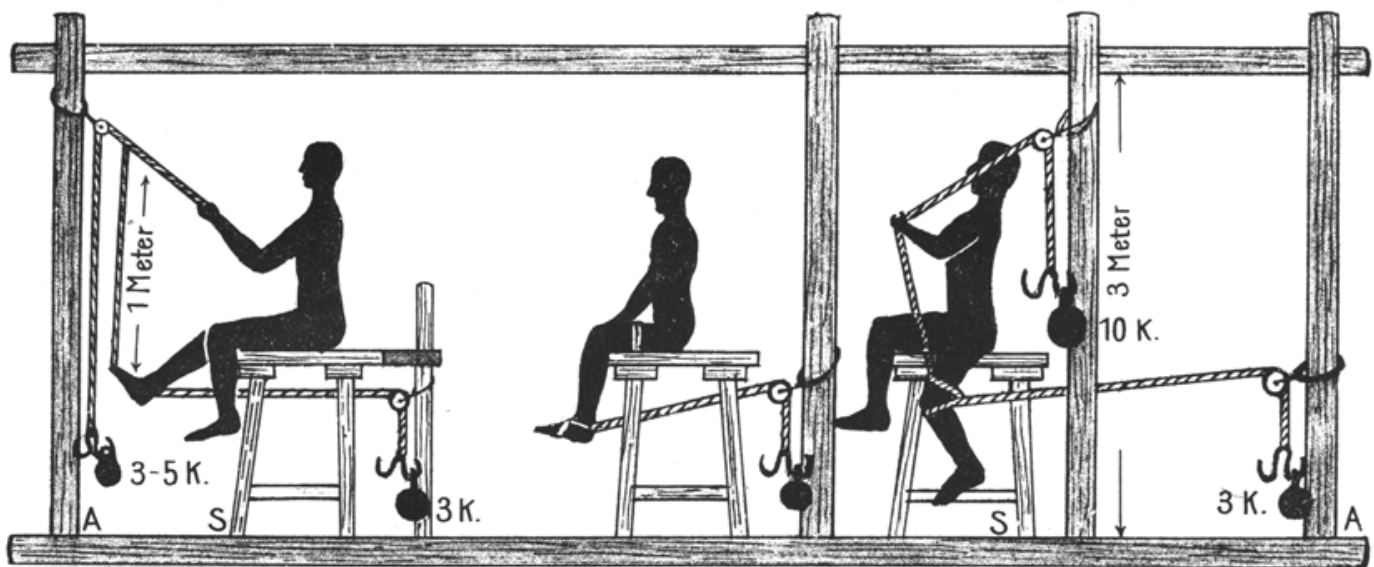

88 Kniestrecken (passiv)
89 Kniestrecken

(m. Wiederstand)
90 Hüftgelenkstrecken

(passiv)

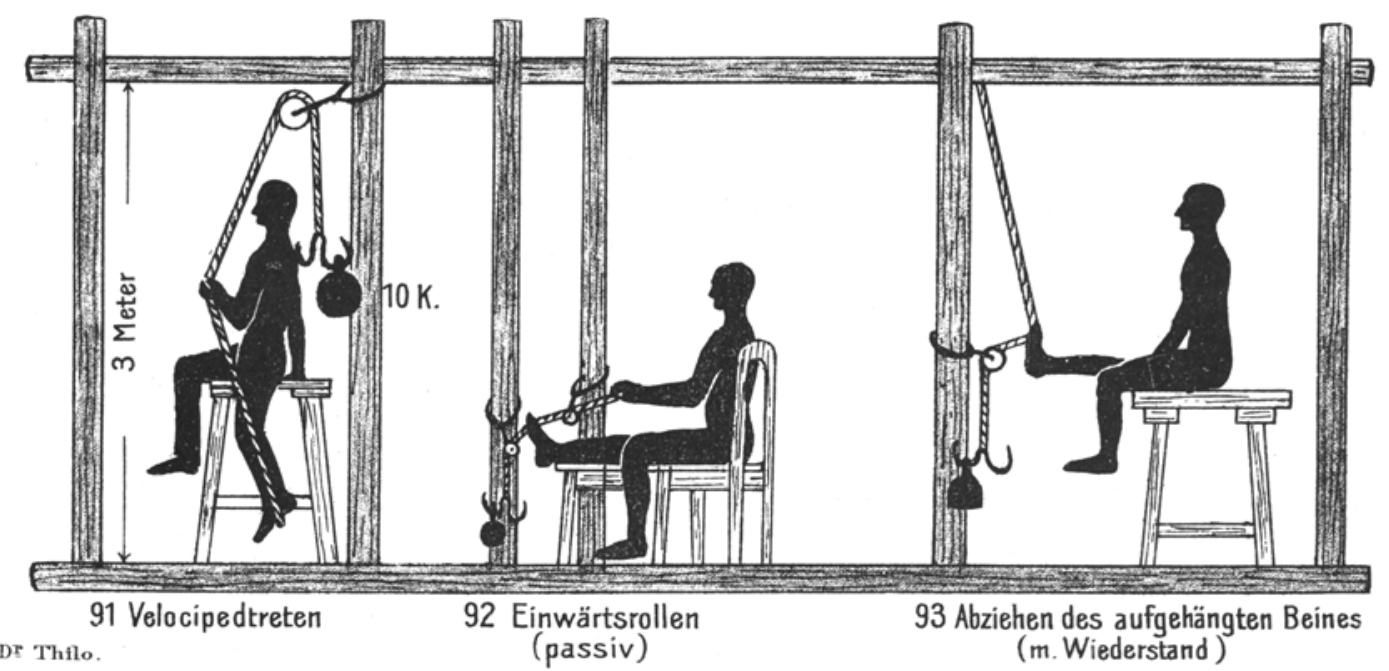




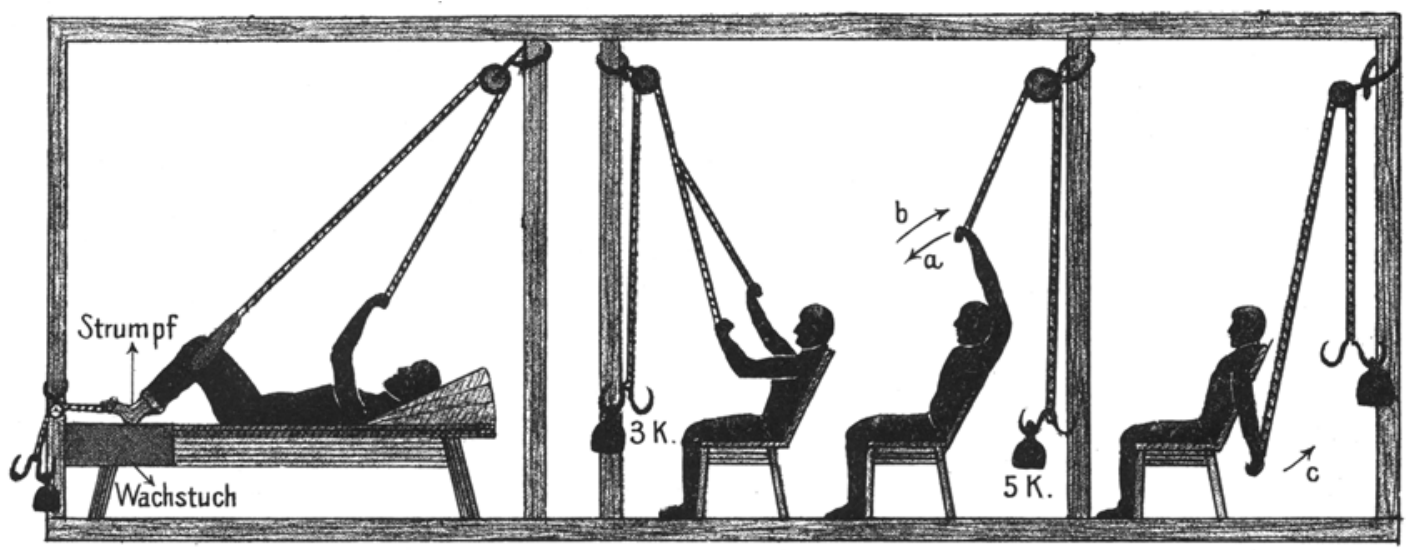

94 Passive Beinbewegungen.

95 Passives Armheben mit ungleichen Schnüren.
96

97

96 u. 97 Armkreisen.
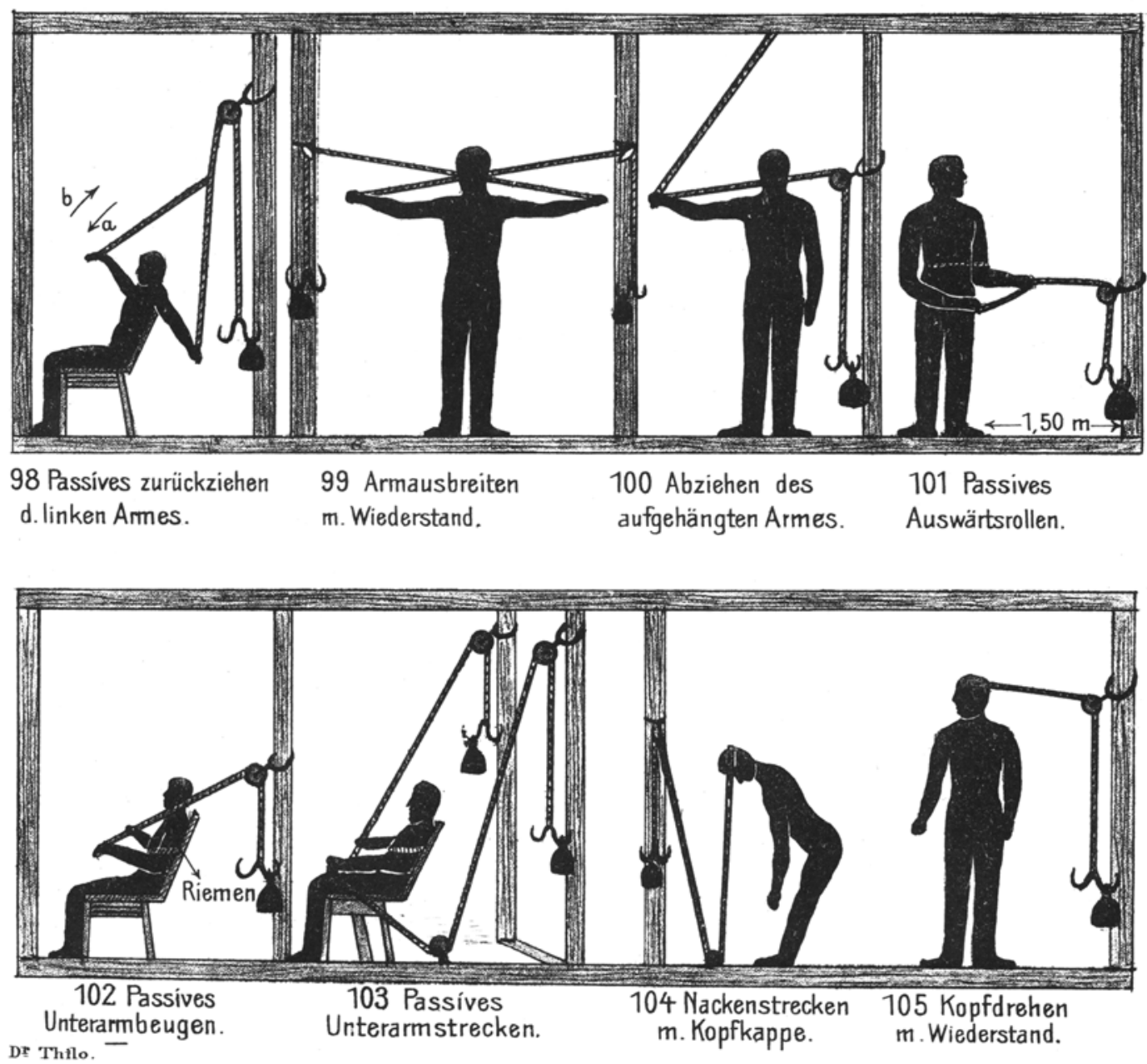


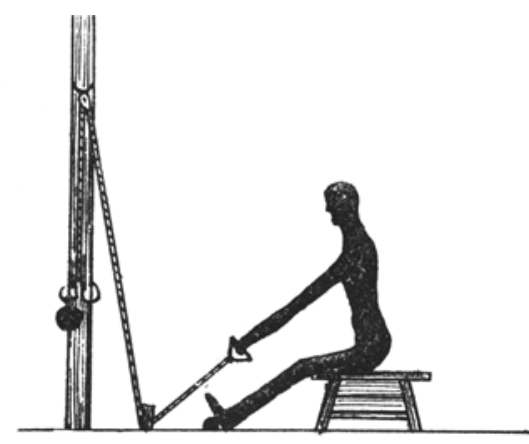

106

Rudern

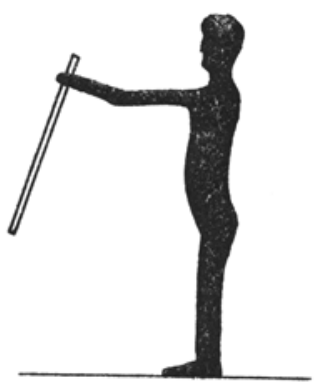

107

Auswärtsrollen m. Widerstand

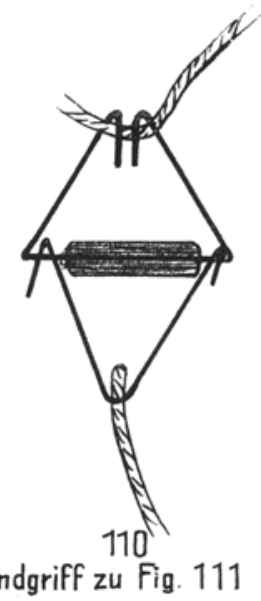

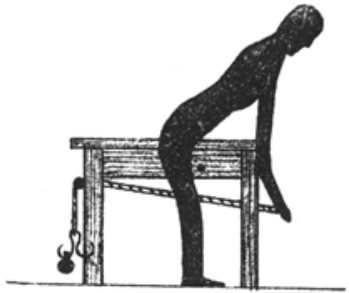

108

Strecken bei hochgradig ge. schwächten Handgelenk. musceln

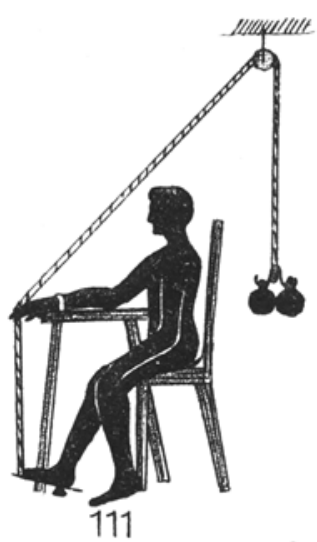

Passives Strecken gegen Greif. hand Befestigung d. Schnüre am Griffe siehe Fig. 110

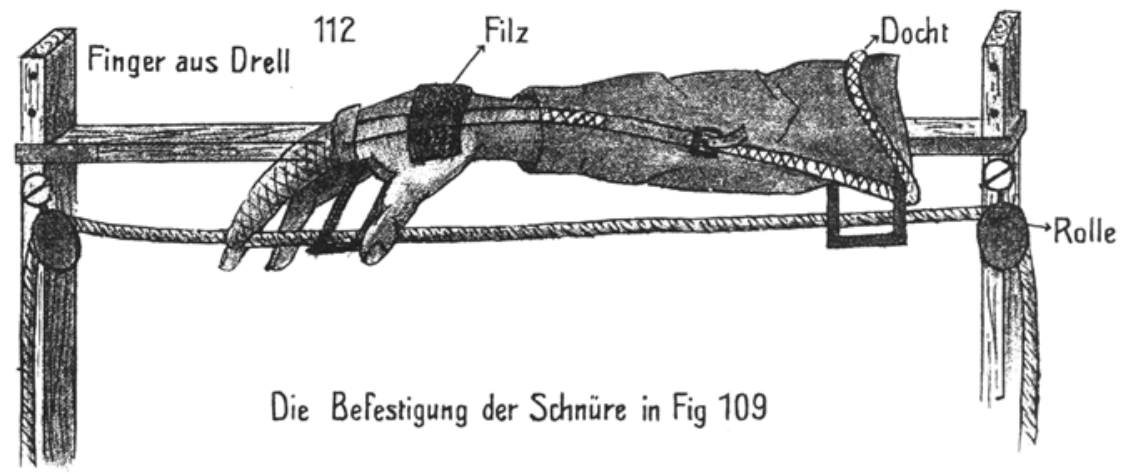




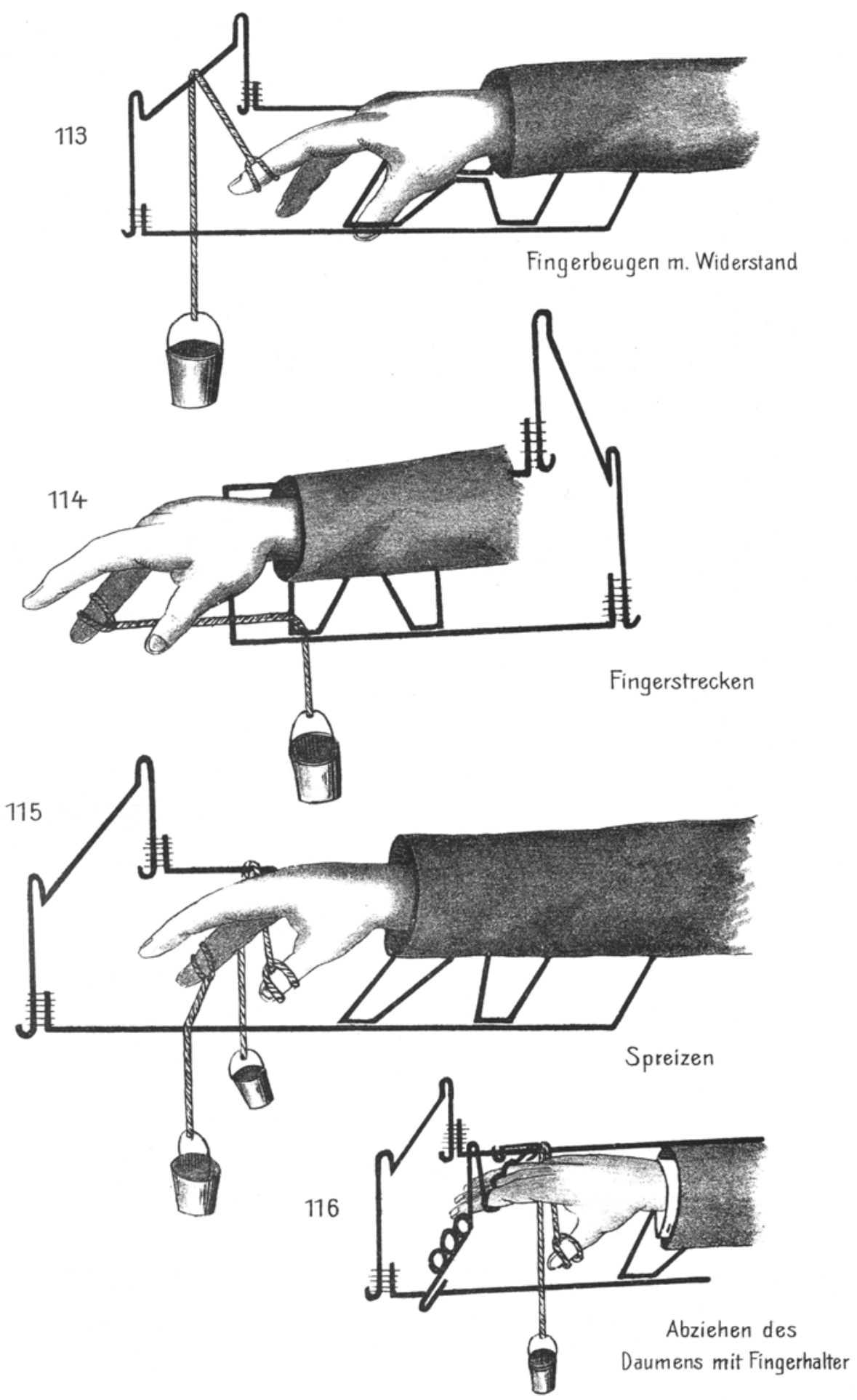




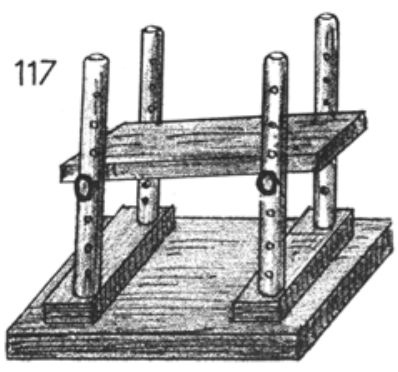

Fusshalter für Beweg. Fig. 85

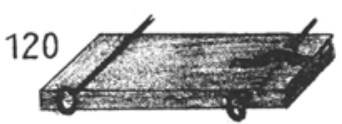

Brett für den Unterschenkel Fig. von unten gesehen. Ein Bolzen ist durch eine Eisenklammer geschoben.

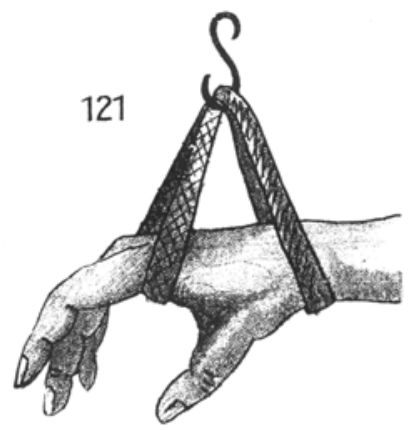

Dochtschlinge

124

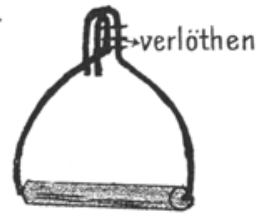

Handgriff aus einem einzigen Stück Draht gebogen.
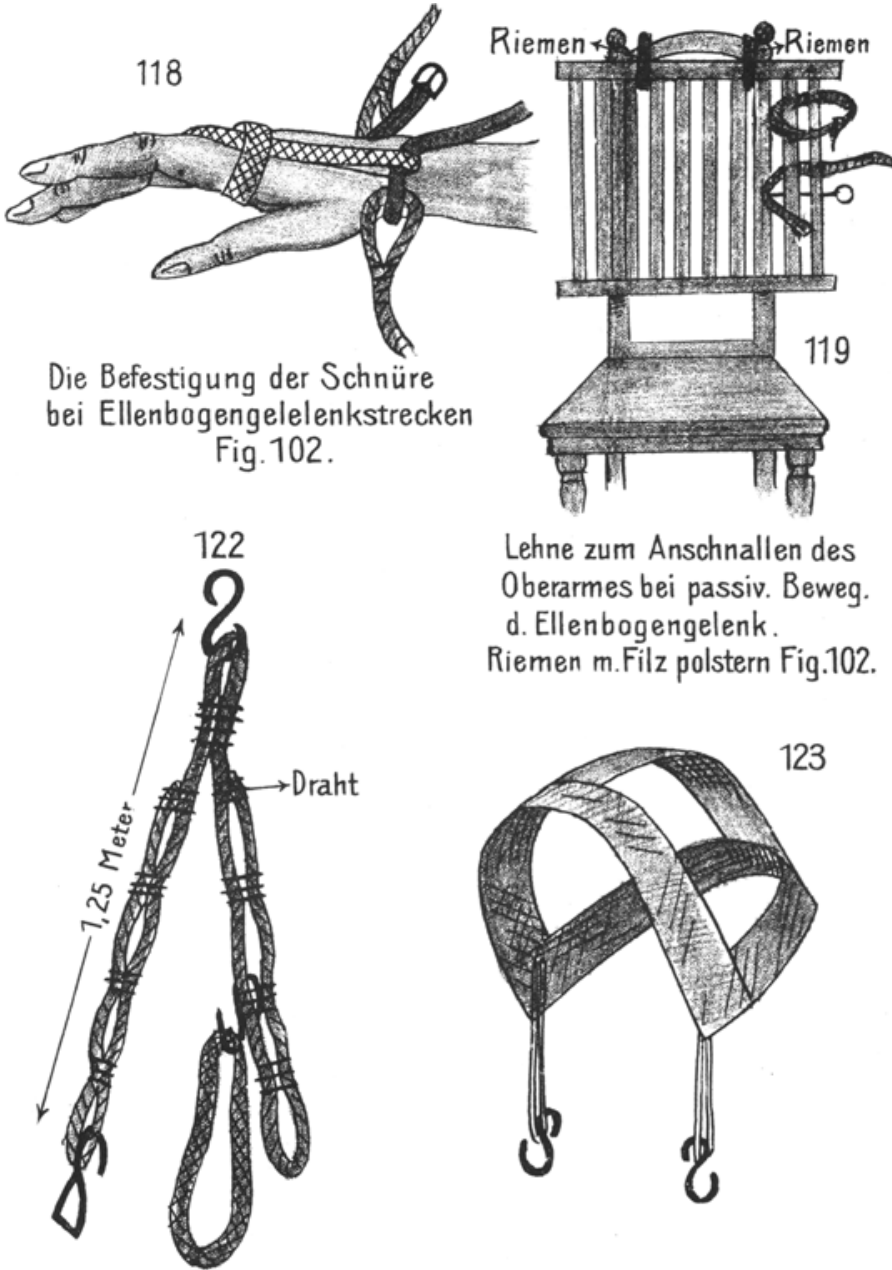

Schnurkette zum Stellen der Handgrille u. Dochtschlingen.

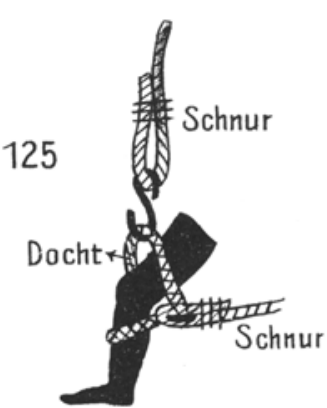

Drahtschlinge für das Knie beim Strecken d. Hüftgelenkes Fig.90.
Lehne zum Anschnallen des Oberarmes bei passiv. Beweg.

d. Ellenbogengelenk.

Riemen m.Filz polstern Fig.102.

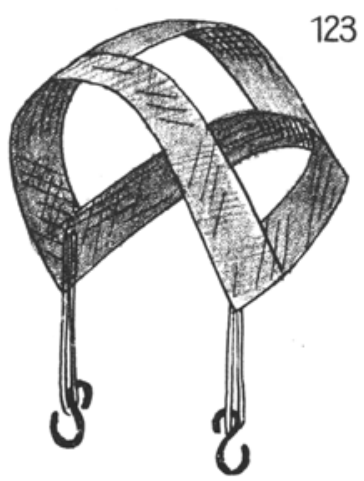

Kopfkappe aus Gurtband für Nackenstreckung Fig. 104.

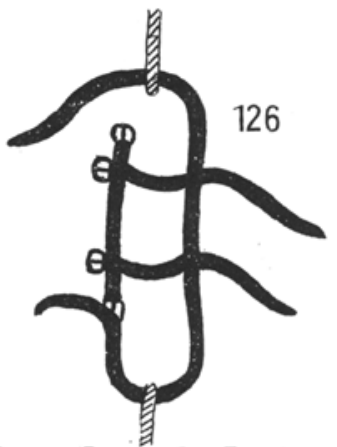

Halfter aus Riemen $f$. d. Fuss beim Strecken d. Kniegelenkes Fig. 88. 
127

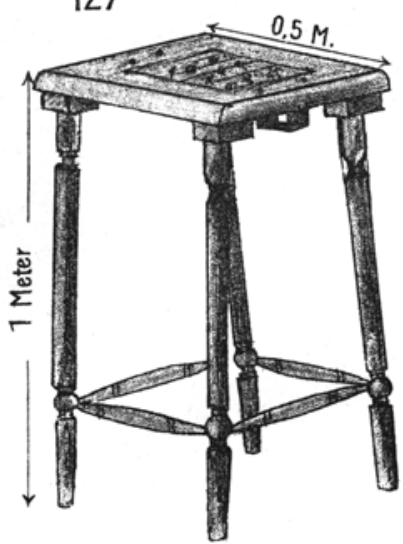

Hoher Sessel

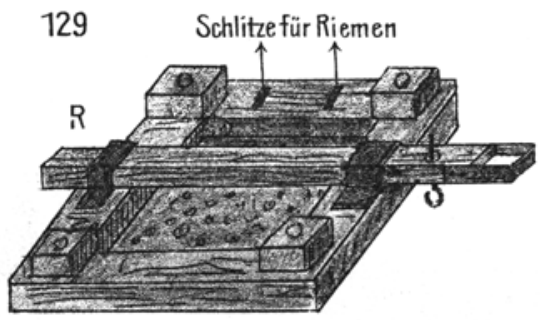

Sitzbrett d hohen Sessels von unten gesehen. Der Rollenhalter R. ist durch die Eisenklammern geschoben.

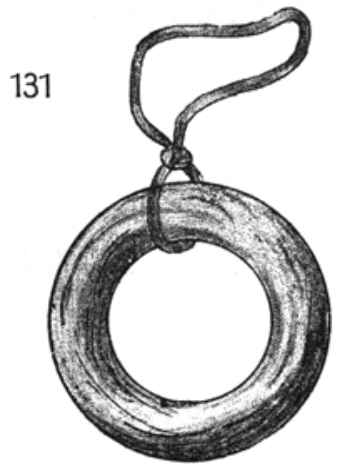

Rouleauxring aus Porzelan zu Uebung Fig. 86.

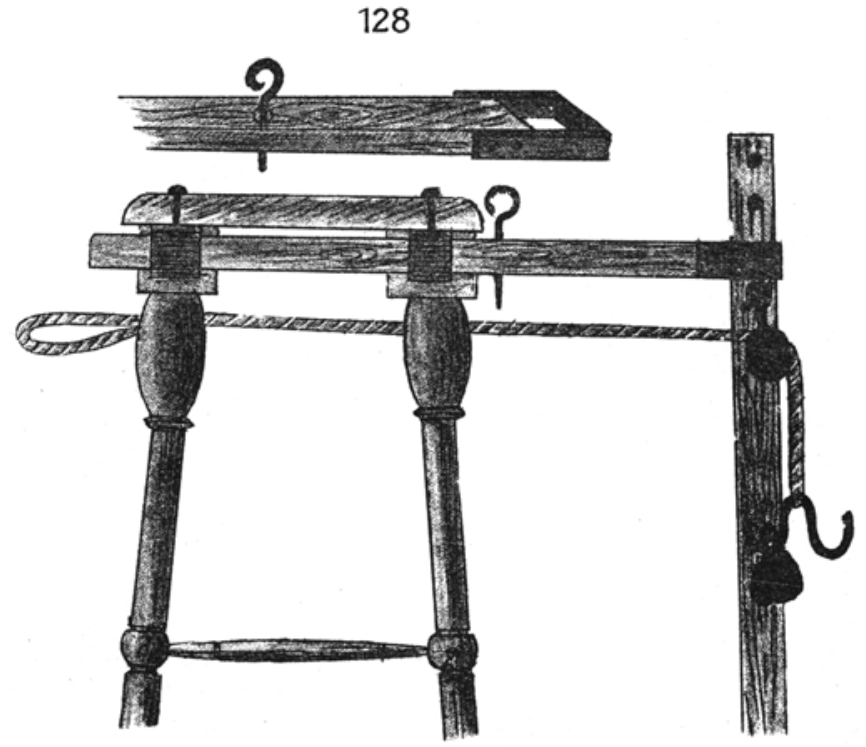

Befestigung der Rolle am hohen Sesself. Kniebeugung Fig.

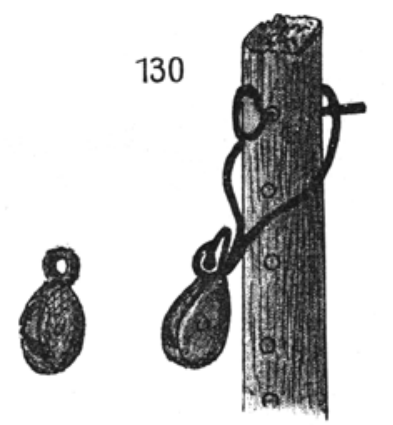

Aufhängung der Rolle am verstellbaren Drahtring.

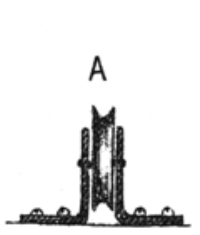

Rolle an den

Fussboden zu schrauben.

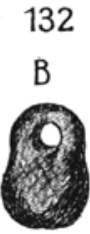

verstellbarer Ring

aus Draht $3 \mathrm{~mm}$.

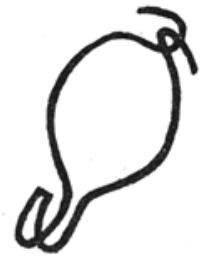

Dr Thilo. 


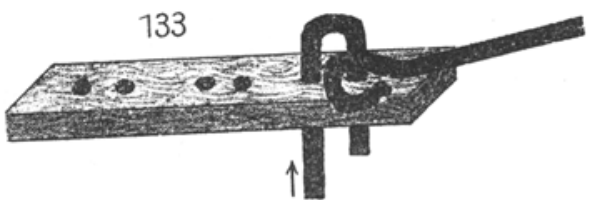

Drahtbieger nach Thilo

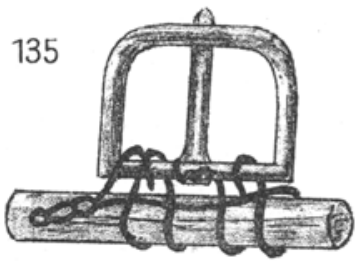

Die Schnalle wird mit Achterwindungen des Bindedraht befestigt, die Drahtenden werden zusammengedreht und zum Dorn hingebogen.
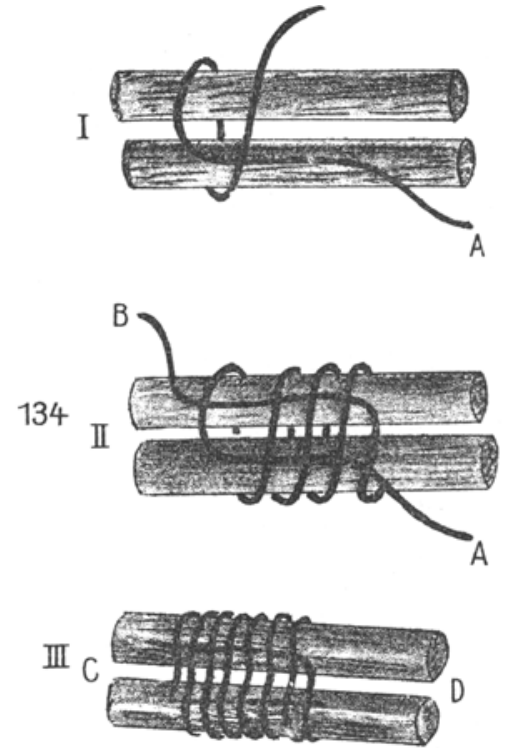

2. Jm Zwischenraum C D (Fiß. III) wird der übergewickelte Bindedraht mit einer stumpfen Kneifzange eingedrückt. Hierauf verzinnen $\mathrm{m}$. Löthlampe.

1. Fiǵ. I,II,III Befestigung der Enden des Bindedrahtes

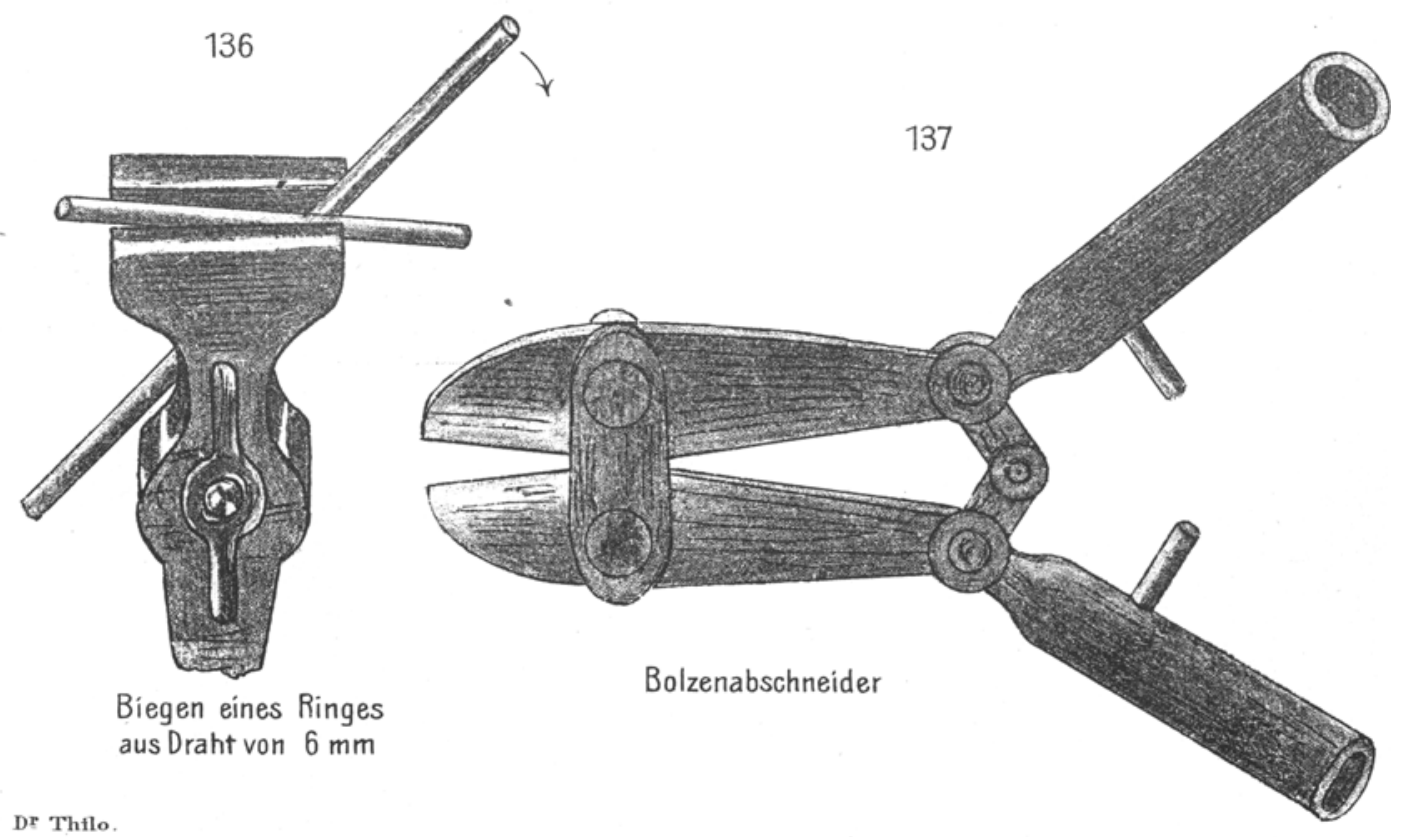




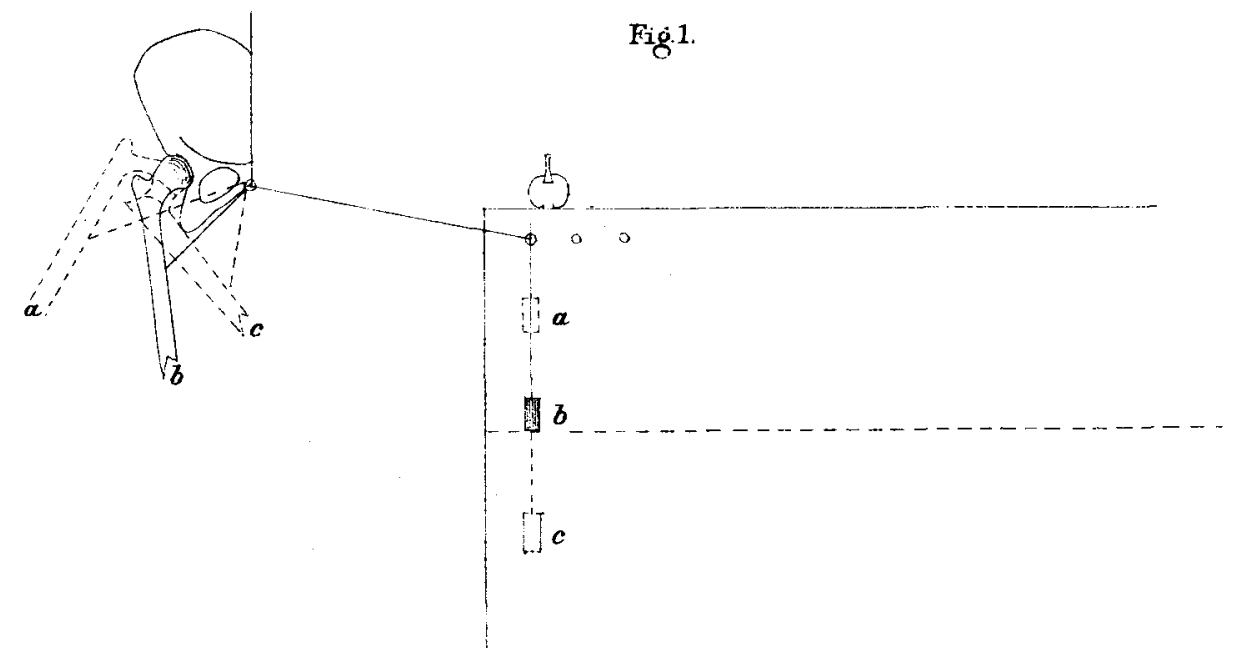

Fig. 3.

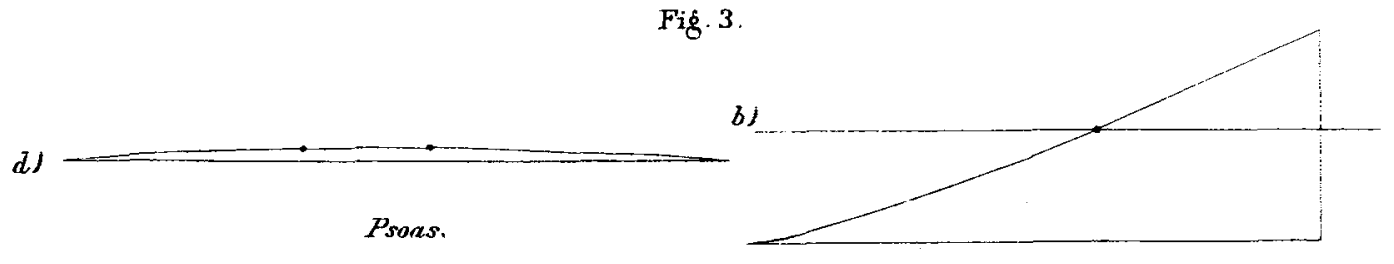

olut med., vordere Partie

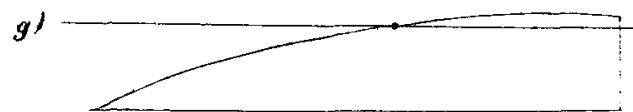

Rectzos.

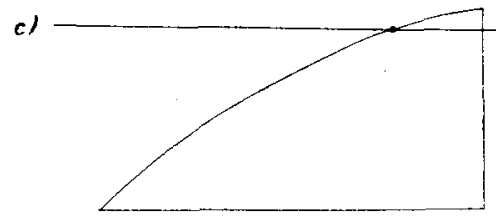

Sartorizs.

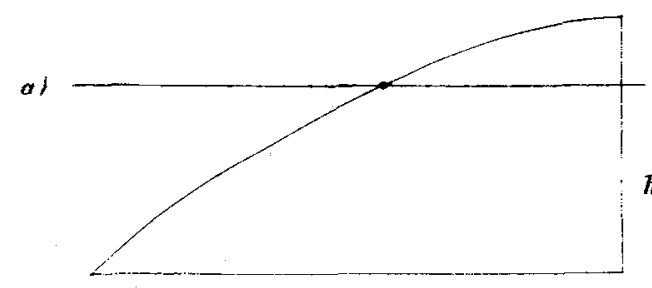

Tensor.

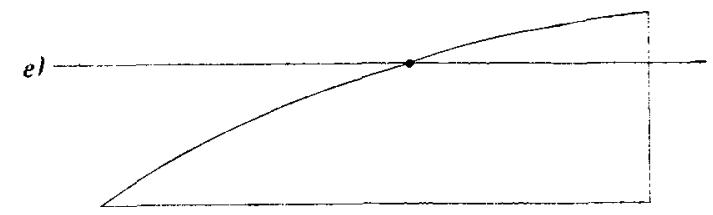

Glut med, mittlere Partie

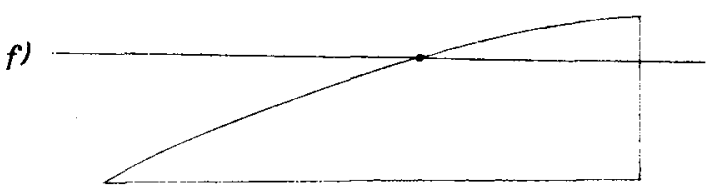

Gbut med., hintere Partie

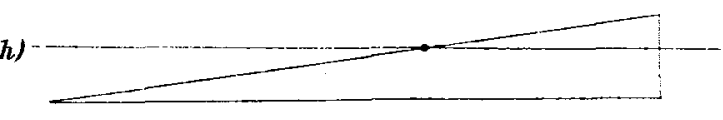

Gbut.max. 
Fis.4.
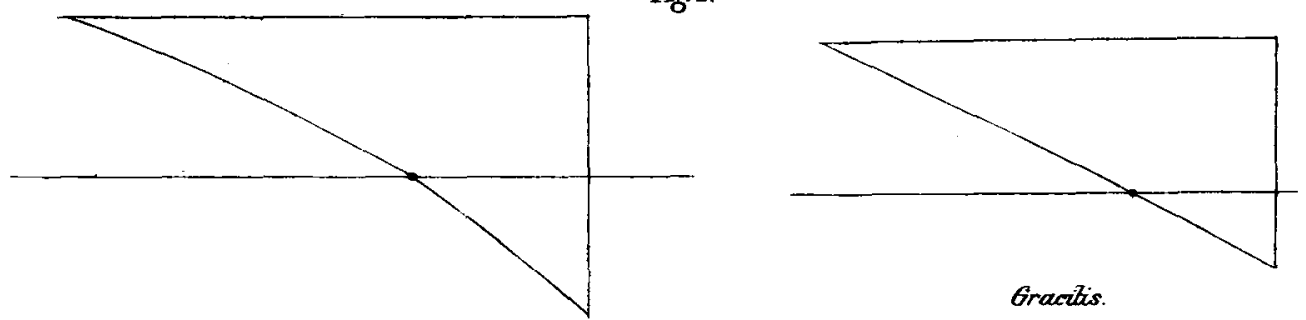

Gractis.

Add. Brev, untere Fusern.

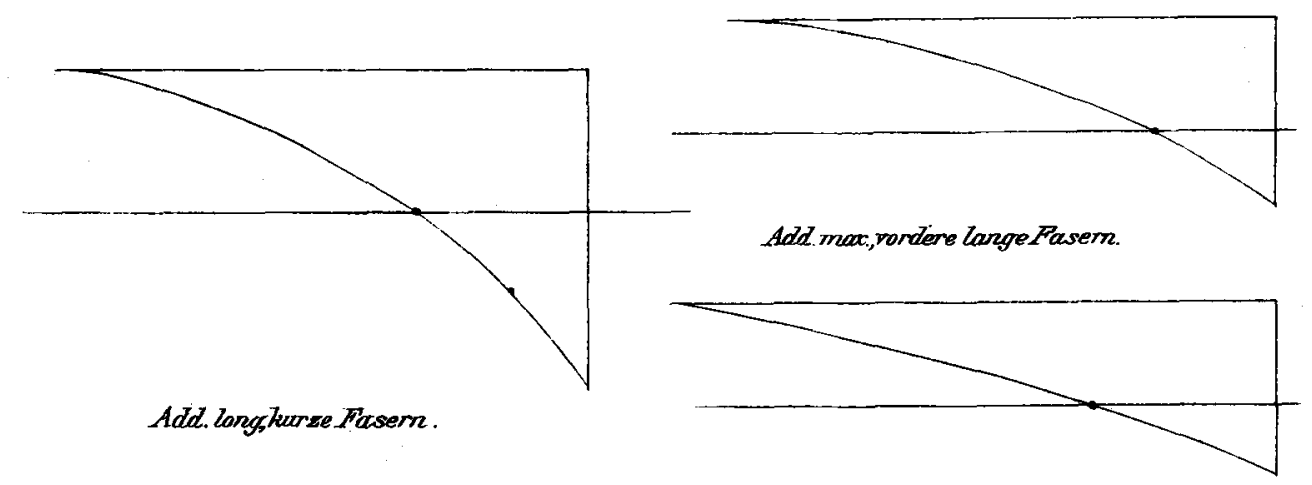

Add max, hintere kurze Fasem.

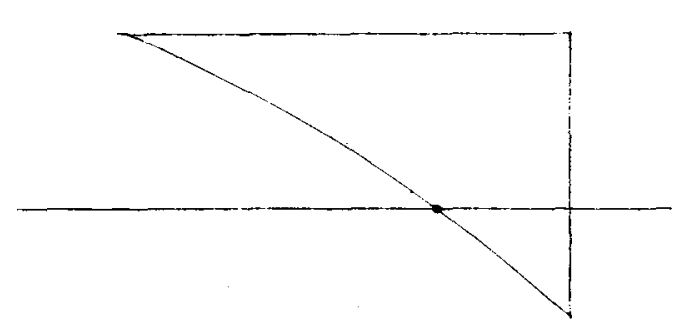

Add long, Zunge Fowern.

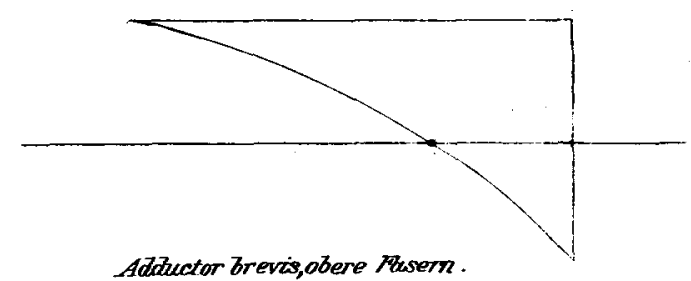

Adbuctor brevis, obere Fuserm

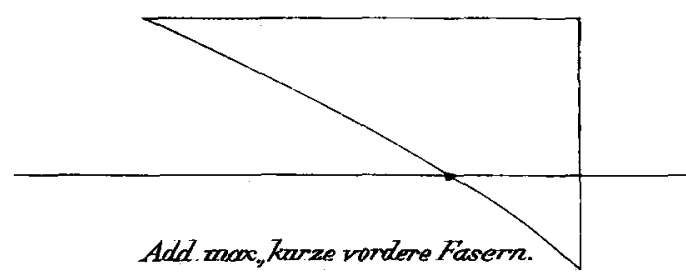

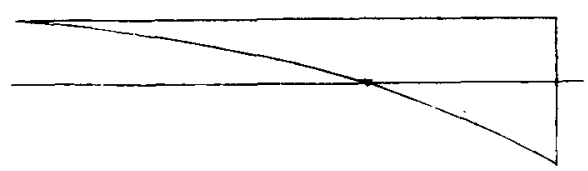

Pectineus.

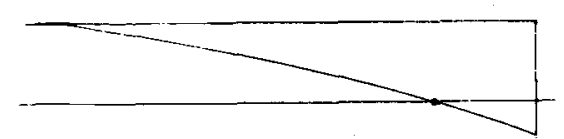

Adductor max, hintere longe Fifwern.

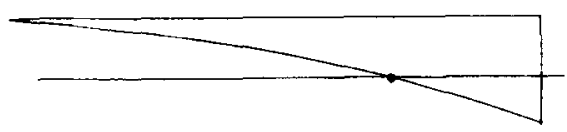

Guacinatas femaris.

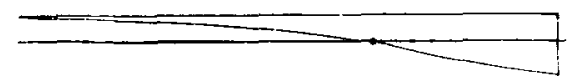

Semimambranosus.

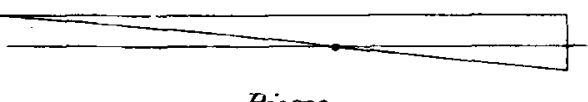

Bicens 
ig. 5 .

a)

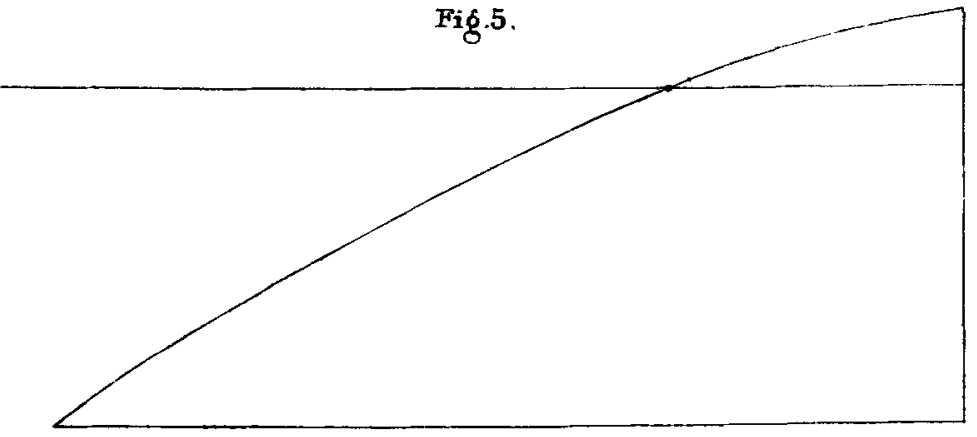

Tensar fasciace loutore.

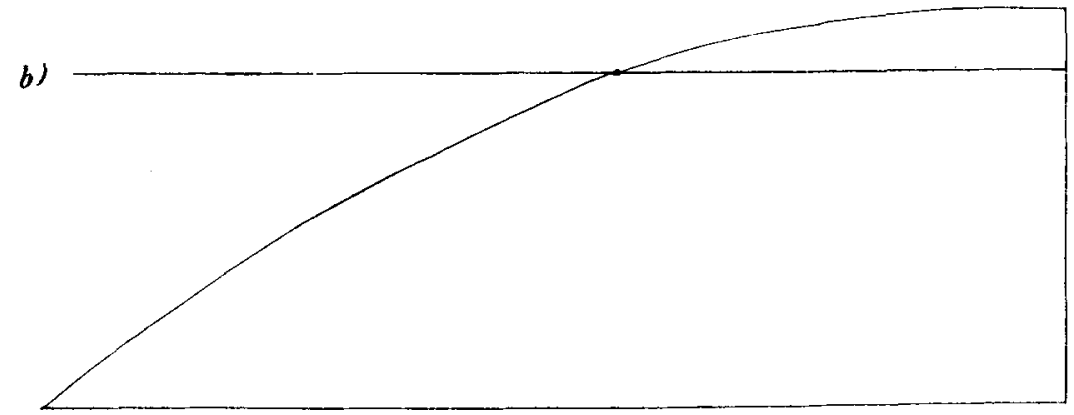

Sartarius

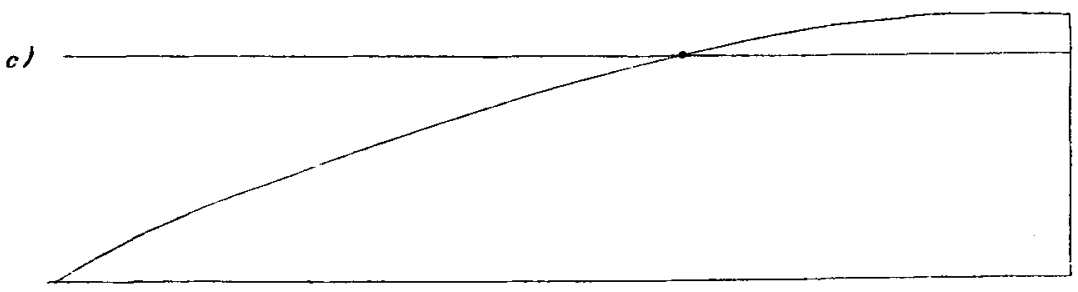

Rectus femoris.

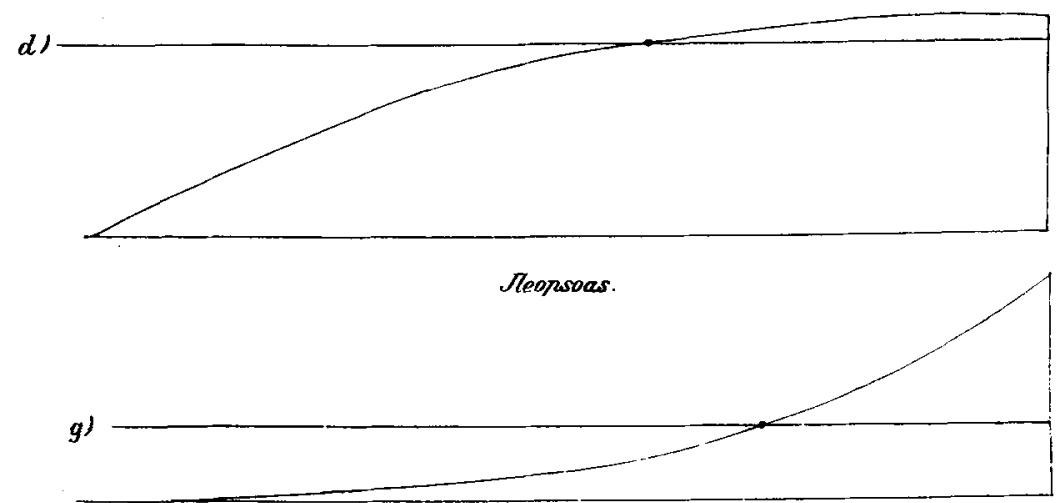

Add. Longus, Zonge Fasern.

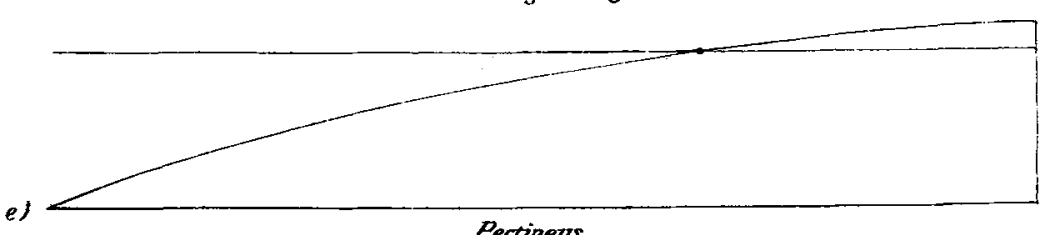

Pectineas. 


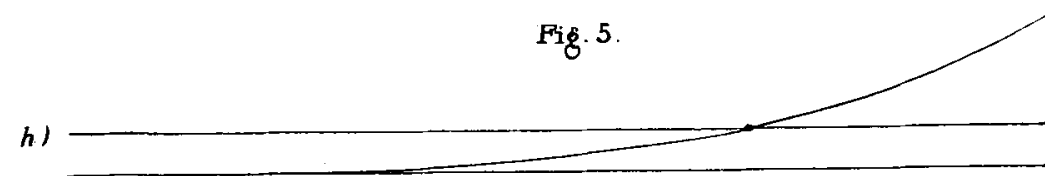

Add. brevis.

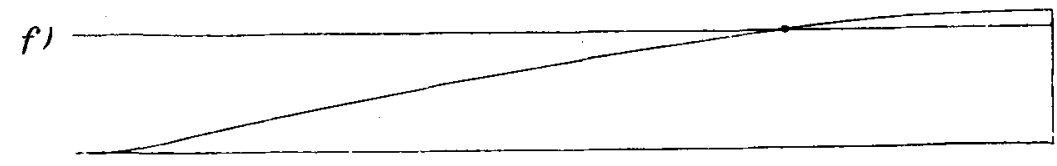

Ghu. med., vordere Fusem.

Fig. 6.
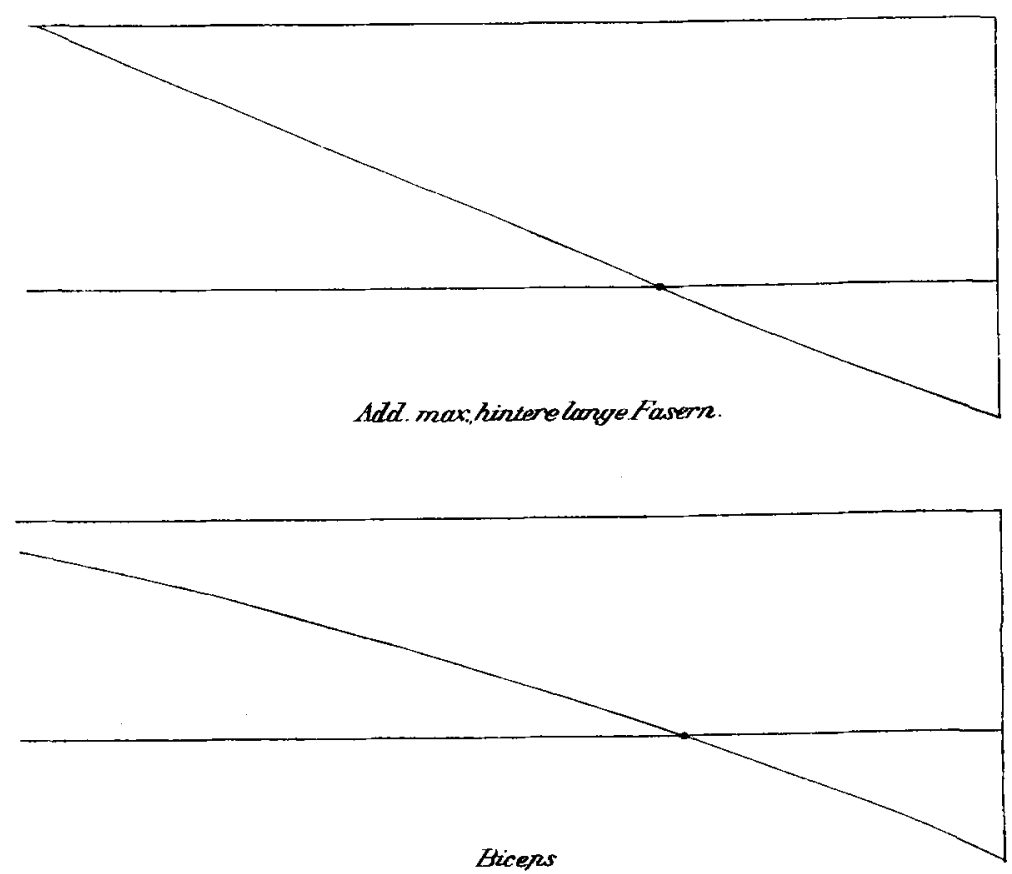

Bricens

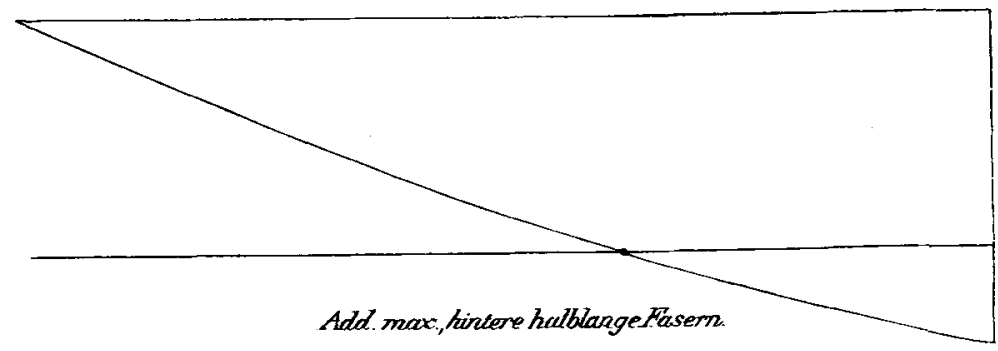


Fis.6.

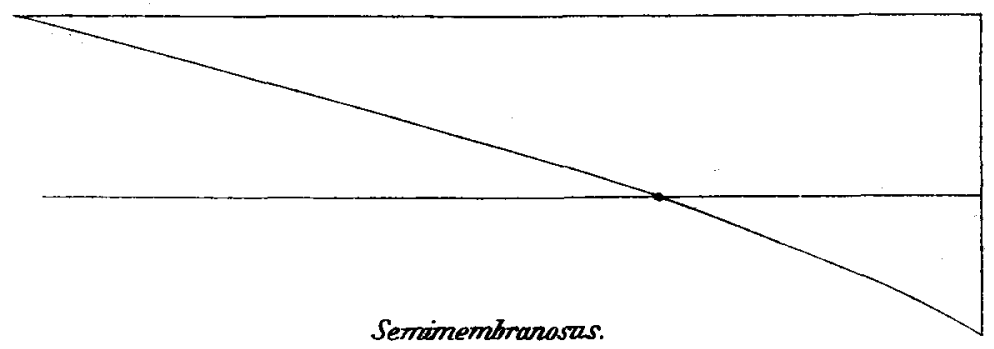

Semimembranasus.

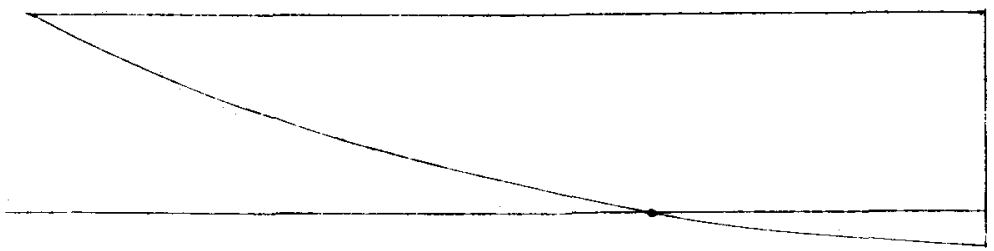

Add. max,vordere lange Fowem.

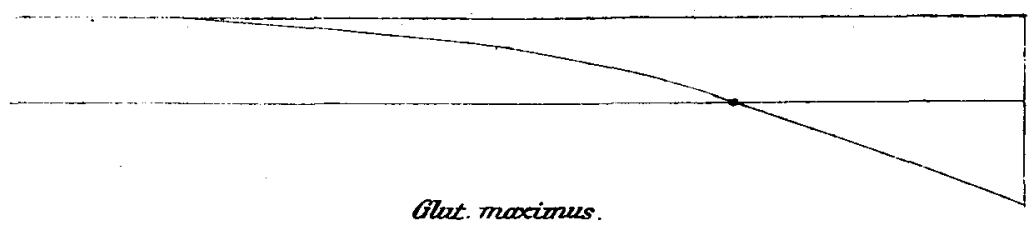

Glat. maximus.

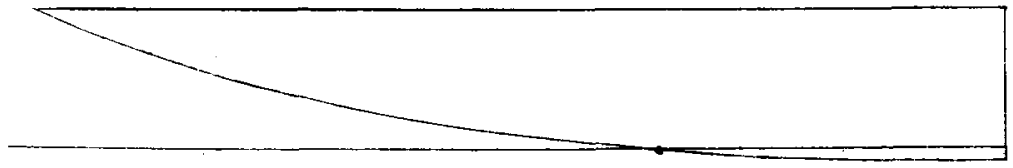

Add maxim, mittlene vordere Frasern.

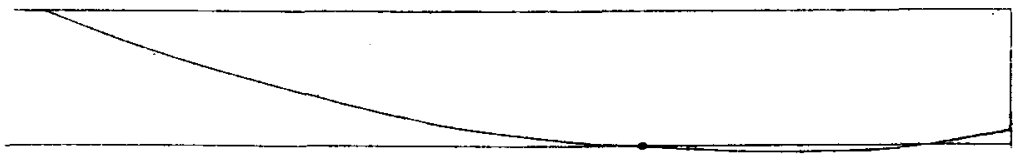

Juadratus femoris.

Gut.med., hintere Fosern. 


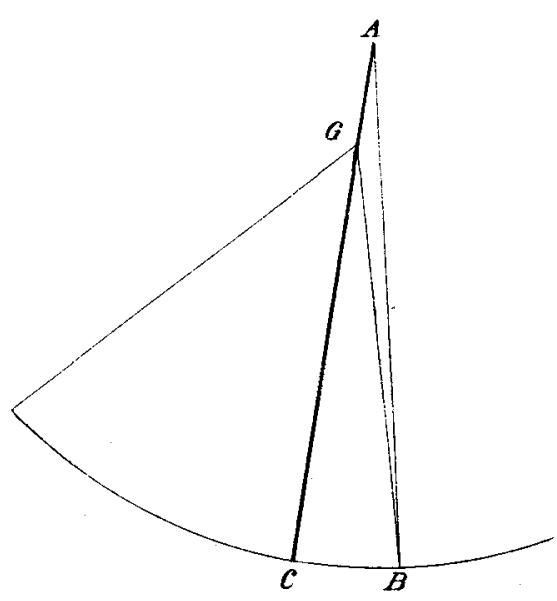

Fig. 7 .

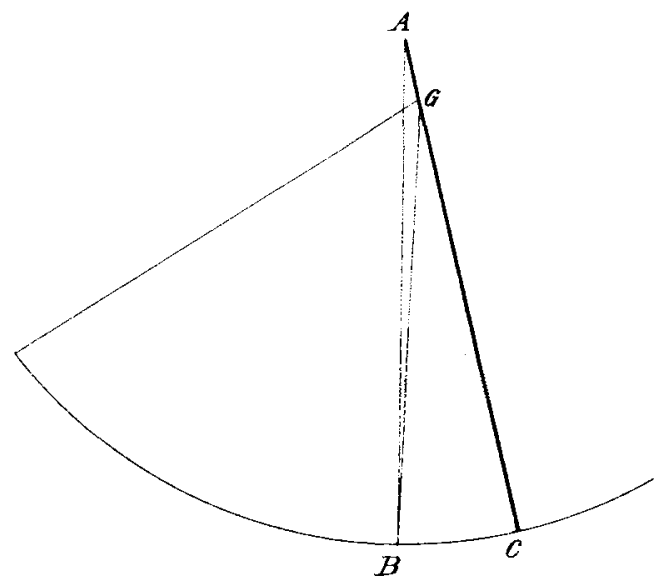

Fi 8.8

F'i ig. 9.
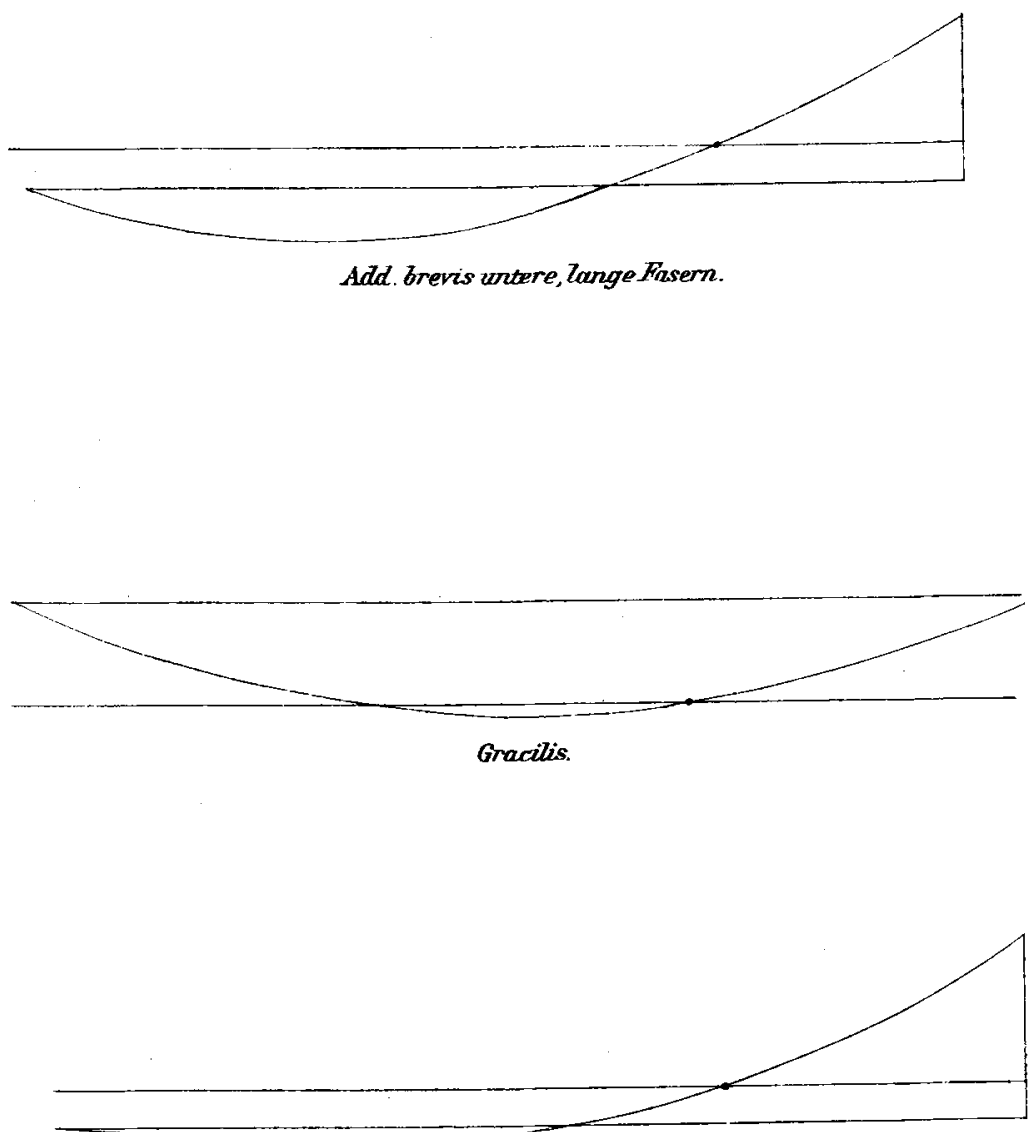

Add. Zng Kaurze Fosern. 


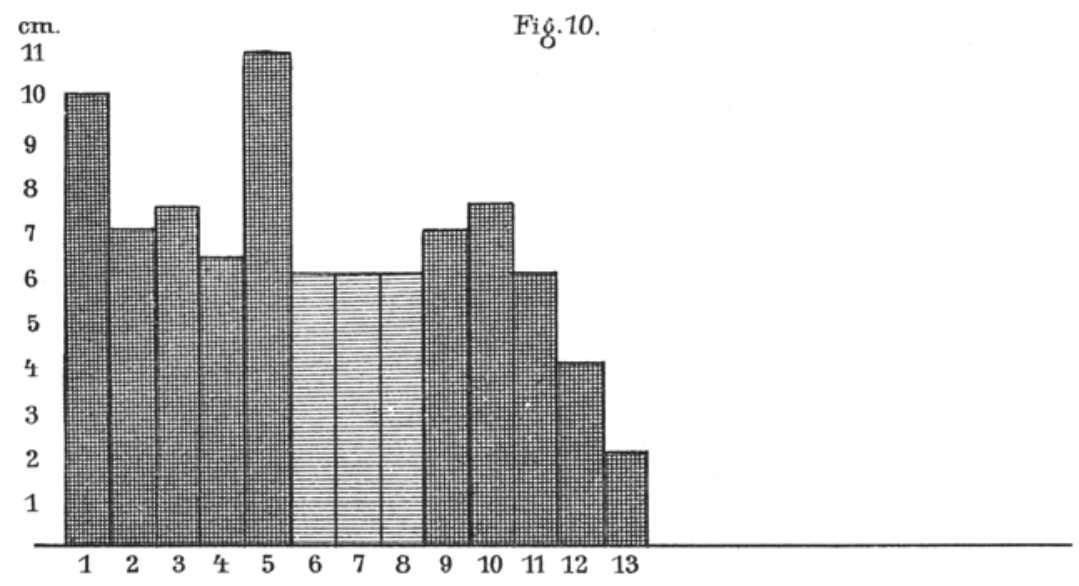

Abduction von 800

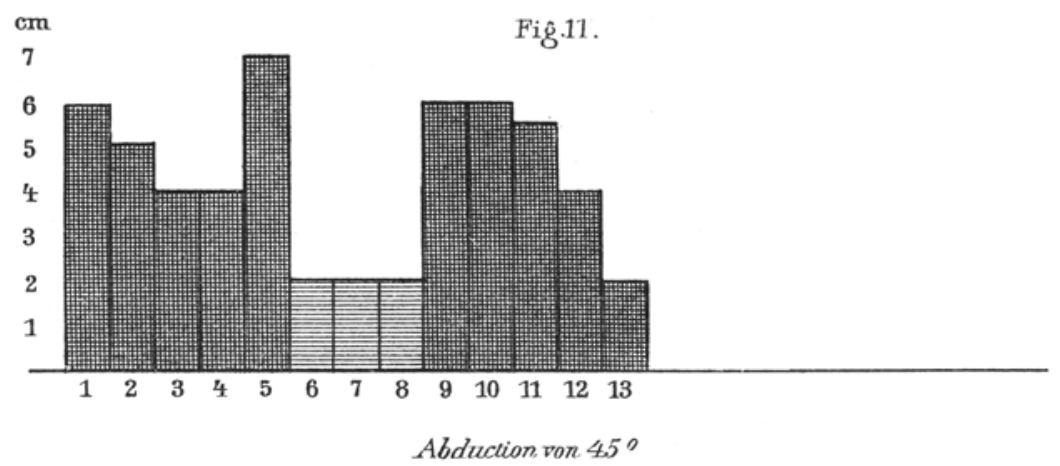

Fig.12.

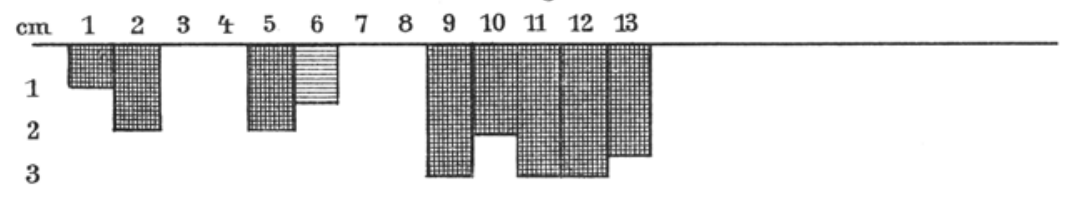

Adduction von $20^{\circ}$

Fig.13.

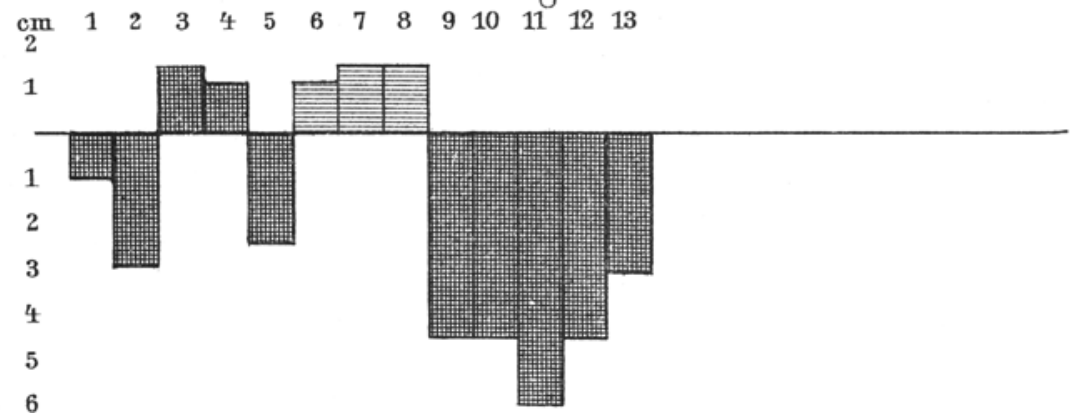


Fig. 14 .

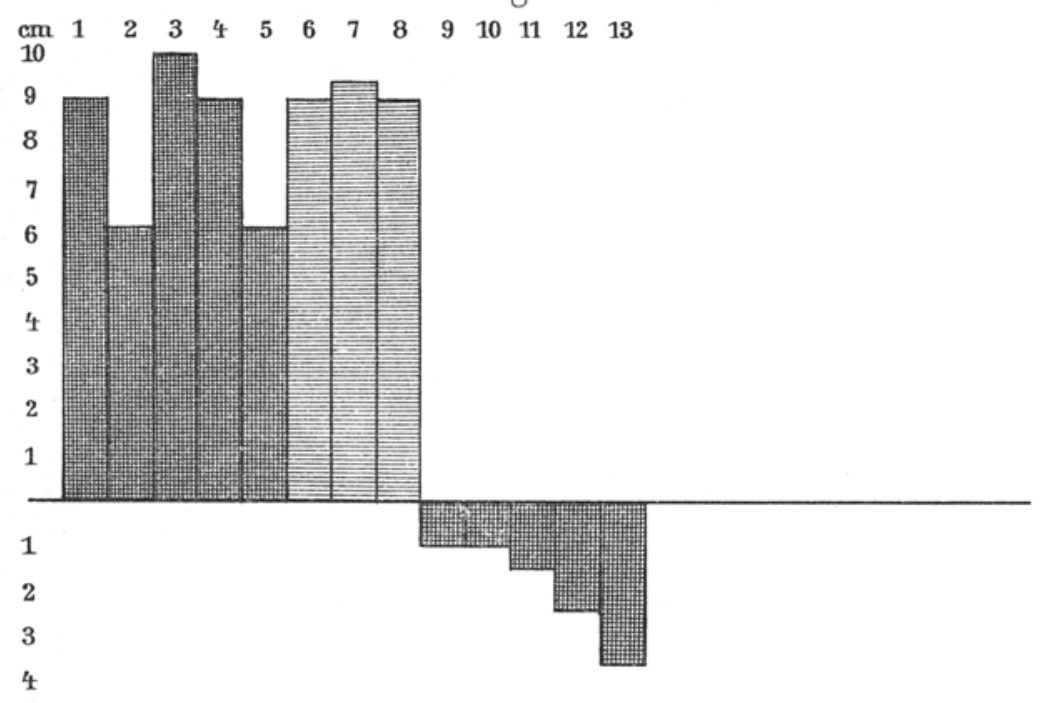

Beugung von $80^{\circ}$

Fig. 15 .

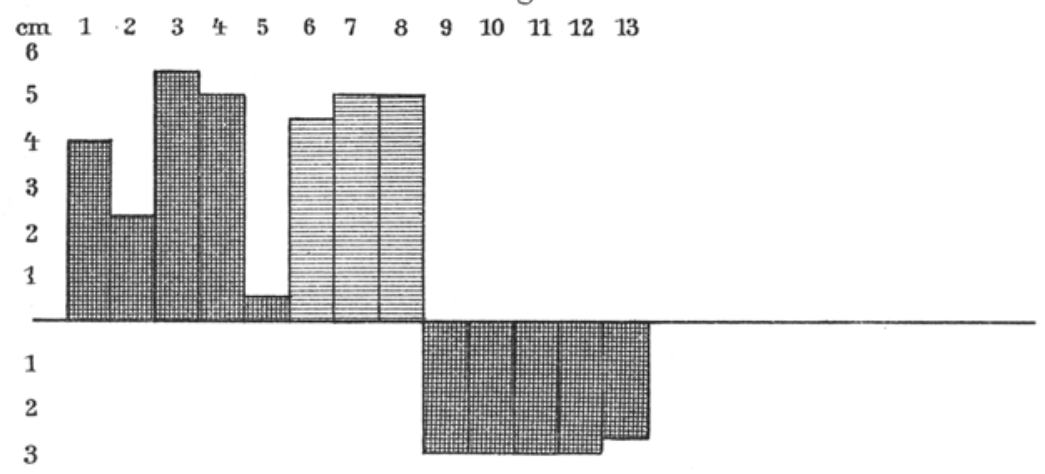

Beugung von $50^{\circ}$

Tig 16.

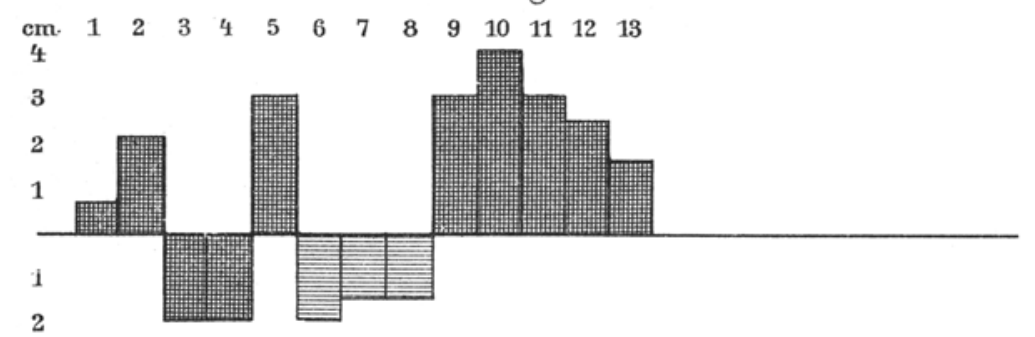

Extensionvon $25^{\circ}$ 